\title{
Triggers for energy expenditure: Thermogenic ingredients \& circadian aspects
}

Citation for published version (APA):

Hursel, R. (2011). Triggers for energy expenditure: Thermogenic ingredients \& circadian aspects.

[Doctoral Thesis, Maastricht University]. https://doi.org/10.26481/dis.20110415rh

Document status and date:

Published: 01/01/2011

DOI:

10.26481/dis.20110415rh

Document Version:

Publisher's PDF, also known as Version of record

\section{Please check the document version of this publication:}

- A submitted manuscript is the version of the article upon submission and before peer-review. There can be important differences between the submitted version and the official published version of record.

People interested in the research are advised to contact the author for the final version of the publication, or visit the DOI to the publisher's website.

- The final author version and the galley proof are versions of the publication after peer review.

- The final published version features the final layout of the paper including the volume, issue and page numbers.

Link to publication

\footnotetext{
General rights rights.

- You may freely distribute the URL identifying the publication in the public portal. please follow below link for the End User Agreement:

www.umlib.nl/taverne-license

Take down policy

If you believe that this document breaches copyright please contact us at:

repository@maastrichtuniversity.nl

providing details and we will investigate your claim.
}

Copyright and moral rights for the publications made accessible in the public portal are retained by the authors and/or other copyright owners and it is a condition of accessing publications that users recognise and abide by the legal requirements associated with these

- Users may download and print one copy of any publication from the public portal for the purpose of private study or research.

- You may not further distribute the material or use it for any profit-making activity or commercial gain

If the publication is distributed under the terms of Article $25 \mathrm{fa}$ of the Dutch Copyright Act, indicated by the "Taverne" license above, 


\section{Triggers for energy expenditure:}

thermogenic ingredients \& circadian aspects 


\section{nivution Thu}

The studies presented in this thesis were performed at the School for Nutrition, Toxicology and Metabolism (NUTRIM), which participates in the Graduate School VLAG (Food Technology, Agrobiotechnology, Nutrition and Health Sciences), accredited by the Royal Netherlands Academy of Arts and Sciences (KNAW).

The research described in chapter 6 and 7 of this thesis was sponsored by Royal FrieslandCampina.

Financial support by Royal FrieslandCampina for the publication of this thesis is gratefully acknowledged.

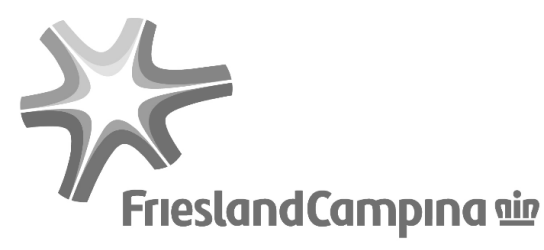

Cover design: Pieter Grégoire

Layout: Rick Hursel

Printed by: Datawyse, Universitaire Pers Maastricht

(C) Copyright Rick Hursel, Maastricht 2011

ISBN 9789461590435 


\title{
Triggers for energy expenditure:
}

\section{thermogenic ingredients \& circadian aspects}

\author{
PROEFSCHRIFT \\ ter verkrijging van de graad van doctor aan de Universiteit Maastricht, \\ op gezag van de Rector Magnificus, Prof. Mr. G.P.M.F. Mols, \\ volgens het besluit van het College van Decanen, \\ in het openbaar te verdedigen op \\ vrijdag 15 april 2011 om 12.00 uur
}

door

Rick Hursel

Geboren te Heerlen op 19 september 1984

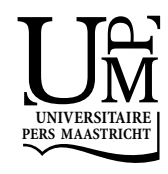




\section{Promotor}

Prof. dr. M.S. Westerterp-Plantenga

\section{Beoordelingscommissie}

Prof. dr. K.R. Westerterp (voorzitter)

Prof. dr. A.V. Astrup (University of Copenhagen, Denmark)

Prof. dr. A.A. Masclee

Prof. dr. R.P. Mensink

Dr. J. Plat

The research described in this thesis was carried out at the department of Human Biology from Maastricht University. 


\section{Table of contents}

$\begin{array}{lll}\text { Chapter } 1 & \text { General Introduction } & 7\end{array}$

$\begin{array}{lll}\text { Chapter } 2 \text { Thermogenic ingredients and body-weight regulation } & 19\end{array}$

Chapter 3 The multifactorial role of dietary protein in body-weight 41 regulation

Chapter 4 The effects of green tea on weight loss and weight main- 61 tenance: a meta-analysis

Chapter 5 The effects of catechin rich teas and caffeine on energy 73 expenditure and fat oxidation: a meta-analysis

Chapter 6 Effects of a breakfast yoghurt, with additional total whey $\quad 89$ protein or caseinomacropeptide-depleted alphalactalbumin enriched whey protein, on diet-induced thermogenesis and appetite suppression

Chapter 7 Consumption of milk protein combined with green tea modulates diet-induced thermogenesis

Chapter 8 Green tea catechin plus caffeine supplementation to a high-protein diet has no additional effect on body-weight maintenance after weight loss

Chapter 9 Effects of sleep fragmentation on energy expenditure, substrate oxidation, physical activity and exhaustion, measured over $48 \mathrm{~h}$ in a respiratory chamber

Chapter 10 General discussion

Summary

Samenvatting

Dankwoord

List of publications 

Chapter 1

General Introduction 
An increasing prevalence of obesity with 400 billion adults worldwide being obese and expectations that these figures will be doubled in 2015 has made research addressing etiology, physiology and pathology of obesity a number one priority for today's society $(1,2)$. Coinciding with an increase in body weight, mainly fat mass, nutritional diseases such as diabetes mellitus type 2, cardiovascular diseases and cancer are currently registered in the top ten causes of death for high-income and middle-income countries according to the World Health Organization and consequently lead to increasing costs for health care (1, $3)$. Thus, developing countries that are Westernizing rapidly, especially in urban settings, are confronted with similar problems thereby making it a global issue. A sedentary lifestyle combined with an increase in energy intake that exceeds energy expenditure, causes a positive energy balance that will lead to weight gain in the long-term. Decreasing body weight and fat mass, with the preservation of lean body mass, which is the main determinant of basal metabolic rate (BMR), is the essential objective $(4,5)$. Different approaches for the treatment of obesity are undertaken as traditional methods such as dieting and increasing physical activity are not successful in the long-term due to lack of compliance. Only $20 \%$ of overweight individuals are successful at long-term weight loss when defined as losing at least $10 \%$ of initial body weight and maintaining the loss for at least 1 year (6). Functional ingredients such as mixtures of green tea catechins and caffeine $(7,8)$, capsaicin $(9,10)$ and a highly thermogenic macronutrient such as protein $(11,12)$, which are separately capable of increasing energy expenditure and fat oxidation, applied to induce weight loss and weight maintenance after initial weight loss may be applicable in everyday life. Synergistic effects of these are currently examined as well, to study whether their efficacy, with respect to stimulating energy expenditure increases when given simultaneously. Another approach, which is currently gaining interest, is the role of circadian misalignment, especially studied as sleep disturbance in the etiology of obesity (13-17). Evidence is obtained that shows the importance of sleep quality and sleep duration in maintaining a healthy body weight. Modern lifestyle intervenes in these factors with decreases in total sleeping time and sleep quality due to frequently waking up at night or by inducing a pattern of longer days and shorter nights.

The previously described approaches which are seen as triggers for energy expenditure will be addressed further in this chapter, preceded by an overview of the concept of energy expenditure and its components, followed by the aims and outline of this thesis.

\section{Energy expenditure and substrate oxidation}

The burning of calories, thereby generating energy, is a complicated process in which many physiological systems collaborate, starting with the ingestion and digestion of food and ending as movement, heat or maintenance of organs. Total 
energy expenditure (TEE) or averaged daily metabolic rate (ADMR) consists of four components: sleeping metabolic rate (SMR), energy costs of arousal, dietinduced thermogenesis (DIT) and activity-induced energy expenditure (AEE). SMR, which is calculated over a three-hour interval at night with the lowest energy expenditure, and energy costs of arousal together are defined as BMR or resting energy expenditure (REE), i.e. the energy expenditure of a person at rest, while being awake, in a post-absorptive state, under thermoneutral conditions (18). BMR accounts on average for $60-80 \%$ of the ADMR and its main determinant is fat free mass, which can be predicted based on gender, height, body weight and age, by using for instance the Harris and Benedict equation (19). Energy expenditure during the night is also referred to as overnight metabolic rate (OMR), from which SMR is a derivative $(18,20)$. DIT or the thermic effect of food is defined as the increase in energy expenditure above the REE after a meal. DIT consist of the energy that is required during the postprandial period for the processing of food, i.e. digestion, intestinal absorption, transportation, implementation of nutrients as fuel or building material, and storage of nonimplemented materials $(18,21)$. DIT on average accounts for $10 \%$ of ADMR when being in energy balance and consuming a meal consisting of representative macronutrient contents $(21,22)$. Energy expenditure may increase by the use of thermogenic ingredients or high-protein diets initially by an increase in DIT, which later on sustains as an increase in $\operatorname{BMR}(22,58,11)$. The final component of TEE is AEE and this is the most variable component that can vary between $5 \%$ of ADMR with a minimum physical activity level (PAL) of 1.2 to levels up to $50 \%$ with a PAL of 2.5. PAL is calculated by subtracting BMR and DIT from TEE or it can be expressed as TEE divided by $\operatorname{BMR}(18,23)$.

Energy expenditure depends on the oxidation of substrates as alcohol, carbohydrates, fat and protein, which can be determined with the use of the respiratory quotient $(R Q)$. The $R Q$ indicates which substrate is being oxidized and consists of the ratio between carbon dioxide production and oxygen consumption. Varying between 1.0 and 0.7 , a ratio of 1.0 indicates carbohydrate oxidation, 0.7 indicates fat oxidation and every ratio in between refers to a mixed diet. Another approach is the use of the formulas of Carpenter, where carbohydrate oxidation and fat oxidation are calculated in grams/day with average daily carbon dioxide production and oxygen consumption and the protein oxidation (24). Protein oxidation is accurately determined from $24 \mathrm{hr}$ urine and its nitrogen content. Fat oxidation can further be determined with labeled palmitic acid.

\section{Green tea catechins and caffeine mixture}

The origin of tea lies in China where many years ago they discovered how to prepare tea from the leaves of the Camellia L. Sinensis. Ever since, tea has become a beverage that is consumed worldwide. Only tea made from the leaves of this plant is considered as proper tea and there are four different types 
depending on the process of oxidation and fermentation: white tea that is made from the youngest buds, green tea that immediately after harvesting is dried and steamed to prevent fermentation, oolong tea that is semifermented before drying and black tea that is completely fermented $(25,26)$. The enzyme polyphenol oxidase converts polyphenols, which provide the bitter taste, during the process of fermentation into for instance thearubigins and theaflavins that are present in black tea. The polyphenols or flavonoids are the components that are known for their health-promoting effects because of their anti-oxidative, anti-mutagenic and anti-carcinogenic capacity and can be found in many of nature's products such as fruit, vegetables and tea. In not fully fermented tea, a group of polyphenols named catechins including epicatechin (EC), epicatechin gallate (ECG), epigallocatechin (EGC) and epigallocatechin gallate (EGCG) is active from which EGCG is the most abundant and active catechin (27). All types of tea differ in composition as this depends, beside the process of fermentation, on numerous factors such as soil, location, weather conditions, amount of sunlight etcetera, making the use of pure EGCG in capsules for standardization necessary. Green tea catechins and caffeine mixture recently has gained interest for obesityrelated research, since studies showed that it has anti-obesogenic capacities such as improving cholesterol levels and blood lipid concentrations. Dulloo et al. and others reported increases in $24 \mathrm{hr}$ energy expenditure and fat oxidation after supplementation with a catechin-caffeine mixture $(7,28-34)$. This lead to longterm studies examining weight loss and weight maintenance after initial weight loss from which some were successful $(8,32,35-39)$ and others less promising (40-43). Effects on body composition seem to be positive as well with a fat free mass sparing effect and decreases in fat mass having been observed. Concerning food intake, green tea decreased energy intake in mice, which is in contrast with humans where only increased feelings of hunger have been reported (44). Green tea contains in addition to catechins also the methylxanthines theobromine, theophylinne and caffeine that more or less have the same stimulating properties. Caffeine is a well-known stimulator and it has been shown that the thermogenic effect of green tea is the result of a combination between the catechins and caffeine, as their synergistic effect is larger than the separate effect (7). Both have different mechanisms to stimulate energy expenditure and fat oxidation, which are illustrated in figure 1, Chapter 2. Mostly the inhibition of catechol-O-methyltransferase (COMT), the catecholamine degrading enzyme, by catechins i.e. the methylation of catechins by COMT that has priority above the degradation of catecholamines and the inhibition of phosphodiesterase by caffeine are seen as the main mechanisms behind the stimulating properties of green tea. Inhibitions of both enzymes will stimulate the sympathetic nervous system that eventually will cause an increase in thermogenesis (45).

Animal studies also have described fat absorption lowering effects of catechins after long-term supplementation. Faeces contained more fat in rodents receiving a catechin treatment compared with their counterparts that received a 
placebo (46-49). This might also be promising for decreasing total fat mass, in addition to an increased fat oxidation, together potentially inducing a favorable negative fat balance.

In addition to green tea catechins and caffeine mixtures other thermogenic ingredients are under investigation as well; Chapter 2 gives an overview addressing green tea catechin and caffeine mixtures, caffeine and capsaicin, the pungent principle in hot red pepper and their thermogenic and satiating properties.

\section{Protein, the weight-managing macronutrient}

Protein is an important macronutrient, composed of essential and non-essential amino acids which ratio determines protein quality, that is involved in many processes as it is incorporated in muscles, hormones and enzymes that maintain the body in homeostasis. A daily protein intake between 10 to $15 \%$ of energy intake provides a continuous balance between anabolism and catabolism, depending on physical activity. Moreover it functions as an energy source as protein cannot be stored after absorption with the exception of the previously mentioned protein incorporating entities.

Diets containing levels of protein above the daily recommended 10 to $15 \%$ of energy, are considered as relatively high-protein diets, and these have been studied in relation to weight loss and weight maintenance. Relatively high-protein diets or absolutely sustained protein diets at the level of 0.8-1.2 g/kg body-mass (50) appear to be successful in decreasing and maintaining body weight due to their ability of preserving fat free mass, increasing energy expenditure, increasing satiety and thereby decreasing subsequent food intake (5, 51-53). A relatively high-protein intake causes a positive protein balance facilitating protein synthesis that may stimulate preservation of lean body mass implying prevention of decreases in REE. Energy costs of processing of protein are higher than the yielded amount of energy, consequently increasing energy expenditure. High ATP costs for urea production and peptide bond synthesis after increased postprandial protein synthesis or elevated gluconeogenesis contribute to the reported protein-induced thermogenesis $(51,54-56)$. The decrease in food intake and protein-induced satiety are partly explained by the following mechanisms: secretion of the satiety-related neuropeptides GLP-1 and PYY, increased amino acid concentrations in the blood that possibly activate a satiety center in the brain that is sensitive for serum amino acid levels also referred to as the aminostatic hypothesis $(57,58)$ and increased energy expenditure with increased oxygen consumption that limits oxygen availability for energy expenditure and therefore is perceived as reduced ability to eat $(59,60)$. These mechanisms are influenced by the quality of the dietary protein, which is determined by the ratio between essential and non-essential amino acids. A distinction is made between 'complete' proteins, having all essential amino acids 
and 'incomplete' proteins; 'complete' proteins tend to be primarily associated with larger increases in energy expenditure and 'incomplete' proteins tend to be primarily related to increased satiety (61-65). Therefore, not only quantity of protein is important but quality matters as well. Chapter 3 discusses long-term and short-term effects of protein supplementation on body weight, energy expenditure, satiety and the mechanisms of action. As previously mentioned, dietary protein and green tea catechins and caffeine mixture are separately capable of increasing energy expenditure and fat oxidation. Synergistic effects have been examined in the short-term, as described in Chapter 7 as well as over the long-term as described in Chapter 8.

\section{Circadian alignment and misalignment}

Usually energy expenditure and substrate oxidation are circadially aligned, and a clear diurnal pattern is present. Recently, epidemiological studies pointed to sleep deprivation or sleep disturbance, disrupting the circadian rhythm, thereby possibly determining a positive energy balance and hence development of overweight and obesity.

Mammalian sleep is an active process that consists of alternating periods of non-rapid eye movement (NREM) and rapid eye movement (REM) sleep (16). The length of each NREM-REM cycle in humans is approximately $90 \mathrm{~min}$ and is repeated four to six times per night. NREM sleep is divided into stages I, II, III and IV of progressively deeper sleep. The synchronization of cortical activity during stages III and IV results in high-amplitude low-frequency electroencephalograph (EEG) waveforms known as 'slow-wave sleep' (SWS). This SWS is thought to be the most "restorative" sleep stage (66). Genetic and environmental factors, such as sex, race/ethnicity, chronological age, socioeconomic status and others, contribute to the considerable inter-individual variability in the quantity and architecture of human sleep (16).

People who sleep less than $7 \mathrm{hrs}$ or more than $8 \mathrm{hrs}$ a night, seem to be at higher risk to become obese (13). People who suffer from sleep fragmentation seem to be even more prone to get obese than people with a chronic sleep deprivation (67). The prevalence of obesity increased synchronically with a decrease in the average duration of sleep in the United States. Sleep restriction/alteration may affect energy balance and result in an up-regulation of appetite, probably related to changes in neuro-endocrinological activities, decreased energy expenditure and reduced physical activity. Altered glucose metabolism that induces insulin resistance and eventually leads to diabetes has been mentioned as a consequence as well (13).

Whether decrease in energy expenditure is based on altered hormone levels, such as a decrease in thyroid stimulating hormone, or a decrease in nonexercise activity thermogenesis (NEAT) and SMR remains unclear. NEAT, energy expenditure that is not initiated by exercise but by performing normal daily 
activities such as cleaning, shopping and walking stairs, may be decreased due to fatigue caused by a reduced sleep quality/quantity $(13,68)$.

\section{Outline of the thesis}

Apart from energy intake, energy expenditure is a main determinant for the development of obesity. Especially the decrease in energy expenditure due to body-weight loss is a pitfall for weight maintenance thereafter, since subjects tend to return to their previous habits of food intake after weight loss, thereby ignoring their decreased energy requirement and thus decreased energy expenditure, due to weight loss induced shrinkage of the body. Therefore it is of utmost importance to find concepts to sustain energy expenditure despite body weight loss. In short-term experiments assessing potential targets for treatment of obesity, this means that in energy balance triggers have to be studied that may stimulate energy expenditure. Different triggers have been studied so far to elucidate whether they might boost energy expenditure; three of them have been investigated and described in this thesis. Current knowledge about short-term effects, long-term effects and mechanisms of action of the thermogenic ingredients caffeine, capsaicin and green tea catechins and caffeine mixture are reported in chapter 2; 'Thermogenic ingredients and body weight regulation'. A review of the effects of the macronutrient protein in this respect is given in chapter 3; 'The multifactorial role of dietary protein in body weight regulation'. The following two chapters report the outcomes of meta-analyses on effects of green tea catechins and caffeine mixture. After more than a decade still different results are published with respect to the weight managing effects of these mixtures. Their short-term effects are discussed in chapter 4; 'The effects of catechin rich teas and caffeine on energy expenditure and fat oxidation: a metaanalysis'. The second meta-analysis reports the overall conclusions of papers that assessed green tea over the long-term as presented in chapter 5; 'The effects of green tea on weight loss and weight maintenance: a meta-analysis'. Dietary proteins differ in the ability of enhancing diet-induced thermogenesis and improving satiety, due to their composition. Two dietary proteins, whey and $\alpha-$ lactabulmin, and their effect on diet-induced thermogenesis and satiety were investigated; this has been reported in chapter 6; 'Effects of a breakfast yoghurt, with additional total whey protein or caseinomacropeptide-depleted $\alpha$ lactalbumin-enriched whey protein, on diet-induced thermogenesis and appetite suppression'. Diet-induced thermogenesis accounts for approximately $10 \%$ of the daily energy expenditure and triggers for energy expenditure may enhance this percentage. However, a combination of certain triggers might increase this percentage to a higher extend, due to synergistic effects. Chapter 7; 'Consumption of milk-protein combined with green tea modulates diet-induced thermogenesis', describes two studies with different protein sources in combination with a green tea-caffeine mixture and their effects on energy expenditure. The 
same combination was assessed after weight-loss in a weight maintenance study as presented in chapter 8; 'Green tea catechin plus caffeine supplementation to a high-protein diet has no additional effect on body weight maintenance after weight loss'. In chapter 9; 'Effects of sleep fragmentation on energy expenditure, substrate oxidation, physical activity and exhaustion, measured over $48 \mathrm{~h}$ in a respiratory chamber', we are switching gears to another approach of studying energy expenditure. Finally, all outcomes of the studies that are presented in this thesis will be generally discussed and summarized in chapter 10.

\section{References}

1. Obesity: preventing and managing the global epidemic. Report of a WHO consultation. World Health Organ Tech Rep Ser 2000;894:i-xii, 1-253.

2. Stunkard AJ. Current views on obesity. Am J Med 1996;100:230-6.

3. Pi-Sunyer FX. Medical hazards of obesity. Ann Intern Med 1993;119:655-60.

4. Westerterp-Plantenga MS. Protein intake and energy balance. Regul Pept 2008;149:67-9.

5. Westerterp-Plantenga MS, Lejeune MP. Protein intake and body-weight regulation. Appetite 2005;45:187-90.

6. Wing RR, Phelan S. Long-term weight loss maintenance. Am J Clin Nutr 2005;82:222S-225S.

7. Dulloo AG, Duret C, Rohrer D, et al. Efficacy of a green tea extract rich in catechin polyphenols and caffeine in increasing 24-h energy expenditure and fat oxidation in humans. Am J Clin Nutr 1999;70:1040-5.

8. Auvichayapat $P$, Prapochanung $M$, Tunkamnerdthai $O$, et al. Effectiveness of green tea on weight reduction in obese Thais: A randomized, controlled trial. Physiol Behav 2008;93:486-91.

9. Yoshioka M, Lim K, Kikuzato S, et al. Effects of red-pepper diet on the energy metabolism in men. J Nutr Sci Vitaminol (Tokyo) 1995;41:647-56.

10. Lejeune MP, Kovacs EM, Westerterp-Plantenga MS. Effect of capsaicin on substrate oxidation and weight maintenance after modest body-weight loss in human subjects. $\mathrm{Br} \mathrm{J}$ Nutr 2003;90:651-59.

11. Lejeune MP, Westerterp KR, Adam TC, Luscombe-Marsh ND, Westerterp-Plantenga MS. Ghrelin and glucagon-like peptide 1 concentrations, 24-h satiety, and energy and substrate metabolism during a high-protein diet and measured in a respiration chamber. Am $\mathrm{J}$ Clin Nutr 2006;83:89-94.

12. Karst $H$, Steiniger J, Noack R, Steglich HD. Diet-induced thermogenesis in man: thermic effects of single proteins, carbohydrates and fats depending on their energy amount. Ann Nutr Metab 1984;28:245-52.

13. Knutson KL, Spiegel K, Penev P, Van Cauter E. The metabolic consequences of sleep deprivation. Sleep Med Rev 2007;11:163-78.

14. Patel SR, Blackwell T, Redline $\mathrm{S}$, et al. The association between sleep duration and obesity in older adults. Int J Obes (Lond) 2008;32:1825-34.

15. Patel SR, Hu FB. Short sleep duration and weight gain: a systematic review. Obesity (Silver Spring) 2008;16:643-53.

16. Penev PD. Sleep deprivation and energy metabolism: to sleep, perchance to eat? Curr Opin Endocrinol Diabetes Obes 2007;14:374-81.

17. Taheri S. Sleep and metabolism: bringing pieces of the jigsaw together. Sleep Med Rev 2007;11:159-62.

18. Westerterp K. Energy expenditure. In: Westerterp-Plantenga M, Frederix E, Steffens A, eds. Food intake and energy expenditure: CRC Press, 1994:235-257.

19. Harris JA, Benedict FG. A Biometric Study of Human Basal Metabolism. Proc Natl Acad Sci U S A 1918;4:370-3.

20. Schoffelen PF, Westerterp KR. Intra-individual variability and adaptation of overnight- and sleeping metabolic rate. Physiol Behav 2008;94:158-63. 
21. Westerterp KR. Diet induced thermogenesis. Nutr Metab (Lond) 2004;1:5.

22. Westerterp KR, Wilson SA, Rolland V. Diet induced thermogenesis measured over $24 \mathrm{~h}$ in a respiration chamber: effect of diet composition. Int J Obes Relat Metab Disord 1999;23:287-92.

23. Westerterp KR. Alterations in energy balance with exercise. Am J Clin Nutr 1998;68:970S-974S.

24. Brouwer E. On simple formulae for calculating the heat expenditure and the quantities of carbohydrate and fat oxidized in metabolism of men and animals, from gaseous exchange (Oxygen intake and carbonic acid output) and urine-N. Acta Physiol Pharmacol Neerl 1957;6:795-802.

25. Cabrera C, Artacho R, Gimenez R. Beneficial effects of green tea--a review. J Am Coll Nutr 2006;25:79-99.

26. Kao YH, Chang HH, Lee MJ, Chen CL. Tea, obesity, and diabetes. Mol Nutr Food Res 2006;50:188-210.

27. Shixian Q, VanCrey B, Shi J, Kakuda Y, Jiang Y. Green tea extract thermogenesis-induced weight loss by epigallocatechin gallate inhibition of catechol-O-methyltransferase. J Med Food 2006;9:451-8.

28. Berube-Parent S, Pelletier C, Dore J, Tremblay A. Effects of encapsulated green tea and Guarana extracts containing a mixture of epigallocatechin-3-gallate and caffeine on $24 \mathrm{~h}$ energy expenditure and fat oxidation in men. Br J Nutr 2005;94:432-6.

29. Komatsu T, Nakamori M, Komatsu K, et al. Oolong tea increases energy metabolism in Japanese females. J Med Invest 2003;50:170-5.

30. Kozuma K, Chikama A, Hishino E, et al. Effect of intake of a beverage containing $540 \mathrm{mg}$ catechins on the body composition of obese women and men. Prog Med 2005;25:185-197.

31. Nagao T, Hase T, Tokimitsu I. A green tea extract high in catechins reduces body fat and cardiovascular risks in humans. Obesity (Silver Spring) 2007;15:1473-83.

32. Nagao $\mathrm{T}$, Komine $\mathrm{Y}$, Soga $\mathrm{S}$, et al. Ingestion of a tea rich in catechins leads to a reduction in body fat and malondialdehyde-modified LDL in men. Am J Clin Nutr 2005;81:122-9.

33. Rudelle S, Ferruzzi MG, Cristiani I, et al. Effect of a thermogenic beverage on 24-hour energy metabolism in humans. Obesity (Silver Spring) 2007;15:349-55.

34. Rumpler W, Seale J, Clevidence B, et al. Oolong tea increases metabolic rate and fat oxidation in men. J Nutr 2001;131:2848-52.

35. Wang H, Wen Y, Du Y, et al. Effects of Catechin Enriched Green Tea on Body Composition. Obesity (Silver Spring) 2009.

36. Nagao T, Meguro S, Soga S, et al. Tea catechins suppress accumulation of body fat in humans. J Oleo Sci 2001;50:717-728.

37. Harada U, Chikama A, Saito S, et al. Effects of long-term ingestion of tea catechins on energy expenditure and dietary fat oxidation in healthy subjects. J Health Sci 2005;51:248-252.

38. Westerterp-Plantenga MS, Lejeune MP, Kovacs EM. Body weight loss and weight maintenance in relation to habitual caffeine intake and green tea supplementation. Obes Res 2005;13:1195204.

39. Kajimoto $\mathrm{O}$, Kajimoto $\mathrm{Y}$, Yabune $\mathrm{M}$, et al. Tea catechins with a galloyl moiety reduce body weight and fat. Journal of Health Science 2005;51:161-171.

40. Kovacs EM, Lejeune MP, Nijs I, Westerterp-Plantenga MS. Effects of green tea on weight maintenance after body-weight loss. Br J Nutr 2004;91:431-7.

41. Diepvens K, Kovacs EM, Nijs IM, Vogels N, Westerterp-Plantenga MS. Effect of green tea on resting energy expenditure and substrate oxidation during weight loss in overweight females. $\mathrm{Br}$ J Nutr 2005;94:1026-34.

42. Diepvens K, Kovacs EM, Vogels N, Westerterp-Plantenga MS. Metabolic effects of green tea and of phases of weight loss. Physiol Behav 2006;87:185-91.

43. Hsu CH, Tsai TH, Kao YH, Hwang KC, Tseng TY, Chou P. Effect of green tea extract on obese women: a randomized, double-blind, placebo-controlled clinical trial. Clin Nutr 2008;27:363-70.

44. Kao YH, Hiipakka RA, Liao S. Modulation of endocrine systems and food intake by green tea epigallocatechin gallate. Endocrinology 2000;141:980-7.

45. Dulloo AG, Seydoux J, Girardier L, Chantre P, Vandermander J. Green tea and thermogenesis: interactions between catechin-polyphenols, caffeine and sympathetic activity. Int J Obes Relat Metab Disord 2000;24:252-8. 
46. Juhel C, Armand M, Pafumi Y, Rosier C, Vandermander J, Lairon D. Green tea extract (AR25) inhibits lipolysis of triglycerides in gastric and duodenal medium in vitro. $\mathrm{J}$ Nutr Biochem 2000;11:45-51.

47. Koo SI, Noh SK. Green tea as inhibitor of the intestinal absorption of lipids: potential mechanism for its lipid-lowering effect. J Nutr Biochem 2007;18:179-83.

48. Wang S, Noh SK, Koo SI. Epigallocatechin gallate and caffeine differentially inhibit the intestinal absorption of cholesterol and fat in ovariectomized rats. J Nutr 2006;136:2791-6.

49. Raederstorff DG, Schlachter MF, Elste V, Weber P. Effect of EGCG on lipid absorption and plasma lipid levels in rats. J Nutr Biochem 2003;14:326-32.

50. Soenen S, Hochstenbach-Waelen A, Westerterp-Plantenga M. Sustained intake of required protein optimal for weight loss, supra-sustained protein intake optimal for weight maintenance. Submitted for publication 2010.

51. Halton TL, Hu FB. The effects of high protein diets on thermogenesis, satiety and weight loss: a critical review. J Am Coll Nutr 2004;23:373-85.

52. Clifton PM, Keogh JB, Noakes M. Long-term effects of a high-protein weight-loss diet. Am J Clin Nutr 2008;87:23-9.

53. Johnstone AM, Horgan GW, Murison SD, Bremner DM, Lobley GE. Effects of a high-protein ketogenic diet on hunger, appetite, and weight loss in obese men feeding ad libitum. Am J Clin Nutr 2008;87:44-55.

54. Mikkelsen PB, Toubro S, Astrup A. Effect of fat-reduced diets on 24-h energy expenditure: comparisons between animal protein, vegetable protein, and carbohydrate. Am J Clin Nutr 2000;72:1135-41.

55. Robinson SM, Jaccard C, Persaud C, Jackson AA, Jequier E, Schutz Y. Protein turnover and thermogenesis in response to high-protein and high-carbohydrate feeding in men. Am J Clin Nutr 1990;52:72-80.

56. Veldhorst MA, Westerterp-Plantenga MS, Westerterp KR. Gluconeogenesis and energy expenditure after a high-protein, carbohydrate-free diet. Am J Clin Nutr 2009;90:519-26.

57. Mellinkoff SM, Boyle D, Frankland M, Greipel M. The effect of amino acid administration upon the blood sugar concentration. Stanford Med Bull 1955;13:117-24.

58. Mellinkoff SM, Frankland M, Boyle D, Greipel M. Relationship between serum amino acid concentration and fluctuations in appetite. J Appl Physiol 1956;8:535-8.

59. Westerterp-Plantenga MS, Rolland V, Wilson SA, Westerterp KR. Satiety related to $24 \mathrm{~h}$ dietinduced thermogenesis during high protein/carbohydrate vs high fat diets measured in a respiration chamber. Eur J Clin Nutr 1999;53:495-502.

60. Westerterp-Plantenga MS, Westerterp KR, Rubbens M, Verwegen CR, Richelet JP, Gardette B. Appetite at "high altitude" [Operation Everest III (Comex-'97)]: a simulated ascent of Mount Everest. J Appl Physiol 1999;87:391-9.

61. Veldhorst $M$, Smeets $A$, Soenen $S$, et al. Protein-induced satiety: effects and mechanisms of different proteins. Physiol Behav 2008;94:300-7.

62. Veldhorst MA, Nieuwenhuizen AG, Hochstenbach-Waelen A, et al. A breakfast with alphalactalbumin, gelatin, or gelatin + TRP lowers energy intake at lunch compared with a breakfast with casein, soy, whey, or whey-GMP. Clin Nutr 2009;28:147-55.

63. Veldhorst MA, Nieuwenhuizen AG, Hochstenbach-Waelen A, et al. Effects of high and normal soyprotein breakfasts on satiety and subsequent energy intake, including amino acid and 'satiety' hormone responses. Eur J Nutr 2009;48:92-100.

64. Veldhorst MA, Nieuwenhuizen AG, Hochstenbach-Waelen A, et al. Effects of complete wheyprotein breakfasts versus whey without GMP-breakfasts on energy intake and satiety. Appetite 2009;52:388-95.

65. Veldhorst MA, Nieuwenhuizen AG, Hochstenbach-Waelen A, et al. Comparison of the effects of a high- and normal-casein breakfast on satiety, 'satiety' hormones, plasma amino acids and subsequent energy intake. Br J Nutr 2009;101:295-303.

66. Tasali E, Leproult R, Ehrmann DA, Van Cauter E. Slow-wave sleep and the risk of type 2 diabetes in humans. Proc Natl Acad Sci U S A 2008;105:1044-9.

67. van den Berg JF, Knvistingh Neven A, Tulen JH, et al. Actigraphic sleep duration and fragmentation are related to obesity in the elderly: the Rotterdam Study. Int J Obes (Lond) 2008. 
68. Levine J, Melanson EL, Westerterp KR, Hill JO. Measurement of the components of nonexercise activity thermogenesis. Am J Physiol Endocrinol Metab 2001;281:E670-5. 



\section{Chapter 2}

\section{Thermogenic ingredients and body- weight regulation}

Hursel R and Westerterp-Plantenga MS

Int J Obes (London) 2010; 34(4): 659-69 


\begin{abstract}
The global prevalence of obesity has increased considerably in the last decade. Tools for obesity management, including consumption of caffeine, capsaicin and different teas such as green, white and oolong tea, have been proposed as strategies for weight loss and weight maintenance, as they may increase energy expenditure (4-5\%), fat oxidation (10-16\%) and have been proposed to counteract the decrease in metabolic rate that is present during weight loss. Daily increases in thermogenesis of approximately $300-400 \mathrm{~kJ}$ can eventually lead to substantial weight loss. However, it becomes clearer that certain conditions have to be met before thermogenic ingredients yield an effect, as intra-variability with respect to body weight regulation has been shown between subjects. Furthermore, the sympathetic nervous system is involved in the regulation of lipolysis, and the sympathetic innervation of white adipose tissue may have an important role in the regulation of total body fat in general. Taken together, these functional ingredients have the potential to produce significant effects on metabolic targets such as satiety, thermogenesis and fat oxidation. A significant clinical outcome may sometimes appear straightforward and may also depend very strongly on full compliance of subjects. Nevertheless, thermogenic ingredients may be considered as functional agents that could help in preventing a positive energy balance and obesity.
\end{abstract}

Keywords: body weight, thermogenic, fat oxidation, energy expenditure, energy intake 


\section{Introduction}

Overweight and obesity represent a rapidly growing threat to the health of populations in an increasing number of countries (1). The ultimate cause of obesity is an imbalance between energy intake and energy expenditure (EE)(2). A negative energy balance is needed to produce weight loss and can be achieved by either decreasing intake or increasing expenditure $(3,4)$. Among others, stimulation of EE (or the prevention of its decline during dieting) by the use of natural herbal ingredients such as teas, caffeine and capsaicin has attracted interest, especially because these ingredients do not contain any energy themselves, yet stimulate expenditure of energy. Green tea (GT), oolong tea (OT) and white tea (WT) are consumed primarily in China, Japan and a few countries in North Africa and the Middle East $(5,6)$. Tea is made from the leaves of Camellia sinensis $L$. species of the Theaceae family, GT being the non-oxidized, non-fermented product, OT the semioxidized, semifermented product; WT is made from the youngest buds of the plant that undergo even less processing than GT. As a consequence of this, all teas contain high quantities of several polyphenolic components such as epicatechin, epicatechin gallate, epigallocatechin and, the most abundant and probably the most pharmacologically active, epigallocatechin gallate (7). Tea leaves that have been processed the least contain the most catechins.

From caffeine, that is also present in GT, it has been reported that it has thermogenic effects and can stimulate fat oxidation in vitro, in part through sympathetic activation of the central nervous system (8). In humans, caffeine has been shown to stimulate thermogenesis and fat oxidation (9-11). GT extracts, containing caffeine and catechin-polyphenols, have been reported to have an effect on body weight $(7,12)$ and EE $(12-14)$. The observation that GT stimulates thermogenesis cannot be completely attributed to its caffeine content because the thermogenic effects of GT extract containing caffeine and catechinpolyphenols is greater than that of an equivalent amount of caffeine (13).

Finally, capsaicin is the major pungent principle in red hot pepper. Hot peppers or capsium species are used in food products and as spices worldwide, but especially in Asia it is very commonly used (15). Over the last decade, capsaicin has been studied for its thermogenic and satiating capacities. Although there may be more thermogenic ingredients than the ones listed here, these are the most promising and have been primarily studied with respect to body weight regulation.

\section{Efficacy of GT, OT and WT}

Green tea has been well studied in the short term (13, 16-20) (Table 1) and over the long term (21-35) (Table 2). EE and fat oxidation in the short term and weight loss and weight maintenance (WM) in the long term are the key issues 
that most of the studies have focused on. A recently published meta-analysis about the effects of GT on weight loss and WM, which included most of the longterm studies presented in Table 2, showed that GT significantly attributed to weight loss and prevents weight regain with on average $1.3 \mathrm{~kg}(36)$. On the basis of the collected data from all the conducted studies so far, GT seems to be a promising agent for body weight regulation. Its fellow members of the tea family, OT and WT, have not been studied very extensively. OT's long-term effects (22, $37-40)$ are more investigated than its acute effects $(18,41)$. No studies have been conducted so far that address the effects of WT on thermogenesis and body weight. Biochemical analyses, however, do show differences between the different processed teas. WT has been shown to contain the largest amount of catechins, from which EGCG is also present abundantly. The amount of caffeine in WT is also substantially larger compared with for instance GT (42-45). More research is needed to study WT's effect on thermogenesis.

\section{Green tea and high-protein diet}

As GT (epigallocatechin gallate + caffeine) and protein have both shown to improve body WM after weight loss, it was investigated whether the effect of a GTcaffeine mixture, added to a high-protein diet (HP), on WM after body weight loss in moderately obese subjects would have a synergistic effect (46). In a randomized placebo-controlled double blind parallel trial in 80 overweight and moderately obese subjects (age: $44 \pm 2$ (s.d.) years; body mass index: $29.6 \pm 2.0 \mathrm{~kg} \mathrm{~m}$ ${ }^{-2}$ ), matched for gender, age, body mass index, height, body mass and with a habitually low caffeine intake, a very low energy diet intervention during 4 weeks was followed by 3 months WM. During the WM period, the subjects received a GT-caffeine mixture (270 mg epigallocatechin gallate $+150 \mathrm{mg}$ caffeine per day), or placebo, both in addition to an adequate protein diet (AP: 50-60 g protein per day) vs a HP (100-120 g protein per day). Subjects lost $7.0 \mathrm{~kg} \pm 1.6$, or $8.2 \% \pm 2.0$ body weight $(p<0.001)$. During the WM phase, WM, resting energy expenditure, fat-free mass were relatively increased, in both the HP groups and in the AP+GT-caffeine mixture group $(p<0.05)$, whereas respiratory quotient and body fat (free mass) were reduced, all compared with the AP+placebo group. Satiety was only increased in both HP groups $(p<0.05)$. The GT-caffeine mixture was only effective in the AP diet. The authors conclude that a GT-caffeine mixture and an HP improved WM independently, through thermogenesis, fat oxidation, sparing fat-free mass, and for the HP through satiety; yet a possible synergistic effect failed to appear (46). 


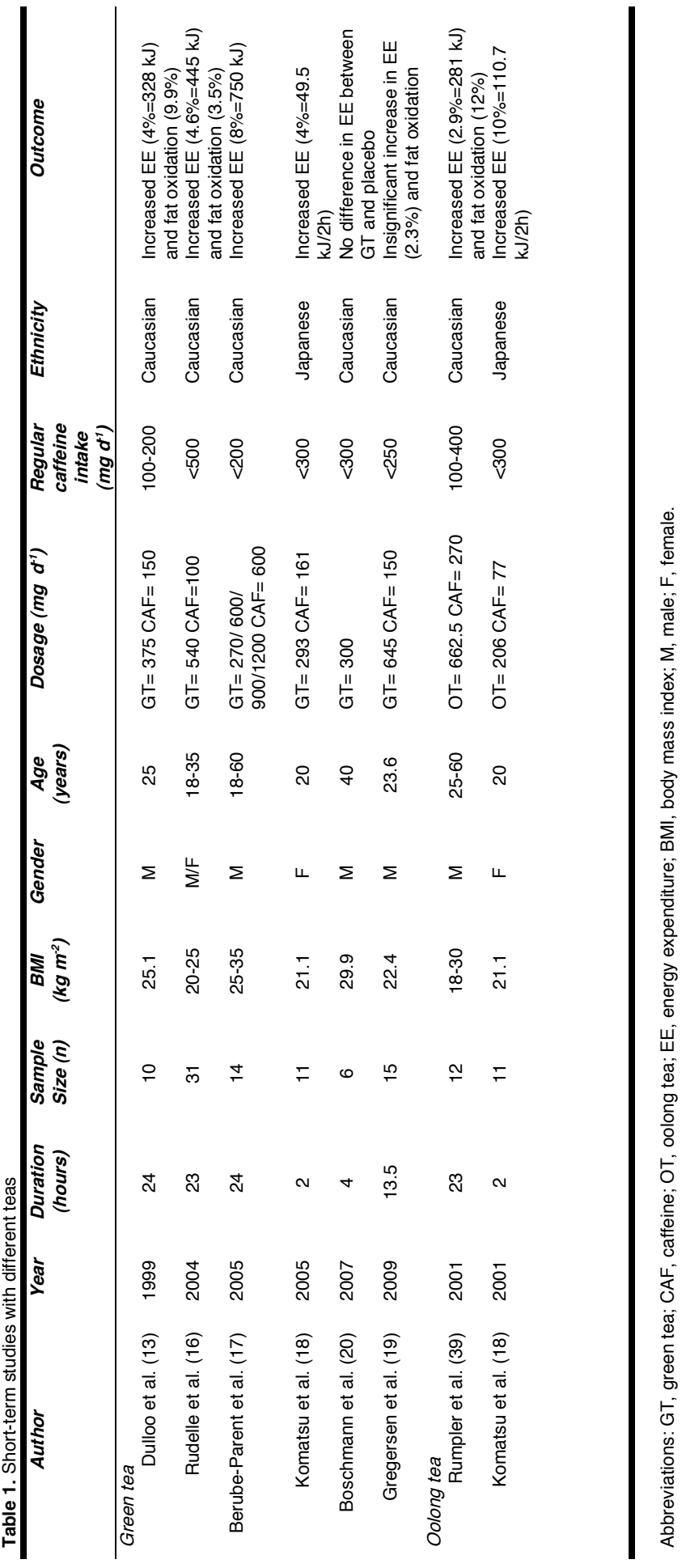




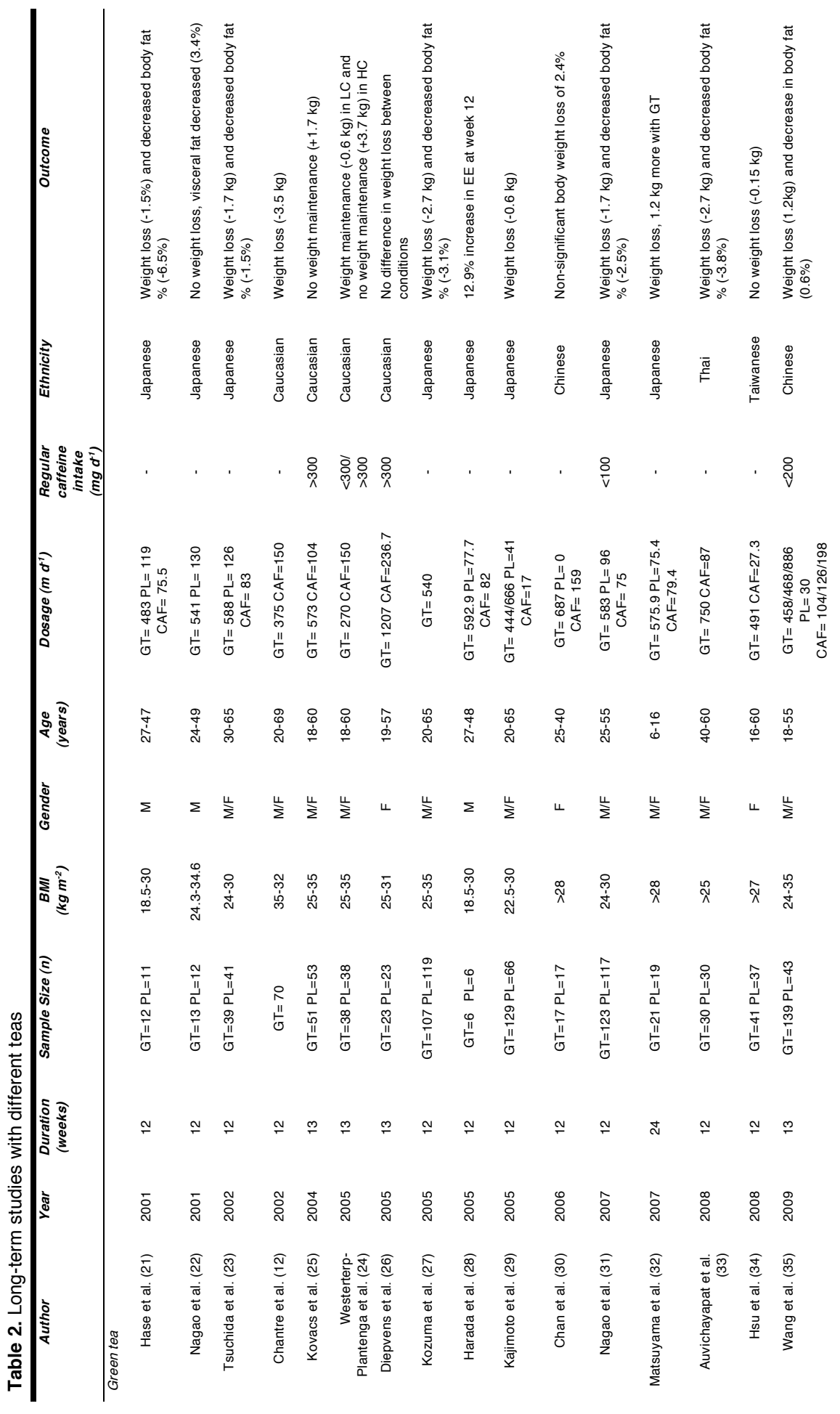




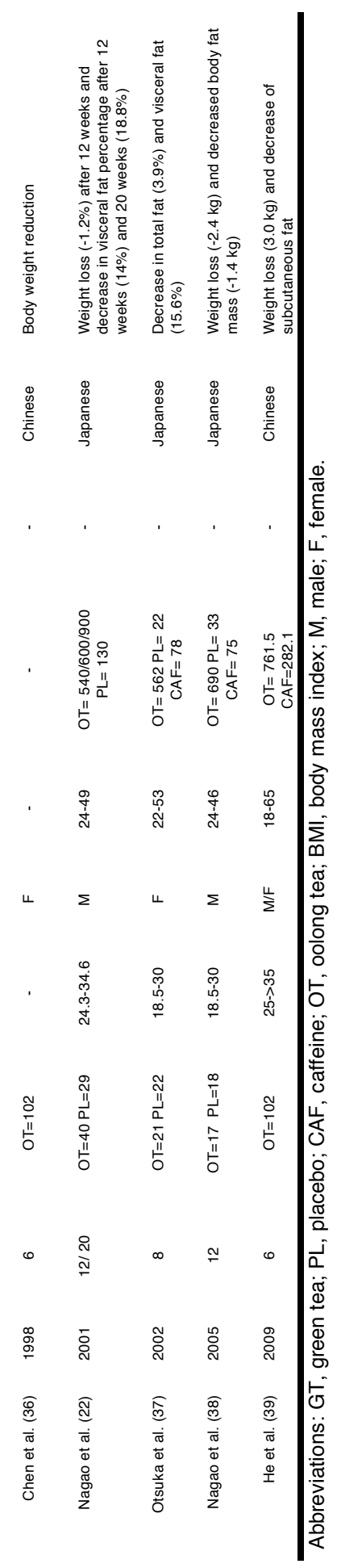




\section{Mechanisms of action}

\section{Teas and caffeine}

Catechins in tea inhibit the enzyme catechol-O-methyltransferase (COMT) that is present in almost every tissue and degrades catecholic compounds such as norepinephrine (NE) $(13,24)$ (Figure 1). COMT decreases the hydrophilicity by methylation, followed by sulfation and glucuronidation to make the excretion in urine and bile possible (47). NE cannot be degraded through the inhibition of COMT, and consequently the sympathetic nerve system (SNS) will be stimulated continuously due to the presence of NE, which attaches to $\beta$-adrenoceptors and causes an increase in EE and fat oxidation (48). The SNS has an important role in the regulation of energy homeostasis but the above-described phenomenon does not always appear equally clear in all ethnic groups. For instance, studies with Asian subjects seem to report more positive results than studies with Caucasian subjects. This may be caused by differences in relevant enzyme activity, causing differences in sensitivity for these ingredients. In that respect, Hodgson et al. (49) stated that there is a wide variability in flavonoid O-methylation, a major pathway of flavonoid metabolism, by the enzyme COMT. The interindividual variability of the activity of COMT could vary as much as threefold. Moreover, there is evidence that there is a difference in COMT enzyme activity between ethnic groups (50). Asian populations have a higher frequency of the thermostable, high activity enzyme, $\mathrm{COMT}_{\mathrm{H}}$ allele ( $\mathrm{Val} / \mathrm{Val}$ polymorphism) than the Caucasian populations. The Caucasian populations have a higher frequency of the thermolabile, low activity enzyme, COMT $\mathrm{C}_{\mathrm{L}}$ allele (Met/Met polymorphism) (50). Fifty percent of the Caucasians are homozygous for the $\mathrm{COMT}_{\mathrm{L}}$ allele $(25 \%)$ and $\mathrm{COMT}_{\mathrm{H}}$ allele (25\%). The other $50 \%$ is heterozygous (Val/Met polymorphism) (50). This may explain the difference in sensitivity to interventions with GT-caffeine mixtures, and why, in some studies with Caucasian subjects, no effect was seen after ingestion of GT.

As caffeine is also present in tea, its effect will also take place after tea consumption. Caffeine affects the thermogenesis by inhibiting the enzyme phosphodiesterase. This enzyme degrades intracellular cyclic amino mono phosphate (51). Phosphodiesterase usually hydrolyses cyclic adenosine monophosphate (CAMP) to AMP, but after consumption of caffeine, cAMP concentration rises and SNS activity will be increased and inactive hormone-sensitive lipase will be activated, which promotes lipolysis (52). The SNS activity and lipoysis are dependent on CAMP, because cAMP activates the protein kinase A (53). Besides the inhibition of phosphodiesterase, caffeine also affects the thermogenesis through the stimulation of substrate cycles such as the Cori-cycle and the FFAtriglyceride cycle (10). Caffeine is a methylxanthine, which has a thermogenic impact. In the Cori-cycle, lactate moves from the muscles to the liver, where it will be converted into pyruvate. The pyruvate will be converted to glucose by the 


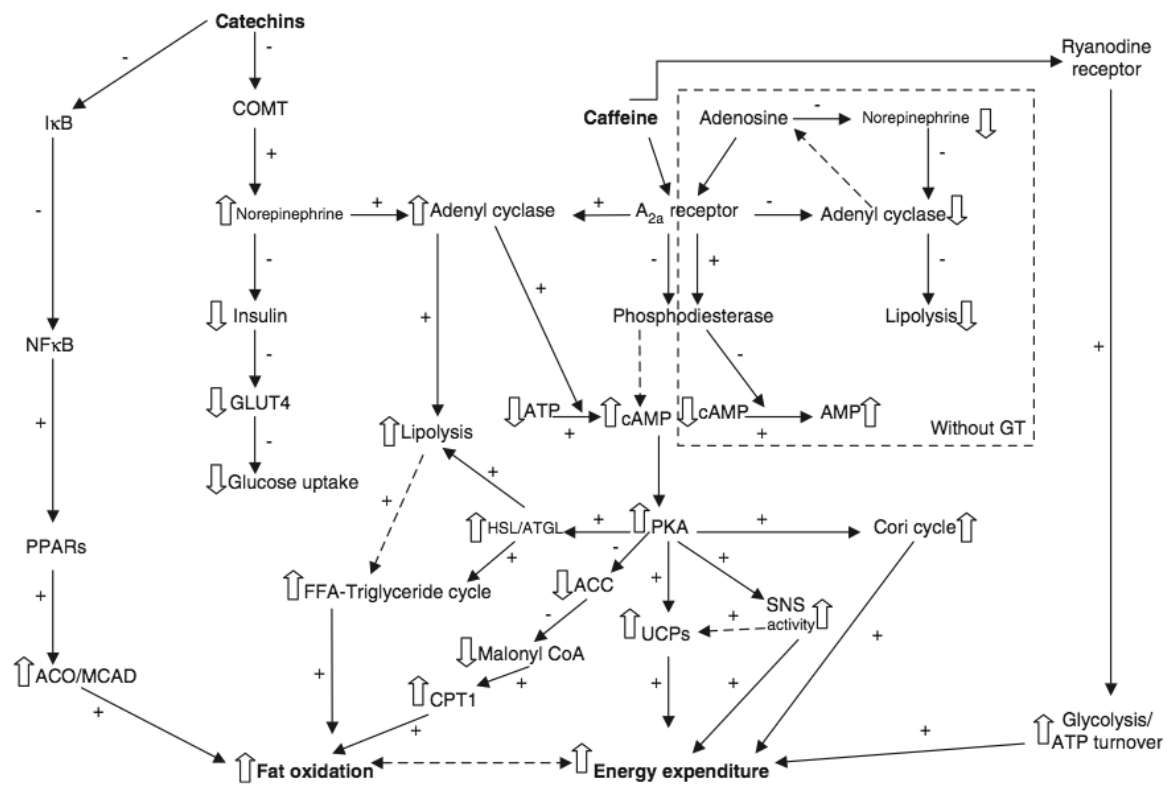

Figure 1. Mechanism of action after supplementation of a green tea-caffeine mixture. Catechins upregulate lipid-metabolizing enzymes via NFKB and thereby stimulate fat oxidation. Catechins also inhibit COMT that leads to an increase in norepinephrine and adenyl cyclase. Glucose uptake is decreased and lipolysis is enhanced. Caffeine antagonizes adenosine that usually decreases levels of norepinephrine. Phosphodiesterase is inhibited by caffeine and PKA is increased because of the catechins and caffeine. Stimulation of sympathetic nervous system, hormone sensitive lipase and upregulation of UCPs lead to an increased energy expenditure and fat oxidation. Also indicated in the pathway what occurs without the mixture. GT, green tea-caffeine mixture; COMT, catechol-O-

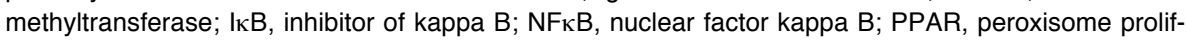
erators activated receptors; ACO/ MCAD, acyl-CoA oxidase/ medium chain acyl CoA dehydrogenase; GLUT 4, insulin-regulated glucose transporter; FFA, free fatty acids; HSL, hormone-sensitive lipase; ACC, acetyl-CoA carboxylase; CPT1, carnitine palmitoyltransferase 1; ATP, adenosine triphosphate; cAMP, cyclic adenosine monophosphate; $A_{2 a}$-receptor, adenosine 2 a receptor; PKA, protein kinase A; UCP, uncoupling protein; SNS, sympathetic nervous system.

enzyme lactate dehydrogenase and circulate back to the muscles through the blood (10).Acheson et al. (52) showed that FFA turnover and lipid oxidation are increased after the consumption of caffeine but that it requires a large increase in FFA turnover to have a small increase in lipid oxidation. Non-oxidative lipid turnover, the hydrolysis and reesterification of triacylglycerol, is greater than the increase in oxidative lipid disposal (52). They also found that caffeine antagonizes the inhibitory effects of adenosine on lipolysis by adenylyl cyclase. Nonadrenergic thermogenic mechanisms can also be involved, as caffeine antagonizes the ryanodine receptor, the calcium ion release channel of sarcoplasmatic reticulum in skeletal muscle that for instance increases glycolysis and adenosine triphosphate turnover after stimulation (52).

Catechins and caffeine inhibit two enzymes, which interrupt the pathway of NE-activated thermogenesis (54). As SNS activity is determined by the concen- 
tration of NE, more NE means a higher activity and increased EE. SNS activity regulates the resting metabolic rate, which is the largest component of the daily EE. NE makes it possible to increase the usage of adenosine triphosphate through ion pumping and substrate cycling (14). The rate of mitochondrial oxidation is also involved in the increased the mogenesis due to the poor coupling of adenosine triphosphate synthesis, which leads to heat production. Catechins also have a direct effect on the gene expression of different uncoupling proteins (UCPs) that influence the thermogenesis with the production of heat (55). Gene expression of the UCPs also increases when camp activates the protein kinase A, after the inhibition of phophodiesterase by caffeine (56). The protein kinase A stimulates hormone-sensitive lipase, which increases the concentration of free fatty acids by the conversion of triglycerides. UCP activity will be enhanced through this (56).

The increase in EE is accompanied by a change in substrate oxidation, as Dulloo et al. showed an increase in fat oxidation after the supplementation of GT (13). Another mechanism is triggered by the tea catechins that block the nuclear factor- $\kappa B$ activation by inhibiting the phosphorylation of inhibitor of $\kappa B(57)$. Nuclear factor- $\kappa \mathrm{B}$ is an oxidative stress sensitive transcription factor that regulates the expression of several genes, which are important in cellular responses such as inflammation and growth (57). Nuclear factor- $\kappa B$ is no longer able to inhibit the peroxisome proliferator-activated receptors that are important transcription factors for lipid metabolism (58). The mRNA expression of lipid-metabolizing enzymes, such as acyl-CoA oxidase and medium chain acyl-CoA dehydrogenase, is upregulated. Acyl-CoA oxidase is a peroxisomal $\beta$-oxidation enzyme and medium chain acyl-CoA dehydrogenase is a mitochondria $\beta$-oxidation enzyme in the liver (58). The upregulation of these lipid-metabolizing enzymes makes it clear that $\beta$-oxidation activation after the supplementation of tea catechins is enhanced followed by an increase in fat oxidation.

With respect to the failure to show synergy between effects of a GT-caffeine mixture and an HP, the following mechanisms may shed light on this issue (46). Already in 1963, it was reported that proteins formed complexes with the polyphenols in tea. Especially caseins, which are present in milk protein, tend to bind the polyphenols (59). In the absence of caseins, $\alpha$-lactalbumin and $\beta$ lactoglobulin can form complexes with the flavonoids. The protein 'wraps' itself around the catechins, a process named non-covalent crosslinking. This process might reduce the bioavailability and accessibility of the polyphenols (60). There is still some controversy about whether addition of milk to tea inhibits the beneficial effects of tea drinking. In an epidemiological study in a Welsh population, tea drinking appeared to be associated with a higher risk of developing coronary heart diseases (61). This was in contrast to the results of a comparable study in a Dutch population, where tea drinking was inversely associated with coronary heart diseases. The only difference between the populations, as both consume mainly black tea, is that people in Great Britain add milk to their tea. Addition of 
milk to tea lowered the concentrations of catechins in vitro, together with a significant reduction of the endothelial function after tea with milk in comparison with tea alone. The added milk lowered the vascular protective effects of tea, and the antioxidant capacity of tea to a maximum of $28 \%$ (62). The fat content of milk is not of importance, yet the interactions between flavonoids and proteins impede the gastric hydrolysis and thereby reduce the absorption of the polyphenols. It was also found that total antioxidant capacity was not lowered due to the addition of milk to tea, but the polyphenols were rather unavailable for absorption as the polyphenol-protein complexes were resistant to gastric hydrolysis. Moreover, absorption may be reduced because the $\mathrm{pH}$ of the stomach changes through the milk. The polyphenols have weak acid compounds that are easily absorbed in their non-ionised form. If the $\mathrm{pH}$ in the stomach rises due to the addition of milk, this can increase the ionization, which impedes the passage of the polyphenols through the gastric mucosa (63). In contrast, studies have shown no lowered antioxidant potential but a delay through the interference with absorption by milk. From the different explanations, the most proclaimed is the reduction in absorption after the formation of a protein-polyphenol complex that is resistant to gastric hydrolysis. The formation of such complexes takes place in the upper part of the digestive tract. If the complexes would be resistant to gastric hydrolysis from the beginning of the gastrointestinal system and therefore cannot be absorbed, how is it then possible that the HP + GT-caffeine mixture group has nearly the same effect as the HP + placebo group and the AP + GTcaffeine mixture group from which the proteins and polyphenols are absorbed? Most presumably, there is a surplus of proteins such as $\alpha$-lactalbumin and $\beta$ lactoglobulin that only binds to flavonoids during the absence of caseins. These proteins may still be absorbed when the rest has formed complexes with polyphenols and they are known for their ability to reduce energy intake by a hunger suppressive effect, increase diet-induced thermogenesis and preserve lean body mass at the expense of fat mass (46).

\section{Safety of tea administration}

Tea has been widely consumed in China and Japan for many centuries and is considered safe. A possible side effect of GT consumption is a minor increase in blood pressure as seen by Berube-Parent et al. (17). They observed a nonsignificant increase $(7 \mathrm{mmHg})$ in $24 \mathrm{hr}$ systolic blood pressure accompanied by a significant increase $(5 \mathrm{mmHg})$ in $24 \mathrm{hr}$ diastolic blood pressure. No increase in heart rate was seen (17). This small short-term increase in blood pressure induced by GT might be neglected, as systolic blood pressure, diastolic blood pressure and heart rate were not affected by GT in other short-term (13) or longterm research $(12,26)$. 


\section{Efficacy of caffeine}

For many years caffeine is known for its stimulating properties and the thermogenic effects have been extensively examined. Besides enhancing EE, ca feine also affects energy intake. However, these acute effects $(9-11,13,19,41$, $52,64-67$ ) have not resulted into a successful long-term approach yet (68) (Table 3). Only in a prospective study from Lopez-Garcia et al. (69), who studied the effect of caffeine on long-term weight change in a cohort, it was found that people who increased the caffeine consumption over 12 years gained less weight than those who decreased the caffeine consumption. Previous studies suggest that sensitivity to caffeine may be lost over time, which means that body weight regulation cannot be sustained for a longer period of time while receiving the same dosage.

\section{Safety of caffeine administration}

Caffeine appears to be a safe thermogenic agent for weight control. In adults, the short-term lethal dose for caffeine is estimated at $5-10 \mathrm{~g} \mathrm{day}^{-1}$ (either intravenously or orally), which is equivalent to 75 cups of coffee, 125 cups of tea or 200 cola beverages (70). Long-term ingestion of caffeine has been suggested to have some minor adverse effects on human health. Astrup et al. (10) observed only small and insignificant changes in blood pressure and pulse rate after 100 and $200 \mathrm{mg}$ caffeine. In contrast, $400 \mathrm{mg}$ caffeine significantly increased systolic and diastolic blood pressure by an average value of $6.3 \mathrm{mmHg}$. Furthermore, after $400 \mathrm{mg}$ caffeine, significantly more subjects reported side effects such as palpitation, anxiety, headache, restlessness, dizziness compared with placebo (10). Robertson et al. (71) administrated $250 \mathrm{mg}$ oral caffeine to nine subjects who were not used to coffee. Systolic blood pressure increased $10 \mathrm{mmHg} 1 \mathrm{hr}$ after caffeine consumption. Heart rate showed a decrease after the first hour followed by an increase above baseline after $2 \mathrm{hr}(71)$. However, in a subsequent study that examined the chronic effects of caffeine ingestion (150 mg day ${ }^{-1}$ for 7 days), tolerance to these effects was developed after 1-4 days (72). Thus no long-term effects of caffeine on blood pressure, heart rate or plasma rennin activity were demonstrated. Furthermore, in the short term, Bracco et al. (11) did not find a significantly altered heart rate during the day after $4 \mathrm{mg}$ caffeine per $\mathrm{kg}$ body weight was consumed five times daily. Accordingly, the use of caffeine is relatively safe, as it is quite certain that, although acute caffeine consumption may alter some cardiovascular variables, chronic ingestion of caffeine has little or no health consequences. 


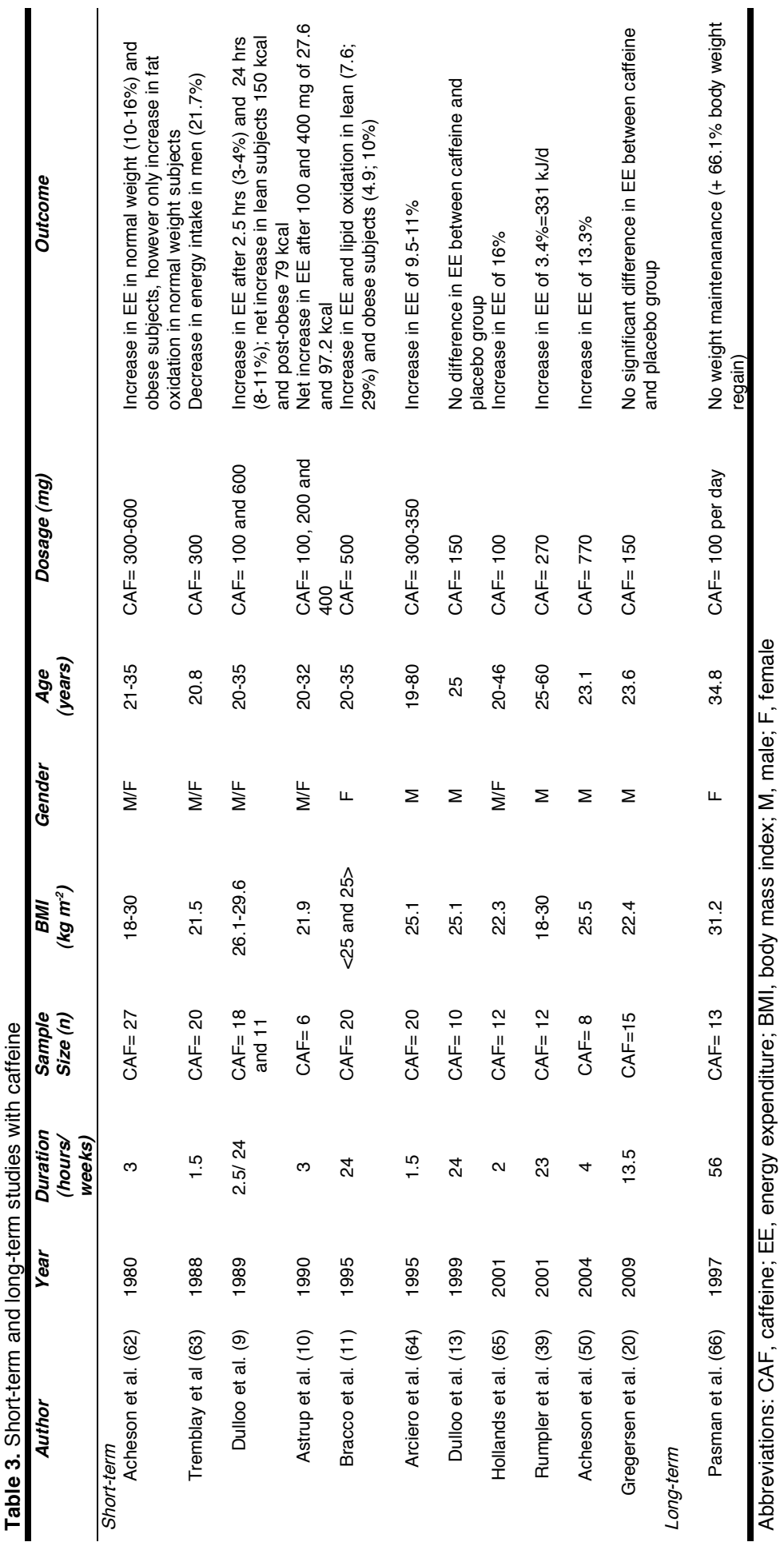




\section{Efficacy of capsaicin}

Studies concerning the thermogenic effects of capsaicin are mainly conducted in Asian populations, where it is more common in the daily food pattern. Effects on energy intake and $E E$ in the short term are evident in such populations (15, 7379). Nevertheless, hardly any long-term studies have been conducted with Asians. In the long-term studies with Caucasians $(80,81)$, compliance often seems to be the problem and therefore fail to result in negative body weight regulation. Although it was suggested that the effect of capsaicin is based on accumulation (78), dosages are often too low in Caucasian studies. The use of $\mathrm{CH}-19$ Sweet pepper, which is the fruit of a non-pungent cultivar of pepper, might be the solution for the compliance issue. Capsiate, in $\mathrm{CH}-19$ Sweet pepper, has a structure similar to capsaicin but no pungency (76) (Table 4).

\section{Mechanisms of action}

Capsaicin has been reported to increase thermogenesis by enhancing catecholamine secretion from the adrenal medulla in rats, mainly through activation of the central nervous system (Figure 2). Increase in thermogenesis induced by capsaicin is probably based on $\beta$-adrenergic stimulation. Both animal and human studies showed that the increase in thermogenesis is abolished after administration of $\beta$-adrenergic blockers such as propranolol. The upregulation of UCPs 1 and 2 after capsiate administration in animals was showed by Masuda et al. (82) and believed to be responsible for the increase in thermogenesis. However, in a more recent study it was shown that UCP 3 was downregulated after capsiate treatment. This reduced UCP 3 gene expression was accompanied with an increase in the mitochondrial adenosine triphosphate production (83). Furthermore, the presence of a functional capsaicin-like vanilloid receptor in the vasculature of the rat hindlimb that mediates oxygen uptake, and thus thermogenesis, was observed. This vanilloid receptor, that is, the transient receptor potential vanilloid receptor-1 (TRPV1), is expressed in sensory neurons, the brain and various non-neuronal tissues, and is also involved in the pain pathway (74). Different polymorphisms for the TRPV1 receptor and UCP 2 promoter region seem to be of importance in the therapeutic response toward capsinoid treatment. The TRPV1 Val585/le polymorphism is associated with more abdominal fat loss compared with the Ile/lle variant. This might explain the variability in outcomes between individuals. 


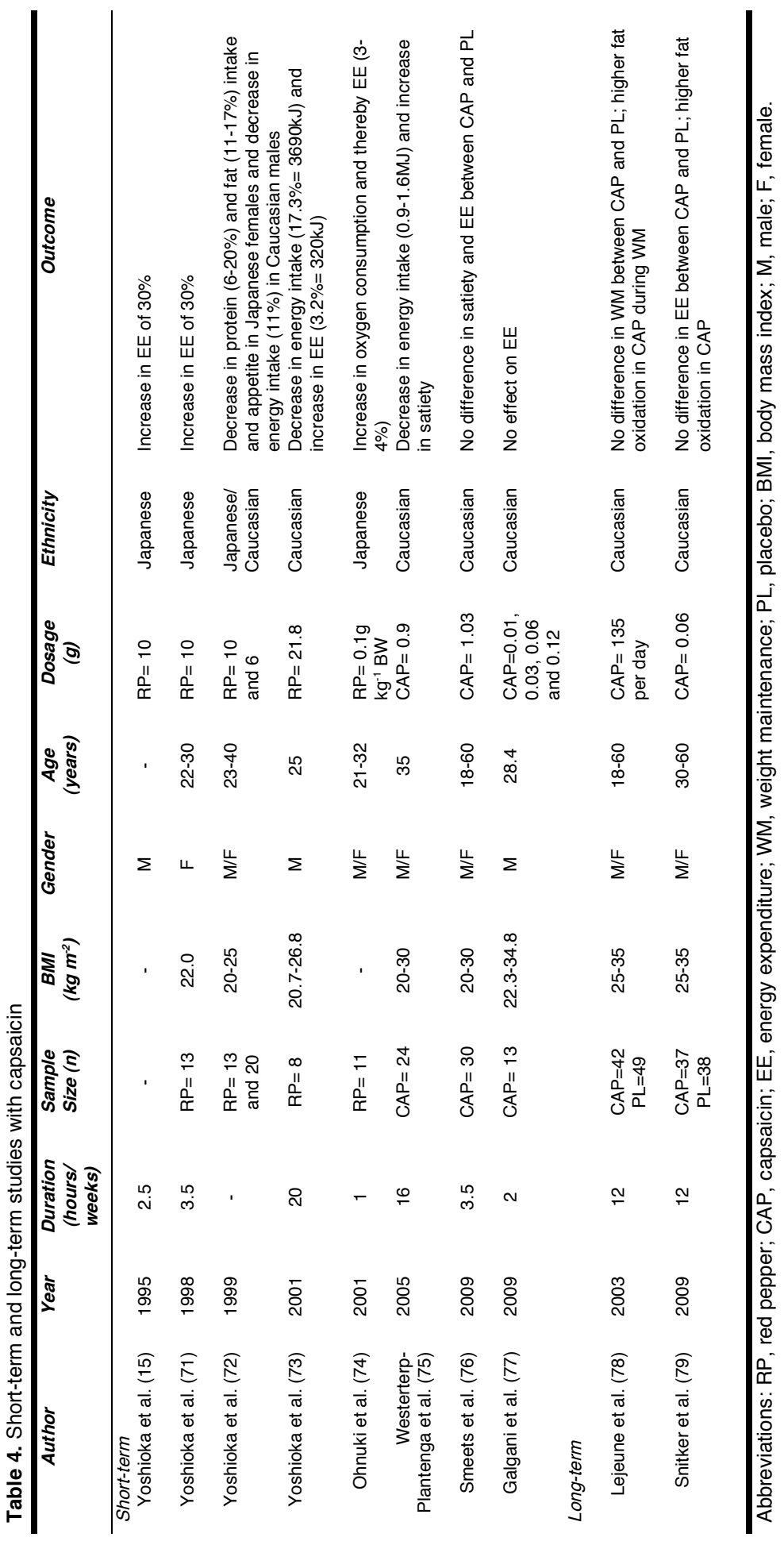




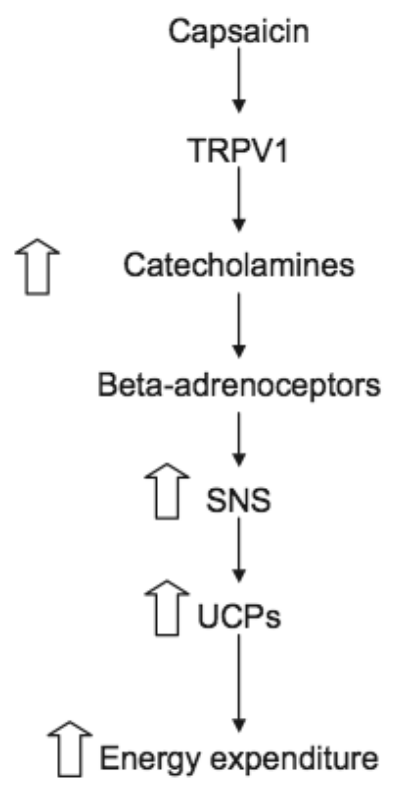

Figure 2. Mechanism of action after supplementation of capsaicin. Capsaicin stimulates catecholamine production via the TRPV1 receptor, which leads to an increased energy expenditure via stimulation of the sympathetic nervous system and the upregulation of UCPs.

TRPV1, transient receptor potential vanilloid; SNS, sympathetic nervous system; UCP, uncoupling protein.

\section{Safety of capsaicin administration}

As mentioned before, the long-term use of capsaicin may be limited by its strong pungency. A possible solution for this may be using $\mathrm{CH}-19$ Sweet. $\mathrm{CH}-19$ Sweet is the fruit of a nonpungent cultivar of pepper. Nevertheless, capsaicin is considered to be safe for human consumption $(15,74,75,77,78)$.

\section{Summary}

Ingredients for obesity management are tea, caffeine and capsaicin, as they increase daily EE with $4-5 \%(=300-400 \mathrm{~kJ})$ without increasing energy intake and counteract the decrease in metabolic rate during weight loss. Studies have shown that these ingredients are useful in losing weight or preventing weight regain after weight loss. These ingredients activate the SNS, which is involved in the regulation of energy balance. Evidence is present with respect to sensitivity of SNS to positive energy balances. In animals, SNS activation is a key element of the counter regulatory response to excessive food intake in heart and brown adipose tissue, and SNS activation is an important aspect of the response to overfeeding. SNS activation increases thermogenesis and wastes excess energy 
as heat, and thereby compensates for surplus energy intake. The result is the prevention of body weight gain.

Nevertheless, certain conditions are required before these tools are efficient. For instance, capsaicin is effective in principle, yet it requires a strong compliance that is not feasible yet. As mentioned, the $\mathrm{CH}-19$ Sweet may be the solution for the compliance problem. Catechins and caffeine in tea, that inhibit catechol-O-methyltransferase and phosphodiesterase, have a bitter taste. Again compliance seems to be a problem, as people prefer different tastes. Furthermore, it has been shown that a GT-caffeine mixture is only efficient in low habitual caffeine consumers (24) and that proteins which also improve WM, through thermogenesis, fat oxidation, sparing fat-free mass and satiety, have no synergistic effect with GT when administered simultaneously (46). However, caffeine, tea and capsaicin can until now be considered as relatively safe.

More studies are focusing on administering a combination of these bioactive ingredients in order to obtain a higher efficiency than when supplied separately. Reinbach et al. (84), for instance, showed a decrease in energy intake after administering a combination of capsaicin and GT or $\mathrm{CH}-19$ Sweet pepper. Twentyseven subjects participated in a study with a crossover design and were randomized to 3 weeks of negative and 3 weeks of positive energy balance, during which they received a combination of thermogenic ingredients. Subjects reduced their energy intake the most during positive energy balance after administering a combination of capsaicin and GT or $\mathrm{CH}-19$ Sweet pepper. However, hunger was most suppressed and satiety was most enhanced after GT and capsaicin during negative energy balance compared with positive energy balance. The authors conclude that thermogenic food ingredients have energy intake reducing effects when used in combinations, and in positive energy balance (84). Belza et al. (85) supplied a combination of GT extract, capsaicin, tyrosine and calcium for a period of 7 days. An increase of approximately $200 \mathrm{~kJ}(2 \%)$ in thermogenesis was seen after this period. A failure of synergism between GT and protein suggests that a combination of bioactive ingredients is not always a key to success. Furthermore, we hypothesized previously that genetic predisposition has an important role in whether or not bioactive ingredients efficiently increase thermogenesis. Studies with functional foods report great intra-variability between subjects concerning effects on satiety and EE. With respect to GT, different polymorphisms for the COMT enzyme exist. Allele frequencies show that the more favorable polymorphism is highly abundant in Asians, in contrast with Caucasians where only a minority possesses this polymorphism. Capsaicin may also have a similar mechanism that underlies their effects. As earlier mentioned, the TRPV1 Val585/le polymorphism, a different genetic variant for the TRPV1 receptor, is associated with more abdominal fat loss compared with the Ile/lle variant after capsiate treatment (81). It is hardly any coincidence that ingredients such as tea and capsaicin are very common in Asia and originate from this region. Asians seem to be more adapted to these ingredients as they are part of their daily lifestyle. Thus far, obesity does not seem to be a problem in this region at least 
not for the people who stick to the traditional diet. This means that thermogenic ingredients can be used as functional foods, and that they prevent a positive energy balance and obesity, when the right terms are met.

\section{Conclusion}

Ingredients for obesity management, including caffeine, capsaicin and different teas such as green, white and oolong tea, have been proposed as strategies for weight loss and weight maintenace, as they may increase EE (4-5\%), fat oxidation (10-16\%) and have been proposed to counteract the decrease in metabolic rate that is present during weight loss. Daily increases in thermogenesis of approximately $300-400 \mathrm{~kJ}$ can eventually lead to substantial weight loss. However, it becomes clearer that certain conditions have to be met before thermogenic ingredients yield an effect, as intra-variability with respect to body weight regulation has been shown between subjects. Taken together, these functional ingredients have the potential to produce significant effects on metabolic targets such as satiety, thermogenesis and fat oxidation. A significant clinical outcome sometimes may appear straightforwardly but also depends very strongly on full compliance of subjects. Nevertheless, thermogenic ingredients may be considered as functional agents that could help in preventing a positive energy balance and obesity.

\section{References}

1. Obesity: preventing and managing the global epidemic. Report of a WHO consultation. World Health Organ Tech Rep Ser 2000; 894: i-xii, 1-253.

2. Stunkard AJ. Current views on obesity. The American journal of medicine 1996; 100: 230-236.

3. Wadden TA, Stunkard AJ, Liebschutz J. Three-year follow-up of the treatment of obesity by very low calorie diet, behavior therapy, and their combination. Journal of consulting and clinical psychology 1988; 56: 925-928.

4. Pasman WJ, Saris WH, Muls E, Vansant G, Westerterp-Plantenga MS. Effect of exercise training on long-term weight maintenance in weight-reduced men. Metabolism 1999; 48: 15-21.

5. Graham HN. Green tea composition, consumption, and polyphenol chemistry. Preventive medicine $1992 ; 21: 334-350$.

6. Weisburger JH. Tea and health: a historical perspective. Cancer letters 1997; 114: 315-317.

7. Kao YH, Hiipakka RA, Liao S. Modulation of endocrine systems and food intake by green tea epigallocatechin gallate. Endocrinology 2000; 141: 980-987.

8. Dulloo AG, Seydoux J, Girardier L. Potentiation of the thermogenic antiobesity effects of ephedrine by dietary methylxanthines: adenosine antagonism or phosphodiesterase inhibition? Metabolism 1992; 41: 1233-1241.

9. Dulloo AG, Geissler CA, Horton T, Collins A, Miller DS. Normal caffeine consumption: influence on thermogenesis and daily energy expenditure in lean and postobese human volunteers. Am J Clin Nutr 1989; 49: 44-50.

10. Astrup A, Toubro S, Cannon S, Hein P, Breum L, Madsen J. Caffeine: a double-blind, placebocontrolled study of its thermogenic, metabolic, and cardiovascular effects in healthy volunteers. Am J Clin Nutr 1990; 51: 759-767. 
11. Bracco D, Ferrarra JM, Arnaud MJ, Jequier E, Schutz Y. Effects of caffeine on energy metabolism, heart rate, and methylxanthine metabolism in lean and obese women. Am J Physiol 1995; 269: E671-678.

12. Chantre P, Lairon D. Recent findings of green tea extract AR25 (Exolise) and its activity for the treatment of obesity. Phytomedicine 2002; 9: 3-8.

13. Dulloo AG, Duret C, Rohrer D, Girardier L, Mensi N, Fathi M, et al. Efficacy of a green tea extract rich in catechin polyphenols and caffeine in increasing 24-h energy expenditure and fat oxidation in humans. Am J Clin Nutr 1999; 70: 1040-1045.

14. Dulloo AG, Seydoux J, Girardier L, Chantre P, Vandermander J. Green tea and thermogenesis: interactions between catechin-polyphenols, caffeine and sympathetic activity. Int J Obes Relat Metab Disord 2000; 24: 252-258.

15. Yoshioka M, Lim K, Kikuzato S, Kiyonaga A, Tanaka H, Shindo M, et al. Effects of red-pepper diet on the energy metabolism in men. Journal of nutritional science and vitaminology 1995; 41 : 647-656.

16. Rudelle S, Ferruzzi MG, Cristiani I, Moulin J, Mace K, Acheson KJ, et al. Effect of a thermogenic beverage on 24-hour energy metabolism in humans. Obesity (Silver Spring, Md 2007; 15: 349355.

17. Berube-Parent S, Pelletier C, Dore J, Tremblay A. Effects of encapsulated green tea and Guarana extracts containing a mixture of epigallocatechin-3-gallate and caffeine on $24 \mathrm{~h}$ energy expenditure and fat oxidation in men. Br J Nutr 2005; 94: 432-436.

18. Komatsu T, Nakamori M, Komatsu K, Hosoda K, Okamura M, Toyama K, et al. Oolong tea increases energy metabolism in Japanese females. J Med Invest 2003; 50: 170-175.

19. Gregersen NT, Bitz C, Krog-Mikkelsen I, Hels O, Kovacs EM, Rycroft JA, et al. Effect of moderate intakes of different tea catechins and caffeine on acute measures of energy metabolism under sedentary conditions. Br J Nutr 2009; 102: 1187-1194.

20. Boschmann M, Thielecke F. The effects of epigallocatechin-3-gallate on thermogenesis and fat oxidation in obese men: a pilot study. J Am Coll Nutr 2007; 26: 389S-395S.

21. Hase T, Komine $Y$, Meguro S, Takeda $Y$, Takahashi $H$, Matsui $Y$, et al. Anti-obesity effects of tea catechins in humans. J Oleo Sci 2001; 50: 599-605.

22. Nagao T, Meguro S, Soga S, Otsuka A, Tomonobu K, Fumoto S, et al. Tea catechins suppress accumulation of body fat in humans. J Oleo Sci 2001; 50: 717-728.

23. Tsuchida $\mathrm{T}$, Itakura $\mathrm{H}$, Nakamura $\mathrm{H}$. Reduction of body fat in humans by long-term ingestion of catechins. Prog Med 2002; 22: 2189-2203.

24. Westerterp-Plantenga MS, Lejeune MP, Kovacs EM. Body weight loss and weight maintenance in relation to habitual caffeine intake and green tea supplementation. Obes Res 2005; 13: 11951204.

25. Kovacs EM, Lejeune MP, Nijs I, Westerterp-Plantenga MS. Effects of green tea on weight maintenance after body-weight loss. Br J Nutr 2004; 91: 431-437.

26. Diepvens K, Kovacs EM, Nijs IM, Vogels N, Westerterp-Plantenga MS. Effect of green tea on resting energy expenditure and substrate oxidation during weight loss in overweight females. $\mathrm{Br}$ J Nutr 2005; 94: 1026-1034.

27. Kozuma K, Chikama A, Hishino E, Kataoka K, Mori K, Hase T, et al. Effect of intake of a beverage containing $540 \mathrm{mg}$ catechins on the body composition of obese women and men. Prog Med 2005; 25: 185-197.

28. Harada U, Chikama A, Saito S, Takase H, Nagao T, Hase T, et al. Effects of long-term ingestion of tea catechins on energy expenditure and dietary fat oxidation in healthy subjects. J Health Sci 2005; 51: 248-252.

29. Kajimoto O, Kajimoto Y, Yabune M, Nakamura H, Kotani K, Suzuki Y, et al. Tea catechins with a galloyl moiety reduce body weight and fat. J Health Sci 2005; 51: 248-252.

30. Chan CC, Koo MW, Ng EH, Tang OS, Yeung WS, Ho PC. Effects of Chinese green tea on weight, and hormonal and biochemical profiles in obese patients with polycystic ovary syndromea randomized placebo-controlled trial. Journal of the Society for Gynecologic Investigation 2006; 13: $63-68$.

31. Nagao T, Hase T, Tokimitsu I. A green tea extract high in catechins reduces body fat and cardiovascular risks in humans. Obesity (Silver Spring, Md 2007; 15: 1473-1483. 
32. Matsuyama T, Tanaka Y, Kamimaki I, Nagao T, Tokimitsu I. Catechin safely improved higher levels of fatness, blood pressure, and cholesterol in children. Obesity 2008.

33. Auvichayapat $\mathrm{P}$, Prapochanung M, Tunkamnerdthai O, Sripanidkulchai BO, Auvichayapat N, Thinkhamrop B, et al. Effectiveness of green tea on weight reduction in obese Thais: A randomized, controlled trial. Physiol Behav 2008; 93: 486-491.

34. Hsu CH, Tsai TH, Kao YH, Hwang KC, Tseng TY, Chou P. Effect of green tea extract on obese women: a randomized, double-blind, placebo-controlled clinical trial. Clinical nutrition (Edinburgh, Scotland) 2008; 27: 363-370.

35. Wang H, Wen Y, Du Y, Yan X, Guo H, Rycroft JA, et al. Effects of Catechin Enriched Green Tea on Body Composition. Obesity (Silver Spring, Md) 2009 e-pub ahead of print.

36. Hursel R, Viechtbauer W, Westerterp-Plantenga MS. The effects of green tea on weight loss and weight maintenance: a meta-analysis. International journal of obesity (2005) 2009; 33: 956-961.

37. Chen WY, Yang ZB, Hosoda K, Chen L, Lin BH, Kimura J, et al. Clinical efficacy of oolong tea on anti-simple obesity. Jpn J Clin Nutr 1998; 20: 83-90.

38. Otsuka K, Uchida H, Yuzawa M, Fumoto S, Tomonobu K, Chikama A, et al. Effects of tea catechins on body fat metabolism in women. Japanese Journal of Nutritional Assessment 2002; 19: 365-376.

39. Nagao T, Komine Y, Soga S, Meguro S, Hase T, Tanaka Y, et al. Ingestion of a tea rich in catechins leads to a reduction in body fat and malondialdehyde-modified LDL in men. Am J Clin Nutr 2005; 81: 122-129.

40. He RR, Chen L, Lin BH, Matsui Y, Yao XS, Kurihara H. Beneficial effects of oolong tea consumption on diet-induced overweight and obese subjects. Chinese journal of integrative medicine 2009; 15: 34-41.

41. Rumpler W, Seale J, Clevidence B, Judd J, Wiley E, Yamamoto S, et al. Oolong tea increases metabolic rate and fat oxidation in men. J Nutr 2001; 131: 2848-2852.

42. Hilal $\mathrm{Y}$, Engelhardt U. Characterisation of white tea-Comparison to green and black tea. JVerbrLebensm 2007; 2: 414-421.

43. Sohle J, Knott A, Holtzmann U, Siegner R, Gronniger E, Schepky A, et al. White Tea extract induces lipolytic activity and inhibits adipogenesis in human subcutaneous (pre)-adipocytes. Nutrition \& metabolism 2009; 6: 20.

44. Alcazar A, Ballesteros O, Jurado JM, Pablos F, Martin MJ, Vilches JL, et al. Differentiation of green, white, black, Oolong, and Pu-erh teas according to their free amino acids content. Journal of agricultural and food chemistry 2007; 55: 5960-5965.

45. Santana-Rios G, Orner GA, Amantana A, Provost C, Wu SY, Dashwood RH. Potent antimutagenic activity of white tea in comparison with green tea in the Salmonella assay. Mutation research 2001; 495: 61-74.

46. Hursel R, Westerterp-Plantenga MS. Green tea catechin plus caffeine supplementation to a highprotein diet has no additional effect on body weight maintenance after weight loss. Am J Clin Nutr 2009; 89: 822-830.

47. Shixian Q, VanCrey B, Shi J, Kakuda Y, Jiang Y. Green tea extract thermogenesis-induced weight loss by epigallocatechin gallate inhibition of catechol-O-methyltransferase. Journal of medicinal food 2006; 9: 451-458.

48. Borchardt RT, Huber JA. Catechol O-methyltransferase. 5. Structure-activity relationships for inhibition by flavonoids. Journal of medicinal chemistry 1975; 18: 120-122.

49. Hodgson JM, Puddey IB, Burke V, Croft KD. Is reversal of endothelial dysfunction by tea related to flavonoid metabolism? Br J Nutr 2006; 95: 14-17.

50. Palmatier MA, Kang AM, Kidd KK. Global variation in the frequencies of functionally different catechol-O-methyltransferase alleles. Biological psychiatry 1999; 46: 557-567.

51. Cornelis MC, El-Sohemy A, Campos H. Genetic polymorphism of the adenosine A2A receptor is associated with habitual caffeine consumption. Am J Clin Nutr 2007; 86: 240-244.

52. Acheson KJ, Gremaud G, Meirim I, Montigon F, Krebs Y, Fay LB, et al. Metabolic effects of caffeine in humans: lipid oxidation or futile cycling? Am J Clin Nutr 2004; 79: 40-46.

53. Belza A, Frandsen E, Kondrup J. Body fat loss achieved by stimulation of thermogenesis by a combination of bioactive food ingredients: a placebo-controlled, double-blind 8-week intervention in obese subjects. International journal of obesity (2005) 2007; 31: 121-130. 
54. Kao YH, Hiipakka RA, Liao S. Modulation of obesity by a green tea catechin. Am J Clin Nutr 2000; 72: $1232-1234$.

55. Klaus S, Pultz S, Thone-Reineke C, Wolfram S. Epigallocatechin gallate attenuates diet-induced obesity in mice by decreasing energy absorption and increasing fat oxidation. International journal of obesity (2005) 2005; 29: 615-623.

56. Lowell BB, Spiegelman BM. Towards a molecular understanding of adaptive thermogenesis. Nature 2000; 404: 652-660.

57. Yang F, Oz HS, Barve S, de Villiers WJ, McClain CJ, Varilek GW. The green tea polyphenol (-)epigallocatechin-3-gallate blocks nuclear factor-kappa B activation by inhibiting I kappa B kinase activity in the intestinal epithelial cell line IEC-6. Molecular pharmacology 2001; 60: 528-533.

58. Murase T, Nagasawa A, Suzuki J, Hase T, Tokimitsu I. Beneficial effects of tea catechins on dietinduced obesity: stimulation of lipid catabolism in the liver. Int J Obes Relat Metab Disord 2002; 26: 1459-1464.

59. Brown PJ, Wright WB. An Investigation of the Interactions between Milk Proteins and Tea Polyphenols. Journal of chromatography 1963; 11: 504-514.

60. Jobstl E, Howse JR, Fairclough JP, Williamson MP. Noncovalent cross-linking of casein by epigallocatechin gallate characterized by single molecule force microscopy. Journal of agricultural and food chemistry 2006; 54: 4077-4081.

61. Hertog MG, Sweetnam PM, Fehily AM, Elwood PC, Kromhout D. Antioxidant flavonols and ischemic heart disease in a Welsh population of men: the Caerphilly Study. Am J Clin Nutr 1997; 65: 1489-1494.

62. Lorenz M, Jochmann N, von Krosigk A, Martus P, Baumann G, Stangl K, et al. Addition of milk prevents vascular protective effects of tea. European heart journal 2007; 28: 219-223.

63. Serafini M, Ghiselli A, Ferro-Luzzi A. In vivo antioxidant effect of green and black tea in man. Eur J Clin Nutr 1996; 50: 28-32.

64. Arciero PJ, Gardner AW, Calles-Escandon J, Benowitz NL, Poehlman ET. Effects of caffeine ingestion on NE kinetics, fat oxidation, and energy expenditure in younger and older men. Am J Physiol 1995; 268: E1192-1198.

65. Acheson KJ, Zahorska-Markiewicz B, Pittet P, Anantharaman K, Jequier E. Caffeine and coffee: their influence on metabolic rate and substrate utilization in normal weight and obese individuals. Am J Clin Nutr 1980; 33: 989-997.

66. Tremblay A, Masson E, Leduc S, Houde A, Despres JP. Caffeine reduces spontaneous energy intake in men but not in women. Nutr Res 1988; 8: 553-558.

67. Hollands MA, Arch JR, Cawthorne MA. A simple apparatus for comparative measurements of energy expenditure in human subjects: the thermic effect of caffeine. Am J Clin Nutr 1981; 34: 2291-2294.

68. Pasman WJ, Westerterp-Plantenga MS, Saris WH. The effectiveness of long-term supplementation of carbohydrate, chromium, fibre and caffeine on weight maintenance. Int J Obes Relat Metab Disord 1997; 21: 1143-1151.

69. Lopez-Garcia E, van Dam RM, Rajpathak S, Willett WC, Manson JE, Hu FB. Changes in caffeine intake and long-term weight change in men and women. Am J Clin Nutr 2006; 83: 674-680.

70. Curatolo PW, Robertson D. The health consequences of caffeine. Ann Intern Med 1983; 98: 641653.

71. Robertson D, Frolich JC, Carr RK, Watson JT, Hollifield JW, Shand DG, et al. Effects of caffeine on plasma renin activity, catecholamines and blood pressure. N Engl J Med 1978; 298: 181-186.

72. Robertson D, Wade D, Workman R, Woosley RL, Oates JA. Tolerance to the humoral and hemodynamic effects of caffeine in man. J Clin Invest 1981; 67: 1111-1117.

73. Yoshioka M, St-Pierre S, Suzuki M, Tremblay A. Effects of red pepper added to high-fat and high-carbohydrate meals on energy metabolism and substrate utilization in Japanese women. $\mathrm{Br}$ J Nutr 1998; 80: 503-510.

74. Yoshioka M, St-Pierre S, Drapeau V, Dionne I, Doucet E, Suzuki M, et al. Effects of red pepper on appetite and energy intake. Br J Nutr 1999; 82: 115-123.

75. Yoshioka M, Doucet E, Drapeau V, Dionne I, Tremblay A. Combined effects of red pepper and caffeine consumption on $24 \mathrm{~h}$ energy balance in subjects given free access to foods. Br $\mathrm{J}$ Nutr 2001; 85: 203-211. 
76. Ohnuki K, Niwa S, Maeda S, Inoue N, Yazawa S, Fushiki T. CH-19 sweet, a non-pungent cultivar of red pepper, increased body temperature and oxygen consumption in humans. Bioscience, biotechnology, and biochemistry 2001; 65: 2033-2036.

77. Westerterp-Plantenga MS, Smeets A, Lejeune MP. Sensory and gastrointestinal satiety effects of capsaicin on food intake. International journal of obesity (2005) 2005; 29: 682-688.

78. Smeets AJ, Westerterp-Plantenga MS. The acute effects of a lunch containing capsaicin on energy and substrate utilisation, hormones, and satiety. European journal of nutrition 2009.

79. Galgani JE, Ryan DH, Ravussin E. Effect of capsinoids on energy metabolism in human subjects. Br J Nutr 2009: 1-5.

80. Lejeune MP, Kovacs EM, Westerterp-Plantenga MS. Effect of capsaicin on substrate oxidation and weight maintenance after modest body-weight loss in human subjects. Br J Nutr 2003; 90 : 651-659.

81. Snitker S, Fujishima Y, Shen H, Ott S, Pi-Sunyer X, Furuhata Y, et al. Effects of novel capsinoid treatment on fatness and energy metabolism in humans: possible pharmacogenetic implications. Am J Clin Nutr 2009; 89: 45-50.

82. Masuda Y, Haramizu S, Oki K, Ohnuki K, Watanabe T, Yazawa S, et al. Upregulation of uncoupling proteins by oral administration of capsiate, a nonpungent capsaicin analog. J Appl Physiol 2003; 95: 2408-2415.

83. Faraut B, Giannesini B, Matarazzo V, Marqueste T, Dalmasso C, Rougon G, et al. Downregulation of uncoupling protein-3 in vivo is linked to changes in muscle mitochondrial energy metabolism as a result of capsiate administration. Am J Physiol Endocrinol Metab 2007; 292: E14741482.

84. Reinbach HC, Smeets A, Martinussen T, Moller P, Westerterp-Plantenga MS. Effects of capsaicin, green tea and $\mathrm{CH}-19$ sweet pepper on appetite and energy intake in humans in negative and positive energy balance. Clinical nutrition (Edinburgh, Scotland) 2009; 28: 260-265.

85. Belza A, Toubro S, Astrup A. The effect of caffeine, green tea and tyrosine on thermogenesis and energy intake. Eur J Clin Nutr 2007; 63: 57-64. 


\section{Chapter 3}

\section{The multifactorial role of dietary protein in body-weight regulation}

Hursel R and Westerterp-Plantenga MS

Curr Top Pept Protein Res. 2009; 10: 23-36 


\begin{abstract}
Dietary protein plays a multifactorial role in weight loss and weight maintenance as it influences crucial targets for body weight regulation such as body composition; satiety; thermogenesis and energy efficiency. Protein induced changes in body composition favor an increase of fat free mass, thereby enhancing basic metabolic rate as fat free mass is its main determinant, and a decrease in fat mass that may be mainly due to amino acids fed in excess which under normal leisure time physical activity are used for muscle protein synthesis. Protein induced satiety may be mainly due to oxidation of amino acids fed in excess, especially with diets with 'incomplete' proteins, and to gluconeogenesis restoring glucose homeostasis. Protein induced energy expenditure may be mainly due to protein and urea synthesis; 'complete' proteins having all essential amino acids, show larger increases in energy expenditure than lower quality proteins. This review provides an overview of how sustaining absolute protein intake affects metabolic targets for weight loss and weight maintenance during negative energy balance, i.e. sustaining satiety, energy expenditure, sparing fat free mass, resulting in energy inefficiency, and showing that long term relationship between net protein synthesis and sparing fat free mass remains to be elucidated.
\end{abstract}

Keywords: energy expenditure, gluconeogenesis, thermogenesis, appetite, satiety 


\section{Introduction}

Obesity is a multifactorial disorder with serious comorbidities $(1,2)$ that arise when energy intake exceeds energy expenditure. A weight reduction of $10-15 \%$ is sufficient to induce beneficial effects for one's health. Usually, weight loss can be more readily achieved than weight maintenance after body weight loss, and body weight regain appears to be the pitfall $(2,3)$. Dietary protein intake initiates body weight loss and prevents body weight regain when administered in high quantity. Conditions for weight maintenance after weight loss are (i) sustained satiety despite negative energy balance, (ii) sustained basal energy expenditure despite body weight loss due to (iii) sparing of fat-free mass, being the main determinant of basal energy-expenditure. Diets, with a relatively high-protein content have been shown to act on these metabolic targets (3). Subsequently effects on body weight and body composition are highlighted. Finally, underlying mechanisms, i.e. satiety and energy expenditure will be dealt with.

\section{Relative and absolute protein intake}

The World Health Organization recommends that dietary protein should account for around $10-15 \%$ of energy when individuals are in energy balance and weight stable (4). The average daily protein intakes of various countries indicate that these recommendations are reflective of what is being consumed (5-9). Protein intake may be expressed in grams, or as percentage of energy intake. When recommending high protein diets, the difference between these two measures should be taken into account. For instance, $108 \mathrm{~g}$ protein/day with a weight maintenance diet of $12 \mathrm{MJ} / \mathrm{d}$ provides $15 \%$ of energy from protein; but the same protein intake as part of a weight loss diet of $6 \mathrm{MJ} / \mathrm{d}$ provides $30 \%$ of energy from protein, and as part of a weight maintenance diet after weight loss of $9 \mathrm{MJ} / \mathrm{d}$ provides $22.5 \%$ of energy from protein. To ensure that subjects are not in a negative nitrogen and protein balance during weight loss, and, therefore, lose their metabolically active fat-free mass (FFM), the absolute amount of protein is of greater importance than the percentage of protein. Varying the protein content of a formula diet from 0 to $50 \mathrm{~g} / \mathrm{d}$ resulted in a protein loss of between 1202 to 91 grams, respectively, as measured over 28 days (10). The fat loss as a percentage of total weight loss varied from $43 \%$ with $0 \mathrm{~g} / \mathrm{d}$ protein, up to $79 \%$ with $50 \mathrm{~g} / \mathrm{d}$ protein (10). These results indicate that a higher protein intake changes body composition in a way that spares FFM. Similarly, a weight maintenance diet following weight loss, sustained at an absolute amount of protein at $108 \mathrm{~g}$, will preserve FFM but lead to a reduction in fat mass (FM). Since weight maintenance after weight loss usually implies a slight weight regain, Stock's model can be applied (11). In this model the greatest metabolic efficiency of weight gain is shown when protein intake is $10-15 \%$ of energy during overfeeding, and inefficiency is shown with $<5 \%$ and $>20 \%$ of energy 
from protein. The latter metabolic inefficiency is related to body composition. To build $1 \mathrm{~kg}$ of body weight with 60\% FM and 40\% FFM, an additional $30 \mathrm{MJ}$ needs to be ingested, whereas to build only $1 \mathrm{~kg}$ of FFM, an additional 50-70 MJ is needed $(11,12)$. Therefore, a high-protein diet may promote weight maintenance by its metabolic inefficiency because of the cost involved in sparing FFM. Therefore, recommendations of 'high-protein, negative energy balance diets' are based on keeping the amount of protein ingested at the same level, in general representing $10-15 \%$ of energy at energy balance, despite lower energy intakes (3).

\section{Body weight loss}

Sustained protein diets for body weight loss have been assessed during different periods of time. A relatively high-protein diet, containing $25 \%$ of energy implying $75 \mathrm{~g}$ of protein per day, was compared with a control diet in order to evaluate weight loss over 6 months, when energy intake was ad libitum (13). The effect of $25 \%$ vs. $12 \%$ of energy intake from protein, $45 \%$ carbohydrate and $30 \%$ fat vs. $58 \%$ carbohydrate and $30 \%$ fat, on weight loss in subjects with a body mass index over $30 \mathrm{~kg} / \mathrm{m}^{2}$ was examined. It was found that weight loss, $8.9 \mathrm{vs} .5 .1 \mathrm{~kg}$, and fat loss, 7.6 vs. $4.3 \mathrm{~kg}$, were higher in the sustained protein group, due to a lower energy intake, 5.0 MJ/d vs. $6.2 \mathrm{MJ} / \mathrm{d}(\mathrm{p}<0.05)$. In a follow-up study, it was observed that after 12 months the weight loss was not significantly greater among the subjects in the high-protein group, but they had a greater reduction in intra-abdominal adipose tissue (14). Also a favorable effect of a high protein diet on body weight was found during 6 days ad libitum feeding (15). The low glycaemic index, low-fat, high-protein diet resulted in a spontaneous decrease in energy intake of $25 \%$ compared to a high-carbohydrate, low-fat diet, $8.8 \mathrm{MJ} / \mathrm{d}$ vs. 11.7 MJ/d, in the ad lib situation. Body weight loss was $2.3 \mathrm{~kg}$ over 6 days compared to no weight loss on the high-carbohydrate diet. However, in comparison to an iso-energetic high-carbohydrate diet there was no significant difference in body weight loss. Weight loss on the high-protein diet was not different from the control group, probably due to lack of difference in energy intake.

Weigle et al. confirmed this phenomenon in a controlled feeding study with 19 subjects (16). When the subjects received an iso-energetic high-protein diet protein/fat/carbohydrate: $30 / 20 / 50 \%$ of energy, satiety was considerably increased, but body weight remained stable during the week the subjects consumed this diet. When the subjects subsequently received the same high-protein diet ad libitum, for six weeks, they consumed less of it, keeping their satiety levels at their original, 'usual' level. During the iso-energetic high-protein diet subjects did not lose body weight, whereas during the ad libitum high-protein diet they lost $4.9 \pm 0.5 \mathrm{~kg}$, with a decrease in FM of $3.7 \pm 0.4 \mathrm{~kg}$.

Clifton, Keogh and Noakes (17) conclude from their assessment on longterm effects of a high-protein weight loss diet that a reported higher protein 
intake appears to confer a weight loss benefit; however, cardiovascular disease risk factors, biomarkers of disease, and serum vitamins and minerals improved due to weight loss, yet not to types of diet (17). Johnston et al. assigned healthy adults $(n=20)$ randomly to 1 of 2 low-fat (<30\% energy), energy-restricted groups: high-protein (30\% energy) or high-carbohydrate (60\% energy) (18). They controlled $24 \mathrm{hr}$ intakes during the 6 week trial. Both diets were equally effective at reducing body weight $(-6 \%, \mathrm{p}<0.05)$ and FM $(-9$ to $-11 \%, \mathrm{p}<0.05)$; however, subjects consuming the high-protein diet reported more satisfaction and less hunger in the first month of the trial. Creatinin clearance was not altered by diet treatments, and nitrogen balance was more positive in subjects consuming the high-protein diet vs. the high-carbohydrate diet $(3.9 \pm 1.4$ and $0.7 \pm 1.7 \mathrm{~g} \mathrm{~N} / \mathrm{d}$, respectively, $\mathrm{p}<0.05)$. They concluded that low-fat, energy-restricted diets of varying protein content $(15-30 \%$ energy) promoted healthful weight loss, but satisfaction with the diet was greater amongst those consuming the high protein diet (18).

Furthermore, Alexandra Johnstone and collegues assessed effects of a high-protein ketogenic diet on hunger, appetite, and weight loss in obese men feeding ad libitum (19). These seventeen obese men were studied in a residential trial, with food provided daily. Food was 2 high-protein (30\% of energy) ad libitum diets, each for a 4 week period. A Low-carb (4\% carbohydrate) ketogenic diet and an Medium-carb (35\% carbohydrate) diet, randomized in a crossover design. With the low-carb diet ad libitum intakes were lower, as was hunger. Weight loss was greater (6.34 vs. $4.35 \mathrm{~kg}$ ). The low-carb diet induced ketosis with higher $\beta$-hydroxybutyrate concentrations. They concluded that in the short term, high-protein, low-carbohydrate ketogenic diets reduce hunger and lower food intake significantly more than do high-protein, medium-carbohydrate nonketogenic diets (19).

These studies together suggest that body weight loss on a sustained, often indicated as a relatively high-protein diet, appears to be greater under conditions of ad libitum energy intake than under conditions of iso-energetic diets. The explanation for this is that satiety is a key factor in applying high-protein diets. Under ad libitum conditions subjects eat less from the high-protein diet than under isoenergetically fed conditions (16). Such diets contain a sufficient absolute amount of protein but lead to decreased energy intake, suggesting that in addition to metabolic effects of protein on body weight loss, energy intake plays an important role. This is underscored by the phenomenon that under iso-energetic conditions no statistically significant difference between body weight losses on a highprotein or high-carbohydrate diet was shown. Moreover, most of the studies on protein intake in relation to body weight management show an improved body composition (i.e. an increased FFM/FM) and metabolic profile with a relatively high-protein diet. The relatively high-protein negative energy balance diets all consist of $25-30 \%$ of energy from protein implying a sustained normal protein intake in grams, while energy intake is decreased. 


\section{Body weight maintenance}

Studies suggest that high protein diets can promote weight maintenance. For example, overweight to moderately obese men and women who had recently lost weight $(7.5 \pm 2.0 \%$ body weight loss over 4 weeks) who consumed $18 \%$ of energy intake as protein, regained less weight $(1 \mathrm{~kg})$ after 3 months, compared to those consuming $15 \%$ of energy as protein (weight regain $2 \mathrm{~kg}$ )

(20). This was not a consequence of possible differences in dietary restraint or in physical activity between the high protein and the control group, indicating a metabolic effect of protein (20). The composition of the body mass regained was more favorable in the higher protein group (i.e. no regain of FM, but only of FFM, resulting in a lower percentage body fat) (20). Energy efficiency (kg body-mass regain/energy intake) was significantly lower in the higher protein group. The observations with respect to energy efficiency during weight regain were comparable to the 'Stock hypothesis' described for weight gain (11). The FFM sparing effect was also shown in a study from Soenen et al. where 17 subjects were fed in energy balance, receiving either a high-protein diet or a normal protein diet for 12 weeks [21]. Subjects on the high-protein diet consumed an additional amount of $37 \mathrm{~g}$ of protein per day with regard to the control group. After the 3 month intervention period the higher protein intake resulted in a significantly lower FM ($0.90 \mathrm{~kg})$ and an increased FFM $(+0.74 \mathrm{~kg})$. The higher protein intake explained $24 \%$ of the change in \%FFM and $29 \%$ of the variation in change in body composition (21).

With a similar design as the previously mentioned weight maintenance study by Westerterp-Plantenga et al. (20), Lejeune and colleagues demonstrated a weight 'regain' of $0.8 \mathrm{~kg}$ (high-protein group) vs. $3.0 \mathrm{~kg}$ (control group) $(\mathrm{p}<0.05)$ after 6 months on a weight maintenance diet (22). During follow-up one year after the weight loss programme, these figures were $1.0 \mathrm{~kg}$ vs. $3.9 \mathrm{~kg}(p<0.05)$. Thus evidence shows that a relatively high-protein intake sustains weight maintenance by (i) favouring regain of FFM at the cost of FM at a similar physical activity level, (ii) reducing the energy efficiency with respect to the body mass regained, and (iii) increasing satiety. Similar observations were reported by Lacroix et al. from a long-term relatively high-protein diet that markedly reduced adipose tissue without major side effects in Wistar male rats (23).

Summarizing the role of dietary protein in to body weight loss and body weight maintenance thereafter, there is a need to distinguish absolute protein intake from proportionate protein intake. Absolute protein intake seems to be more important than the proportion of protein in the diet. When energy intake is reduced protein intake should be sustained, so that expressed in grams/day the protein content is normal. Therefore, 'high-protein negative energy balance diets' should mean keeping the grams of protein ingested at the same level, i.e. representing $10-15 \%$ of energy at energy balance, despite lower energy intakes. Protein influences body weight regulation via its effects on: satiety; thermogenesis; energy efficiency; and body composition. These aspects are partly related to 
each other. Under conditions of slight body weight regain, while aiming for weight maintenance, a sustained protein diet shows reduced energy efficiency related to the body composition of the body weight regained, i.e. in favor of FFM. Here, the main issue is that building FFM requires, on average, an additional energy ingestion of $52 \mathrm{MJ} / \mathrm{kg}$ body mass built, whereas building a normal proportion of FM and FFM takes $30 \mathrm{MJ} / \mathrm{kg}$ body mass built. During body weight loss, as well as during weight maintenance thereafter, a high-protein diet preserves or increases FFM and reduces FM, and improves the metabolic profile.

\section{Satiety}

A hierarchy has been observed for the satiating efficacies of the macronutrients protein, carbohydrate and fat, with protein being the most satiating and fat the least. This sequence also represents the priority with respect to metabolizing these macronutrients (24). In daily life, as well as in many experiments, mixed proteins are consumed, from meat, fish, dairy products, or plants. A dose dependent satiating effect of mixed protein has been shown, with quite a range of concentrations of protein offered acutely, in a single meal, to subjects who are in energy balance and weight stable $(24,25)$. In addition, persistent proteininduced satiety has been shown when a mixed high-protein diet was given for 24 hrs up to several days $(20,22,26)$. This section discusses acute, high-protein meal- or drink-induced satiety, and medium-term, high-protein diet-induced satiety. Mechanisms contributing to protein-induced satiety are considered.

Protein-induced satiety has been shown acutely, with single meals, with contents of $25 \%$ to $81 \%$ of energy from mixed protein or specific proteins, followed by subsequent energy intake reduction (25). Given the range of 'normal' protein intake of on average $10-15 \%$ of energy, meals with on average $20 \%$ to $30 \%$ of energy from protein are representative for high protein diets, when consumed in energy balance (3). Using these protein levels, Smeets et al. showed, in healthy volunteers with a body mass index (BMI) of $23.8 \pm 2.8 \mathrm{~kg} / \mathrm{m}^{2}$ and a percentage body fat of $26.0 \pm 8.9 \%$ that after a high-protein lunch satiety and energy expenditure were significantly higher than after a normal-protein lunch, without differences in ghrelin, and PYY (peptide tyrosintyrosin) responses (25). The lower GLP-1 (glucagon-like peptide 1) response following the high-protein lunch was due to the comparison with the high-carbohydrate induced GLP-1 response during the normal-protein lunch. This shows clearly that a GLP-1 response is primarily nutrient related, and only secondarily satiety related (25).

Optimal use of satiating power of a high-protein meal was shown when timing of the interval between the first administration of a meal containing protein versus control and the subsequent test meal, synchronizes with timing of the amino acid profiles following protein intake (27), ghrelin concentrations (28), or VAS (visual analogue scale) satiety ratings (28). Visual analogue scale ratings on $100 \mathrm{~mm}$ visual analogue rating scales, represent 'feelings' of satiety, hunger 
fullness or desire to eat detected by the subject. For these ratings appetite profile related questions are anchored with the extreme negative and positive answers. A point on the scale then gives the value of hunger, satiety, etc. Veldhorst et al. timed test meals beforehand, by running the experiments, in healthy normal weight subjects (BMI: $23.9 \pm 0.3 \mathrm{~kg} / \mathrm{m}^{2}$ ), twice: first determining the moment in time when differences in satiety or ghrelin concentrations were still significantly present, then offering the test meal at that moment in the next experiment $(24$, 28-30). Outcomes appeared to differ due to type or quantity of protein intake, or both. Higher satiating effects due to higher concentrations of casein (29) and soy (30) (25 en\% vs. 10 en \%) were related to kinetics of amino acid profiles $(24,29$, 30). For instance, a positive relationship between satiety or hunger suppression and the concentration of taurine was observed after the breakfast containing $25 \%$ of energy from soy protein (30). The higher satiating effects of the high concentrations in both studies did not coincided with the satiety hormones, as no differences were found between ghrelin and GLP-1 between the 25 en\% condition and the 10 en \% condition. Although satiety was increased this had no effect on energy intake at lunch in both studies. No significant differences were found between both conditions after an ad libitum lunch $(29,30)$.

With whey as a single protein in a subject specifically standardized custard breakfast, energy intake was decreased by $13 \%$ at $3 \mathrm{hrs}$ after a breakfast with whey containing glyco-macropeptide (GMP) compared to energy intake after a breakfast with whey without GMP, irrespective of the whey-protein content being 10 or $25 \%$ of energy in the custard breakfast, co-inciding with increased concentrations of certain amino acids, e.g. serine, threonine, alanine, and isoleucine (31). Although not translated into an increase in satiety or food intake effects, GLP-1 and insulin increased to a higher extent after the high-protein condition compared with the adequate protein condition. Also, larger decreases in ghrelin were found after the breakfast with $25 \%$ of energy (31).

Veldhorst et al. also compared the three abovementioned proteins to each other with respect to the different levels of energy and their effect on satiety (32). At a level of $10 \%$ energy from protein, a breakfast containing whey reduced hunger more than a breakfast with casein, and at the short-term also more than a breakfast containing soy protein. Whey also triggered the strongest response in GLP-1 concentrations after a breakfast with a level of $25 \%$ energy from protein, as whey inhibits the enzyme dipeptidyl peptidase IV that degrades GLP-1. Also, insulin was significantly increased after whey and soy compared to the breakfast with $25 \%$ casein (32). Insulin inhibits GLP-1 secretion, therefore when GLP-1 concentrations are elevated this also occurs with insulin concentrations. Again, increased amino acid concentrations are responsible for the suppression of hunger. These results also suggest that tryptophan may be involved in the satiety process, as the increase in concentration of this amino acid coincides with an increase in satiety after the breakfast with whey with a level of $10 \%$ energy from protein, compared to soy and casein (32). 
In another study comparing different protein sources, it was shown that tryptophan did not play a key role in satiety. Nieuwenhuizen et al. observed stronger hunger suppression $4 \mathrm{hrs}$ after a breakfast with alpha-lactalbumin compared to gelatin with or without added tryptophan as the only protein source (33) in healthy normal weight subjects (BMI: $23.8 \pm 0.4 \mathrm{~kg} / \mathrm{m}^{2}$ ). Total plasma amino acid responses, plasma tryptophan concentrations, plasma tryptophan/LNAA (large neutral amino acids) ratios, as well as GLP-1 and ghrelin concentrations were not related to hunger, and energy intake during subsequent lunch was similar for all 3 diets. They conclude that plasma tryptophan/LNAA ratios did not contribute to satiety, as has been hypothesized before (33). The suppression of hunger by $\alpha$-lactalbumin was also found by Hursel et al. (34), when comparing high-protein (41en\% of protein, $1.74 \mathrm{MJ}$ ) yoghurt breakfasts containing either $\alpha$-lactalbumin enriched whey or total whey-protein. They found that $\alpha$-lactalbumin significantly suppressed hunger (21.6\%) and desire to eat (33.1\%) more than whey over 4 hrs.

Comparing effects of seven different proteins in two different concentrations, on energy intake during the subsequent meal, Veldhorst et al. observed in the same healthy normal weight subjects as mentioned above, a more satiating effect from incomplete protein, i.e. those that lack some essential amino-acids vs. complete proteins, those that have the essential amino-acids on board (35). At the level of 10 energy percentage and of 25 energy percentage from one type of protein consumed with a breakfast custard, energy intake at lunch was about $20 \%$ less after an alpha-lactalbumin or gelatin with or without added tryptophan breakfast, compared with after a casein, soy, or whey breakfast; differences in energy intakes of about $20 \%$ where a function of differences in satiety ratings, that showed a difference of about $40 \%$ (35). Assessing different proteins and hydrolysates, Diepvens et al. showed in healthy overweight subjects (BMI: 27.6 $\pm 1.7 \mathrm{~kg} / \mathrm{m}^{2}$; body fat $\% 32.6 \pm 7.9$ ) indications of lower hunger and desire to eat or higher satiety after consumption of pea-protein hydrolysate (PPH) or wheyprotein (WP) compared to milk-protein (MP) or WP + PPH (36). Effects on relevant hormones were primarily nutrient related. CCK (cholecystokinin) and GLP-1 concentrations were relatively more increased by MP while PYY concentrations were relatively more elevated and ghrelin concentrations more reduced by WP + PPH [36]. No effect on El was seen (36). A similar effect of protein consumption on PYY concentration changes was shown by Batterham et al., observing significantly higher plasma PYY responses to a high-protein meal in both lean and obese subjects (37). With respect to different fractions of protein, such as $\alpha$ lactalbumin or $\beta$-lactoglobulin, Pichon et al. observed that food intake and body weight gain were significantly lower in rats fed the diet containing $\beta$-lactoglobulin, which was unrelated to palatability (38).

When different proteins or amino acids were consumed at very high levels, satiety was very high, and no differences in satiating effects were observed anymore. For instance Bowen et al. did not find different effects between casein 
and whey protein, with high-protein meals inducing larger satiating effect than high-carbohydrate meals $(39,40)$, in healthy normal weight subjects. Furthermore, they noted different appetite regulatory hormone responses after whey, soy, or gluten preload despite similar reductions in ad libitum energy intake (39).

Also Burton-Freeman et al. studied food intake in healthy normal weight to overweight (BMI: $25 \pm 1.5 \mathrm{~kg} / \mathrm{m}^{2}$ ) and did not find a difference at the test meal, between the conditions with preloads consisting of whey with or without GMP, while CCK release coincided with magnitude of satiety ratings (41).

Effects of protein containing drinks vs. control appear when sufficient protein and energy is present in the drinks.

Bertenshaw et al. compared in normal weight men (BMI: $22.6 \pm 0.4 \mathrm{~kg} / \mathrm{m}^{2}$ ) iso-energetic dairy fruit drink preloads $(300 \mathrm{~mL}, 1.25 \mathrm{MJ})$ differing in macronutrient composition and observed that significantly less energy was consumed at lunch $120 \mathrm{~min}$ after the protein (3.2 MJ) compared to the control (3.5 MJ) and $\mathrm{CHO}$ preloads (3.6 MJ), without showing complete energy intake compensation (42). Harper et al. compared in healthy subjects (BMI: $22 \pm 2 \mathrm{~kg} / \mathrm{m}^{2}$ ) effects of a sugar-sweetened beverage (cola) and a chocolate milk drink $(0.9 \mathrm{MJ}, 500 \mathrm{~mL})$, and observed satiety and fullness being significantly greater $30 \mathrm{~min}$ after chocolate milk than after cola, while no significant difference in energy intake occurred during lunch (3.2 MJ after chocolate milk vs. 3.3 MJ after cola) [43]. Soenen et al. showed in healthy normal weight subjects (BMI: $22.1 \pm 1.9 \mathrm{~kg} / \mathrm{m}^{2}$ ) no different effects from a comparison between appetite, energy intake or energy intake compensation $50 \mathrm{~min}$ after $800 \mathrm{ml}, 1.5 \mathrm{MJ}$ milk or carbohydrate drinks, in 40 young healthy normal weight men and women (44). A study in normal weight and obese boys showed that following glucose and whey-protein drinks $(250 \mathrm{~mL}$, $3.5 \mathrm{MJ}$ ) subsequent food intake $60 \mathrm{~min}$ later was suppressed by whey protein (2.7 MJ) more than by glucose (3.1 MJ), or control (3.6 MJ) (45). Taken together, there is a band-width in protein amount and concentrations where relatively more protein is more satiating and promotes less energy intake, supported by relatively elevated aminoacid concentrations, anorexigenic hormones or energy expenditure, feeding back on the central nervous system. Mellinkoff (46) suggested already in 1956 that an elevated concentration of blood or plasma amino acids, which cannot be channeled into protein synthesis, serves as a satiety signal for a food intake regulating mechanism and thereby results in depressed food intake. With respect to central regulation, Faipoux et al. (47) showed in rats, that protein induced satiety was related to vagal feedback to i. the nucleus tractus solitarius in the brainstem, where it represents satiety at almost a reflex level, and ii. The hypothalamus, where it suppresses feelings of hunger (47).

When high-protein menus are offered at each meal, lasting for one to several days, one gets into the condition of a high protein diet, when metabolic reactions have been established $(3,24,26,48)$. In several high protein diet studies in normal weight healthy subjects, a continuously higher satiety has been shown throughout the day after the high compared with the normal protein diet, for instance in the energy balance controlled environment of a respiration chamber (3, 
$24,26,48)$. Here, a normal-protein diet given in energy balance contains $10-15 \%$ of energy from protein (3), and a high-protein diet in energy balance contains 20$30 \%$ of energy from protein (3). A high-protein diet in the presence of carbohydrate stimulated GLP-1 release $(26,48)$, which triggers insulin release. More importantly, high-protein diet-induced satiety was primarily related to elevated energy expenditure $(3,24,26,48)$, implying increased oxygen consumption and an increase in body temperature both leading to feeling deprived of oxygen and thus promoting satiety $(3,24)$. Energy expenditure is different due to different protein sources, and mediated by the high ATP (adenosintriphosphate) costs of postprandial protein synthesis while digestion rate also plays a role (3). Moreover, during high-protein diets substrate oxidation changes, in that less protein is oxidized than consumed resulting in a positive protein balance, and more fat is oxidized than consumed, resulting in a negative fat balance; moreover, energy expenditure is continuously elevated $(3,24,26,48)$. Description and discussion of the latter topics is elaborated on in the next section.

Hochstenbach-Waelen et al. studied the effects of specific types of protein in either $25 \%$ or $10 \%$ of energy, on appetite, substrate balance and energy expenditure in a respiration chamber for $36 \mathrm{hrs}$. For 3 days, subjects ate a similar diet at home as what they consumed in the respiration chamber in order to be fed in energy balance. Casein (49) and gelatin (50) were the single protein sources being tested and with respect to appetite the 25 en\% diet lowered hunger and desire to eat and increased satiety compared to the 10 en\% diet. For gelatin no differences were observed in GLP-1 and PYY concentrations (50), casein however, showed significantly lowered concentrations of these hormones after the 25 en\% of protein (49), just as insulin and glucose concentrations that were lowered as well with both protein types after this condition $(49,50)$. When comparing both protein types with each other, only at the level of 10 en\% of protein there was a difference in appetite ratings, as hunger was $44 \%$ more suppressed after the gelatin diet than after the casein diet (51). GLP-1 levels were increased after both en\% levels when compared to casein. There were no differences between both proteins for insulin, glucose and PYY (51).

These highly controlled medium term studies overcome possible differences due to solid, semi-solid or liquid food, timing and macronutrient exchange, and imply the possibility to assess satiety, energy expenditure and substrate oxidation at the same time. More of this type of studies needs to be executed with different types of proteins, in overweight subjects in neutral, positive and negative energy balances.

Summarizing, studies have shown that high-protein diets increase satiety and suppress hunger significantly, which is seemingly not caused by satiety hormones such as GLP-1 and PYY. Besides being a 'fast' or 'slow' protein the distinction between 'complete' and 'incomplete' protein contributes significantly to the satiating capacity of a diet. Complete proteins contain more essential amino acids, that have the ability to increase satiety, as has been shown in some of the above described studies. 


\section{Energy Expenditure}

As indicated briefly above, protein intake increases energy expenditure. Potential mechanisms include the ATP required for the initial steps of metabolism, storage and oxidation including urea synthesis. The magnitude of the thermogenic effect is affected by the level of energy intake in relation to energy requirement in combination with the type of protein. The most energy consuming metabolic processes are protein synthesis and gluconeogenesis. The thermogenic effect of protein is clearly illustrated by the difference between the gross energy value of $22-25 \mathrm{~kJ} / \mathrm{g}$ and the net metabolizable energy of $13 \mathrm{~kJ} / \mathrm{g}$. Effects as observed are short-term as well as long-term.

The effect of protein intake on energy expenditure is reflected mainly in two of the four components that daily energy expenditure consists of, i.e. the sleeping metabolic rate (SMR) and the energy cost of arousal forming together the energy expenditure for maintenance or basal metabolic rate, the thermic effect of food or diet-induced energy expenditure (DEE), and the energy cost of physical activity or activity-induced energy expenditure (AEE), where SMR is usually the main component of average daily metabolic rate (ADMR) (52). Protein intake affects primarily DEE and ultimately SMR. Effects of protein intake on AEE are usually described in the opposite way, physical activity affecting protein metabolism, more specifically protein turnover. Thus below, the effect of protein intake on energy expenditure is subsequently described for DEE, SMR and protein turnover.

The main determinant of DEE is the energy content of the food, followed by the protein fraction of the food. Diet-induced energy expenditure is related to the stimulation of energy-requiring processes during the post-prandial period. The intestinal absorption of nutrients, the initial steps of their metabolism and the storage of the absorbed but not immediately oxidized nutrients (53). As such, the amount of food ingested quantified as the energy content of the food is a determinant of DEE. The most common way to express DEE is derived from this phenomenon, the difference between energy expenditure after food consumption and basal energy expenditure, divided by the rate of nutrient energy administration. Theoretically, based on the amount of ATP required for the initial steps of metabolism and storage, the DEE is different for each nutrient. Reported DEE values for separate nutrients are 0 to $3 \%$ for fat, 5 to $10 \%$ for carbohydrate, 20 to $30 \%$ for protein (53), and 10 to $30 \%$ for alcohol (54). In healthy subjects with a mixed diet, DEE represents about $10 \%$ of the total amount of energy ingested over $24 \mathrm{hr}$. When a subject is in energy balance, where intake equals expenditure, DEE is $10 \%$ of daily energy expenditure (55).

One of the first studies clearly showing the effect of protein intake on DEE was a study over $24 \mathrm{hr}$ in a respiration chamber (54). Healthy female volunteers were fed a high-protein and -carbohydrate $(30 \%, 60 \%$, and $10 \%$ energy from 
protein, carbohydrate and fat, respectively) and high-fat diet (10\%, 30\%, and $60 \%$ energy from protein, carbohydrate and fat, respectively), both iso-energetic, iso-volumetric, composed of normal food items and matched the organoleptic properties taste, smell, appearance. Subjects each spent two $36 \mathrm{hr}$ periods in a resp ration chamber consuming both test diets in random order. Diet-induced energy expenditure was higher in all subjects while on the high- protein and carbohydrate diet (1295 vs. $931 \mathrm{~kJ} / \mathrm{d} ; 14.6$ vs. $10.5 \%$ of energy intake; $p<0.02$ ). There was no significant difference in other components or total $24 \mathrm{hr}$ energy expenditure, though there was a trend towards higher energy expenditure on the high-protein and -carbohydrate diet. A high-protein and -carbohydrate diet induces a greater thermic response in healthy individuals when compared to a high-fat diet. Similar results were obtained in a study where DEE was compared between lean and obese women after two iso-energetic meals, one rich in protein and one rich in fat (56). The meals were consumed as a breakfast with a total energy content of $2.03 \mathrm{MJ}$ in a randomized crossover design with an interval of one week. The high-protein breakfast consisted of $102 \mathrm{~g}$ protein, $18 \mathrm{~g}$ carbohydrate and $0 \mathrm{~g}$ fat, the high-fat breakfast consisted of $12 \mathrm{~g}$ protein, $20 \mathrm{~g}$ carbohydrate and $39 \mathrm{~g}$ fat. Energy expenditure and substrate oxidation was measured for 30 minutes before breakfast and for 30 minutes every hour for a total of three hours after breakfast. Protein intake was associated with almost threefold higher diet-induced energy expenditure in comparison with fat intake. Diet-induced energy expenditure was not different between lean and obese participants. It was concluded that over the long-term, high diet-induced energy expenditure may contribute to the prevention of obesity or, vice versa, regular or frequent fat intake may contribute to the development and maintenance of obesity (56).

More recent studies investigating DEE acutely with a ventilated hood and in the long-term in a respiration chamber found contrasting results and some of them addressed the effect of 'complete' vs. 'incomplete' proteins on DEE. Smeets et al. did not find a significant difference between a high-protein lunch and an adequate-protein lunch although there was a tendency towards a higher DEE after the high-protein lunch (25). Nevertheless, Hursel et al. (34) found a significant difference between high-protein yoghurt breakfasts and an adequateprotein yoghurt breakfast as DEE increased $20-30 \%$. Between the high-protein yoghurt breakfasts either containing $\alpha$ - lactalbumin enriched whey or total whey protein there was no significant difference in DEE although $\alpha$-lactalbumin increased DEE more than whey. In the previously mentioned $36 \mathrm{hr}$ respiration chamber studies from Hochstenbach-Waelen et al. the effect of the single protein sources casein and gelatin on DEE was examined in different en\% levels. These studies showed that an increase in protein from 10 en $\%$ to 25 en $\%$ from casein and gelatin increased total energy expeniture (TEE) respectively with $2.6 \%$ and $2.1 \%$. However, no differences in TEE were seen between casein and gelatin at both en\% levels (49-51). 
The effect of proteins on DEE is dependent on the quantity of protein, the rate of absorption and thereby increasing the level of amino acids in the bloodstream and also the concentration of essential amino acids, which determines whether a protein is 'complete' or 'incomplete'. This lack of certain amino acids decreases the ability for protein synthesis postprandially and increases amino acid oxidation. To support the latter more research is needed with different protein sources to distinguish between these types of protein and their ability to increase thermogenesis.

Four studies reported a protein-induced increase in SMR $(26,49,50,57)$. In the first study, substitution of carbohydrate with $17-18 \%$ of energy as either porkmeat or soy protein produced $3 \%$ higher $24 \mathrm{hr}$ energy expenditure. The increase in energy expenditure was visible despite a $10-15 \%$ lower energy intake at the high-protein diets because of a higher satiating effect. Twenty-four hour energy expenditure was measured on the $4^{\text {th }}$ day on each diet. The observed increase in energy expenditure was visible in SMR as well as in DEE. The biological rationale behind the higher thermogenic effect of protein than of carbohydrate was explained by the fact that the body has no storage capacity to cope with high intakes of protein and therefore has to process it metabolically, which readily increases thermogenesis (26). The second study used a similar diet in a similar design. Subjects were fed in energy balance an adequate protein diet, $10 \%$, $60 \%$, and $30 \%$ energy from protein, carbohydrate and fat, respectively, or a highprotein diet, 30\%, 40\%, and 30\% energy from protein, carbohydrate and fat, respectively, for four days in a randomized crossover design. Energy expenditure was measured at the last day in a respiration chamber. The high-protein diet, compared with the adequate-protein diet, fed at energy balance for four days increased $24 \mathrm{hr}$ satiety, thermogenesis, sleeping metabolic rate, protein balance, and fat oxidation. As was mentioned before, satiety was related to protein intake, and incidentally to ghrelin and GLP-1 concentrations, only at the high-protein diet (57). The remaining two studies had similar study designs, only differing in types of protein as one study used casein as the main protein source and the other gelatin $(49,50)$. Subjects were fed in energy balance for three days before the $36 \mathrm{hr}$ measurement in the respiration chamber. In both studies the diets differed in level of energy \% from protein, these were either 10 en\% or 25 en\%. The latter condition showed an increase in SMR and in TEE compared to the 10 en\%. The increase in TEE was mainly because of a higher SMR, obtained most likely through an adaptation of the body to a high-protein diet with respect to protein turnover, as subjects were already on a high-protein diet for 3 days (58). Combining the studies on protein intake, DEE and SMR, it can be concluded that protein intake causes an acute increase in DEE and, when sustained over three days, results in an increase in SMR as well.

The ATP required for the initial steps of metabolism and oxidation including urea synthesis might explain the short-term protein-induced increase in DEE. The long-term protein-induced increase of SMR might be explained by stimulation of protein synthesis and protein turnover. Indirect evidence for the latter 
comes from the study of Mikkelsen et al. (57), where animal protein in pork meat produced $2 \%$ higher $24 \mathrm{hr}$ energy expenditure than did the vegetable protein in soy. The amount of protein synthesis after protein intake depends on how well the composition of essential amino acids in the dietary protein matches the optimum requirements for protein synthesis in the body. A well-balanced amino acid mixture produces a higher thermogenic response than does an amino acid mixture with a lower biological value, i.e., a different amino acid composition than is used for protein synthesis. This may explain why intake of soy protein results in less protein synthesis than does intake of animal protein.

\section{Protein turnover-, metabolism and gluconeogenesis}

Protein turnover- and metabolism is strongly influenced by protein quality, as protein synthesis requires adequate availability of essential amino acids. In other words, the intake of sufficient levels of these amino acids is crucial for preventing negative protein turnover. A specific appetite for essential amino acids has therefore been suggested, which is supported by the observation that rats, when fed a diet deficient in one or more essential amino acids, are able to recognize the presence of these amino acids in a range of diets with or without these amino acids $(59,60)$. Such a sensing mechanism stresses the physiological importance of maintaining an adequate rate of protein synthesis.

When ingested in surplus of postprandial protein synthesis, amino acids can readily be used as substrate for oxidation. In elderly women, increasing the amount of dietary protein from 10 to 20 energy $\%$ resulted in a 63 to $95 \%$ increase in protein oxidation, depending on the protein source (61). The largest $(95 \%)$ increase in protein oxidation was observed when the predominant protein source was of animal origin, whereas this increase was only $63 \%$ when soy protein was the predominant protein source in the diet (61). Accordingly, as was already mentioned in the previous section, Mikkelsen et al. observed a higher diet-induced thermogenesis with pork meat than with soy protein (57). Differences in digestion rate of the various protein sources may contribute to differences in postprandial protein oxidation. Thus, ingestion of rapidly digested protein results in a stronger increase in postprandial protein synthesis and amino acid oxidation than slowly digested protein (62-64).

The metabolic efficacy of protein oxidation largely depends on the amino acid composition of the protein, since large differences exist with respect to the efficacy by which amino acids are oxidized. This is due to the large variety of carbon chains and co-factors that are resulting from amino acid catabolism (65). For instance, the number of amino groups that undergo conversion to urea in the urea cycle (at a cost of 4 ATP) ranges from 1 for an amino acid such as proline or alanine to 3 for histidine $(65,66)$. Thus, taking into account the stoichiometry of amino acid catabolism and urea synthesis, the calculated energy expenditure to produce ATP is ranging from $153 \mathrm{~kJ} / \mathrm{ATP}$ for cysteine, to $99 \mathrm{~kJ} / \mathrm{ATP}$ for 
glutamate (for glucose, this value is $91 \mathrm{~kJ} / \mathrm{ATP}$ ) (66). The relatively low metabolic efficacy of amino acid oxidation (for glucose and fatty acids, the calculated energy expenditure to produce ATP is 91 and $96 \mathrm{~kJ} / \mathrm{ATP}$, respectively) may contribute to the higher diet-induced energy expenditure of a high-protein meal, which, in turn, has shown to be related to subjective feelings of satiety.

The production of glucose through gluconeogenesis has been also hypothesized to play a role in postprandial amino acid metabolism. The metabolic pathway involved in gluconeogenesis and glycogen synthesis is dependent upon the pattern of nutrient availability. The energy expenditure that it requires as well as the glucose homeostatis that it restores may support the protein-induced satiety and energy expenditure. The main gluconeogenic organ is the liver and de novo synthesis of glucose in the liver from gluconeogenic precursors including amino acids is stimulated by a high-protein diet in the fed state (67). This hepatic gluconeogenesis may be an alternative biochemical pathway to cope with postprandial amino acid excess, i.e., when amino acids are ingested in surplus of protein synthesis. This process could be involved in the satiating effect of protein through a modulation of glucose homeostasis and glucose signaling to the brain. When the protein content of the diet is increased Phosphoenolpyruvate Carboxylase (PEPCK) that controls the initial conversion of oxaloacetate to phosphoenolpyruvate is up-regulated either in the fasted and in the fed state, whereas glucose 6-phosphatase (G6Pase), that controls the last step of gluconeogenesis is up-regulated in the fasted state and down-regulated in the fed state.

The amino acid composition of the diet may influence postprandial gluconeogenesis, as not all amino acids are preferentially used for gluconeogenesis, but can also be converted into ketone bodies through ketogenesis. The amino acids threonine, isoleucine, phenylalanine, tryptophan, and tyrosine can either be converted into glucose or ketone bodies, whereas lycine and leucine are strictly ketogenic and therefore not used as a substrate for gluconeogenesis (65). Veldhorst et al. (68) found that an increase in SMR was related to an increase in gluconeogenesis, in glycogen depleted subjects on a high-protein, carbohydrate- free diet. This may explain the increase in energy expenditure after a high-protein diet.

Summarizing, dietary protein plays a multifactorial role in body weight regulation as relatively high-protein intake induces weight loss and sustains weight maintenance by (i) favouring regain of FFM at the cost of FM at a similar physicalactivity level, (ii) reducing the energy efficiency with respect to the body mass regained, and (iii) increasing satiety. A high-protein diet may promote weight maintenance by its metabolic inefficiency because of the cost involved in sparing FFM. Therefore, recommendations of 'high-protein, negative energy balance diets' are based on keeping the amount of protein ingested at the same level, in general representing $10-15 \%$ of energy at energy balance, despite lower energy intakes. Distinguishing between absolute amount of proteins and percentage is necessary because the absolute amount remains the same when total daily energy intake varies, in contrast to percentages. Body weight loss on a 
sustained, relatively high-protein diet, appears to be greater under conditions of ad libitum energy intake than under conditions of iso-energetic diets. The explanation for this is that more protein is more satiating and promotes less energy intake, supported by relatively elevated amino acid concentrations, anorexigenic hormones or energy expenditure, feeding back on the central nervous system. An elevated concentration of blood or plasma amino acids, which cannot be channeled into protein synthesis, serves as a satiety signal for a food intake regulating mechanism, resulting in depressed food intake and affects DEE as well. The lack of certain amino acids decreases the ability for protein synthesis postprandially and increases amino acid oxidation. The ATP required for the initial steps of metabolism and oxidation including urea synthesis might explain the short-term protein-induced increase in DEE. The long-term protein-induced increase of SMR might be explained by stimulation of protein synthesis, protein turnover and gluconeogenesis.

\section{Conclusions}

Prevention of weight gain after weight loss and during weight maintenance, can be achieved when certain metabolic targets such as sustained satiety, sustained energy expenditure, sparing of fat free mass are stimulated, together resulting in a high energy inefficiency. These requirements need to be fulfilled despite being in negative energy balance, as a successful weight loss or weight maintenance study depends in the combination of the three. Amino acids, quantity as well as quality, in terms of 'complete' and 'incomplete' proteins, play an important role as an excessive intake leads to a sustained satiety and sustained energy expenditure mainly by gluconeogenesis (as recently shown) and net protein synthesis. The possible relationship between net protein synthesis and sparing fat free mass remains to be elucidated.

\section{Acknowledgements}

Part of this paper is an update of Westerterp-Plantenga et al., Dietary protein, Weight loss and Weight maintenance, Annual Review of Nutrition, August 2009: Vol. 29, with permission.

\section{References}

1. Seidell, J. C. 1995, Obes Res, 3 Suppl 2, 89s.

2. Pi-Sunyer, F. X. 1993, Ann Intern Med, 119, 655.

3. Westerterp-Plantenga, M. S., Luscombe-Marsh, N. D., Lejeune, M. P. G. M., Diepvens, K., Nieuwenhuizen, A., Engelen, M. P. K. J., Deutz, N. E. P., Azzout-Marnich, D., Tome, D. and Westerterp, K. R. 2006, IJO, 30, S16.

4. Obesity: preventing and managing the global epidemic. Report of a WHO consultation, 2000, 894 , i. 
5. Hulshof, K. F. A. M., Ocke, M. C., van Rossum, C. T. M., Buurma-Rethans, E. J. M., Brants, H. A. M. and Drijvers, J. J. M. M. 2004, Results of the food consumption survey 2003, Publisher.

6. Wright, J. D., Kennedy-Stephenson, J., Wang, C. Y., McDowell, M. A. and Johnson, C. L. 2004, JAMA, 291, 1193.

7. McLennan, W. and Podger, A. 1998, National Nutrition Survey: nutrient intakes and physical measurements, Publisher.

8. Nutrition profile of the South-East Asia region 2000, Publisher.

9. Division, F. S. http://www.fao.org/es.ess.faostat/foodsecurity/index.

10. Ditschuneit, H. H. 1984, Ergebnisse ambulante Adipositastherapie mit verschiedenen proteinereichen Diaeten, Ditschuneit, H. H. and Wechsler, J. G. perimed Fachbuch-Verlagsgesellschaft $\mathrm{mbH}$, Erlangen, 171.

11. Stock, M. J. 1999, Int J Obes Relat Metab Disord, 23, 1105.

12. Pullar, J. D. and Webster, A. J. 1977, Br J Nutr, 37, 355.

13. Skov, A. R., Toubro, S., Ronn, B., Holm, L. and Astrup, A. 1999, Int J Obes Relat Metab Disord, 23, 528.

14. Due, A., Toubro, S., Skov, A. R. and Astrup, A. 2004, Int J Obes Relat Metab Disord, 28, 1283.

15. Dumesnil, J. G., Turgeon, J., Tremblay, A., Poirier, P., Gilbert, M., Gagnon, L., St-Pierre, S., Garneau, C., Lemieux, I., Pascot, A., Bergeron, J. and Despres, J. P. 2001, Br J Nutr, 86, 557.

16. Weigle, D. S., Breen, P. A., Matthys, C. C., Callahan, H. S., Meeuws, K. E., Burden, V. R. and Purnell, J. Q. 2005, Am J Clin Nutr, 82, 41.

17. Clifton, P. M., Keogh, J. B. and Noakes, M. 2008, Am J Clin Nutr, 87, 23.

18. Johnston, C. S., Tjonn, S. L. and Swan, P. D. 2004, J Nutr, 134, 586.

19. Johnstone, A. M., Horgan, G. W., Murison, S. D., Bremner, D. M. and Lobley, G. E. 2008, Am J Clin Nutr, 87, 44.

20. Westerterp-Plantenga, M. S., Lejeune, M. P., Nijs, I., van Ooijen, M. and Kovacs, E. M. 2004, Int J Obes Relat Metab Disord, 28, 57.

21. Soenen, S. and Westerterp-Plantenga, M., Submitted.

22. Lejeune, M. P., Kovacs, E. M. and Westerterp-Plantenga, M. S. 2005, Br J Nutr, 93, 281.

23. Lacroix, M., Gaudichon, C., Martin, A., Morens, C., Mathe, V., Tome, D. and Huneau, J. F. 2004, Am J Physiol Regul Integr Comp Physiol, 287, R934.

24. Veldhorst, M., Smeets, A., Soenen, S., Hochstenbach-Waelen, A., Hursel, R., Diepvens, K., Lejeune, M., Luscombe-Marsh, N. and Westerterp-Plantenga, M. 2008, Physiol Behav, 94, 300.

25. Smeets, A. J., Soenen, S., Luscombe-Marsh, N. D., Ueland, O. and Westerterp-Plantenga, M. S. 2008, J Nutr, 138, 698.

26. Lejeune, M. P., Westerterp, K. R., Adam, T. C., Luscombe-Marsh, N. D. and WesterterpPlantenga, M. S. 2006, Am J Clin Nutr, 83, 89.

27. Luhovyy, B. L., Akhavan, T. and Anderson, G. H. 2007, J Am Coll Nutr, 26, 704S.

28. Veldhorst, M. A. B., Nieuwenhuizen, A., Hochstenbach-Waelen, A., Westerterp, K. R., Engelen, M. P. K. J., Brummer, R. M., Deutz, N. E. P. and Westerterp-Plantenga, M. S. 2007, Appetite, 49, 336.

29. Veldhorst, M. A., Nieuwenhuizen, A. G., Hochstenbach-Waelen, A., Westerterp, K. R., Engelen, M. P., Brummer, R. J., Deutz, N. E. and Westerterp-Plantenga, M. S. 2009, Br J Nutr, 101, 295.

30. Veldhorst, M. A., Nieuwenhuizen, A. G., Hochstenbach-Waelen, A., Westerterp, K. R., Engelen, M. P., Brummer, R. J., Deutz, N. E. and Westerterp-Plantenga, M. S. 2009, European journal of nutrition.

31. Veldhorst, M. A., Nieuwenhuizen, A. G., Hochstenbach-Waelen, A., Westerterp, K. R., Engelen, M. P., Brummer, R. J., Deutz, N. E. and Westerterp-Plantenga, M. S. 2008, Appetite.

32. Veldhorst, M., Nieuwenhuizen, A., Hochstenbach-Waelen, A., Van Vught, A., Westerterp, K., Engelen, M. P., Brummer, R. J., Deutz, N. E. and Westerterp-Plantenga, M. 2009, Physiol Behav, 96, 675 .

33. Nieuwenhuizen, A. G., Hochstenbach-Waelen, A., Veldhorst, M. A., Westerterp, K. R., Engelen, M. P., Brummer, R. J., Deutz, N. E. and Westerterp-Plantenga, M. S. 2008, Br J Nutr, 1.

34. Hursel, R., van der Zee, L., Westerterp-Plantenga, M. S. 2009, Br. J. Nutr., 103,1. 
35. Veldhorst, M. A., Nieuwenhuizen, A. G., Hochstenbach-Waelen, A., Westerterp, K. R., Engelen, M. P., Brummer, R. J., Deutz, N. E. and Westerterp-Plantenga, M. S. 2009, Clinical nutrition (Edinburgh, Scotland).

36. Diepvens, K., Haberer, D. and Westerterp-Plantenga, M. 2008, International journal of obesity (2005), 32, 510.

37. Batterham, R. L., Heffron, H., Kapoor, S., Chivers, J. E., Chandarana, K., Herzog, H., Le Roux, C. W., Thomas, E. L., Bell, J. D. and Withers, D. J. 2006, Cell Metab, 4, 223.

38. Pichon, L., Potier, M., Tome, D., Mikogami, T., Laplaize, B., Martin-Rouas, C. and Fromentin, G. 2008, Br J Nutr, 99, 739.

39. Bowen, J., Noakes, M., Trenerry, C. and Clifton, P. M. 2006, J Clin Endocrinol Metab, 91, 1477.

40. Bowen, J., Noakes, M. and Clifton, P. M. 2006, J Clin Endocrinol Metab, 91, 2913.

41. Burton-Freeman, B. M. 2008, Physiol Behav, 93, 379.

42. Bertenshaw, E. J., Lluch, A. and Yeomans, M. R. 2008, Physiol Behav, 93, 427.

43. Harper, A., James, A., Flint, A. and Astrup, A. 2007, Br J Nutr, 97, 579.

44. Soenen, S. and Westerterp-Plantenga, M. S. 2007, Am J Clin Nutr, 86, 1586.

45. Bellissimo, N., Desantadina, M. V., Pencharz, P. B., Berall, G. B., Thomas, S. G. and Anderson, G. H. 2008, International journal of obesity (2005), 32, 362.

46. Mellinkoff, S. M., Frankland, M., Boyle, D. and Greipel, M. 1956, J Appl Physiol, 8, 535.

47. Faipoux, R., Tome, D., Gougis, S., Darcel, N. and Fromentin, G. 2008, J Nutr, 138, 1172.

48. Westerterp-Plantenga, M., Lejeune, M., Smeets, A. and Luscombe-Marsh, N., submitted.

49. Hochstenbach-Waelen, A., Veldhorst, M. A., Nieuwenhuizen, A. G., Westerterp-Plantenga, M. S. and Westerterp, K. R. 2009, Am J Clin Nutr, 89, 831.

50. Hochstenbach-Waelen, A., Veldhorst, M., Nieuwenhuizen, A., Westerterp-Plantenga, M. and Westerterp, K. 2009, Journal of Nutrition, Submitted.

51. Hochstenbach-Waelen, A., Westerterp-Plantenga, M., Veldhorst, M. and Westerterp, K. 2009, submitted.

52. Westerterp, K. 2003, Eur. Resp. Monogr., 24, 1.

53. Tappy, L. 1996, Reprod Nutr Dev, 36, 391.

54. Westerterp, K. R., Wilson, S. A. and Rolland, V. 1999, Int J Obes Relat Metab Disord, 23, 287.

55. Westerterp, K. R. 2004, Nutrition \& metabolism, 1, 5.

56. Tentolouris, N., Pavlatos, S., Kokkinos, A., Perrea, D., Pagoni, S. and Katsilambros, N. 2008, Metabolism, 57, 313.

57. Mikkelsen, P. B., Toubro, S. and Astrup, A. 2000, Am J Clin Nutr, 72, 1135.

58. Zangarelli, A., Chanseaume, E., Morio, B., Brugere, C., Mosoni, L., Rousset, P., Giraudet, C., Patrac, V., Gachon, P., Boirie, Y. and Walrand, S. 2006, Faseb J, 20, 2439.

59. Gietzen, D. W., Hao, S. and Anthony, T. G. 2007, Annu Rev Nutr, 27, 63.

60. Tome, D. 2004, Br J Nutr, 92 Suppl 1, S27.

61. Pannemans, D. L., Wagenmakers, A. J., Westerterp, K. R., Schaafsma, G. and Halliday, D. 1998, Am J Clin Nutr, 68, 1228.

62. Boirie, Y., Dangin, M., Gachon, P., Vasson, M. P., Maubois, J. L. and Beaufrere, B. 1997, Proc Natl Acad Sci U S A, 94, 14930.

63. Dangin, M., Boirie, Y., Garcia-Rodenas, C., Gachon, P., Fauquant, J., Callier, P., Ballevre, O. and Beaufrere, B. 2001, Am J Physiol Endocrinol Metab, 280, E340.

64. Dangin, M., Boirie, Y., Guillet, C. and Beaufrere, B. 2002, J Nutr, 132, 3228 S.

65. Stryer, L. 1988, Biochemistry, W.H. Freeman and Company, New York.

66. van Milgen, J. 2002, J Nutr, 132, 3195.

67. Azzout-Marniche, D., Gaudichon, C., Blouet, C., Bos, C., Mathe, V., Huneau, J. F. and Tome, D. 2007, Am J Physiol Regul Integr Comp Physiol, 292, R1400.

68. Veldhorst, M. A., Westerterp-Plantenga M.S., and Westerterp, K.R. 2009, Am. J. Clin. Nutr., 90, 519. 



\section{Chapter 4}

\section{The effects of green tea on weight loss and weight maintenance: a meta-analysis}

Hursel R, Viechtbauer W and Westerterp-Plantenga MS

Int J Obes (London). 2009; 33(9): 956-61 


\section{Abstract}

Introduction. Different outcomes of the effect of green tea on weight loss (WL) and weight maintenance (WM) have been reported in studies with subjects differing in ethnicity and habitual caffeine intake.

Purpose. To elucidate by meta-analysis whether or not green tea indeed has a function in body-weight regulation.

Methods. English-language studies about WL and WM after green tea supplementation (GT) were identified through PubMed and based on the references from retrieved articles. Out of the 49 studies initially identified, a total of 11 articles fitted the inclusion criteria and provided useful information for the metaanalysis. Effect-sizes (mean weight change in treatment versus control group) were computed and aggregated based on a random-effects model. The influence of several moderators on the effect-sizes was examined.

Results. Catechins significantly decreased body-weight and significantly maintained body-weight after a period of $W L(\hat{\mu}=-1.31 \mathrm{~kg} ; \mathrm{p}<0.001)$. Inhibition of this effect by high habitual caffeine intake $(>300 \mathrm{mg} / \mathrm{d})$ failed to reach significance ( $\hat{\mu}=-0.27 \mathrm{~kg}$ for high and $\hat{\mu}=-1.60 \mathrm{~kg}$ for low habitual caffeine intake; $\mathrm{p}=0.09$ ). Also the seemingly smaller effect of catechins in Caucasian $(\hat{\mu}=-0.82 \mathrm{~kg})$ subjects compared with Asians ( $\hat{\mu}=-1.51 \mathrm{~kg} ; \mathrm{p}=0.37$ ) did not reach significance. Interaction of ethnicity and caffeine intake was a significant moderator $(p=0.04)$.

Conclusions. Catechins or an epigallocatechin gallate (EGCG)-caffeine mixture have a small positive effect on WL and on WM. The results suggest that habitual caffeine intake and ethnicity may be moderators, as they may influence the effect of catechins.

Keywords: green tea, caffeine, weight loss, weight maintenance, ethnicity 


\section{Introduction}

Green tea is the most widely consumed beverage next to water in Asian countries. Moreover, people in Asia have been aware of the beneficial effects of green tea on health for already hundreds of years (1). On the other hand, only recently is green tea gaining interest in the Westernized world, where mainly black tea is drunken. Green tea is made from the fresh leaves of Camellia sinensis, which are processed rapidly by means of steam to prevent fermentation. Black tea is made from the same plant as green tea but the leaves endure an extra enzymatic oxidation step during the processing (1). The polyphenols in green tea such as epigallocatechin gallate (EGCG), epigallocatechin, and epicatechin gallate, which are responsible for its beneficial effects (such as the antioxidant potential and anti-mutagenic capacity) are converted into thearubigins and theaflavins in black tea (2). Although black tea still can improve one's health, the conversion attenuates the effects reported after intake of green tea (3-5).

Since the 1990s, green tea is also seen as a natural herb that can enhance energy expenditure and fat oxidation and thereby induce weight loss (WL) $(6,7)$. The fact that an EGCG-caffeine mixture stimulates energy expenditure cannot be completely attributed to its caffeine content because the thermogenic effect of an EGCG-caffeine mixture is greater than that of an equivalent amount of caffeine (8). Twenty-four hour studies showed a significant increase in energy expenditure and fat oxidation $(8,9)$. From these short-term studies, studies over the longer term originated in which the effect from an EGCG-caffeine mixture on WL was studied and soon studies concerning the effect on weight maintenance (WM) followed.

Almost all of the studies conducted with Asian subjects have shown positive results about the anti-obesity effects of catechins (10-17). On the other hand, studies with Caucasian subjects reported mixed results (18-20). Moreover, the amount of regular caffeine intake may also influence the effectiveness of catechins. In a study from Westerterp-Plantenga et al. (20), it was shown that a regular caffeine intake of $>300 \mathrm{mg} /$ day in Caucasian subjects diminished the effects of an EGCG-caffeine mixture on WM, in comparison with subjects that had a regular caffeine intake of $<300 \mathrm{mg} /$ day.

Hence, the aim of this study was to do a systematic review and metaanalysis of all the available long-term studies that have examined the effects of EGCG on WL and WM, to establish whether catechins contribute to the regulation of body weight. Possible moderators, such as regular caffeine intake and ethnicity, are included in the meta-analysis, to investigate whether they have any impact on the effects of an EGCG-caffeine mixture on body weight. 


\section{Methods}

\section{Identification of relevant studies}

PubMed was searched for English-language studies that reported the long-term effects from catechins on WL and WM. The databases were searched up to July 2008 with the following keywords: green tea, body weight, WL, WM, catechins, epigallocatechin gallate, or EGCG. References from the retrieved articles were examined to identify possible additional articles.

\section{Inclusion and exclusion criteria}

A study was valid for inclusion in the review if (a) the study's participants were randomly assigned to conditions, (b) the results allowed a direct comparison of the effects of catechins (either in the form of catechins versus no catechins or high-dosage versus low-dosage catechins) on either WL or WM, (c) subjects were kept blind to the condition assigned, and (d) the study lasted for at least 12 weeks. An EGCG-caffeine mixture tea could either be administered as regular tea or as capsules. An important exclusion criterion was the use of any tea other than an EGCG-caffeine mixture (such as oolong tea).

\section{Data abstraction}

Various characteristics were extracted from the original reports using a standardized data extraction form. We recorded the study's author(s), year of publication, the duration of the treatment phase (in weeks), whether the study used a WL or WM design, and the age range, ethnicity, average body mass index, gender, and average regular caffeine intake (in $\mathrm{mg}$ per day) of the participants in the study. Moreover, for each condition, we recorded the number of participants and the dosage of green tea administered (in mg per day).

For each condition, we calculated or extracted the mean weight change (in kilograms) between the post-treatment and the baseline assessment. For WL studies, the baseline corresponds to the point just before the commencement of the WL phase, whereas for WM studies, the baseline corresponds to the point before the commencement of the WM phase. The post-treatment mean was always based on the time point immediately following the intervention. Regardless of the study design, negative values for the mean change, therefore, indicate WL, a value of zero indicates no change, and positive values indicate an increase in the body mass on average. The effect size measure for the metaanalysis was then the difference between the mean change value for the treatment minus the mean change value for the control group. Negative values for the observed effect size, therefore, indicate more WL (or less weight gain) on aver- 
age in the treatment compared with the control group and, therefore, a positive treatment effect of the EGCG-caffeine mixture on WL/WM.

The following three variables were a priori chosen for examination as potential moderators: the ethnicity of the participants (either Asian or Caucasian), the average regular caffeine intake of the participants in the study (either low or high, with $300 \mathrm{mg}$ per day being the cutoff), and the difference in dosage of the EGCG-caffeine mixture administered in the treatment and the control group.

\section{Statistical analysis}

The effect size estimates were aggregated based on a random-effects model, using restricted maximum-likelihood (REML) estimation to estimate the amount of heterogeneity in the effect sizes (21). We report the estimated average effect $(\hat{\mu})$, the estimated amount of heterogeneity in the true effects $\left(\hat{\tau}^{2}\right)$, and the estimated percentage of the total amount of variability that can be attributed to heterogeneity $\left(I^{2}\right)$. Corresponding $95 \%$ confidence intervals are given for all of these statistics. We also provide the results from the test for heterogeneity. The moderators were examined individually and in combination using mixed-effects models, again using REML estimation for the amount of (residual) heterogeneity. For these models, we report the estimated effect sizes within each level of a moderator with corresponding $95 \%$ confidence intervals.

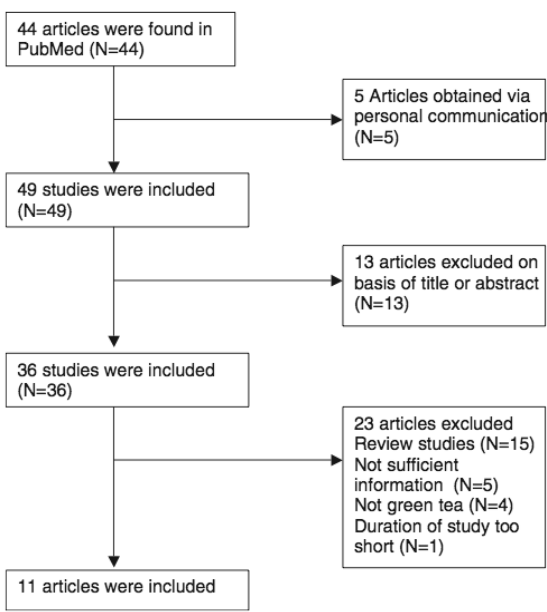

Figure 1. Process of study selection. 


\section{Results}

Forty-four potentially relevant studies were found initially. From these, 15 review articles were excluded immediately, as these contributed no additional data besides the original studies, which were already included. Another 13 studies were excluded on basis of title and abstract, as these were studies conducted with animals. Five articles from Asian authors were obtained via personal communication $(10-12,14,17)$. Four of them only had an English abstract and were further written in Japanese. These articles were sent to us with an English translation, as we contacted the institution (Kao Corporation, Tokyo, Japan) where Nagao et al. (13) are employed, after finding their study in PubMed. Information from the fifth Asian study by Wang et al. (17) was also obtained via personal communication, as the results were not published during the data abstraction. Of the remaining 21 studies, 9 did not use green tea (e.g., oolong tea) or did not provide sufficient information to compute effect sizes. Only one study was excluded due to the time period, as it lasted for 8 weeks. No studies were excluded because of lack of randomization or blinding. Finally, 11 articles fulfilled the inclusion criteria (10-20). Figure 1 shows the process of study selection.

The selected articles all had comparable designs: in the WL studies (10-18), participants immediately started to consume an EGCG-caffeine mixture for 12 weeks following randomization; in the WM studies $(19,20)$, subjects first lost weight for 4 weeks using a very low energy diet, followed by randomization and then an EGCG-caffeine mixture supplementation for either 12 or 13 weeks (Table 1). In all but one study (17), subjects were randomly assigned to two conditions, with seven studies $(10,15-20)$ using a true placebo group and the remaining four studies (11-14) comparing a high with a low dose of an EGCG-caffeine mixture.

Almost every article reported the relevant information about the moderators, for instance as an important inclusion criterion. If regular caffeine intake was not reported by the Asian studies it was assumed to be low (22).

From three studies it was possible to calculate more than one effect size estimate. Kozuma et al. (10) reported their results separately for men and women, which therefore yields two effect size estimates for the meta-analysis. Also the data from Westerterp-Plantenga et al. (20) allowed the calculation of two estimates, one for subjects with high and the other for subjects with low regular caffeine intake. Finally, three effect size estimates were obtained from the study by Wang et al. (17) as it contained three treatment groups that received either a different dosage or an equivalent dosage distributed in a different number of servings. A total of 15 effect size estimates could, therefore, be extracted from the 11 studies. Figure 2 shows a plot of the individual effect size estimates with corresponding $95 \%$ confidence intervals.

The random-effects model indicated a modest, but significant positive effect of catechins on WL/WM ( $\hat{\mu}=-1.31,95 \% \mathrm{Cl}:-2.05$ to $-0.57 ; \mathrm{p}<0.001)$. Therefore, it is estimated that subjects in the treatment groups lost on average $1.31 \mathrm{~kg}$ 


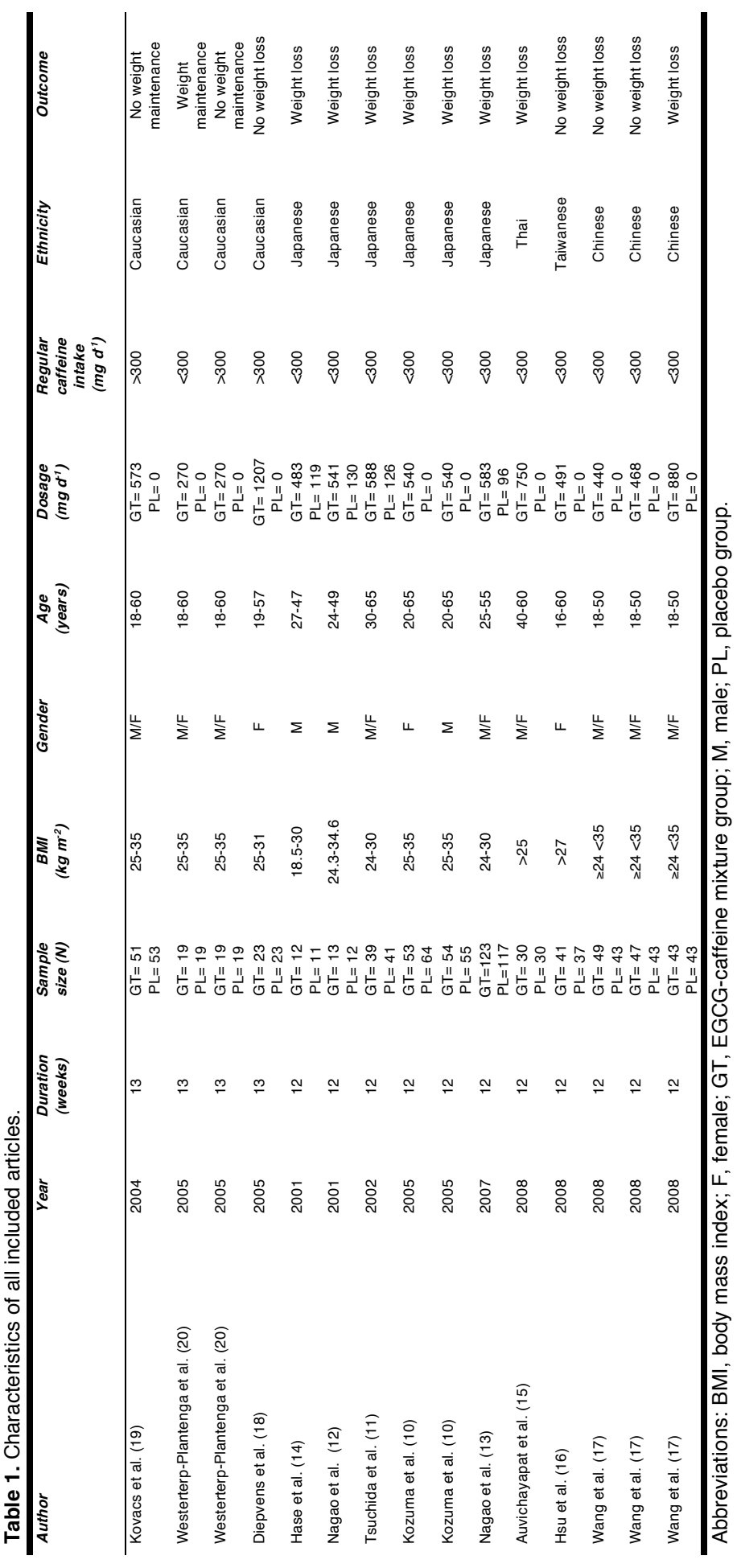


more weight (or gained on average $1.31 \mathrm{~kg}$ less weight) than people in the control groups. Removal of any individual study from the meta-analysis did not alter this conclusion (with $\hat{\mu}$ values ranging from -1.07 to -1.47 ; all $p<0.004$ ). However, the results were clearly heterogeneous $\left(\hat{\tau}^{2}=1.13\right.$ with $95 \% \mathrm{Cl}: 0.25$ to $3.80 ; l^{2}=94 \%$ with $95 \% \mathrm{Cl}: 77 \%$ to $98.0 \%$; test for heterogeneity: $\mathrm{p}<0.001$ ).

The difference in dosage of the EGCG-caffeine mixture between the treatment and the placebo group was not a significant moderator, whether examined in combination with the other two moderators or individually $(p=0.34$ and 0.76 , respectively). Although the average effect was larger for studies with Asian ( $\hat{\mu}=$ $-1.51,95 \% \mathrm{Cl}:-2.37$ to -0.65$)$ than Caucasian $(\hat{\mu}=-0.82,95 \% \mathrm{Cl}:-2.13$ to $0.50)$ samples, the difference did not reach statistical significance $(p=0.19$ when examined in combination with the other two moderators and $p=0.37$ when examined individually).

The estimated effect was larger for samples with a low $(\hat{\mu}=-1.60,95 \% \mathrm{Cl}$ : -2.38 to -0.83$)$ in comparison to a moderate-to-high regular caffeine intake ( $\hat{\mu}$ $=-0.27,95 \% \mathrm{Cl}:-1.63$ to 1.10$)$. The difference was significant when examined in combination with the other moderator, but not when examined individually $(p=0.04$ and $p=0.09$, respectively). The estimated amount of (residual) heterogeneity was equal to $\hat{\tau}^{2}=0.92$ after inclusion of this moderator in the model, suggesting that $\sim 19 \%$ of the total amount of heterogeneity could be accounted for based on information about the regular caffeine intake of the samples in the set of studies.

\section{Discussion}

The results of this meta-analysis show that an EGCG-caffeine mixture has an effect on WL and on WM after a period of negative energy balance. It is also shown that interaction of ethnicity and habitual caffeine intake is a moderator. Dosage of catechins in the treatment or in the placebo, did not have any significant effect on the outcome of the studies that were included.

However, the overall result implies some heterogeneity. This may be caused by studies differing in the possible moderators ethnicity and habitual caffeine intake. In particular, all Asian studies had a low caffeine intake and nearly all Caucasian studies had a high caffeine intake. Only one treatment group of the Westerterp-Plantenga et al. (20) study had a low caffeine intake. Although caffeine intake was a significant moderator when examined together in a model including ethnicity, inclusion of more studies with both ethnicities with different amounts of caffeine intake would provide a clearer picture of how these moderators influence the effectiveness of catechins. 


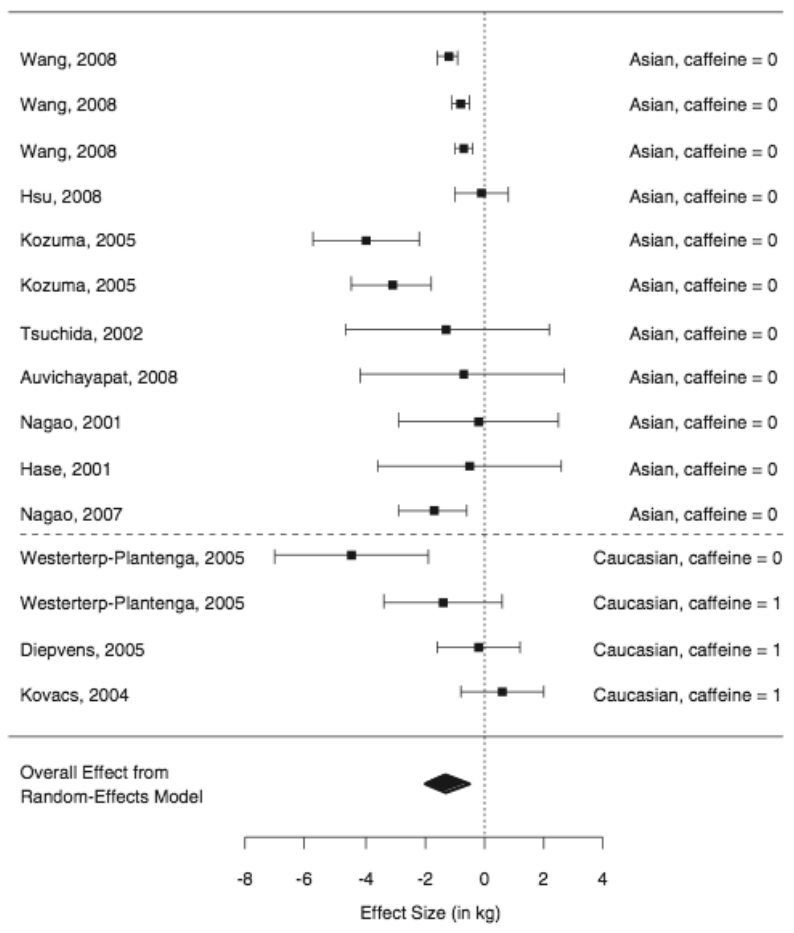

Figure 2. Forest plot of the individual effect size estimates (mean weight change within the treatment group minus mean weight change within the control group) with corresponding $95 \%$ confidence intervals (caffeine $=0 / 1$ for low $(0)$ or moderate to high (1) regular caffeine intake).

Interaction between the possible moderators maybe due to differences in allele frequencies of polymorphisms between ethnicities. For instance, people who drink caffeine regularly not only get habituated to the effects of caffeine, but also tolerate caffeine intake. Cornelis et al. (23) showed that Hispanic Americans with an ADORA2A 1083 TT genotype are more likely to limit their caffeine intake than the $C C$ and $C T$ genotype. These persons appeared to be more sensitive for the differences between caffeine and the adenosinergic system. This genotype codes for the $\mathrm{A}_{2 \mathrm{a}}$ receptor, at which caffeine antagonizes the actions of adenosine, a key process in the stimulating properties of caffeine. CYP1A2, which codes for the enzymes of cytochrome P450 (the metabolizers of caffeine), does not seem to have a function (23). Therefore it may well be that the habitually low caffeine consumers do not tolerate high amounts of caffeine intake and, therefore, react more sensitively to the small amount of caffeine added to the green tea mixture. When the allele frequencies of the genes coding for the activity of the enzyme differ between ethnic groups, this may explain the observed differences in response to the treatment. For this reason, ethnicity was included as a moderator. Although ethnicity was not a significant moderator, the results sug- 
gest that it may affect the effect an EGCG-caffeine mixture has on thermogenesis as the Asian subjects lost more weight than the Caucasian subjects. However, before the moderating role of ethnicity can be examined in more detail, additional studies with Caucasian samples should be conducted to offset the larger number of studies with Asian samples.

The inhibition of several enzymes may be the mechanism by which the components of green tea induce WL/WM. Catechins inhibit catechol-Omethyltransferase (COMT) and caffeine inhibits phosphodiesterase. Levels of norepinephrine and cAMP rise because degradation by these enzymes is ceased. Consequently, parasymphatic activity is increased (8). This phenomenon does not appear equally clear in all ethnic groups, because of the differences in relevant enzyme activity, causing differences in sensitivity for these ingredients. In that respect Hodgson et al. (24) stated that there is a wide variability in flavonoid O-methylation, a major pathway of flavonoid metabolism, by the enzyme COMT. The inter-individual variability of the activity of COMT could vary as much as three-fold (24). Moreover, COMT enzyme activity differs between ethnic groups (25), in that Asian populations have a higher frequency of the thermostable, high activity enzyme, $\mathrm{COMT}^{\mathrm{H}}$ allele (Val/Val polymorphism) than the Caucasian populations. The Caucasian populations have a higher frequency of the thermolabile, low activity enzyme, COMT ${ }^{\mathrm{L}}$ allele (Met/Met polymorphism) (3). In all, $50 \%$ of Caucasians are homozygous for the $\mathrm{COMT}^{\mathrm{L}}$ allele $(25 \%)$ and $\mathrm{COMT}^{\mathrm{H}}$ allele $(25 \%)$. The other $50 \%$ is heterozygous (Val/Met polymorphism) (25). This may explain the difference in sensitivity to interventions with EGCG-caffeine mixtures, and why, in some studies with Caucasian subjects, no effect was seen after ingestion of an EGCG-caffeine mixture. The observations described above suggests interaction between the two possible moderators. Not until the two moderators were taken together, the difference in estimated effect between samples with low and moderate-to-high regular caffeine intake became significant, probably because of coincidence of polymorphisms ADORA2A, COMT and ethnicity.

The results of the meta-analysis also show that the difference in dosage of the catechins in the EGCG-caffeine mixture between treatment and control groups had no effect on size of the effect. This finding is consistent with the results from the study of Berube-Parent et al. (9) in which four different mixtures of EGCG and caffeine with a different dosage of catechins were examined. The results from that study showed that all mixtures increased $24 \mathrm{hr}$ energy expenditure and that the increase was similar for all doses of EGCG in the mixtures, which was also found in the study from Wang et al. (17).

Taken together, this meta-analysis has shown that EGCG-caffeine mixtures have a positive effect on WL and on WM. Moreover, it also shows that habitual caffeine intake and ethnicity may be moderators, especially because of interactions of the different $A D O R A 2 A$ and COMT polymorphisms and ethnicity, whereas different doses of catechins do not have a significantly different effect. 
Experimental research is needed to find out whether and to what extent people are genetically predisposed for the effect of EGCG-caffeine mixtures.

\section{Acknowledgements}

$\mathrm{RH}$ and MSW-P designed the study. $\mathrm{RH}$ collected and prepared the data. WV analyzed the data. $\mathrm{RH}$ and $\mathrm{WV}$ wrote the manuscript and MSW-P contributed to the interpretation of the data and reviewed the manuscript. The study was executed under the supervision of MSW-P. None of the authors had a personal or financial conflict of interest.

\section{References}

1. Shixian Q, VanCrey B, Shi J, Kakuda Y, Jiang Y. Green tea extract thermogenesis-induced weight loss by epigallocatechin gallate inhibition of catechol-O-methyltransferase. J Med Food 2006;9:451-8.

2. Wolfram S, Wang Y, Thielecke F. Anti-obesity effects of green tea: from bedside to bench. Mol Nutr Food Res 2006;50:176-87.

3. Krul C, Luiten-Schuite A, Tenfelde A, van Ommen B, Verhagen H, Havenaar R. Antimutagenic activity of green tea and black tea extracts studied in a dynamic in vitro gastrointestinal model. Mutat Res 2001;474:71-85.

4. Langley-Evans SC. Antioxidant potential of green and black tea determined using the ferric reducing power (FRAP) assay. Int J Food Sci Nutr 2000;51:181-8.

5. Serafini M, Ghiselli A, Ferro-Luzzi A. In vivo antioxidant effect of green and black tea in man. Eur J Clin Nutr 1996;50:28-32.

6. Westerterp-Plantenga M, Diepvens K, Joosen AM, Berube-Parent S, Tremblay A. Metabolic effects of spices, teas, and caffeine. Physiol Behav 2006;89:85-91.

7. Diepvens K, Westerterp KR, Westerterp-Plantenga MS. Obesity and thermogenesis related to the consumption of caffeine, ephedrine, capsaicin, and green tea. Am J Physiol Regul Integr Comp Physiol 2007;292:R77-85.

8. Dulloo AG, Duret C, Rohrer D, et al. Efficacy of a green tea extract rich in catechin polyphenols and caffeine in increasing 24-h energy expenditure and fat oxidation in humans. Am J Clin Nutr 1999;70:1040-5.

9. Berube-Parent S, Pelletier C, Dore J, Tremblay A. Effects of encapsulated green tea and Guarana extracts containing a mixture of epigallocatechin-3-gallate and caffeine on $24 \mathrm{~h}$ energy expenditure and fat oxidation in men. Br J Nutr 2005;94:432-6.

10. Kozuma K, Chikama A, Hishino E, et al. Effect of intake of a beverage containing $540 \mathrm{mg}$ catechins on the body composition of obese women and men. Prog Med 2005;25:185-197.

11. Tsuchida $\mathrm{T}$, Itakura $\mathrm{H}$, Nakamura $\mathrm{H}$. Reduction of body fat in humans by long-term ingestion of catechins. Prog Med 2002;22:2189-2203.

12. Nagao T, Meguro S, Soga S, et al. Tea catechins suppress accumulation of body fat in humans. J Oleo Sci 2001;50:717-728.

13. Nagao T, Hase T, Tokimitsu I. A green tea extract high in catechins reduces body fat and cardiovascular risks in humans. Obesity (Silver Spring) 2007;15:1473-83.

14. Hase T, Komine $\mathrm{Y}$, Meguro S, et al. Anti-obesity effects of tea catechins in humans. J Oleo Sci 2001;50:599-605.

15. Auvichayapat $P$, Prapochanung $M$, Tunkamnerdthai $O$, et al. Effectiveness of green tea on weight reduction in obese Thais: A randomized, controlled trial. Physiol Behav 2008;93:486-91.

16. Hsu CH, Tsai TH, Kao YH, Hwang KC, Tseng TY, Chou P. Effect of green tea extract on obese women: a randomized, double-blind, placebo-controlled clinical trial. Clin Nutr 2008;27:363-70. 
17. Wang $M$, Wen $Y$, Du $Y$, et al. The effects of 90 days consumption of a high-catechin green tea beverage on body weight. Eur J Clin Nutr 2008;Submitted.

18. Diepvens K, Kovacs EM, Nijs IM, Vogels N, Westerterp-Plantenga MS. Effect of green tea on resting energy expenditure and substrate oxidation during weight loss in overweight females. $\mathrm{Br}$ J Nutr 2005;94:1026-34.

19. Kovacs EM, Lejeune MP, Nijs I, Westerterp-Plantenga MS. Effects of green tea on weight maintenance after body-weight loss. Br J Nutr 2004;91:431-7.

20. Westerterp-Plantenga MS, Lejeune MP, Kovacs EM. Body weight loss and weight maintenance in relation to habitual caffeine intake and green tea supplementation. Obes Res 2005;13:1195204.

21. Viechtbauer W. Bias and efficiency of meta-analytic variance estimators in the random-effects model. . Journal of Educational and Behavioral Statistics 2005;30:261-293.

22. Grigg D. The worlds of tea and coffee: Patterns of consumption. GeoJournal 2002;57:283-294.

23. Cornelis MC, El-Sohemy A, Campos H. Genetic polymorphism of the adenosine A2A receptor is associated with habitual caffeine consumption. Am J Clin Nutr 2007;86:240-4.

24. Hodgson JM, Puddey IB, Burke V, Croft KD. Is reversal of endothelial dysfunction by tea related to flavonoid metabolism? Br J Nutr 2006;95:14-7.

25. Palmatier MA, Kang AM, Kidd KK. Global variation in the frequencies of functionally different catechol-O-methyltransferase alleles. Biol Psychiatry 1999;46:557-67. 
Chapter 5

\section{The effects of catechin rich teas and caffeine on energy expenditure and fat oxidation: a meta-analysis}

Hursel R, Viechtbauer W, Dulloo AG, Tremblay A, Tappy L, Rumpler W and Westerterp-Plantenga MS

Obes Rev. 2011; in press 


\begin{abstract}
Different outcomes of the effect of catechin-caffeine mixtures and caffeine-only supplementation on energy expenditure and fat oxidation have been reported in short-term studies. Therefore, a meta-analysis was conducted to elucidate whether catechin-caffeine mixtures and caffeine-only supplementation indeed increase thermogenesis and fat oxidation. First, English-language studies measuring daily energy expenditure and fat oxidation by means of respiration chambers after catechin-caffeine mixtures and caffeine-only supplementation were identified through PubMed. Six articles encompassing a total of 18 different conditions fitted the inclusion criteria. Second, results were aggregated using random/mixed-effects models and expressed in terms of the mean difference in 24 hr energy expenditure and fat oxidation between the treatment and placebo conditions. Finally, the influence of moderators such as BMI and dosage on the results was examined as well. The catechin-caffeine mixtures and caffeine-only supplementation increased energy expenditure significantly over $24 \mathrm{hr}(428.0 \mathrm{~kJ}$ (4.7\%); $p<0.001$ and 429.1kJ (4.8\%); $p<0.001$, respectively). However, $24 \mathrm{hr}$ fat oxidation was only increased by catechin-caffeine mixtures $(12.2 \mathrm{~g}(16.0 \%) ; \mathrm{p}<$ 0.02 and $9.5 \mathrm{~g}(12.4 \%) ; p=0.11$, respectively). A dose-response effect on $24 \mathrm{~h}$ energy expenditure and fat oxidation occurred with a mean increase of $0.53 \mathrm{~kJ}$ $\mathrm{mg}^{-1}(\mathrm{p}<0.01)$ and $0.02 \mathrm{~g} \mathrm{mg}^{-1}(\mathrm{p}<0.05)$ for catechin-caffeine mixtures and 0.44 $\mathrm{kJ} \mathrm{mg}^{-1}(\mathrm{p}<0.001)$ and $0.01 \mathrm{~g} \mathrm{mg}^{-1}(\mathrm{p}<0.05)$ for caffeine-only. In conclusion, catechin-caffeine mixtures or a caffeine-only supplementation stimulates daily energy expenditure dose-dependently by 0.4-0.5 $\mathrm{kJ} \mathrm{mg}^{-1}$ administered. Compared with placebo, daily fat-oxidation was only significantly increased after catechincaffeine mixtures ingestion.
\end{abstract}

Keywords: caffeine, catechins, green tea, oolong tea, 


\section{Introduction}

Tea is the most widely consumed beverage next to water in the world. People in Asia have been aware of the beneficial effects of green tea on health for hundreds of years (1), but it is only recently that green tea and oolong tea have been gaining interest in the westernized world, where mainly black tea is drunk. Both green tea and black tea are made from the fresh leaves of Camellia sinensis, but they differ in the way that the leaves are processed. In particular, green tea is processed rapidly by means of steam to prevent fermentation. Black tea is made from the same plant as green tea but the leaves endure an extra enzymatic oxidation step during the processing (1). The polyphenols in green tea and oolong tea such as epigallocatechin gallate (EGCG), epigallocatechin (EGC), epicatechin gallate (ECG) and epicatechin (EC), which are responsible for its beneficial effects (such as the anti-oxidant potential and anti-mutagenic capacity), are converted into thearubigins and theaflavins in black tea (2). Although black tea still can improve one's health, the conversion attenuates the effects reported after intake of green tea and oolong tea (3-5).

According to traditional Chinese belief, tea seems to be effective in the control of body weight. Since the 1990s, green tea and oolong tea are also viewed in the westernized world as natural herbs that can enhance energy expenditure and fat oxidation by activating the sympathoadrenal system and thereby inducing weight loss $(6,7)$. Several long-term studies have been conducted to examine the effects of catechin-caffeine mixtures on weight loss (8-16) and on weight maintenance following weight loss $(17,18)$. The mixed results from these studies were recently summarized in a meta-analysis showing that catechin-caffeine mixtures have a positive effect on weight loss and on weight maintenance (8). Although the evidence was limited, habitual caffeine intake and ethnicity were found to be potential moderators of these effects. A difference in genetic predisposition of subjects, probably due to multiple variants of the catechol-Omethyltransferase (COMT) polymorphism, might explain the discrepancy in the outcome between studies. Furthermore, different doses of catechin-caffeine mixtures did not appear to yield significantly different effects (19).

Moreover, the stimulatory effects of a catechin-caffeine mixture on energy expenditure cannot be completely attributed to its caffeine content because the thermogenic effect of a catechin-caffeine mixture is greater than that of an equivalent amount of caffeine (20). However, the evidence remains mixed: Some $24 \mathrm{hr}$ studies measuring energy expenditure and fat oxidation by means of respiration chambers showed significant increases in energy expenditure and/or fat oxidation $(20,21)$, but other more acute studies, lasting over a few hours, did not (22-24). Similar to the long-term studies, the presence of responders and nonresponders may have led to mixed results, again suggesting a possible role for the genotype.

The aim of the present study was to conduct a systematic review and metaanalysis of the available short-term studies that have examined the effects of 
catechin-caffeine mixtures and caffeine-only supplementation on $24 \mathrm{hr}$ energy expenditure and fat oxidation, in order to establish whether catechin-caffeine mixtures and caffeine-only supplementation contribute to thermogenesis. Possible moderators, namely the body mass index (BMI) of the subjects and the catechin/caffeine dosage, are included in the meta-analysis, to investigate whether they have any impact on overall energy expenditure and fat oxidation and the effects of caffeine-only or catechin-caffeine mixtures.

\section{Methods}

\section{Identification of relevant studies}

PubMed was searched for English-language studies that reported the short-term effects from catechin-caffeine mixtures and caffeine-only supplementation on energy expenditure and fat oxidation. The databases were searched up to January 2010 with the following keywords: green tea, oolong tea, caffeine, energy expenditure, thermogenesis, fat oxidation, catechins, epigallocatechin gallate, or EGCG. References from the retrieved articles were examined to identify possible additional articles.

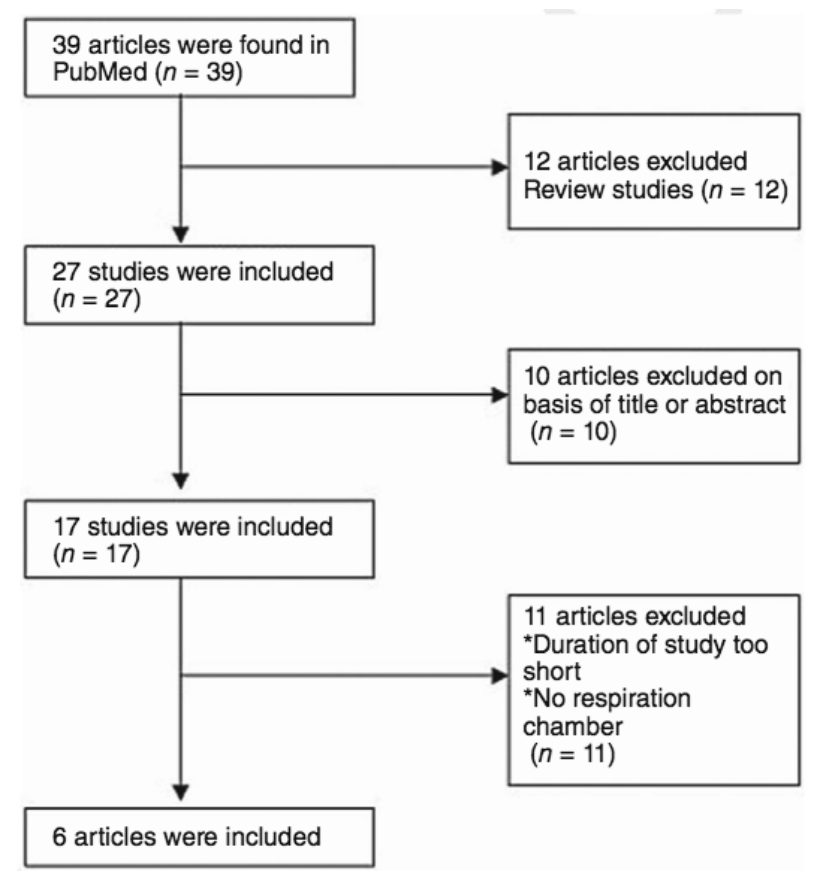

Figure 1. Process of study selection. 


\section{Inclusion and exclusion criteria}

A study was valid for inclusion in the review if (i) the study's participants were randomly assigned to conditions or treatment orders (in case of a within-subjects design); (ii) the results allowed a direct comparison of the effects of catechincaffeine mixtures or caffeine-only supplementation (either in the form of catechin-caffeine mixtures or caffeine-only supplementation vs. no treatment or highvs. low-dosage) on energy expenditure and/or fat oxidation; (iii) subjects were kept blind to the condition assigned; (iv) the study lasted for at least $23 \mathrm{hr}$ and (v) had to be conducted in a respiration chamber. The caffeine-only or catechincaffeine mixture could either be administered as a regular beverage or as capsules.

\section{Data abstraction}

Various characteristics were extracted from the original reports using a standardized data extraction form. We recorded the study's author(s), year of publication, the duration of the measurement (in hours), and the age range, mean BMI, gender, and mean regular caffeine intake (in $\mathrm{mg} \mathrm{d}^{-1}$ ) of the participants in the study (Table 1). Moreover, for each condition, we recorded the number of participants included from each trial, the dosage of total catechins, EGCG and caffeine administered (in $\mathrm{mg} \mathrm{d}^{-1}$ ), the mean energy expenditure (in $\mathrm{kJ} \mathrm{d}^{-1}$ ) and fat oxidation (in $\mathrm{g} \mathrm{d}^{-1}$ ), and the corresponding standard errors of these means. Finally, we computed the difference in the mean energy expenditure and fat oxidation after catechin-caffeine mixtures or caffeine-only supplementation when compared with placebos. A positive value for this effect size measure therefore indicates higher energy expenditure on average after treatment and therefore a stimulatory effect of catechin-caffeine mixtures or caffeine-only on thermogenesis.

\section{Statistical analysis}

We used mixed-effects meta-regression models to estimate the mean energy expenditure and fat oxidation when only receiving placebos and the additive effects of either catechin-caffeine mixtures or caffeine-only supplementation on the mean energy expenditure and fat oxidation when compared with placebos. Since the included studies all used cross-over designs (see below), an armbased meta-analysis model was used for this purpose, allowing the estimated mean outcome (either energy expenditure or fat oxidation) for the same subjects in different conditions (study arms) to be correlated and using dummy variables to code the three different conditions (i.e., placebo, catechin-caffeine mixture, or caffeine-only supplementation). We also estimated the change in the mean energy expenditure and fat oxidation for a one-unit increase in the mean BMI of the subjects (by including mean BMI as an additional variable in the model) and for 


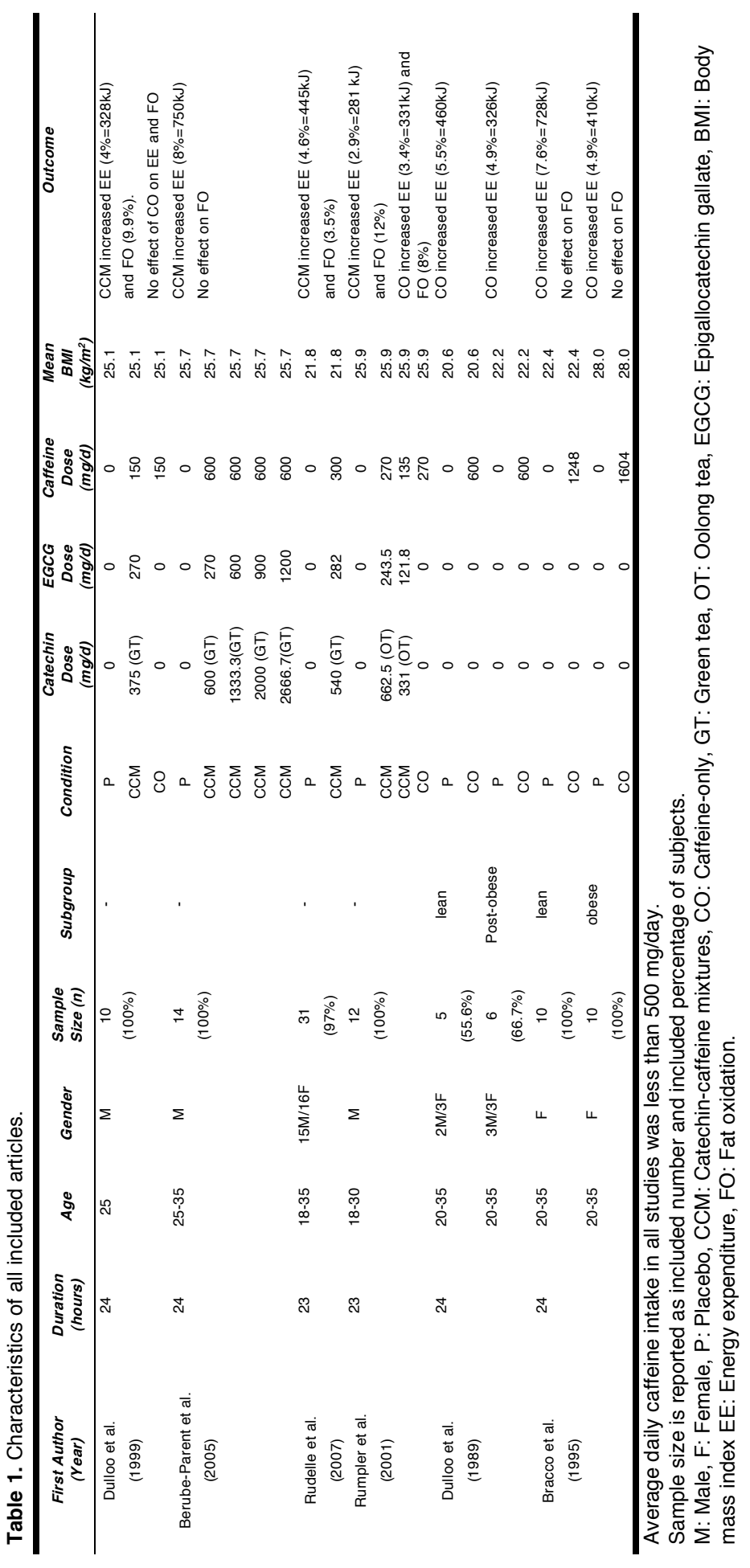


each $\mathrm{mg} \mathrm{d}^{-1}$ increase in the catechin and caffeine dosage administered (by replacing the dummy variables with the variables that indicate the actual catechin and caffeine dosages administered in a particular condition).

The models were fitted using restricted maximum-likelihood (REML) estimation (25). We report the estimated mean energy expenditure and fat oxidation under placebos $\left(\hat{\beta}_{0}\right)$ and the effects of catechin-caffeine mixtures $\left(\hat{\beta}_{G}\right)$ and caffeine-only supplementation $\left(\hat{\beta}_{C}\right)$ on the mean energy expenditure and fat oxidation, and the estimated amount of heterogeneity in these effects $\left(\hat{\tau}^{2}\right)$. Corresponding $95 \%$ confidence intervals (Cls) are given for all of these statistics. We also provide the results from likelihood-ratio tests for heterogeneity. To examine whether the conclusions regarding the effects of catechin-caffeine mixtures and caffeine-only supplementation hinge on the results from a single study, sensitivity analyses were conducted for both outcomes by repeating the analyses while removing each study in turn. For the models involving BMI and the catechin and caffeine dosages, we report the estimated model coefficients with corresponding $95 \%$ Cls.

\section{Results}

Thirty-nine potentially relevant studies were found initially. From these, 12 review articles were excluded immediately, as these contributed no additional data besides the original studies, which were already included. Another 10 studies were excluded on the basis of title and abstract, as these were studies conducted with animals (seven studies) or specifically focused on the effects of catechin-caffeine mixtures or caffeine-only supplementation in combination with strenuous exercise (three studies). Of the remaining 17 studies, an additional set of 11 studies had to be excluded either because measurements lasted less than $23 \mathrm{hr}$ or because they were not performed in a respiration chamber. Among the remaining studies, lack of randomization or blinding did not occur. Therefore, six articles fulfilled the inclusion criteria $(20,21,26-29)$. Figure 1 shows the process of study selection.

The selected articles all had comparable cross-over designs: in each study, subjects participated in all conditions in random order with at least 5 days in between as wash-out period. Subjects stayed in a respiration chamber for either 23 or $24 \mathrm{hr}$ and received an intervention or placebo together with their meals. In all studies, subjects were randomly assigned to two or more conditions, and a true placebo group was used.

Almost every article reported the relevant information about the moderators, for instance as an important inclusion criterion. All studies provided information about the mean energy expenditure and fat oxidation except one, which only reported the mean energy expenditure of the subjects. A total of 18 different 


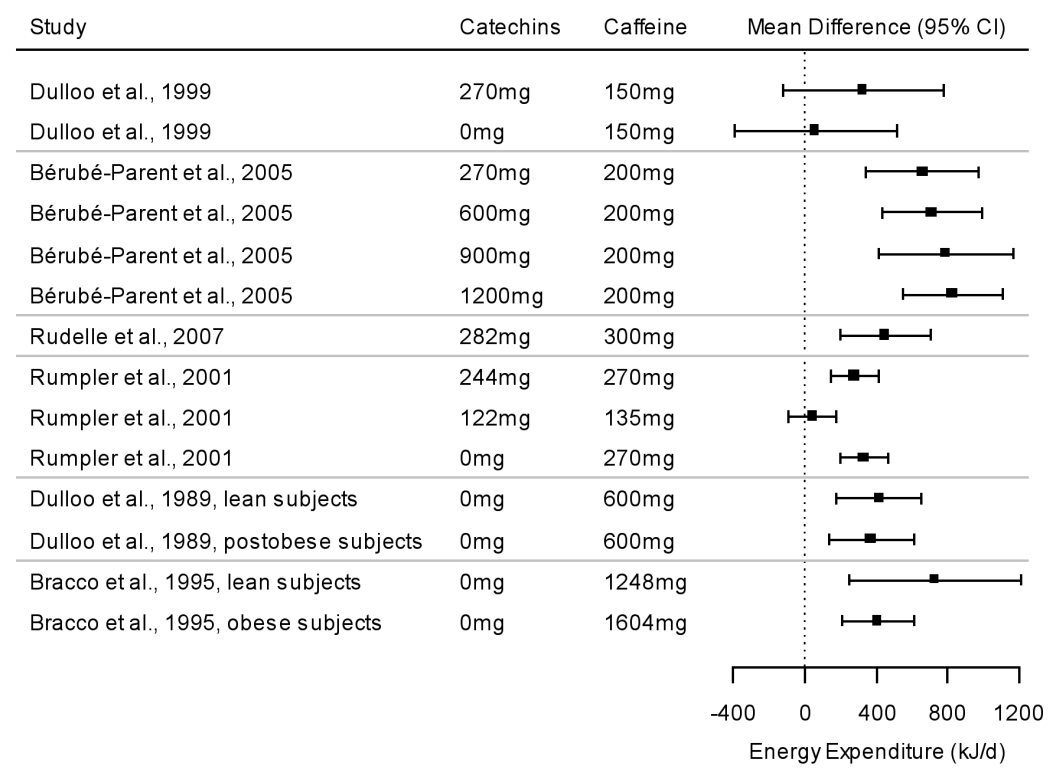

Figure 2. Plot of the mean differences (green/oolong tea or caffeine condition vs. placebo condition) with $95 \%$ conficdence intervals $(\mathrm{Cl})$ for energy expenditure.

conditions were examined in the studies (6 placebo, 8 catechin-caffeine mixures, and 4 caffeine-only conditions).

Because several studies had a cross-over design that measured energy expenditure and/or fat oxidation under more than two conditions (either because the effects of an catechin-caffeine mixture and caffeine-only supplementation or because the effects of different dosages were compared in the same study), it was possible to calculate more than one effect size estimate for these studies. In addition, two studies reported the results separately for two subgroups of participants ("lean" vs. "post-obese" in the first, and "lean" vs. "obese" subjects in the second study). Therefore, a total of 14 effect size estimates could be extracted from the six studies for energy expenditure and 12 estimates for fat oxidation. Figure 2 and 3 show a plot of the individual effect size estimates with corresponding $95 \% \mathrm{Cls}$ for energy expenditure and fat oxidation.

The mean energy expenditure in placebo conditions was estimated to be $\hat{\beta}_{0}$ $=9020.3 \mathrm{~kJ} \mathrm{~d}^{-1}$ (95\% Cl: 8161.0 to 9879.6). A significant positive effect on energy expenditure was found both for catechin-caffeine mixtures $\left(\hat{\beta}_{G}=428.0\right.$ $\mathrm{kJ} / \mathrm{d}, 95 \% \mathrm{Cl}: 252.7$ to $603.4 ; \mathrm{p}<0.001)$ and caffeine-only supplementation $\left(\hat{\beta}_{C}=\right.$ $429.1 \mathrm{~kJ} \mathrm{~d}^{-1}, 95 \% \mathrm{Cl}: 260.7$ to $\left.597.5 ; \mathrm{p}<0.001\right)$. Therefore, it is estimated that subjects receiving catechin-caffeine mixtures and caffeine-only increase energy expenditure on average by $4.7 \%$ and $4.8 \%$, respectively. Removal of any indi- 
vidual study from the meta-analysis did not alter this conclusion, with effects for catechin-caffeine mixtures ranging from 296 to $601 \mathrm{~kJ} \mathrm{~d}^{-1}$ (all $\mathrm{p}<0.002$ ) and effects for caffeine-only supplementation ranging from 398 to $468 \mathrm{~kJ} \mathrm{~d}^{-1}$ (all $\mathrm{p}<0.001)$. However, the results were clearly heterogeneous $\left(\hat{\tau}^{2}=28069.5 ; 95 \%\right.$ $\mathrm{Cl}$ : 6513.6 to 117096.3; likelihood-ratio test for heterogeneity: $x^{2}=23.28$, $\mathrm{p}<0.001)$. For a one-point increase in mean BMI of the subjects, the mean energy expenditure was estimated to increase by a $344.1 \mathrm{~kJ} \mathrm{~d}^{-1}$ points $(95 \% \mathrm{Cl}$ : 75.2 to $613.0 ; p<0.02$ ). Finally, a clear dose-response relationship was found for both catechins and caffeine: A $1 \mathrm{mg}$ increase in the catechins dosage was estimated to yield a 0.53-point increase in mean energy expenditure $(95 \% \mathrm{Cl}: 0.20$ to $0.86 ; p<0.002$ ), while for caffeine, mean energy expenditure was estimated to increase by 0.44 points ( $95 \% \mathrm{Cl}: 0.23$ to 0.65 ; $\mathrm{p}<0.001$ ) per $\mathrm{mg}$.

Mean fat oxidation under placebo conditions was estimated at $\hat{\beta}_{0}=76.4 \mathrm{~g}$ $d^{-1}(95 \% \mathrm{Cl}: 60.5$ to 92.3$)$. Treatments with catechin-caffeine mixtures yielded a significant increase of on average $\hat{\beta}_{G}=12.2$ grams of fat oxidized $(95 \% \mathrm{Cl}: 1.7$ to 22.8 ; $p<0.02$ ), i.e., an increase of $16.0 \%$. While caffeine-only supplementation was estimated to yield a mean increase of $\hat{\beta}_{C}=9.5$ grams of fat oxidized $(95 \%$ $\mathrm{Cl}$ : -2.1 to 21.0$)$ or $12.4 \%$, the effect was not significant $(p=0.11)$. Removal of each study in turn yielded effects of catechin-caffeine mixtures from 8.6 to $15.7 \mathrm{~g}$ $d^{-1}$ (all $p<0.05$, except for one $p=0.13$ ) and effects of caffeine-only supplementation from 7.0 to $11.6 \mathrm{~g} \mathrm{~d}^{-1}$ (all $p>0.05$, except for one $\mathrm{p}=0.04$ ). Again, the results were heterogeneous ( $\hat{\tau}^{2}=142.7 ; 95 \% \mathrm{Cl}: 43.7$ to 558.6 ; likelihood-ratio test for heterogeneity: $\left.x^{2}=63.61, p<0.001\right)$. The mean BMI of the subjects had no significant influence on the mean fat oxidation $(p=0.58)$. However, significant doseresponse relationships were again found for both catechins (0.02-point increase for each $1 \mathrm{mg}$ increase; $95 \% \mathrm{Cl}$ : 0.01 to $0.03, \mathrm{p}=0.01)$ and caffeine $(0.01$-points increase; $95 \% \mathrm{Cl}$ : 0.00 to $0.02, \mathrm{p}=0.02)$.

\section{Discussion}

The results of this meta-analysis show that catechin-caffeine mixtures and caffeine-only have a significant effect on energy expenditure. Moreover, compared with placebo, catechin-caffeine mixtures increased fat oxidation as well, in contrast to caffeine-only which did not yield a significant effect on fat oxidation. However, the overall result implies heterogeneity, most of which is accounted for by differentiating the three conditions.

Another moderator that might add some heterogeneity is BMI. Subjects with a higher BMI at baseline correspond to higher energy expenditure, although this is not the case for fat oxidation. Having a higher BMI and therefore higher energy 


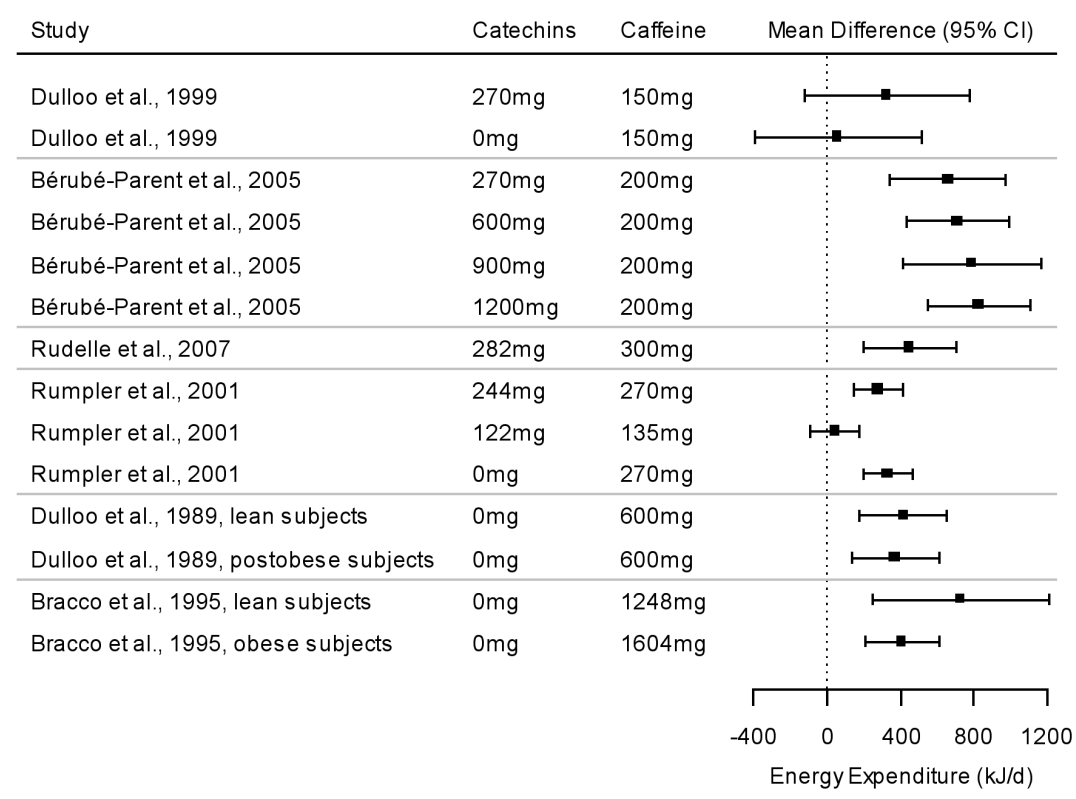

Figure 3. Plot of the mean differences (green/oolong tea or caffeine condition vs. placebo condition) with $95 \%$ conficdence intervals $(\mathrm{Cl})$ for energy fat oxidation.

expenditure is logical as heavier subjects have more fat free mass, which is the main determinant of basal metabolic rate. An elevated sympathetic activity in the obese, that might explain the higher energy expenditure in obese subjects, has also been suggested in the past. However, there was doubt as studies reported both a diminished (30) and an increased (31) sympathetic activity in the obese state. Nowadays it is accepted that there lies truth in both findings, as tissues have different magnitudes of sympathetic activity. For instance, the sympathetic nerve activity of muscle in obese subjects is over $50 \%$ higher compared with normal weight subjects, whereas the normal weight subjects have an increased cardiac sympathetic activity (32). For whole body sympathetic activity there does not seem to be a difference (32). In our study, BMI does not seem to influence the effects of catechin-caffeine mixtures and caffeine-only on energy expenditure and fat oxidation suggesting that subjects with higher BMI may also benefit from sympathoadrenal stimulating ingredients.

A higher BMI at baseline did not correspond to increased fat oxidation after catechin-caffeine mixtures and caffeine-only supplementation. Usually subjects with an increased fat mass already have an increased fat oxidation over time as shown by Schutz et al. (33); however, Westerterp et al. (34) observed a reduction in percentage of post-prandial dietary fat oxidation in subjects with a higher percentage body fat. It is also known that fat oxidation does not abruptly 
increase in proportion to fat consumption (35). Hence, catechin-caffeine mixtures and caffeine-only might be expected to be less effective in increasing fat oxidation in subjects with high BMI as their absolute fat oxidation may already be at a high level. Furthermore, it is known that high intake of catechins can diminish dietary fat absorption (36-39), which might prevent storage of an adequate amount of fat and thereby resulting in less fat available for oxidation. The literature shows conflicting results with respect to the stimulatory effects of green tea on fat oxidation $(20,21)$. A balance between fat absorption and fat oxidation might be one underlying cause as some individuals might respond through a decrease in fat absorption and others are more likely to enhance fat oxidation. However, until now such a balance has not been reported.

In our previous meta-analysis (19), ethnicity and regular caffeine intake contributed to the heterogeneity and acted as a moderator. The current metaanalysis could not take these moderators into account, as there were only Caucasian subjects involved in the included studies. Habitual caffeine intake was below $500 \mathrm{mg} \mathrm{d}^{-1}$ for each study, which is more than the $300 \mathrm{mg}$ that is normally used to discriminate between high and low habitual caffeine intakes. However, analyses were not conducted for the effect of habitual caffeine intake because most studies reported a range of caffeine intake above and below $300 \mathrm{mg}$ and not a specific threshold. Another moderator that might contribute to the variability of the results is composition or way of processing of the catechin-caffeine mixtures. Three out of four studies used an extraction while Rumpler et al. (28) used unfermented dry tealeaves to prepare a beverage. Further, catechin composition will most likely differ between studies with differences in for instance amounts of EGC, ECG and EC. Only in the study by Rumpler et al. (28) catechin composition was reported, the other studies only reported total catechin and EGCG content due to the use of patented extracts, which made an additional analysis, that could discriminate between effects of different catechins, impossible. Catechin composition differs strongly between teas, depending on features such as geographical location and environmental conditions like soil and temperature.

The inhibition of several enzymes may be the mechanism by which catechins and caffeine increase energy expenditure and fat oxidation, separately or synergistically in case of a catechin-caffeine mixture. Catechins inhibit COMT and caffeine inhibits phosphodiesterase (20). Levels of norepinephrine and cAMP rise because degradation by these enzymes is inhibited, thereby leading to increased thermogenesis and fat oxidation (20). Furthermore, after ingestion of catechins, hormone sensitive lipase may be increased, which stimulates lipolysis (40) and will decrease acetyl CoA carboxylase that increases fat oxidation via malonyl CoA and carnitine palmitoyltransferase 1 (41). Fat metabolism may also be affected via other pathways by catechins: upregulation of lipidmetabolizing enzymes via inhibition of NFKB (42), decrease of fat absorption by inhibition of pancreatic and gastric lipases thereby probably attenuating fat emulsification (43) and finally, inhibition of the glucose transporters GLUT4 and SGLT1, thereby decreasing carbohydrate oxidation (44). Hence, catechins may 
activate multiple routes to stimulate fat oxidation in contrast to caffeine, which might explain why no significant effect was found on fat oxidation with caffeineonly in the current study.

Similar to the previous meta-analysis, it seems that there are also responders and non-responders to catechins and caffeine in short-term studies. Although, ethnicity could not be included in the current meta-analysis as a moderator because only studies with Caucasians studies fulfilled the inclusion criteria; differences in relevant enzyme activity, causing differences in sensitivity for these ingredients might explain why there are responders and non-responders. In that respect, Hodgson et al. stated that there is a wide variability in flavonoid O-methylation, a major pathway of flavonoid metabolism, by the enzyme COMT (45). The inter-individual variability of the activity of COMT could vary as much as threefold (45). Moreover, COMT enzyme activity differs between ethnic groups (46), in which Asian populations have a higher frequency of the thermostable, high activity enzyme, $\mathrm{COMT}^{\mathrm{H}}$ allele (Val/Val polymorphism) than the Caucasian populations. The Caucasian populations have a higher frequency of the thermolabile, low activity enzyme, COMT ${ }^{\mathrm{L}}$ allele (Met/Met polymorphism) (3). Fifty per cent of Caucasians are homozygous for the $\mathrm{COMT}^{\mathrm{L}}$ allele $(25 \%)$ and $\mathrm{COMT}^{\mathrm{H}}$ allele $(25 \%)$. The other $50 \%$ is heterozygous (Val/Met polymorphism) (46). This may explain the difference in sensitivity to interventions with catechincaffeine mixtures, and why, in some studies with Caucasian subjects, no effect was seen after ingestion of a catechin-caffeine mixture. Furthermore, the previously discussed difference in catechin composition and way of processing might affect the qualitative and quantitative profiles of the catechins in tea after consumption, that will alter absorption and likely metabolism by COMT or other pathways such as glucuronidation and sulfation. Hence, the metabolism and ultimate 'activity' of the catechin mixture is likely influenced by tea composition as well.

The results of the meta-analysis also show that the difference in dosage between treatment and placebo had an effect on size of the effect. This finding is inconsistent with the results from the previous meta-analysis (19). This can be explained by the larger variation in dosage between the studies in the current meta-analysis. However, interesting is the fact that all studies supply their subjects with similar dosages, instead of administrating a subject-specific dosage per kilogram body-weight, that might yield more unambiguous results. $A$ dose-response effect on energy expenditure occurred with a mean increase of $0.53 \mathrm{~kJ} \mathrm{mg}^{-1}$ for catechins and $0.44 \mathrm{~kJ} \mathrm{mg}^{-1}$ for caffeine. While on average the effect of caffeine-only supplementation is not significantly different compared with placebo, there does appear to be a dose-response relationship on fat oxidation, with a mean increase of $0.02 \mathrm{~g} \mathrm{mg}^{-1}$ for catechins and $0.01 \mathrm{~g} \mathrm{mg}^{-1}$ for caffeine. To our knowledge, this is the first time that it has been determined in which proportion energy expenditure and fat oxidation increase with increasing dosage. However, given the limited precision of these estimates and the limited 
generalizability of the findings due to the small number of subjects, these results must be treated with caution.

Taken together, this meta-analysis shows that a catechin-caffeine mixture and caffeine-only have a stimulating effect on energy expenditure. Furthermore, a catechin-caffeine mixture has also a stimulating effect on fat oxidation compared with placebo. Moreover it also shows that people with increased BMI might benefit from the sympathoadrenal stimulating effect of a catechin-caffeine mixture while different doses of catechins have a significantly different effect. More research, especially focused on the balance between fat absorption and fat oxidation, genetic predisposition and catechin composition is needed to find out why the effects after catechin-caffeine mixture supplementation do not occur in all individuals.

\section{Acknowledgements}

$\mathrm{RH}$ and MSW-P designed the study. $\mathrm{RH}$ collected and prepared the data. WV analyzed the data. $\mathrm{RH}$ and $\mathrm{WV}$ wrote the manuscript and MSW-P contributed to the interpretation of the data and reviewed the manuscript. AGD, AT, LT and WR provided the data and reviewed the manuscript. The study was executed under the

\section{References}

1 Shixian Q, VanCrey B, Shi J, Kakuda Y and Jiang Y. Green tea extract thermogenesis-induced weight loss by epigallocatechin gallate inhibition of catechol-O-methyltransferase. J Med Food. 2006: 9: 451-8.

2 Wolfram S, Wang $Y$ and Thielecke F. Anti-obesity effects of green tea: from bedside to bench. Mol Nutr Food Res. 2006: 50: 176-87.

3 Krul C, Luiten-Schuite A, Tenfelde A, van Ommen B, Verhagen H and Havenaar R. Antimutagenic activity of green tea and black tea extracts studied in a dynamic in vitro gastrointestinal model. Mutat Res. 2001: 474: 71-85.

4 Langley-Evans SC. Antioxidant potential of green and black tea determined using the ferric reducing power (FRAP) assay. Int J Food Sci Nutr. 2000: 51: 181-8.

5 Serafini M, Ghiselli A and Ferro-Luzzi A. In vivo antioxidant effect of green and black tea in man. Eur J Clin Nutr. 1996: 50: 28-32.

6 Westerterp-Plantenga M, Diepvens K, Joosen AM, Berube-Parent S and Tremblay A. Metabolic effects of spices, teas, and caffeine. Physiol Behav. 2006: 89: 85-91.

7 Diepvens K, Westerterp KR and Westerterp-Plantenga MS. Obesity and thermogenesis related to the consumption of caffeine, ephedrine, capsaicin, and green tea. Am J Physiol Regul Integr Comp Physiol. 2007: 292: R77-85.

$8 \mathrm{Hsu} \mathrm{CH}$, Tsai TH, Kao YH, Hwang KC, Tseng TY and Chou P. Effect of green tea extract on obese women: a randomized, double-blind, placebo-controlled clinical trial. Clin Nutr. 2008: 27: 363-70.

9 Nagao T, Hase T and Tokimitsu I. A green tea extract high in catechins reduces body fat and cardiovascular risks in humans. Obesity (Silver Spring). 2007: 15: 1473-83.

10 Nagao T, Komine Y, Soga S, Meguro S, Hase T, Tanaka $Y$ and Tokimitsu I. Ingestion of a tea rich in catechins leads to a reduction in body fat and malondialdehyde-modified LDL in men. Am J Clin Nutr. 2005: 81: 122-9. 
11 Auvichayapat P, Prapochanung M, Tunkamnerdthai O, Sripanidkulchai BO, Auvichayapat N, Thinkhamrop B, Kunhasura S, Wongpratoom S, Sinawat S and Hongprapas P. Effectiveness of green tea on weight reduction in obese Thais: A randomized, controlled trial. Physiol Behav. 2008: 93: 486-91.

12 Hase T, Komine Y, Meguro S, Takeda Y, Takahashi H, Matsui Y, Inaoka S, Katsuragi Y, Tokimitsu I, Shimasaki H and Itakura H. Anti-obesity effects of tea catechins in humans. J Oleo Sci. 2001: 50: 599-605.

13 Kozuma K, Chikama A, Hishino E, Kataoka K, Mori K, Hase T, Katsuragi Y, Tokimitsu I and Nakamura $\mathrm{H}$. Effect of intake of a beverage containing $540 \mathrm{mg}$ catechins on the body composition of obese women and men. Prog Med. 2005: 25: 185-197.

14 Tsuchida $\mathrm{T}$, Itakura $\mathrm{H}$ and Nakamura $\mathrm{H}$. Reduction of body fat in humans by long-term ingestion of catechins. Prog Med. 2002: 22: 2189-2203.

15 Wang H, Wen Y, Du Y, Yan X, Guo H, Rycroft JA, Boon N, Kovacs EM and Mela DJ. Effects of Catechin Enriched Green Tea on Body Composition. Obesity (Silver Spring). 2009: e-pub ahead of print.

16 Diepvens K, Kovacs EM, Nijs IM, Vogels N and Westerterp-Plantenga MS. Effect of green tea on resting energy expenditure and substrate oxidation during weight loss in overweight females. $\mathrm{Br}$ J Nutr. 2005: 94: 1026-34.

17 Kovacs EM, Lejeune MP, Nijs I and Westerterp-Plantenga MS. Effects of green tea on weight maintenance after body-weight loss. Br J Nutr. 2004: 91: 431-7.

18 Westerterp-Plantenga MS, Lejeune MP and Kovacs EM. Body weight loss and weight maintenance in relation to habitual caffeine intake and green tea supplementation. Obes Res. 2005: 13: 1195-204.

19 Hursel R, Viechtbauer W and Westerterp-Plantenga MS. The effects of green tea on weight loss and weight maintenance: a meta-analysis. Int J Obes (Lond). 2009: 33: 956-61.

20 Dulloo AG, Duret C, Rohrer D, Girardier L, Mensi N, Fathi M, Chantre P and Vandermander J. Efficacy of a green tea extract rich in catechin polyphenols and caffeine in increasing 24-h energy expenditure and fat oxidation in humans. Am J Clin Nutr. 1999: 70: 1040-5.

21 Berube-Parent S, Pelletier C, Dore J and Tremblay A. Effects of encapsulated green tea and Guarana extracts containing a mixture of epigallocatechin-3-gallate and caffeine on $24 \mathrm{~h}$ energy expenditure and fat oxidation in men. Br J Nutr. 2005: 94: 432-6.

22 Boschmann $M$ and Thielecke $F$. The effects of epigallocatechin-3-gallate on thermogenesis and fat oxidation in obese men: a pilot study. J Am Coll Nutr. 2007: 26: 389S-395S.

23 Gregersen NT, Bitz C, Krog-Mikkelsen I, Hels O, Kovacs EM, Rycroft JA, Frandsen E, Mela DJ and Astrup A. Effect of moderate intakes of different tea catechins and caffeine on acute measures of energy metabolism under sedentary conditions. Br J Nutr. 2009: 102: 1187-94.

24 Belza A, Toubro S and Astrup A. The effect of caffeine, green tea and tyrosine on thermogenesis and energy intake. Eur J Clin Nutr. 2009: 63: 57-64.

25 Viechtbauer W. Bias and efficiency of meta-analytic variance estimators in the random-effects model. J Educ Behav Stat. 2005: 30: 261-293.

26 Bracco D, Ferrarra JM, Arnaud MJ, Jequier E and Schutz Y. Effects of caffeine on energy metabolism, heart rate, and methylxanthine metabolism in lean and obese women. Am J Physiol. 1995: 269: E671-8.

27 Rudelle S, Ferruzzi MG, Cristiani I, Moulin J, Mace K, Acheson KJ and Tappy L. Effect of a thermogenic beverage on 24-hour energy metabolism in humans. Obesity (Silver Spring). 2007: 15: 349-55.

28 Rumpler W, Seale J, Clevidence B, Judd J, Wiley E, Yamamoto S, Komatsu T, Sawaki T, Ishikura $\mathrm{Y}$ and Hosoda $\mathrm{K}$. Oolong tea increases metabolic rate and fat oxidation in men. J Nutr. 2001: 131: 2848-52.

29 Dulloo AG, Geissler CA, Horton T, Collins A and Miller DS. Normal caffeine consumption: influence on thermogenesis and daily energy expenditure in lean and postobese human volunteers. Am J Clin Nutr. 1989: 49: 44-50.

30 Bray GA. Obesity, a disorder of nutrient partitioning: the MONA LISA hypothesis. J Nutr. 1991: 121: $1146-62$. 
31 Landsberg L. Diet, obesity and hypertension: an hypothesis involving insulin, the sympathetic nervous system, and adaptive thermogenesis. Q J Med. 1986: 61: 1081-90.

32 Davy KP and Orr JS. Sympathetic nervous system behavior in human obesity. Neurosci Biobehav Rev. 2009: 33: 116-24.

33 Schutz Y, Tremblay A, Weinsier RL and Nelson KM. Role of fat oxidation in the long-term stabilization of body weight in obese women. Am J Clin Nutr. 1992: 55: 670-4.

34 Westerterp KR, Smeets A, Lejeune MP, Wouters-Adriaens MP and Westerterp-Plantenga MS. Dietary fat oxidation as a function of body fat. Am J Clin Nutr. 2008: 87: 132-5.

35 Schutz Y, Flatt JP and Jequier E. Failure of dietary fat intake to promote fat oxidation: a factor favoring the development of obesity. Am J Clin Nutr. 1989: 50: 307-14.

36 Raederstorff DG, Schlachter MF, Elste V and Weber P. Effect of EGCG on lipid absorption and plasma lipid levels in rats. J Nutr Biochem. 2003: 14: 326-32.

37 Juhel C, Armand M, Pafumi Y, Rosier C, Vandermander J and Lairon D. Green tea extract (AR25) inhibits lipolysis of triglycerides in gastric and duodenal medium in vitro. J Nutr Biochem. 2000: 11: 45-51.

38 Koo SI and Noh SK. Green tea as inhibitor of the intestinal absorption of lipids: potential mechanism for its lipid-lowering effect. J Nutr Biochem. 2007: 18: 179-83.

39 Wang S, Noh SK and Koo SI. Epigallocatechin gallate and caffeine differentially inhibit the intestinal absorption of cholesterol and fat in ovariectomized rats. J Nutr. 2006: 136: 2791-6.

40 Acheson KJ, Gremaud G, Meirim I, Montigon F, Krebs Y, Fay LB, Gay LJ, Schneiter P, Schindler $\mathrm{C}$ and Tappy L. Metabolic effects of caffeine in humans: lipid oxidation or futile cycling? Am J Clin Nutr. 2004: 79: 40-6.

41 Hursel R and Westerterp-Plantenga MS. Thermogenic ingredients and body weight regulation. Int J Obes (Lond). 2010: 34(4):659-69.

42 Yang F, Oz HS, Barve S, de Villiers WJ, McClain CJ and Varilek GW. The green tea polyphenol (-)-epigallocatechin-3-gallate blocks nuclear factor-kappa B activation by inhibiting I kappa B kinase activity in the intestinal epithelial cell line IEC-6. Mol Pharmacol. 2001: 60: 528-33.

43 Shishikura Y, Khokhar S and Murray BS. Effects of tea polyphenols on emulsification of olive oil in a small intestine model system. J Agric Food Chem. 2006: 54: 1906-13.

$44 \mathrm{Kao} \mathrm{YH}$, Hiipakka RA and Liao S. Modulation of endocrine systems and food intake by green tea epigallocatechin gallate. Endocrinology. 2000: 141: 980-7.

45 Hodgson JM, Puddey IB, Burke V and Croft KD. Is reversal of endothelial dysfunction by tea related to flavonoid metabolism? Br J Nutr. 2006: 95: 14-7.

46 Palmatier MA, Kang AM and Kidd KK. Global variation in the frequencies of functionally different catechol-O-methyltransferase alleles. Biol Psychiatry. 1999: 46: 557-67. 

Chapter 6

Effects of a breakfast yoghurt, with additional total whey protein or caseinomacropeptide-depleted alphalactalbumin enriched whey protein, on diet-induced thermogenesis and satiety

Hursel R, van der Zee L, Westerterp-Plantenga MS.

Br J Nutr 2010; 103(5): 775-80 


\begin{abstract}
Previous studies have shown effects of high-protein diets, especially wheyprotein on energy expenditure and satiety, yet a possible distinction between effects of whey or $\alpha$-lactalbulmin, has not been made. The present study assessed the effects of addition of total whey protein (whey) or caseinomacropeptide-depleted $\alpha$-lactalbulmin-enriched whey protein $(\alpha-\operatorname{lac})$ to a breakfast yoghurt drink on energy expenditure and appetite suppression in human subjects. A total of eighteen females and seventeen males (age: $20.9 \pm 1.9$ years; BMI: $23.0 \pm$ $2.1 \mathrm{~kg} / \mathrm{m}^{2}$ ) participated in an experiment with a randomised, three-arm, crossover design where diet-induced energy expenditure, respiratory quotient and satiety were measured. Breakfasts were iso-energetic and subject-specific: normal-protein (NP) consisting of whole milk (15, 47 and $38 \%$ energy from protein, carbohydrates and fat, respectively), a high-protein (HP) breakfast with additional whey or HP containing $\alpha$-lac $(41,47$ and $12 \%$ energy from protein, carbohydrates and fat, respectively). Resting energy expenditure did not differ between the three conditions. HP breakfasts (area under the curve: whey, $217.1 \pm$ $10.0 \mathrm{~kJ} \times 4 \mathrm{hr} ; \alpha$-lac, $234.3 \pm 11.6 \mathrm{~kJ} \times 4 \mathrm{hr} ; \mathrm{p}<0.05)$, increased diet-induced thermogenesis more compared with a NP yoghurt at breakfast $(179.7 \pm 10.9 \mathrm{~kJ} x$ $4 \mathrm{hr} ; \mathrm{p}<0.05)$. Hunger and desire to eat were significantly more suppressed after $\alpha$-lac (hunger, $-6627 \pm 823$; desire to eat, $-6750 \pm 805 \mathrm{~mm}$ visual analogue scale (VAS) $\times 4 \mathrm{hr}$; $\mathrm{p}<0.05$ ) than after the whey HP breakfast (hunger, $-5448 \pm 913$; desire to eat, $-5070 \pm 873 \mathrm{~mm}$ VAS $\times 4 \mathrm{hr}$; $\mathrm{p}<0.05)$. After the HP breakfasts, a positive protein balance occurred $(\alpha$-lac, $0.35 \pm 0.18 \mathrm{MJ} / 4 \mathrm{hr}$; whey, $0.37 \pm 0.20$ $\mathrm{MJ} / 4 \mathrm{hr} ; \mathrm{p}<0.001)$; after the NP breakfast a positive fat balance occurred (1.03 \pm $0.29 \mathrm{MJ} / 4 \mathrm{hr} ; \mathrm{p}<0.001)$. In conclusion, consumption of a breakfast yoghurt drink with added whey or $\alpha$-lac increased energy expenditure, protein balance and decreased fat balance compared with NP breakfast. The $\alpha$-lac-enriched yoghurt drink suppressed hunger and the desire to eat more than the whey-enriched yoghurt drink.
\end{abstract}

Keywords: obesity, high-protein, milk-protein, energy expenditure, protein balance 


\section{Introduction}

The obese population is growing worldwide as energy intake exceeds energy expenditure and consequently more individuals are at risk of developing obesityrelated diseases such as type 2 diabetes mellitus and CVD (1). High-protein diets have been shown to induce weight loss and weight maintenance after a weight-loss period, through, an appetite-suppressing effect and increased dietinduced thermogenesis (DIT), as proteins are not energy efficient (2-4). Highprotein diets may be helpful in preventing overweight or decreasing body weight in obese individuals, as they are effective for the regulation of food intake. Absorption of different proteins can vary, as proven by Boirie et al. (5), who showed that whey protein passes quicker through the stomach than casein. Whey protein reaches the jejunum intact in contrast to casein that coagulates under the acidic environment of the stomach. Whey protein releases peptides in the intestine after peptic hydrolysis. This process occurs slowly, which ensures that the digestion and absorption take place over a larger length of the small intestine while descending (5-7). As a result, whey protein has been shown to reduce shortterm energy intake and affects appetite suppression through an increase in plasma amino acid levels, mainly branched-chain amino acids such as leucine $(6,8)$. Other mechanisms such as the utilisation of amino acids for gluconeogenesis and the thermic effects of proteins may contribute as well to the differences seen in appetite suppression (9).

Whey protein itself is a constituent of milk protein $(20 \%)$, and consists of 20 $25 \%$ of $\alpha$-lactalbulmin. In a study by Bourthegourd et al., rats that received a meal with $\alpha$-lac increased their energy expenditure more than rats that were fasting or rats that received a meal containing either glucose or whole milk protein (10). This increase in energy expenditure could in its entirety be attributed to the increase in protein oxidation, as lipid oxidation was equal with the other groups that ate a meal. Glucose oxidation was increased in rats that consumed a meal enriched with glucose, compared with the other groups. The oxidation of glucose had a protein-sparing effect, through which protein oxidation remained unchanged. The elevated protein oxidation after $\alpha$-lac-enriched whey-protein was the result of a rapid rise in plasma amino acid levels (10), related to the so called 'slow' and 'fast' proteins. It remains unknown whether the increased energy expenditure after $\alpha$-lac-enriched whey-protein could be attributed to the total whey protein or to the enrichment with $\alpha$-lac.

Therefore, the aim of the present study was to examine whether the addition of total whey protein (whey) or caseinomacropeptide-depleted $\alpha$-lac-enriched whey protein ( $\alpha$-lac) to a normal milk protein yoghurt drink in order to achieve a specific high-protein yoghurt drink, which was served as breakfast, had an effect on energy expenditure and appetite suppression in human subjects, and whether $\alpha-$ lac and whey differed in these effects. 
Table 1.Subject characteristics

(mean values and standard deviations)

\begin{tabular}{|c|c|c|c|c|c|c|}
\hline & \multicolumn{2}{|c|}{ Male $(n=17)$} & \multicolumn{2}{|c|}{ Female $(n=18)$} & \multicolumn{2}{|c|}{ Total $(n=35)$} \\
\hline & Mean & SD & Mean & SD & Mean & SD \\
\hline Age (years) & 21.1 & 1.9 & 20.7 & 2.0 & 20.9 & 1.9 \\
\hline Body mass $(\mathrm{kg})$ & 80.3 & 8.1 & 66.4 & 6.4 & 73.2 & 10.1 \\
\hline Height (m) & 1.85 & 0.07 & 1.72 & 0.07 & 1.78 & 0.09 \\
\hline BMI $\left(\mathrm{kg} / \mathrm{m}^{2}\right)$ & 23.6 & 2.0 & 22.5 & 2.1 & 23.0 & 2.1 \\
\hline \multicolumn{7}{|l|}{ Body composition } \\
\hline FFM $(\mathrm{kg})$ & 66.0 & 6.5 & 47.8 & 4.3 & 56.6 & 10.7 \\
\hline $\mathrm{FM}(\mathrm{kg})$ & 14.4 & 5.2 & 18.6 & 4.6 & 16.5 & 5.3 \\
\hline Body fat (\%) & 17.7 & 5.7 & 27.8 & 4.9 & 22.9 & 7.3 \\
\hline \multicolumn{7}{|l|}{ TFEQ\# } \\
\hline TFEQ F1 & 2.9 & 2.2 & 4.3 & 2.1 & 3.7 & 2.2 \\
\hline TFEQ F2 & 3.2 & 1.5 & 4.4 & 1.4 & 3.9 & 1.6 \\
\hline TFEQ F3 & 4.4 & 2.7 & 4.6 & 2.7 & 4.5 & 2.6 \\
\hline
\end{tabular}

FFM: fat free mass; FM: fat mass; data collected prior to the last test day). TFEQ, Three Factor Eating Questionnaire; F1, cognitive restraint; F2, disinhibition; F3, hunger.

\#The TFEQ measures three different factors of human eating behaviour.

\section{Subjects and Methods}

\section{Subjects}

Thirthy-five healthy subjects (eighteen females, seventeen males) with a mean age of $20.9 \pm 1.9$ years and with a mean BMI of $23.0 \pm 2.1 \mathrm{~kg} / \mathrm{m}^{2}$ participated in the present study. The subjects were recruited by advertisements in local newspapers and on notice boards at the university. All volunteers ( $n$ 94) participated in an initial screening that involved measurements of body weight and height and included the completion of a questionnaire related to eating behavior (Three Factor Eating Questionnaire (11)) and the completion of a questionnaire related to health, use of medication, physical activity, alcohol consumption, food allergies, smoking behaviour and daily caffeine consumption. All subjects were in good health, non-smokers, not using medication (except for contraception), at most moderate alcohol consumers and unrestrained eaters (as assessed by factor 1 of the Three Factor Eating Questionnaire). Baseline characteristics of the subjects are presented in Table 1.

\section{Experimental design}

The study had a randomised, three-arm, single-blind, cross-over design. Subjects attended the university laboratory once per week, during three consecutive weeks. They traveled by public transport or car, in order to avoid physical activity that would have increased resting energy expenditure (REE). Subjects arrived in the fasted state at 08.15 hours and were kept in time-blinded surroundings. They emptied their bladder before the test. After resting on a bed for $30 \mathrm{~min}$, the REE and the substrate oxidation of the subjects were measured for 30 min by means 
of an open-circuit, ventilated-hood system. Gas analysis was performed by a paramagnetic oxygen analyser (OmniCal type 1155B; Servomex, Crowborough, East Sussex, UK) and an infrared carbon dioxide analyser (OmniCal type 1520/1507; Servomex). Energy expenditure was calculated using Weir's formula (12). Respiratory quotient was calculated as $\mathrm{CO}_{2}$ produced $/ \mathrm{O}_{2}$ consumed. The subjects were lying in the supine position. After measuring the REE, subjects received one of the three breakfasts, consisting of either the control which was a normal-protein (NP) yoghurt drink with whole milk protein (Friesland Foods, Leeuwarden; 15, 47 and $38 \%$ energy from protein, carbohydrates and fat, respectively), a high-protein (HP) yoghurt with added total whey protein (Hiprotal ${ }^{\circledR}$ 60 MP; Friesland Foods Domo ${ }^{\circledR}$, Zwolle, The Netherlands; 41,47 and $12 \%$ energy from protein, carbohydrates and fat, respectively), or a HP yoghurt that contained caseinomacropeptide-depleted $\alpha$-lactabulmin-enriched whey protein (Vivinal ${ }^{\circledR}$ Alpha; Friesland Foods Domo ${ }^{\circledR}$, Zwolle, The Netherlands; 41,47 and 12 $\%$ energy from protein, carbohydrates and fat, respectively). The 41 energy \% as protein in the HP breakfasts consisted of $14 \%$ energy from casein protein and $27 \%$ energy from total whey protein or caseinomacropeptide-depleted $\alpha$-lacenriched whey protein. It was unknown how much extra $\alpha$-lactabulmin was included in the $\alpha$-lac yoghurt compared with the whey yoghurt or the NP yoghurt. Breakfasts were iso-energetic, had the same flavour (vanilla) and contained the same volume for each condition; also the HP breakfasts had the same energy density $(3.2 \mathrm{~kJ} / \mathrm{g})$. Before the study started, ratings for palatability and acceptability were assessed with visual analogue scales. With an average rating of 64 $\mathrm{mm}$, subjects experienced no significant differences between conditions concerning colour, taste and viscosity. The energy content of the breakfast meal was tailored to the energy requirements of each subject by calculating BMR with the Harris-Benedict equation, which uses sex, age, height and weight (13). To estimate the total energy requirement, the BMR was multiplied with a physical activity index of 1.6, estimated by means of a computer simulation program (14). The breakfast contained $15 \%$ of the daily energy need. Energy content varied from 1.42 to $2.28 \mathrm{MJ}$, with an average of $1.74 \mathrm{MJ}$. During the consumption of the breakfast the hood was removed temporarily.

After the subjects had finished their breakfast the hood was placed back and the measurements continued for another $4 \mathrm{hr}$, during which DIT was determined. During the measurements questionnaires concerning appetite sensations were completed every 30 min as well as immediately before and after breakfast. Subjects were not allowed to talk, laugh, move or sleep while lying under the hood (15). The urine collected during and after the experiment was used to determine protein turnover. Body composition was measured previous to their last test-day. 


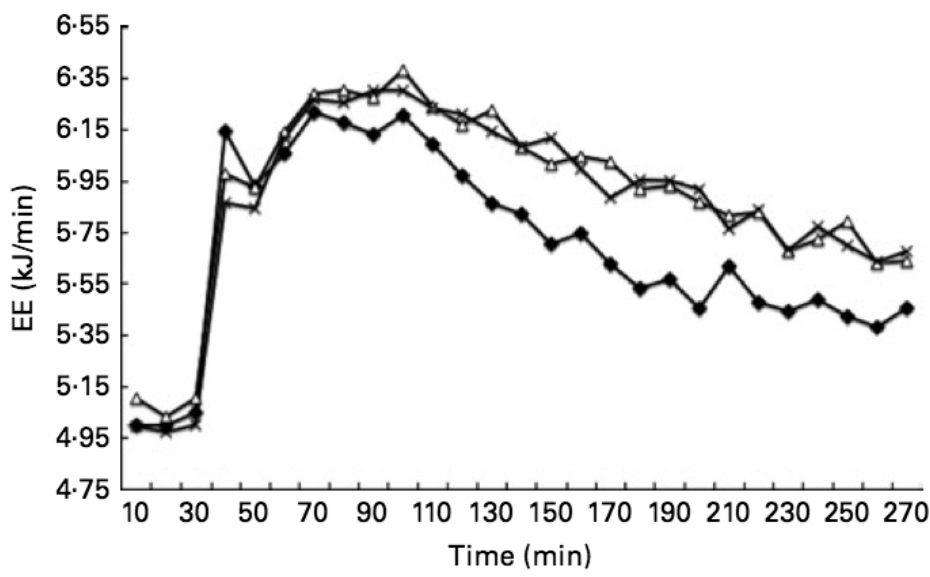

Figure 1. Energy expenditure (EE; kJ/min) during the entire measurement for the placebo $(-\bullet-)$, total whey protein $(-\Delta-)$ and caseinomacropeptide-depleted $\alpha$-lactalbumin-enriched whey protein ($\mathrm{x}-)$ conditions in thirty-five subjects (eighteen women and seventeen men). Resting EE was measured during the first $30 \mathrm{~min}$, followed by a breakfast and another $4 \mathrm{hr}$ of measuring. Values are means. Data were analysed by repeated-measures ANOVA.

\section{Anthropometry}

Body composition was measured using the ${ }^{2} \mathrm{H}_{2} \mathrm{O}$ dilution technique. The dilution of ${ }^{2} \mathrm{H}$ isotope is a measure for total body water (16). In the evening before the last test day, the subjects ingested a dose of ${ }^{2} \mathrm{H}$-enriched water $\left({ }^{2} \mathrm{H}_{2} \mathrm{O}\right.$; Cambridge Isotope Laboratories, Inc., Andover, MA, USA) after collecting a background urine sample. After ingestion of the ${ }^{2} \mathrm{H}$ solution no further fluid or food consumption was permitted. The following morning, another urine sample (second voiding) was collected. ${ }^{2} \mathrm{H}$ concentration in the urine samples was measured using an isotope ratio mass spectrometer (Micromass Optima, Manchester, UK). Total body water was obtained by dividing the measured ${ }^{2} \mathrm{H}$ dilution space by 1.04 to correct for exchange of the ${ }^{2} \mathrm{H}$ label with non-aqueous hydrogen of body solids (17). Fat-free mass was calculated by dividing the total body water by a hydrating factor (0.73). By subtracting fat-free mass from body weight, fat mass was obtained. Fat mass expressed as a percentage of body weight gives percentage of body fat.

\section{Questionnaires}

The appetite questionnaire was composed of visual analogue scale (in $\mathrm{mm}$ ) questions on subjective feelings of hunger, fullness, appetite suppression, thirst and desire to eat. Opposing extremes of each feeling were described at either end of a $100 \mathrm{~mm}$ horizontal line, and subjects marked the line to indicate how they felt at that moment. 


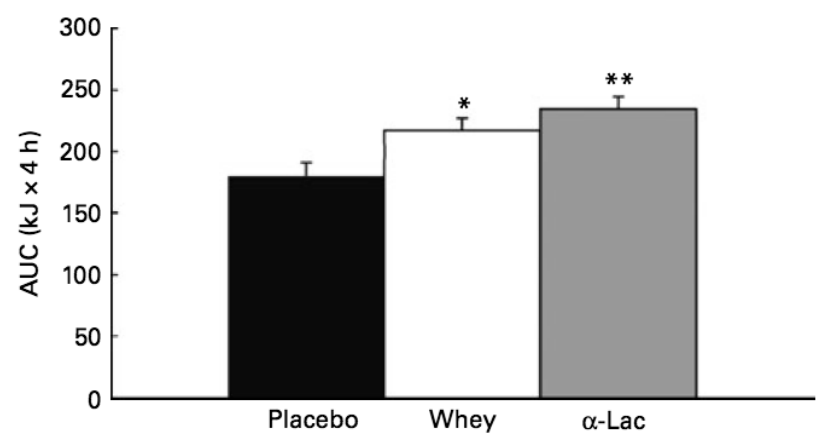

Figure 2. Areas under the curve $(A \cup C)$ for energy expenditure after the placebo, total whey protein (Whey) and caseinomacropeptide-depleted $\alpha$-lactalbumin-enriched whey protein ( $\alpha$-lac) conditions in thirty-five subjects (eighteen women and seventeen men). Values are means, with standard errors represented by vertical bars. Mean value was significantly different from that for the placebo condition: ${ }^{\star} \mathrm{p}<0.05,{ }^{\star \star} \mathrm{p}<0.01$ (repeated-measures ANOVA).

\section{Statistical analysis}

Data are presented as means and standard deviations or standard errors. Data were analysed using SPSS 11 (SPSS, Inc., Chicago, IL, USA). A three-factor repeated-measures ANOVA including a Scheffe $F$ post-hoc test was used to determine a possible difference between breakfast effects on DIT and appetite ratings. Factor DIT, which expresses DIT after correction for body size, was calculated as follows: (REE + DIT)/REE. The level for establishing significant differences was taken at $\mathrm{p}<0.05$.

This study was conducted according to the guidelines laid down in the Declaration of Helsinki and all procedures involving human subjects were approved by the Medical Ethical Committee of Maastricht University Medical Centre. Written informed consent was obtained from all subjects.

\section{Results}

No adverse events occurred, as no subjects reported any feelings of discomfort after consuming the yoghurt drinks. No different effects for men or women were observed so these data were analysed together. Average energy intake was equal in all three conditions $(1.74 \pm 0.25 \mathrm{MJ})$. There were significant treatment effects $(p<0.05)$ for energy expenditure after consumption of the yoghurt drinks. REE did not differ between the three conditions before consuming the whey, $\alpha$ lac or NP yoghurt drinks $(5.08 \pm 0.89 \mathrm{~kJ} / \mathrm{min}, 4.99 \pm 0.83 \mathrm{~kJ} / \mathrm{min}$, and $5.02 \pm 0.80$ $\mathrm{kJ} / \mathrm{min}$, respectively) (Figure 1). On average, across the $4 \mathrm{hr}$ post-breakfast period, total energy expenditure increased significantly compared with baseline 


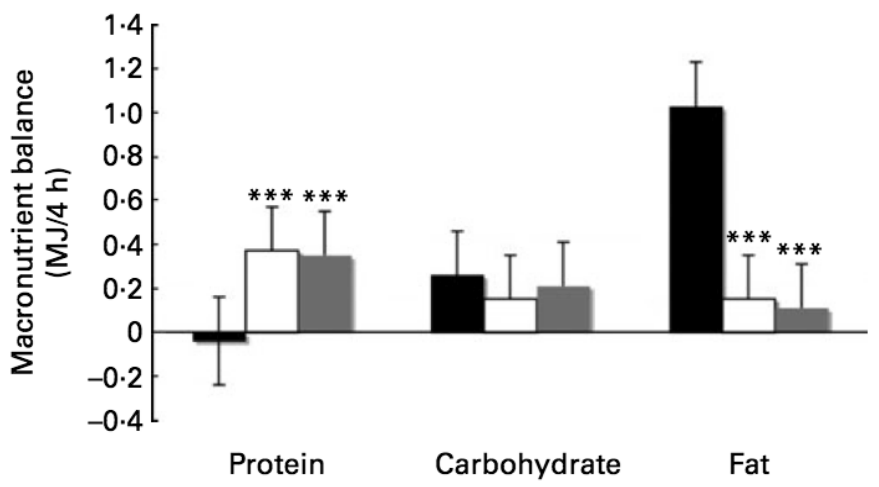

Figure 3. Macronutrient balances for the placebo (Black), total whey protein (White) and caseinomacropeptide-depleted $\alpha$-lactalbumin-enriched whey protein (Grey) conditions in thirty-five subjects (eighteen women and seventeen men). Values are means, with standard deviations represented by vertical bars. ${ }^{\star * *}$ Mean value was significantly different from that for the placebo condition: $(p<0.001$; repeated-measures ANOVA).

measurements in all three conditions $(5.99 \pm 0.93 \mathrm{~kJ} / \mathrm{min}, 5.97 \pm 1.02 \mathrm{~kJ} / \mathrm{min}$, and $5.77 \pm 0.96 \mathrm{~kJ} / \mathrm{min} ; \mathrm{p}<0.001)$. Areas under the curve for energy expenditure increased significantly after the HP yoghurt drink with whey and after the HP yoghurt drink with $\alpha$-lac compared with after the NP yoghurt drink (217.05 \pm $10.00 \mathrm{~kJ} \times 4 \mathrm{hr}(\mathrm{p}<0.05) ; 234.30 \pm 11.61 \mathrm{~kJ} \times 4 \mathrm{hr}(\mathrm{p}<0.01)$; vs $179.71 \pm 10.87 \mathrm{~kJ}$ $x 4 \mathrm{hr}(\mathrm{p}<0.05)$, respectively) (Figure 2). No sex differences were seen after comparing the increase of DIT in percentages between all conditions, between males and females. This was also supported after correction for body size by means of calculating factor DIT, where the increase in energy expenditure remained significantly different between whey and placebo $(p<0.05)$ as well as $\alpha$ lac and NP yoghurt drink $(\mathrm{p}<0.001)$. Total energy expenditure was positively related to fat-free mass (whey, $r^{2} 0.81, y=0.08 x+1.54 ; \alpha$-lac: $r^{2} 0.76, y=0.08 x+$ 1.24; NP, $r^{2} 0.78, y=0.08 x+1.26 ; p<0.001$ ), as was REE (whey, $r^{2} 0.75, y=$ $0.07 x+0.96 ; \alpha$-lac $, r^{2}=0.78, y=0.07 x+1.12 ;$ and NP, $r^{2} 0.78, y=0.07 x+1.24$; $\mathrm{p}<0.001)$ respectively, for all conditions.

Subjects were in positive energy balance during the $4 \mathrm{hr}$ post-treatment, and energy balance was significantly different between the HP conditions and the NP condition (whey, $0.67 \pm 0.14 \mathrm{MJ} / 4 \mathrm{hr}$; $\alpha$-lac, $0.68 \pm 0.16 \mathrm{MJ} / 4 \mathrm{hr}$; and NP, $1.25 \pm$ $0.21 \mathrm{MJ} / 4 \mathrm{hr} ; \mathrm{p}<0.001)$. No significant differences in respiratory quotient were seen between the three conditions at baseline (whey, $0.87 \pm 0.08$; $\alpha$-lac, $0.86 \pm$ 0.06 ; NP, $0.87 \pm 0.06$, NS) and post-treatment (whey, $0.88 \pm 0.07$; $\alpha$-lac, $0.87 \pm$ 0.05 ; NP, $0.86 \pm 0.04$, NS). Figure 3 shows the separate macronutrient balances. The protein and fat balances were significantly different between the NP and the HP conditions. Fat balance was lower after the HP breakfasts compared with the NP breakfast $(\alpha$-lac, $0.11 \pm 0.26 \mathrm{MJ} / 4 \mathrm{hr}$; whey, $0.15 \pm 0.29 \mathrm{MJ} / 4 \mathrm{hr}$ vs. placebo, $1.03 \pm 0.29 \mathrm{MJ} / 4 \mathrm{hr} ; \mathrm{p}<0.001)$ and protein balance was higher in the HP 


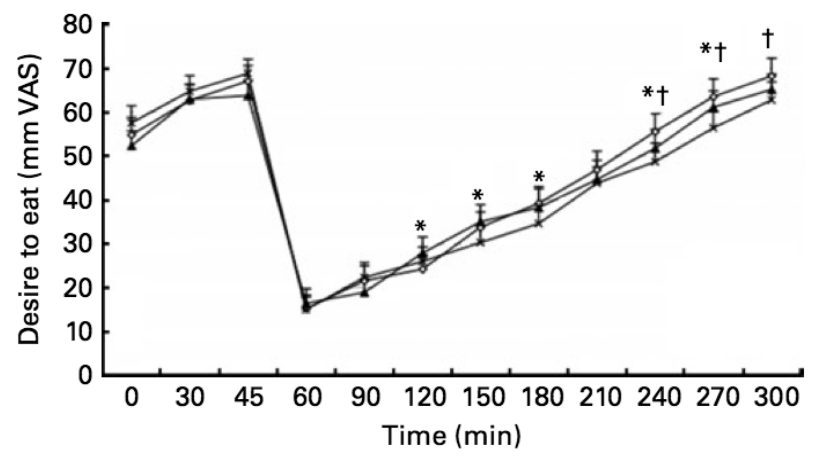

Figure 4. Changes in desire to eat (mm visual analogue scale; VAS) after the placebo (- -$)$, total whey protein $\left(-\Delta^{-}\right)$and caseinomacropeptide-depleted $\alpha$-lactalbumin-enriched whey protein $(-x-)$ conditions in thirty-five subjects (eighteen women and seventeen men). Values are means, with standard errors represented by vertical bars. *Mean value for the $\alpha$-lac condition was significantly lower than that for the total whey protein condition $(p<0.05$; repeated-measures ANOVA). †Mean value for the $\alpha$-lac condition was significantly lower than that for the placebo condition $(p<0.05$; repeated-measures ANOVA).

conditions compared with the NP condition ( $\alpha$-lac, $0.35 \pm 0.18 \mathrm{MJ} / 4 \mathrm{hr}$; whey, $0.37 \pm 0.20 \mathrm{MJ} / 4 \mathrm{hr}$ vs. placebo, $-0.04 \pm 0.16 \mathrm{MJ} / 4 \mathrm{hr} ; \mathrm{p}<0.001)$.

Baseline values of the measured variables from the appetite questionnaires (hunger, fullness, satiety and desire to eat) were not significantly different between the conditions. The results and the areas under/above curve of the VAS are presented in Figure 4 (desire to eat) and Table 2. The area above the curve was significantly higher after the $\alpha$-lac condition compared with the whey condition, for hunger and desire to eat $(p<0.01)$. No differences were seen between placebo and $\alpha$-lac or placebo and whey concerning are above the curve.

Table 2. Area Under (or Above) Curve of desire to eat, hunger, appetite suppression and fullness (mmVAS $x 4 \mathrm{hr}$ ) as rated by 35 subjects (eighteen women and seventeen men).

(Mean values with their standard errors)

\begin{tabular}{lcccccc} 
& \multicolumn{2}{c}{ Placebo (NP) } & \multicolumn{2}{c}{ Whey (HP) } & \multicolumn{2}{c}{$\alpha$-lac (HP) } \\
\cline { 2 - 7 } & Mean & SE & Mean & SE & Mean & SE \\
\hline Desire to eat & -5589.2 & 840.3 & -5070.4 & 873.8 & -6750.6 & $805.5 \#$ \\
Hunger & -6013.5 & 824.6 & -5448.0 & 913.0 & -6627.4 & $823.2^{*}$ \\
Appetite suppression & 7324.9 & 834.8 & 6175.5 & 842.0 & 6583.5 & 730.2 \\
Fullness & 7023.4 & 811.3 & 6245.6 & 840.7 & 6584.1 & 763.3 \\
\end{tabular}

NP, normal-protein breakfast; whey, total whey protein yoghurt; HP, high-protein yoghurt; $\alpha$-lac, caseinomacropeptide-depleted $\alpha$-lactalbumin-enriched whey yoghurt.

Mean value was significantly lower than that after the Whey breakfast. ${ }^{*} \mathrm{P}<0.05$, ${ }^{\star \star} \mathrm{P}<0.01$ (repeated measures ANOVA). 


\section{Discussion}

Consumption of a high-protein breakfast with either added whey or a-lac is more thermogenic than consumption of a normal-protein breakfast containing milk protein. The results of the present study confirmed that high-protein breakfasts enhance thermogenesis more compared with a normal-protein breakfast (18). The NP breakfast contained milk protein, which consists of $80 \%$ casein and 20 $\%$ whey. Milk protein has a higher energy efficiency due to casein, which has the lowest cost for ATP production (8.2 kJ/ATP) compared with $\alpha$-lac and whey (8.6 and $8.4 \mathrm{~kJ} / \mathrm{ATP}$ ) (19). Much research has already been conducted concerning the effect of high-protein diets on DIT in comparison with normal-protein diets, in the long-term as well as in acute studies (2,3,20-25). Moreover, effects of highprotein diets on weight loss and weight maintenance have been shown, through the thermogenic effect and preservation of fat-free mass, following a relatively high-protein diet, which is the main determinant of REE (3). Together, this guarantees sustained thermogenesis on a high-protein diet. The positive protein balance after the HP conditions indicate that anabolism was taking place, which may support the preservation of fat-free mass (26). However, more amino acids are available after the HP breakfasts compared with the NP condition, which will cause an increase in protein oxidation in the postprandial and post-absorptive state. As a consequence the daily protein balance will probably be less positive. The low fat content of the HP conditions compared with the NP condition resulted in a fat balance that was reduced, which means that less fat was stored after the HP conditions. The present study was performed under acute conditions; therefore subjects were not adapted to the HP breakfast. This might also explain some of the effects observed with the HP meals compared with the NP meal and particularly the reduction in fat balance.

An explanation for the thermogenic effect of $\alpha$-lac may be that it is a complete protein. The effect of proteins on DIT is dependent on the quantity of protein, the rate of absorption and thereby increasing the level of amino acids in the bloodstream and also the concentration of essential amino acids, which determines whether a protein is 'complete' or 'incomplete'. $\alpha$-Lac is a well-balanced protein, which contains high concentrations of indispensable amino acids such as cystine, lysine and tryptophan (27). Not all amino acids are used for protein synthesis and those that remain are oxidised, causing an increase in energy expenditure. Costs for ATP production are higher after $\alpha$-lac compared with whey and milk protein ( 8.6 vs. 8.4 vs. $8.3 \mathrm{~kJ} / \mathrm{ATP})$, which means that $\alpha$-lac is not as energy efficient as whey and milk protein i.e. the higher the cost for ATP production, the more thermogenic the protein (19). There are hardly any studies that have investigated the thermogenic properties of whey and $\alpha$-lac. The study mentioned before from Bouthegourd et al. showed that whey enriched with $\alpha$-lac caused an increase in DIT in rats, but in the present study whole milk protein had a comparable effect size (10). 
Appetite scores showed that the HP breakfast with $\alpha$-lac suppressed hunger significantly more than the HP breakfast with whey and the NP breakfast. No suppressive effect on hunger of the HP breakfast with whey compared with the NP breakfast was seen. The suppressive effect of hunger by $\alpha$-lac may be attributed to the fast rise in amino acid levels in plasma, as Mellinkoff stated in his aminostatic theory in 1956 that elevated concentrations of plasma amino acids create a appetite suppressing signal (28). Furthermore, $\alpha$-lac contains high concentrations of leucine and lysine, which are ketogenic amino acids (27). It is known that hunger is suppressed during a ketogenic state (29). However, compared with total whey protein there is not much difference between concentrations of ketogenic amino acids (27). Nieuwenhuizen et al. found the same hunger suppressive effect in a study where they compared $\alpha$-lac with gelatin, and with gelatin with added tryptophan (30). They concluded that tryptophan, which is present in high concentrations in $\alpha$-lac and often seen as a modulator of appetite regulation via serotonin, was not involved in the suppressive effect. Neither involved were the ratio between tryptophan and large neutral amino acids or total amino acids, glucagon-like peptide-1 or ghrelin responses (30). In a study by Veldhorst et al. the lowering effect of $\alpha$-lac on energy intake was also demonstrated. Energy intake at lunch, after a breakfast with $\alpha$-lac was $19 \%$ lower than after a breakfast with whey (18).

Furthermore in a rodent study, Pichon et al. showed that energy intake was reduced after a high-protein diet with whey compared with a normal-protein diet with milk protein (31). Diepvens et al. found that after a breakfast with whey protein subjects were more satiated than after a breakfast with milk protein (32). Bowen et al. and Hall et al. have studied the effects between casein and whey, the constituents of milk protein. Both studies found different results, as only Hall et al. could demonstrate that energy intake was lower after a whey preload compared with a casein preload $(7,33)$.

Summarising, HP breakfasts increased thermogenesis more than a NP breakfast, which can be attributed to amount of protein but also to the higher bioactivity of $\alpha$-lac and whey compared with milk protein. Furthermore, $\alpha$-lac suppressed hunger more than whey and placebo. In conclusion, the addition of $\alpha$-lac, i.e. whey, to a NP milk protein yoghurt drink increases diet-induced thermogenesis; additional $\alpha$-lac also suppresses hunger and the desire to eat.

\section{Acknowledgements}

We would like to acknowledge Friesland Foods Domo for sponsoring the study and providing us the yoghurt drinks. $\mathrm{RH}, \mathrm{LZ}$ and MSW-P designed the study. $\mathrm{RH}$ collected and analysed the data. $\mathrm{RH}$ wrote the manuscript and MSW-P contributed to the interpretation of the data and reviewed the manuscript. The study was executed under the supervision of MSW-P. RH and MSW-P had no per- 
sonal or financial conflict of interest. $L Z$ is nutritional R\&D manager at Friesland Foods, which funded the study.

\section{References}

1. Seidell, J.C. Obesity in Europe. Obes Res 3 Suppl 2, 89s-93s (1995).

2. Lejeune, M.P., Westerterp, K.R., Adam, T.C., et al. Ghrelin and glucagon-like peptide 1 concentrations, 24-h satiety, and energy and substrate metabolism during a high-protein diet and measured in a respiration chamber. Am J Clin Nutr 83, 89-94 (2006).

3. Westerterp-Plantenga, M.S. The significance of protein in food intake and body weight regulation. Curr Opin Clin Nutr Metab Care 6, 635-638 (2003).

4. Weigle, D.S., Breen, P.A., Matthys, C.C., et al. A high-protein diet induces sustained reductions in appetite, ad libitum caloric intake, and body weight despite compensatory changes in diurnal plasma leptin and ghrelin concentrations. Am J Clin Nutr 82, 41-48 (2005).

5. Boirie, Y., Dangin, M., Gachon, P., et al. Slow and fast dietary proteins differently modulate postprandial protein accretion. Proc Natl Acad Sci U S A 94, 14930-14935 (1997).

6. Luhovyy, B.L., Akhavan, T. \& Anderson, G.H. Whey proteins in the regulation of food intake and satiety. J Am Coll Nutr 26, 704S-712S (2007).

7. Hall, W.L., Millward, D.J., Long, S.J., et al. Casein and whey exert different effects on plasma amino acid profiles, gastrointestinal hormone secretion and appetite. $\mathrm{Br} J$ Nutr 89, 239-248 (2003).

8. Anderson, G.H., Tecimer, S.N., Shah, D., et al. Protein source, quantity, and time of consumption determine the effect of proteins on short-term food intake in young men. J Nutr 134, 3011-3015 (2004).

9. Veldhorst, M., Smeets, A., Soenen, S., et al. Protein-induced satiety: effects and mechanisms of different proteins. Physiol Behav 94, 300-307 (2008).

10. Bouthegourd, J.C., Roseau, S.M., Makarios-Lahham, L., et al. A preexercise alpha-lactalbuminenriched whey protein meal preserves lipid oxidation and decreases adiposity in rats. Am J Physiol Endocrinol Metab 283, E565-572 (2002).

11. Stunkard, A.J. \& Messick, S. The three-factor eating questionnaire to measure dietary restraint, disinhibition and hunger. Journal of psychosomatic research 29, 71-83 (1985).

12. Weir, J.B. New methods for calculating metabolic rate with special reference to protein metabolism. J Physiol 109, 1-9 (1949).

13. Harris, J.A. \& Benedict, F.G. A Biometric Study of Human Basal Metabolism. Proc Natl Acad Sci U S A 4, 370-373 (1918).

14. Westerterp, K.R., Donkers, J.H., Fredrix, E.W., et al. Energy intake, physical activity and body weight: a simulation model. Br J Nutr 73, 337-347 (1995).

15. Schoffelen, P.F., Westerterp, K.R., Saris, W.H., et al. A dual-respiration chamber system with automated calibration. J Appl Physiol 83, 2064-2072 (1997).

16. Westerterp, K.R., Wouters, L. \& van Marken Lichtenbelt, W.D. The Maastricht protocol for the measurement of body composition and energy expenditure with labeled water. Obes Res 3 Suppl 1, 49-57 (1995).

17. Schoeller, D.A., van Santen, E., Peterson, D.W., et al. Total body water measurement in humans with ${ }^{18} \mathrm{O}$ and ${ }^{2} \mathrm{H}$ labeled water. Am J Clin Nutr 33, 2686-2693 (1980).

18. Veldhorst, M.A., Nieuwenhuizen, A.G., Hochstenbach-Waelen, A., et al. A breakfast with alphalactalbumin, gelatin, or gelatin + TRP lowers energy intake at lunch compared with a breakfast with casein, soy, whey, or whey-GMP. Clinical nutrition (Edinburgh, Scotland) 28, 147-155 (2009).

19. van Milgen, J. Modeling biochemical aspects of energy metabolism in mammals. J Nutr 132 , 3195-3202 (2002).

20. Luscombe, N.D., Clifton, P.M., Noakes, M., et al. Effect of a high-protein, energy-restricted diet on weight loss and energy expenditure after weight stabilization in hyperinsulinemic subjects. Int J Obes Relat Metab Disord 27, 582-590 (2003). 
21. Crovetti, R., Porrini, M., Santangelo, A., et al. The influence of thermic effect of food on satiety. Eur J Clin Nutr 52, 482-488 (1998)

22. Karst, H., Steiniger, J., Noack, R., et al. Diet-induced thermogenesis in man: thermic effects of single proteins, carbohydrates and fats depending on their energy amount. Annals of nutrition \& metabolism 28, 245-252 (1984).

23. LeBlanc, J., Diamond, P. \& Nadeau, A. Thermogenic and hormonal responses to palatable protein and carbohydrate rich food. Hormone and metabolic research. Hormon- und Stoffwechselforschung 23, 336-340 (1991).

24. Mikkelsen, P.B., Toubro, S. \& Astrup, A. Effect of fat-reduced diets on 24-h energy expenditure: comparisons between animal protein, vegetable protein, and carbohydrate. Am J Clin Nutr 72, 1135-1141 (2000).

25. Smeets, A.J., Soenen, S., Luscombe-Marsh, N.D., et al. Energy expenditure, satiety, and plasma ghrelin, glucagon-like peptide 1 , and peptide tyrosine-tyrosine concentrations following a single high-protein lunch. J Nutr 138, 698-702 (2008).

26. Soenen, S. \& Westerterp-Plantenga, M.S. Proteins and satiety: implications for weight management. Curr Opin Clin Nutr Metab Care 11, 747-751 (2008).

27. Heine, W.E., Klein, P.D. \& Reeds, P.J. The importance of alpha-lactalbumin in infant nutrition. J Nutr 121, 277-283 (1991).

28. Mellinkoff, S.M., Frankland, M., Boyle, D., et al. Relationship between serum amino acid concentration and fluctuations in appetite. J Appl Physiol 8, 535-538 (1956).

29. Johnstone, A.M., Horgan, G.W., Murison, S.D., et al. Effects of a high-protein ketogenic diet on hunger, appetite, and weight loss in obese men feeding ad libitum. Am J Clin Nutr 87, 44-55 (2008).

30. Nieuwenhuizen, A.G., Hochstenbach-Waelen, A., Veldhorst, M.A., et al. Acute effects of breakfasts containing alpha-lactalbumin, or gelatin with or without added tryptophan, on hunger, 'satiety' hormones and amino acid profiles. Br J Nutr, 1-8 (2008).

31. Pichon, L., Potier, M., Tome, D., et al. High-protein diets containing different milk protein fractions differently influence energy intake and adiposity in the rat. Br J Nutr 99, 739-748 (2008).

32. Diepvens, K., Haberer, D. \& Westerterp-Plantenga, M. Different proteins and biopeptides differently affect satiety and anorexigenic/orexigenic hormones in healthy humans. International journal of obesity (2005) 32, 510-518 (2008).

33. Bowen, J., Noakes, M., Trenerry, C., et al. Energy intake, ghrelin, and cholecystokinin after different carbohydrate and protein preloads in overweight men. J Clin Endocrinol Metab 91, 1477-1483 (2006). 

Chapter 7

\section{Consumption of milk protein combined with green tea modulates diet-induced thermogenesis}

Hursel R and Westerterp-Plantenga MS

Submitted for publication 


\section{Abstract}

Introduction. Green tea and protein separately are able to increase diet-induced thermogenesis. Although their effects on long-term weight-maintenance also were present separately, they were not additive.

Objective. To examine the effect of milk protein (MP) in combination with green tea on diet-induced thermogenesis (DIT).

Methods. Thirty-five subjects (aged 18-60 years; BMI: $23.0 \pm 2.1 \mathrm{~kg} / \mathrm{m}^{2}$ ) participated in an experiment with a randomised, six-arm, cross-over design where energy expenditure, and respiratory quotient (RQ) were measured. Green tea (GT) vs. placebo (PL) capsules were either given in combination with water or with breakfasts containing milk protein in two different dosages: 15 gram (15MP) (energy\% P/C/F: 15/47/38 1.7MJ/500ml), and 3.5 gram (3.5MP) (energy\% $\mathrm{P} / \mathrm{C} / \mathrm{F}: 41 / 59 / 0 ; 146.4 \mathrm{~kJ} / 100 \mathrm{ml})$. After measuring resting energy expenditure (REE) for $30 \mathrm{~min}$, diet-induced energy expenditure was measured for another 3.5 hours after the intervention.

Results. There was an overall significance between conditions $(p<0.001)$. Posthoc, areas under the curve (AUCs) for diet-induced energy expenditure were significantly different for GT + water $(42.0 \pm 6.6 \mathrm{~kJ} .3 .5 \mathrm{hr})$ vs. PL + water, $\mathrm{GT}+3.5 \mathrm{MP}$ and $\mathrm{PL}+3.5 \mathrm{MP}(13.2 \pm 5.7 \mathrm{~kJ} .3 .5 \mathrm{hr}, 14.5 \pm 4.4 \mathrm{~kJ} .3 .5 \mathrm{hr}$ and 14.1 \pm 4.4 kJ.3.5 hr; ps0.001), but not between GT + 3.5MP, PL + 3.5MP and PL + water, indicating that MP inhibited DIT following GT. DIT after GT + 15MP (175.5 $\pm 56.9 \mathrm{~kJ} .3 .5 \mathrm{hr})$ and $\mathrm{PL}+15 \mathrm{MP}(179.7 \pm 64.3 \mathrm{~kJ} .3 .5 \mathrm{hr})$ was significantly increased vs. $P L+$ water $(p<0.001)$, but not differently from each other indicating that 15 gram MP stimulated DIT, but inhibited the GT effect on DIT. No significant differences in $R Q$ were seen between conditions for baseline and posttreatment.

Conclusion. Consumption of milk-protein inhibits the effect of green tea on DIT.

Keywords: obesity, catechins, polyphenol-protein complexes, energy expenditure 


\section{Introduction}

With a growing prevalence of obesity worldwide it is becoming one of the main factors contributing to increased mortality. As people take more energy to them than they can expend, weight gain will be the consequence (1). Natural and healthy ingredients, such as green tea and proteins, can prevent weight gain or even induce weight loss when consumed in adequate amounts. Green tea has been shown to increase $24 \mathrm{hr}$ and long-term energy expenditure and fat oxidation and also has a positive effect on body-weight regulation (2-5). Proteins as well as green tea individually have the ability to enhance energy expenditure, but it is still unknown whether administration of catechins simultaneously with a meal that contains protein will enhance energy expenditure more than protein by itself. Recently we showed that when given together, green tea and protein have no synergistic effect. After a four week intervention with a very low energy diet followed by a three month weight-maintenance period, similar results in subjects on a high-protein diet plus green tea-caffeine mixture were found as in subjects receiving either a high-protein diet plus placebo or an adequate-protein diet plus green tea-caffeine mixture (6). One of the explanations through which this synergistic effect failed to occur is the formation of complexes between proteins and the polyphenols in tea, which was reported first in 1963 by Brown and Wright (7). Especially caseins, which are present in milk protein (MP), tend to bind the polyhenols. Several studies have confirmed the formation of such complexes where the protein 'wraps' itself around the catechins, a process named non-covalent cross-linking (8-11). This process might reduce the bioavailability and accessibility of the polyphenols (12). Several studies examined the difference in antioxidative and anti-mutagenic capacity between tea with or without the addition of milk (13-21). Serafini et al. (13) found that total anti-oxidant capacity had not decreased due to the addition of milk to tea, but the polyphenols were rather unavailable for absorption as the polyphenol-protein complexes were resistant to gastric hydrolysis. Other studies did not find a difference in the anti-oxidant capacity of tea after the addition of milk compared to tea alone $(18,20-22)$.

Hence, the aim of this study was to examine the effect on diet-induced thermogenesis of a combination of different amounts of milk-protein and green tea.

\section{Subjects and Methods}

\section{Subjects}

Thirty-five subjects (18 females, 17 males) participated in this study, they were healthy, aged 18 to 60 years and had a BMI between 20 and $33 \mathrm{~kg} / \mathrm{m}^{2}$. The subjects were recruited by advertisements in local newspapers and on notice 
boards at the university. All volunteers ( $n$ 94) participated in an initial screening that

Table 1. Composition of the green tea capsules.

\begin{tabular}{lcc}
\hline & GT $(\mathbf{m g})$ & PL $(\mathbf{m g})$ \\
\hline Total polyphenols & 207.1 & - \\
Total catechins & 169.0 & - \\
$\quad$ Epigallocatechin gallate (EGCG) & 84.5 & - \\
Caffeine & 2.1 & - \\
Soy oil & 316.9 & 528.2 \\
Total filling weight (mg/capsule) & 528.2 & 528.2 \\
Total weight (mg/capsule) & 757.0 & 757.0 \\
Total weight (mg/testday) & 1584.6 & 1584.6
\end{tabular}

$\mathrm{PL}$, placebo; GT, green tea

GT: Sunphenon 90 LB (Taiyo Kagaku Co. Ltd, Mie, Japan) decaffeinated green tea extract.

involved measurements of body weight and height and included the completion of a questionnaire related to eating behavior (Three Factor Eating Questionnaire, TFEQ (23)) and the completion of a questionnaire related to health, use of medication, physical activity, alcohol consumption, food allergies, smoking behavior and daily caffeine consumption. All subjects were in good health, non-smokers, not using medication (except for contraception), at most moderate alcohol consumers and unrestrained eaters (as assessed by factor 1 of the TFEQ). All subjects gave their written informed consent and the Medical Ethical Committee of Maastricht University approved the study.

\section{Experimental design}

The study had a randomized, six-arm, single-blind, cross-over design. Subjects attended the university laboratory once a week, during six consecutive weeks. They were instructed to abstain from caffeine-rich products like tea, coffee, colatype soft drinks and energy drinks. They traveled by public transport or car, in order to avoid physical activity that would increase REE. Subjects arrived in the fasted state at 08.15 hours and were kept in time-blinded surroundings. They emptied their bladder before the test. After resting on a bed for $30 \mathrm{~min}$, the REE and the substrate oxidation of the subjects was measured for 30 min by means of an open-circuit, ventilated-hood system. Gas analysis was performed by a paramagnetic oxygen analyzer (OmniCal type 1155B; Servomex, Crowborough, East Sussex, UK) and an infrared carbon dioxide analyzer (OmniCal type 1520/1507; Servomex). Energy expenditure was calculated using Weir's formula (24). The $R Q$ was calculated as $\mathrm{CO}_{2}$ produced/ $\mathrm{O}_{2}$ consumed. The subjects were lying in the supine position.

The present study tested the effect of GT vs. PL on diet-induced thermogenesis with or without different amounts of milk protein. Subjects received in random order one of the six interventions after measuring the REE, consisting of 
either water $(100 \mathrm{ml}), 3.5$ grams MP or 15 grams MP, in addition to which the subjects ingested three GT capsules (Sunphenon ${ }^{\circledR} 90$ LB, Taiyo Kagaku Co. Ltd, Mie, Japan), or the control, which were three PL capsules (Gelkaps, Falkenhagen, Germany). The 3.5 grams of MP were obtained from a $100 \mathrm{ml}$ dairy product (FrieslandCampina, Leeuwarden energy\% P/C/F: 41/59/0; 146.4 kJ/100ml). The 15 grams MP were obtained from a dairy product (FrieslandCampina, Leeuwarden, energy\% P/C/F: 15/47/38). Flavour was sufficient, without significant differences between products. The 15MP dairy products were subject-specifically calculated, by calculating basic metabolic rate (BMR) of each subject with the Harris-Benedict equation, which uses gender, age, height and weight (25). To estimate the total energy need, the outcome of the equation was multiplied with a physical activity index (26) of 1.6 , estimated by means of a computer simulation program (27). The dairy products contained $15 \%$ of the daily energy need and had an energy density of $3.2 \mathrm{~kJ} / \mathrm{g}$. Energy content varied from 1.4 to $2.3 \mathrm{MJ}$, with an average of $1.7 \mathrm{MJ}$. The capsules all had the same appearance. The composition and the dose of the capsules are presented in Table 1. During the consumption of the intervention the hood was removed temporarily. After the intervention the hood was placed back and the measurements continued for another 3.5 hours, during which the diet-induced thermogenesis was determined. Subjects were not allowed to talk, laugh, move or sleep while lying under the hood (28).

\section{Statistical analysis}

Data are presented as means and standard deviations, unless otherwise indicated. Data were analyzed using PASWStatistics 18.0 (SPSS Inc. Chicago, Illinios, USA). Non-parametric tests such as Mann-Whitney $U$ (post-hoc analysis) and Kruskall-Wallis (overall significance) were used to determine a possible difference between effects of the six interventions on diet-induced thermogenesis. Initially, a test with merely the two $15 \mathrm{MP}$ conditions, in which thirty-five subjects participated, was planned. After this test the subjects were asked to participate in four additional conditions. Since seventeen subjects dropped out for various reasons, the following four conditions were conducted with the remaining eightteen subjects. Therefore, comparisons are sometimes made between groups that partly differ in subjects and differences were analyzed nonparametrically. Factor DIT, which expresses DIT after correction for body size, was calculated as follows: (REE + DIT)/REE (29). The level for establishing significant differences was taken at $p<0.05$.

\section{Results}

No adverse events occurred as no subjects reported any feelings of discomfort after consuming the interventions and the capsules. No different effects for men or women were observed therefore these data have been taken together. 
A significant overall treatment $(p<0.001)$ effect for energy expenditure after the interventions was obtained. Areas under the curve for energy expenditure were significantly different for GT + 15MP $(175.5 \pm 56.9 \mathrm{~kJ} .3 .5 \mathrm{hr})$ and $\mathrm{PL}+$ 15MP (179.7 $\pm 64.3 \mathrm{~kJ} .3 .5 \mathrm{hr})$ compared with GT + water $(42.0 \pm 6.6 \mathrm{~kJ} .3 .5 \mathrm{hr})$, $\mathrm{PL}+$ water (13.2 $\pm 5.7 \mathrm{~kJ} .3 .5 \mathrm{hr}), \mathrm{GT}+3.5 \mathrm{MP}(14.5 \pm 4.4 \mathrm{~kJ} .3 .5 \mathrm{hr})$ and PL + 3.5MP $(14.1 \pm 4.4 \mathrm{~kJ} .3 .5 \mathrm{hr})(\mathrm{p}<0.001)$. Furthermore, $\mathrm{GT}+$ water differed significantly from $\mathrm{PL}+$ water, $\mathrm{GT}+3.5 \mathrm{MP}$ and $\mathrm{PL}+3.5 \mathrm{MP}(\mathrm{p} \leq 0.001)$. No significant differences were found between $\mathrm{GT}+15 \mathrm{MP}$ and $\mathrm{PL}+15 \mathrm{MP}$ and also not between PL + water, GT + 3.5MP and PL + 3.5MP (Figure 1). Post-hoc, DIT after GT + water was significantly increased compared to DIT after PL + water $(p<0.001)$, indicating that GT alone stimulated DIT. However, DIT after PL + 3.5MP was not increased compared to $P L+$ water $(p=0.09)$, nor was DIT after GT + 3.5MP $(p=0.09)$, indicating that 3.5MP inhibited the GT alone effect on DIT. Furthermore, DIT after PL + 15MP was significantly increased, as well as DIT after $\mathrm{GT}+15 \mathrm{MP}$, both compared to $\mathrm{PL}+$ water $(\mathrm{p}<0.001)$, indicating that $15 \mathrm{MP}$ stimulated DIT. However, GT + 15MP was not different from PL + 15MP $(p=0.66)$, indicating that MP prevented an additional GT effect on DIT.

No gender-differences were seen after comparing the percentages of all conditions between males and females. This was also shown after correction for body size by means of calculating factor DIT, where outcomes for energy expenditure remained similar between the interventions.

Furthermore, no significant differences between conditions were found for $R Q$ and macronutrient balances.

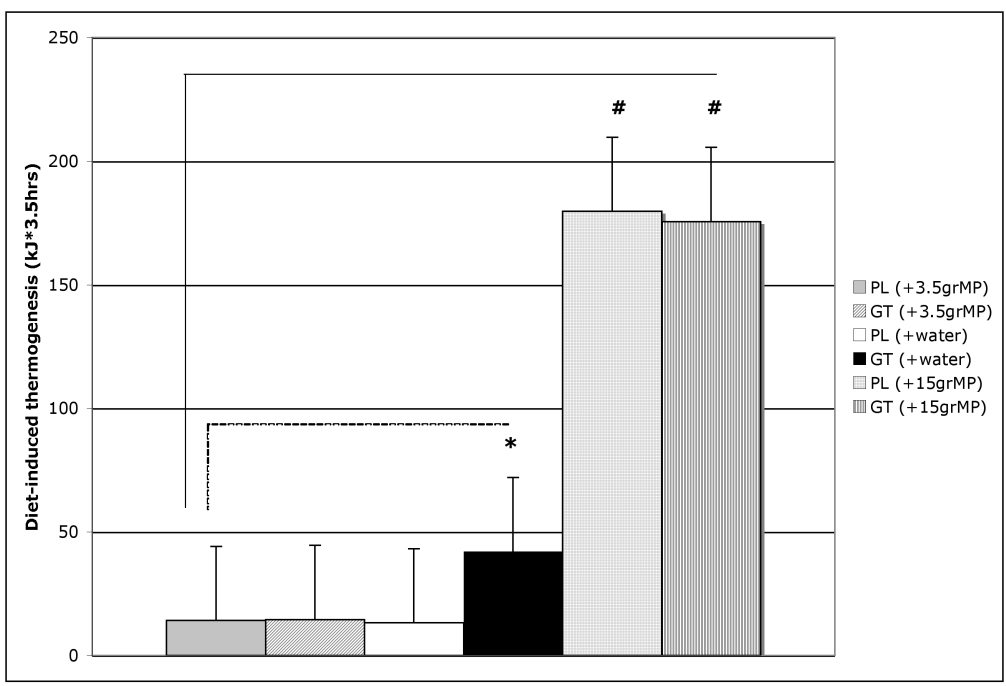

Figure 1. Areas under the curve (AUCs) for energy expenditure after the GT+water, PL+water, GT+3.5grMP, PL+3.5grMP, GT+15grMP and PL+15grMP conditions in 35 subjects (men and women). Values are means $\pm \mathrm{SD} .{ }^{*} \mathrm{P} \leq 0.001$ (Mann-Whitney $U$ test). 


\section{Discussion}

After examining the effect of a combination between green tea and different amounts of dietary protein, the results show that no additional effect occurs when green tea and milk protein are simultaneously administered. GT + 15MP had a similar significant effect on DIT compared to PL + 15MP. Yet, since the DIT of GT + water was significantly elevated, we may conclude that $15 \mathrm{MP}$ inhibited a possible additional effect of GT. Furthermore, GT + water increased DIT more than $\mathrm{PL}+$ water, $\mathrm{GT}+3.5 \mathrm{MP}$ or $\mathrm{PL}+3.5 \mathrm{MP}$. Green tea alone did increase DIT, which did not appear when green tea was given together with 3.5MP. The combination of milk protein and green tea on DIT did not yield an additional effect and was similar to milk protein alone at a higher dosage of milk protein. Apparently there is no synergistic effect from catechins and milk protein when given simultaneously. The increase from milk protein, for 3.5MP and 15MP alone was not elevated by the catechins to a higher extend, as they do when compared to placebo (GT + water vs. PL + water) (2). With GT + 15MP the milk protein prevented an additional effect, thereby showing a similar effect compared with $\mathrm{PL}+15 \mathrm{MP}$. While in case of the GT + 3.5MP, it even extinguished the complete green tea effect through which GT + 3.5MP generated a significantly lower effect compared to GT + water and not a similar one. With respect to fat oxidation, previous studies did find an effect of green tea on fat oxidation (2). However, there was no additive effect of green tea on fat oxidation seen in the current study, since the differences between baseline and post-treatment $R Q$ values did not differ. It could be that with GT mainly dietary fat oxidation is stimulated, and that this effect was not shown in the present study because the breakfast contained hardly any or very little fat.

Previously, in concurrence with the theory of Brown and Wright (7) we reported that the formation of complexes between catechins and proteins, in particular the proline-rich $\beta$-casein that is preferred by polyphenols, prevented a synergistic effect of catechins and green tea after three months of weight maintenance. Controversy remains about whether combining proteins with tea inhibits the beneficial effect of tea drinking, and different mechanistic explanations exist for this phenomenon (13-21) For instance, the addition of protein increases the $\mathrm{pH}$ of the stomach resulting in a reduced absorption of catechins and affects the weak acid compounds of the polyphenols. Polyphenols are easily absorbed in their non-ionised form, but a rise in stomach $\mathrm{pH}$ increases the ionization thereby impeding the passage of the polyphenols through the gastric mucosa (13). This suggestion leads to another possible explanation through which the synergistic effect of the current study failed to occur, namely, the change of $\mathrm{pH}$ in the stomach by the proteins making it impossible for the casing of the capsules to dissolve. Nevertheless, this seems rather unlikely because the raw material of which the casing consisted was gelatin. This is a common material for producing coating/casing of capsules. 
Some other studies did not find an inhibition of the anti-oxidant capacity of tea after the addition of proteins. Therefore, Van het Hof et al. (18) suggest that not the protein content is the cause of the inhibition but possibly the fat content. Catechins have a complex ring structure and are fat-soluble which causes the formation of complexes between fat and polyphenols (18). This was contradicted by Krul et al. who examined three types of milks (whole milk, semi-skimmed milk and skimmed milk) and found that the fat content of milk did not play a role. After the addition of whole milk that has the largest amount of fat, the anti-mutagenic effect of tea was reduced the least compared to the semi-skimmed and skimmed milk (15). In this study, where a non-fat dairy product was used for the 3.5MP conditions, the effect of the green tea that was present with water but without 3.5MP was completely inhibited.

The quantity of milk protein for the 15 MP conditions is sufficient to increase DIT itself, yet also inhibits an additional effect of the green tea. The quantity of milk protein was 15 energy\% of the breakfast. On average this was $16.1 \mathrm{gram}$ for each subject, which usually is considered to be a normal protein intake. The explanation that casein forms complexes with the polyphenols and thereby slows the emptying of the stomach because casein coagulates under the acidic condition of the stomach, is the most acceptable one (30). Finally, it might be possible that protein-polyphenol complexes form metabolites that are taken up in the small intestine similar to the GT metabolites but do not have the same effect. This, however, has never been studied and should be investigated.

In summary, in line with the results from our previous study where green tea in addition to a high-protein diet had no additive effect on weight maintenance over the long-term, supplementation of a combination between green tea and milk protein in different amounts did not have an additional effect on diet-induced thermogenesis, which can be explained by the inhibitory effects of milk protein on the effects of green tea on DIT.

\section{Acknowledgements}

We would like to acknowledge FrieslandCampina for sponsoring the study and providing us the dairy drinks. $\mathrm{RH}$ and MSW-P designed the study. $\mathrm{RH}$ collected and analyzed the data. $\mathrm{RH}$ wrote the manuscript and MSW-P contributed to the interpretation of the data and reviewed the manuscript. The study was executed under the supervision of MSW-P. None of the authors had a personal or financial conflict of interest. 


\section{References}

1. Seidell JC. Obesity in Europe. Obes Res 1995;3 Suppl 2:89s-93s.

2. Dulloo AG, Duret C, Rohrer D, et al. Efficacy of a green tea extract rich in catechin polyphenols and caffeine in increasing $24-\mathrm{h}$ energy expenditure and fat oxidation in humans. Am J Clin Nutr 1999;70:1040-5.

3. Berube-Parent S, Pelletier C, Dore J, Tremblay A. Effects of encapsulated green tea and Guarana extracts containing a mixture of epigallocatechin-3-gallate and caffeine on $24 \mathrm{~h}$ energy expenditure and fat oxidation in men. Br J Nutr 2005;94:432-6.

4. Westerterp-Plantenga MS, Lejeune MP, Kovacs EM. Body weight loss and weight maintenance in relation to habitual caffeine intake and green tea supplementation. Obes Res 2005;13:1195204.

5. Auvichayapat $P$, Prapochanung $M$, Tunkamnerdthai $O$, et al. Effectiveness of green tea on weight reduction in obese Thais: A randomized, controlled trial. Physiol Behav 2008;93:486-91.

6. Hursel R, Westerterp-Plantenga MS. Green tea catechin plus caffeine supplementation to a highprotein diet has no additional effect on body weight maintenance after weight loss. Am J Clin Nutr 2009;89:822-30.

7. Brown PJ, Wright WB. An Investigation of the Interactions between Milk Proteins and Tea Polyphenols. J Chromatogr 1963;11:504-14.

8. Haslam E. Polyphenol-protein interactions. Biochem J 1974;139:285-8.

9. Luck G, Liao H, Murray NJ, et al. Polyphenols, astringency and proline-rich proteins. Phytochemistry 1994;37:357-71.

10. Siebert KJ, Troukhanova NV, Lynn PY. Nature of polyphenol-protein interactions. J Arg Food Chem 1996;44:80-85.

11. Arts MJ, Haenen GR, Voss HP, Bast A. Masking of antioxidant capacity by the interaction of flavonoids with protein. Food Chem Toxicol 2001;39:787-91.

12. Jobstl E, Howse JR, Fairclough JP, Williamson MP. Noncovalent cross-linking of casein by epigallocatechin gallate characterized by single molecule force microscopy. J Agric Food Chem 2006;54:4077-81.

13. Serafini M, Ghiselli A, Ferro-Luzzi A. In vivo antioxidant effect of green and black tea in man. Eur J Clin Nutr 1996;50:28-32.

14. Langley-Evans SC. Antioxidant potential of green and black tea determined using the ferric reducing power (FRAP) assay. Int J Food Sci Nutr 2000;51:181-8.

15. Krul C, Luiten-Schuite A, Tenfelde A, van Ommen B, Verhagen H, Havenaar R. Antimutagenic activity of green tea and black tea extracts studied in a dynamic in vitro gastrointestinal model. Mutat Res 2001;474:71-85.

16. Arts MJ, Haenen GR, Wilms LC, et al. Interactions between flavonoids and proteins: effect on the total antioxidant capacity. J Agric Food Chem 2002;50:1184-7.

17. Lorenz M, Jochmann N, von Krosigk A, et al. Addition of milk prevents vascular protective effects of tea. Eur Heart J 2007;28:219-23.

18. van het Hof $\mathrm{KH}$, Kivits GA, Weststrate JA, Tijburg LB. Bioavailability of catechins from tea: the effect of milk. Eur J Clin Nutr 1998;52:356-9.

19. Leenen R, Roodenburg AJ, Tijburg LB, Wiseman SA. A single dose of tea with or without milk increases plasma antioxidant activity in humans. Eur J Clin Nutr 2000;54:87-92.

20. Hollman PC, Van Het Hof KH, Tijburg LB, Katan MB. Addition of milk does not affect the absorption of flavonols from tea in man. Free Radic Res 2001;34:297-300.

21. Reddy VC, Vidya Sagar GV, Sreeramulu D, Venu L, Raghunath M. Addition of milk does not alter the antioxidant activity of black tea. Ann Nutr Metab 2005;49:189-95.

22. McCarty MF. Promotion of hepatic lipid oxidation and gluconeogenesis as a strategy for appetite control. Med Hypotheses 1994;42:215-25.

23. Stunkard AJ, Messick S. The three-factor eating questionnaire to measure dietary restraint, disinhibition and hunger. J Psychosom Res 1985;29:71-83.

24. Weir JB. New methods for calculating metabolic rate with special reference to protein metabolism. J Physiol 1949;109:1-9. 
25. Harris JA, Benedict FG. A Biometric Study of Human Basal Metabolism. Proc Natl Acad Sci U S A 1918;4:370-3.

26. Palmatier MA, Kang AM, Kidd KK. Global variation in the frequencies of functionally different catechol-O-methyltransferase alleles. Biol Psychiatry 1999;46:557-67.

27. Westerterp KR, Donkers JH, Fredrix EW, Boekhoudt P. Energy intake, physical activity and body weight: a simulation model. Br J Nutr 1995;73:337-47.

28. Schoffelen PF, Westerterp KR, Saris WH, Ten Hoor F. A dual-respiration chamber system with automated calibration. J Appl Physiol 1997;83:2064-72.

29. Hursel R, van der Zee L, Westerterp-Plantenga MS. Effects of a breakfast yoghurt, with additional total whey protein or caseinomacropeptide-depleted alpha-lactalbumin-enriched whey protein, on diet-induced thermogenesis and appetite suppression. Br J Nutr 2010;103:775-80.

30. Boirie Y, Dangin M, Gachon P, Vasson MP, Maubois JL, Beaufrere B. Slow and fast dietary proteins differently modulate postprandial protein accretion. Proc Natl Acad Sci U S A 1997;94:14930-5. 
Chapter 8

\section{Green tea catechin plus caffeine supplementation to a high-protein diet has no additional effect on body weight maintenance after weight loss}

Hursel R and Westerterp-Plantenga MS

Am J Clin Nutr 2009; 89(3): 822-30 


\section{Abstract}

Background. Green tea (epigallocatechin gallate + caffeine) and protein each were shown to improve body weight maintenance after weight loss.

Objective. We investigated the effect of a green tea-caffeine mixture added to a high-protein (HP) diet on weight maintenance (WM) after body weight loss in moderately obese subjects.

Design. A randomized, placebo-controlled, double-blind parallel trial was conducted in 80 overweight and moderately obese subjects [age (mean \pm SD): $44 \pm$ $2 \mathrm{y}$; body mass index $\left(\mathrm{BMl}\right.$; in $\left.\left.\mathrm{kg} / \mathrm{m}^{2}\right): 29.6 \pm 2.0\right]$ matched for sex, age, BMI, height, body mass, and with a habitually low caffeine intake. A very-low-energy diet intervention during 4 wk was followed by 3 mo of WM; during the WM period, the subjects received a green tea-caffeine mixture $(270 \mathrm{mg}$ epigallocatechin gallate $+150 \mathrm{mg}$ caffeine/d) or placebo, both in addition to an adequate protein (AP) diet (50-60 g protein/d) or an HP diet (100-120 g protein/d).

Results. Subjects lost $7.0 \pm 1.6 \mathrm{~kg}$, or $8.2 \pm 2.0 \%$, body weight $(p<0.001)$. During the WM phase, WM, resting energy expenditure, and fat-free mass (FFM) increased relatively in both the HP groups and in the AP + green tea-caffeine mixture group $(p<0.05)$, whereas respiratory quotient and body fat mass decreased, all compared with the AP + placebo group. Satiety increased only in both HP groups $(p<0.05)$. The green tea-caffeine mixture was only effective with the AP diet.

Conclusion. The green tea-caffeine mixture, as well as the HP diet, improved WM independently through thermogenesis, fat oxidation, sparing FFM, and, for the HP diet, satiety; a possible synergistic effect failed to appear.

Keywords: energy expenditure, fat-oxidation, appetite, satiety, thermogenesis 


\section{Introduction}

The increasing incidence of obesity is a recognized medical problem in developed countries (1). Obesity is an important factor for a number of diseases, including coronary heart diseases, hypertension, type 2 diabetes, pulmonary dysfunction, osteoarthritis and certain types of cancer (2-4). The main cause for the development of obesity is increased energy intake during sustained or decreased energy expenditure. Weight loss and loss of body-fat can thus be achieved by reducing energy intake and at the same time sustaining energy expenditure. Treatment of obesity is beneficial in that weight loss reduces the risk of mortality and morbidity. Even modest weight loss, 5 to $10 \%$ of the initial body weight, already leads to beneficial health effects (5-7). Modest weight loss is a realistic goal for most subjects $(5,7)$. However long-term maintenance of the body weight lost can be described as unsuccessful. Most studies on weight maintenance show an undesired weight regain (8-12), indicating that subjects did not change their eating and activity behaviors adequately (13). Interventions to improve long-term weight-maintenance are needed to treat obesity effectively. A rapidly growing therapeutic area is the use of natural herbal supplements. One of these agents is a green tea-caffeine mixture [epigallocatechin gallate (EGCG) plus caffeine], whose claimed anti-obesity properties have been ascribed to increase thermogenesis and fat-oxidation (14-20). A green tea-caffeine mixture contains caffeine that may stimulate thermogenesis and fat oxidation through inhibition of phosphodiesterase, an enzyme that degrades intracellular cyclic AMP, and through antagonism of the negative modulatory effect of adenosine on increased noradrenaline release (14). Human studies have shown that caffeine stimulates thermogenesis and fat oxidation (15-17, 21, 22). In addition, green tea-caffeine mixtures contain large amounts of tea catechins that were shown to inhibit catechol $O$-methyl-transferase, an enzyme that degrades norepinephrine (18). Also in humans, a green tea-caffeine mixture was shown to stimulate thermogenesis and fat oxidation in the short term $(19,23,24)$. Dulloo et al. (19) showed that the effect of a green tea extract containing $90 \mathrm{mg}$ EGCG $+50 \mathrm{mg}$ caffeine was greater than that attributed to $50 \mathrm{mg}$ caffeine alone. On the basis of these studies in humans, we hypothesized that a green tea-caffeine mixture would reduce body weight regain in humans after weight loss, possibly through a thermogenic effect $(19,23-25)$. Moreover, we have shown before that a relatively high-protein (HP) diet improves body weight maintenance after body weight loss $(26,27)$ (R Hursel and M Westerterp-Plantenga, unpublished observations, 2008). Thus the question remains whether there may be a synergistic effect of a green tea-caffeine supplementation added to a HP diet. The following study addresses this research question, with the aim to investigate whether a green tea-caffeine mixture added to an HP diet may improve weight maintenance by preventing or limiting weight regain after weight loss of $5-10 \%$ in moderately obese subjects with a low habitual caffeine intake. 


\section{Subjects and Methods}

\section{Subjects}

The number of subjects needed was calculated according to the differences observed in fat mass (FM) in a previous study (28). With an observed difference of $2.2 \mathrm{~kg}$ and a SD of the population of $4.5 \mathrm{~kg}$, it was calculated that after taking a $10 \%$ dropout into account $\geq 80$ subjects were needed to achieve sufficient power $(90 \%)$ to observe significant $(p<0.05)$ changes in body weight and fat mass as a result of treatment. Male and female overweight and moderately obese subjects $(n=100)$, aged between 18 and $60 \mathrm{y}$, with a body mass index $\left(\mathrm{BMI} ; \mathrm{kg} / \mathrm{m}^{2}\right.$ ) between 25 and 35 , were recruited from the local population in 2006. They underwent a medical screening. Selection was based on being in good health, being a nonsmoker, not using medication, ingesting $\leqq 100 \mathrm{mg}$ caffeine/day (from coffee, tea, chocolate, cola, or energy drinks; the main source of caffeine intake was coffee), not drinking green tea habitually, and being at most a moderate alcohol user. Ninety-two subjects were eligible for participation in the study. During the 4 wk weight-loss period, 12 subjects dropped out of the study, 8 because of moving, changing jobs, or going on vacation, 4 because of not being able to follow the very-low-energy diet (VLED). The remaining 80 subjects were further divided into 4 stratified groups according to, respectively, sex (11 women and 9 men per group), BMI $(27.0 \pm 2.6)$, age $(44 \pm 2 \mathrm{y})$, and weight loss $(7.0 \pm 1.6 \mathrm{~kg})$. All subjects gave their written informed consent. The Medical Ethics Committee of the Academic Hospital in Maastricht approved of the study. Subsequently, subjects were randomly assigned to 4 groups: a green teacaffeine mixture treatment + adequate protein $(A P)$ group, a green tea-caffeine mixture treatment + relatively HP group, an AP + placebo group, and an HP + placebo group for the weight-maintenance phase (Figure 1).

During this weight-maintenance phase, the subjects received a green teacaffeine mixture [45 mg EGCG $+25 \mathrm{mg}$ caffeine $+380 \mathrm{mg}$ placebo (vegetable oil)/capsule; 6 capsules/d; 2 capsules before each meal (corresponding to 2-3 cups of green tea/d and caffeine content alone is comparable to 1-2 cups of coffee/d)] or placebo (450 mg vegetable oil/capsule; 6 capsules/d; 2 capsules before each meal). The dosage of EGCG was the same as used by Dulloo et al. (19); the dosage of caffeine was lower (29). The capsules were manufactured by Novartis $\mathrm{CH}$, Nyon, Switzerland.

The capsules with a green tea-caffeine mixture or placebo were given in addition to an AP diet or an HP diet. With both diets, subjects received a prescription with examples of menus that represented a just-adequate energy intake, based on subjects' resting energy expenditure (REE) multiplied by their physical activity factor (for measurement description see Baseline measurements) or, if the subjects' physical activity factor was not measured, the group average of 1.6 was applied. 


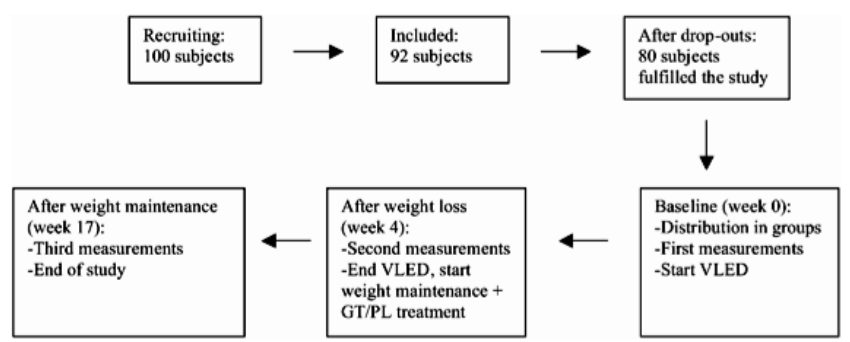

Figure1. Flow diagram of the progress through the phases of the study. VLED, very-low-energy diet; GT, green tea-caffeine mixture; PL, placebo.

In the AP group the prescribed energy intake consisted of $50-60 \mathrm{~g}$ protein ( $\approx 10 \%$ of energy from protein); in the HP group, the prescribed energy intake consisted of $100-110 \mathrm{~g}$ of protein ( $\approx 20 \%$ of energy from protein).

The additional protein was given as $50 \mathrm{~g}$ calcium caseinate, a powder soluble in any fluid, provided by Novartis $\mathrm{CH}$. The subjects were instructed by the dietitians how and when to prepare and consume the diets. Moreover, the subjects had to collect $24 \mathrm{hr}$ urine specimens before the weight maintenance diet started and during the 6 th and 12 th week of the weight-maintenance phase.

\section{Procedure}

\section{Baseline measurements}

Anthropometry. Body-weight was measured with a digital balance (model 707; Seca, Hamburg, Germany; weighing accuracy of $0.1 \mathrm{~kg}$ ) with subjects in underwear, in a fasted state and after emptying their bladder. Height was measured with the use of a wall-mounted stadiometer (model 220; Seca). BMI was calculated. The distribution of fat was investigated by measuring the waist circumference at the site of the smallest circumference between the rib cage and the ileac crest, with the subjects in standing position.

Body composition. Total body water (TBW) was measured with the use of the deuterium $\left({ }^{2} \mathrm{H}_{2} \mathrm{O}\right)$ dilution technique $(30,31)$. In the evening, the subjects ingested a dose of deuterium-enriched water after collecting a background urine sample. After consumption of the deuterium-enriched water, no fluid or food was consumed. The following morning a urine sample from the second voiding was collected between 08:00 hr and 10:00 hr. Deuterium concentration in the urine samples was measured using an isotope ratio mass spectrometer (Micromass Optima, Manchester, United Kingdom). TBW was obtained by dividing the measured deuterium dilution space by 1.04 (30). Fat free mass (FFM) was calculated by dividing the TBW by the hydration factor 0.73 . By subtracting FFM from body weight, FM was obtained. FM expressed as a percentage of body weight gives the percentage of body fat. 
Attitude towards eating. To determine whether attitude toward food intake changed during the experiment, the three-factor eating questionnaire was used (32). Factor 1 indicates cognitive dietary restraint, factor 2 indicates disinhibition of eating, and factor 3 indicates general hunger feelings. In addition, the Herman Polivy questionnaire (33) was used to determine the frequency of previous dieting. In addition to these questionnaires, subjects' baseline caffeine intake was estimated during a food history questionnaire specific for caffeine-containing products.

Postabsorptive appetite profile. To determine the postabsorptive appetite profile, hunger and satiety were rated on anchored $100-\mathrm{mm}$ visual analogue scales (VASs) in the morning before breakfast. This time-point was chosen because we found significant relationships of body weight maintenance with changes in postabsorptive hunger or satiety ratings, i.e., in the fasting state before breakfast, in previous studies $(25,26)$.

Blood parameters. A fasted blood sample of $10 \mathrm{ml}$ was taken and mixed using tubes containing EDTA to prevent clotting. Plasma was obtained by centrifugation, frozen in liquid nitrogen and stored at $-80^{\circ} \mathrm{C}$ until further analysis. Plasma glucose concentrations were measured with the use of the hexokinase method (Glucose HK 125 kit; ABX diagnostics, Montpellier, France). The Wako NEFA C-kit (Wako chemicals, Neuss, Germany) was used to determine free fatty acid (FFA) concentrations. Insulin concentrations were measured with the use of the radioimmunoassay kit (Insulin RIA-100; Kabi-Pharmacia, London, United Kingdom). The glycerol kinase method was used to measure glycerol concentrations (Boehringer Mannheim $\mathrm{GmbH}$, Mannheim, Germany). Triacylglycerol were measured with the use of the GPO-trinder kit (Sigma Diagnostics Inc., St. Louis, $\mathrm{MO})$. Concentrations of triacylglycerol were corrected for glycerol.

The $\beta$-hydroxybutyrate (BHB) dehydrogenase method (Sigma Diagnostics Inc) was used to determine BHB concentrations. Leptin concentrations were measured with the use of the human leptin radioimmunoassay kit (Linco Research Inc., St. Charles, MO).

Adverse events. Frequency and intensity of adverse events during treatment were recorded.

REE and substrate oxidation. REE and substrate oxidation were measured by means of an open-circuit-ventilated hood system. After $30 \mathrm{~min}$ of resting, to make sure that the subjects were rested, REE was measured in the morning with subjects in a fasted state while lying supine for $30 \mathrm{~min}$. Gas analyses were performed by a paramagnetic oxygen analyzer (type 500A; Servomex, Crowborough Sussex, UK) and an infrared carbon dioxide analyzer (Servomex type 500A) (34). Calculation of REE was based on Weir's formula (35). Respiratory quotient was calculated as carbon dioxide produced/oxygen consumed.

Alternately, before or after each REE measurement, the function of the ventilated-hood system was checked with methanol burning during $20 \mathrm{~min}$. The methanol burner has been set to burn 0-2 $\mathrm{g} / \mathrm{min}$, which is equivalent to the production of $150 \mathrm{ml} \mathrm{CO} / \mathrm{min}$ and the consumption of $225 \mathrm{ml} \mathrm{O}_{2} / \mathrm{min}$. Because 
an error percentage depends on burn rate, the expression of the error limit in absolute $\mathrm{ml} / \mathrm{min}$ is preferred; hence the limit values of $7-5 \mathrm{ml} \mathrm{CO}$ and $11 \mathrm{ml}$ $\mathrm{O}_{2} / \mathrm{min}$, respectively (5\% of $150 \mathrm{ml} \mathrm{CO}$ and $5 \%$ of $225 \mathrm{ml} \mathrm{O}_{2}$ ).

Physical activity. Physical activity was partly determined with the use of a CSA accelerometer (Computer Science and Applications Inc., Shalimar, FL) (36), partly with a triaxial accelerometer for movement registration (Tracmor; Philips, Eindhoven, Netherlands) during 1 wk. Half of the subjects from each group wore either the CSA $(n=40)$ or the Tracmor $(n=40)$ device. The Tracmor is a small device $(7 \times 2 \times 0.8 \mathrm{~cm} ; 30 \mathrm{~g})$, which measures accelerations in the anteroposterior, mediolateral and vertical directions of the trunk (37). Subjects were wearing the same type of accelerometer during waking hours in a belt at the back of the waist, during 3 different phases of the study.

PAL (physical activity level) was calculated with the following equations:

$$
\begin{gathered}
\text { CSA: PAL }=[0.000001379 \times(\text { counts } / \mathrm{d} \times 5)]+1.113(36) \\
\text { Tracmor: TEE }=-1.259+(1.552 \times \text { REE })+(0.076 \times \\
\text { counts } / \mathrm{min})(37) \mathrm{PAL}=\mathrm{TEE} / \mathrm{REE}
\end{gathered}
$$

in which TEE (total energy expenditure) and REEare measured in $\mathrm{MJ} / \mathrm{d}$.

Energy expenditure. For subjects who had been wearing the CSA, TEE was calculated by multiplying REE by PAL. For those subjects who had been wearing the Tracmor, TEE was calculated as indicated above.

\section{Weight-loss period}

After determining the subject's baseline measurements, a VLED (2.1 MJ/d) intervention was applied for $4 \mathrm{wk}$, in order to let the subjects lose weight. The diet (Modifast $^{\circledR}$; Nutrition and Santé, Breda, Netherlands) was supplied in three sachets daily, to be dissolved in water in order to obtain a milkshake, pudding, soup or muesli. This diet provided 2.1 MJ/day and was a protein-enriched formula diet, that provided $50 \mathrm{~g}$ carbohydrates, $52 \mathrm{~g}$ protein, $7 \mathrm{~g}$ fat and a micronutrient content, which meets the Dutch recommended daily allowance. Vegetables and fruit were allowed in addition to the diet. The aim was a body weight loss of $\geq 4 \mathrm{~kg}$ over $4 \mathrm{wk}$. After this weight-loss period, the measurements described above were repeated.

\section{Weight-maintenance}

During the weight-maintenance phase the subjects received a green tea-caffeine mixture (45 mg EGCG + $25 \mathrm{mg}$ caffeine $+380 \mathrm{mg}$ vegetable oil/capsule; 6 capsules/day), or placebo (450 mg vegetable oil/capsule; 6 capsules/d). This was given in addition to either the prescribed HP or AP diet. 
The 4 groups were stratified for sex, BMI, age, and body weight loss. A double-blind administration of the supplementation (green tea-caffeine mixture or placebo) was performed.

\section{Compliance to protein intake}

Compliance to additional protein intake was checked by taking $24 \mathrm{hr}$ urine samples and analyzing them for nitrogen. The subjects had to collect $24 \mathrm{hr}$ urine specimens before the weight-maintenance diet started and during the 6th and 12th week of the weight-maintenance phase. Energy intake from protein was calculated from the $24 \mathrm{hr}$ nitrogen output according to the following formula of Isaksson (38).

Protein intake (in $\mathrm{g})=[$ (nitrogen output in $24 \mathrm{hr}$ urine samples in $\mathrm{g} / \mathrm{d})+2 \mathrm{~g}] \times 6.25$

\section{Repeated measurements}

Measurements as described under "Baseline measurements" were executed again 3 mo later. In addition, body weight was determined 1 mo and 2 mo after the start of the weight-maintenance phase.

Body weight maintenance was expressed as rate of regain over the first 3 mo after weight loss. The 3 mo period to measure weight maintenance was based on the stable rate of regain $(0.67 \mathrm{~kg} / \mathrm{mo})$ that we showed before over the first $3 \mathrm{mo}$, and on the strong relation of rates of regain between 3 and 8 or $14 \mathrm{mo}$ $(r=0.9 ; \mathrm{p}<0.0001)(10-12)$.

\section{Data analysis}

The 4 groups were stratified according to the number of males and females, $\mathrm{BMI}$, age, and weight loss, and the differences between these groups were checked with the use of a factorial analysis of variance (ANOVA). Stratification was successful when the $p$-values of this comparison were high, indicating very small differences. P-values for these differences were, respectively, $>0.9$ for sex distribution and $\mathrm{BMI},>0.8$ for age, $>0.5$ for weight loss.

The effects of the 4 treatments were compared with the use of an ANOVA with time as the within-subject factor and group as the between-subject factor. Post hoc, a Scheffe's $F$ test was applied. The difference in nitrogen content of the urine between the AP and HP groups was determined with a factorial ANOVA, in which AP compared with HP was used as factor. The software used was STATVIEW 5.0 SE+GRAPHICS (Abacus Concepts, Berkeley, CA). Statistical significance was set at $p<0.05$. 


\section{Results}

\section{General}

No adverse events occurred. No different effects for men or women were observed; therefore, these data were pooled (Table 1).

\section{Weight loss}

During the VLED intervention, subjects lost a significant amount of their original body weight $(7.0 \pm 1.6 \mathrm{~kg}$, or $8.2 \pm 2.0 \%$; $(\mathrm{p}<0.001)$. Furthermore, body composition changed during weight loss, as did waist circumference, attitude towards eating, Herman-Polivy restraint-scores, hunger scores and satiety scores. The PAL did not change during weight loss. Changes were not different between prospective treatment groups (Table 1).

The blood variables glucose, insulin, triacylglycerol and leptin decreased during weight loss, whereas glycerol, FFAs and BHB increased, without differences in changes between prospective treatment groups (Table 2).

\section{Weight maintenance}

The subjects were compliant to the treatments. The nitrogen content of the $24 \mathrm{hr}$ urine samples was significantly different between the HP and AP groups (14.2 \pm $2.4 \mathrm{~g}$ compared with $8.6 \pm 1.3 \mathrm{~g} ; \mathrm{p}<0.01)$. Calculated energy intake from protein showed that the AP group must have ingested $\approx 10 \%$ of energy as protein $(66.3 \pm$ $10 \mathrm{~g}$ ), whereas the HP group had ingested $\approx 20 \%$ of energy as protein (101.3 \pm $15 \mathrm{~g}$ ). A possible inaccuracy in these calculations could have been caused by the estimation of the energy intake of the subjects, which was based on the Harris and Benedict equation (39), with a PAL of 1.6, and with that the difference of $1 \mathrm{~kg}$ weight loss or gain cumulative is $30 \mathrm{MJ}$. In addition, when returning capsules, only $3 \pm 2$ capsules/mo were returned, without a difference between placebo and green tea + caffeine capsules.

During the weight-maintenance period, significant body weight regain appeared in the AP + placebo group, but not in the HP + placebo group, the green tea caffeine mixture + AP group, or the HP + green tea-caffeine mixture group $(p<0.01 ; 4$-factor treatment $x$ time ANOVA repeated measures, post-hoc Scheffe's $F$ test). Similarly, this was the case with BMI and waist circumference. FFM increased in all 4 groups with a comparable magnitude. FM increased only in the AP + placebo group $(p<0.01)$; moreover, a treatment $x$ time effect also appeared $(p<0.01$; 4-factor ANOVA repeated measures, post-hoc Scheffe's $F$ test). The increase in FFM and FM is the usual composition of the increase in body mass in the AP + placebo group. The increase in FFM and lack of in- 
crease, or even slight decrease, in FM are the FFM-sparing effects during weight maintenance in the HP groups and in the green tea-caffeine mixture + AP group.

Attitude towards eating did not change greatly during weight maintenance, and did not differ between groups, except in the green tea caffeine mixture + placebo group, in which factor 3 , the general hunger score, had increased during weight maintenance. Similarly, the VAS ratings indicated a larger hunger and lower satiety in the green tea caffeine mixture + AP group $(p<0.05$, 4-factor ANOVA repeated measures, post-hoc Scheffe's $F$ test). Related to increases in FFM, REE increased in all groups $(p<0.05)$ without differences between groups (Table 1).

Respiratory quotient increased in all groups $(p<0.01)$, but more in the AP + placebo group ( $p<0.05,4$-factor ANOVA repeated measures, post-hoc Scheffe's $F$ test).

PAL did not change, and TEE increased again in all groups $(p<0.01)$ because REE had increased. A reversal effect of concentrations reversing in the direction of baseline concentration was observed in glucose and to a lesser extent in insulin, BHB, glycerol, FFA, and triacylglycerol. For leptin, only the AP + placebo group reversed; in the other groups the concentrations remained low (Table 2).

\section{Discussion}

No synergistic effect was seen from a green tea-caffeine mixture added to an HP diet, on weight maintenance after weight loss. Interestingly, the green teacaffeine mixture group showed the same body weight maintenance after weight loss, including almost similar changes in the relevant variables, as did the HP group, both in comparison with the AP + placebo group. As we showed before, a green tea-caffeine mixture given during weight maintenance to subjects who are low caffeine consumers ( $<300 \mathrm{mg}$ ) promoted weight maintenance through a FFM-sparing effect that sustained energy expenditure (28). Here, the subjects were compliant to the diet and were low-caffeine consumers, so prerequisites for an effect on weight maintenance were in place. Only subjects with a habitual caffeine intake of $\leq 100 \mathrm{mg}$ were recruited. Because total daily supplementation was $150 \mathrm{mg}$ of caffeine, the maximum caffeine content did not exceed $250 \mathrm{mg}$; therefore, the subjects were low caffeine consumers during all phases.

With the HP diets, also weight maintenance was present, again because of the FFM-sparing effect that sustained energy expenditure but also because of increased satiety $(26,40)$.

Here, also compliance was present, as indicated by the nitrogen in urine. Although the postabsorptive VAS ratings have not been validated by, for instance, a relation with subsequent energy intake, the VAS-ratings were supported by the factor 3 scores that were found in this study. It appears that the factor satiety is the main difference between an HP and green tea-caffeine mixture diet. As 
shown before, an HP diet is extremely satiating, because of either the aminoacid kinetics, satiety hormone concentrations or thermogenesis. A green teacaffeine mixture does not only fail to contribute to satiety, but on the contrary, seems to contribute to hunger feelings (41).

For the failure to show synergy between effects of a green te- caffeine mixture and an HP diet, the following mechanisms may shed light on this issue. Already in 1963, Brown and Wright (42) reported that proteins formed complexes with the polyphenols in tea. Especially caseins, which are present in milk protein, tend to bind the polyphenols. In the absence of caseins, $\alpha$-lactalbumin and $\beta$ lactoglobulin can form complexes with the flavonoids (42). Several studies have confirmed the formation of such complexes (43-46). There are three different caseins; of these $\beta$-casein is usually preferred by different polyhenols because it is casein richest in proline. Polyphenols and proteins can differ in preferences; for instance, EGCG prefers to bind to a proline-rich protein. The protein 'wraps' itself around the catechins, a process named noncovalent cross-linking. This process might reduce the bioavailability and accessibility of the polyphenols (47).

Some controversy still exists about whether the addition of milk to tea inhibits the beneficial effects of tea drinking. In an epidemiologic study, Hertog et al. (48) found in a Welsh population that tea drinking was associated with a higher risk of developing coronary heart diseases. This was in contrast to the results of a comparable study in a Dutch population in which tea drinking was inversely associated with coronary heart diseases. The only difference between the populations, because both consume mainly black tea, is that people in Great Britain add milk to their tea (48). Several studies examined the difference in antioxidative and antimutagenic capacity between tea with or without the addition of milk (49-57). In a recent study it was reported that the addition of milk to tea lowered the concentrations of catechins in vitro. They found a significant reduction of the endothelial function after tea with milk in comparison to tea alone. The added milk lowered the vascular protective effects of tea (53). In another study milk lowered the antioxidant capacity of tea to a maximum of $28 \%$. The authors also found that there was no difference between an addition of cow milk or soy milk, both lowered the antioxidant potential (50). Arts et al. (52) found a $20 \%$ reduction of the total antioxidant capacity because of what they thought were the earlier described interactions between polyphenols and caseins. The antioxidant capacity of a mixture between flavonoids and proteins was lower than the sum of the antioxidant potential of flavonoid and protein separately (52). This is supported by the results of the current study in which a possible synergistic effect of a green tea-caffeine mixture and an HP diet failed to occur as well. Krul et al. (51) studied the influence of a food matrix on the antimutagenic capacity of tea in an in vitro gastrointestinal model that contained tea mixed with milk. Whole milk, 


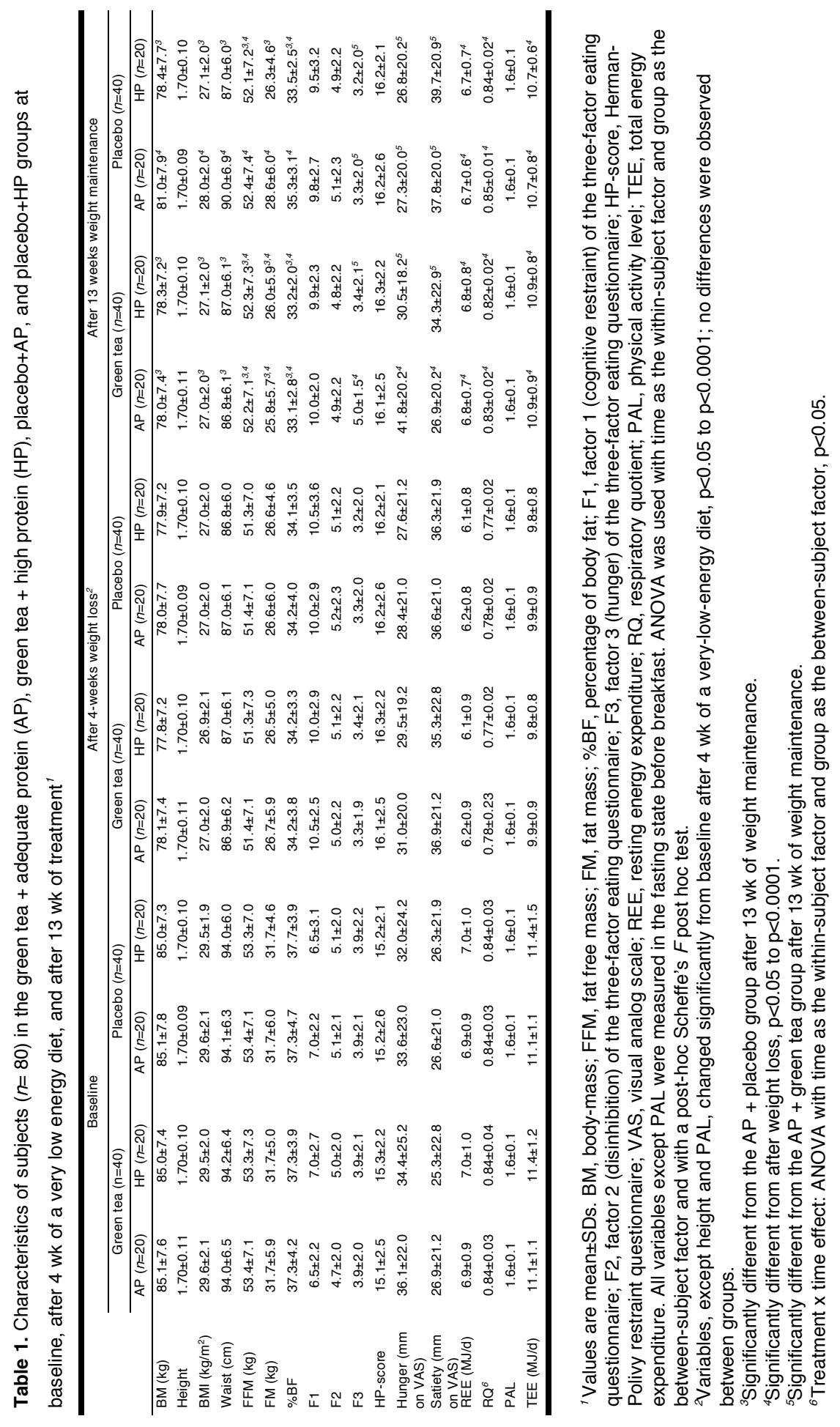




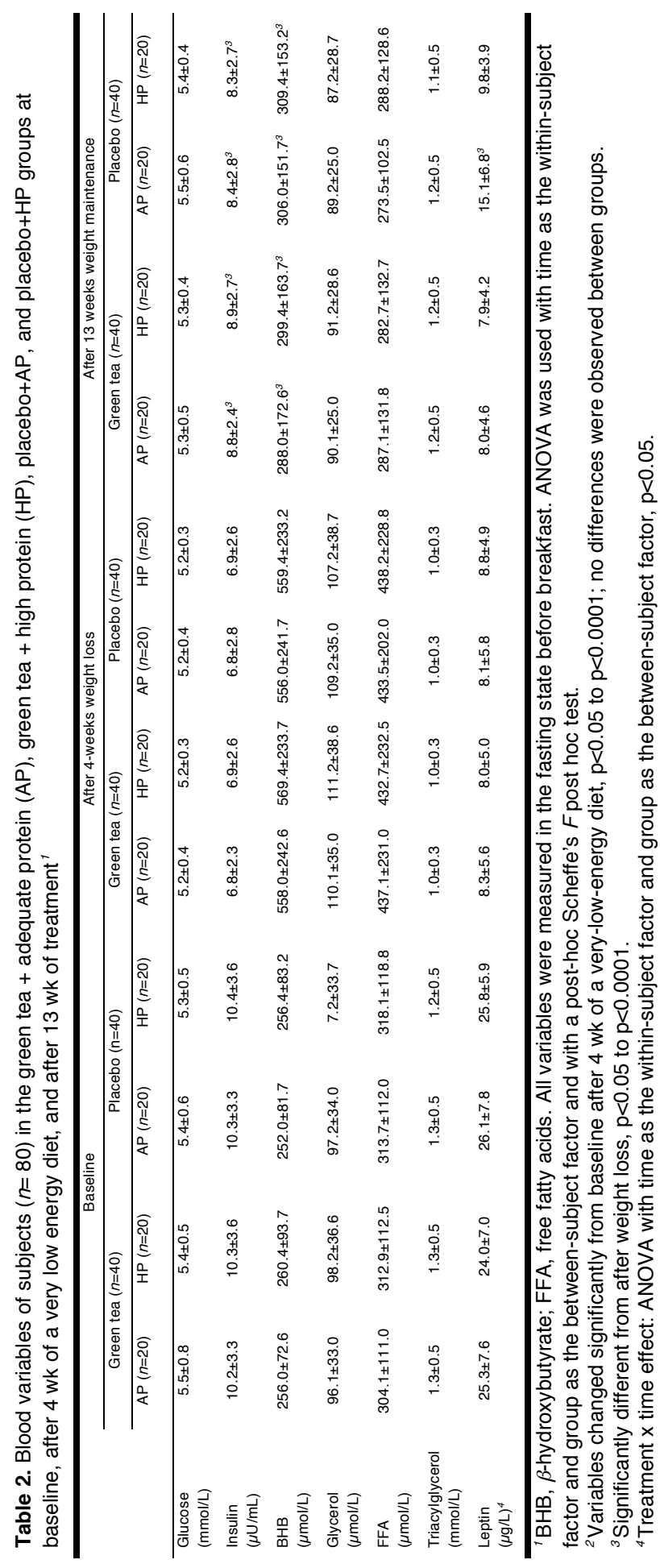


semiskimmed milk and skimmed milk were the 3 types of milk they used. All 3 reduced the antimutagenic capacity of black and green tea (51). Whole milk contained the largest amount of fat, and it reduced the beneficial effects of tea with $22 \%$; skimmed milk contained no fat and abolished the antimutagenic capacity with a reduction of $78 \%$. Semiskimmed milk reduced the beneficial effect by $58 \%$. These results indicate that the fat content of milk might not be of importance; instead, they mention that the interactions between flavonoids and proteins impede the gastric hydrolysis and thereby reduced the absorption of the polyphenols (51). The first study that examined the decrease of antioxidant capacity after addition of milk was published by Serafini et al (49). They found that total antioxidant capacity was not lowered because of the addition of milk to tea, but the polyphenols were less available for absorption because the polyphenolprotein complexes were resistant to gastric hydrolysis. They also suggested that the absorption might be reduced because the $\mathrm{pH}$ of the stomach changed through the milk. The polyphenols have weak acid compounds that are easily absorbed in their nonionized form. If the $\mathrm{pH}$ in the stomach rises as a result of the addition of milk, this can increase the ionization, which impedes the passage of the polyphenols through the gastric mucosa (49). In addition, studies from Leenen et al. (55) and Hollman et al. (56) did not find a difference in the antioxidant capacity of tea after the addition of milk compared with tea alone; their results indicated a normal absorption. Reddy et al. (57) did not find a lowered antioxidant potential but found that it was delayed through the interference with absorption by milk (57). Van het Hof et al. (54) did not find an effect of milk on catechin concentrations in vivo because they were comparable to the catechin concentrations in the blood after tea alone. In contrast to Krul et al. (51), they believed that the fat content might play a role in a possible inhibition of antioxidant capacity and not the proteins. Catechins have a complex ring structure and are fat soluble, which causes the formation of complexes between fat and polyphenols (54).

Many explanations for the antioxidant-reducing effects have been given by the previous studies, but the most widely given explanation is the reduction in absorption after the formation of a protein-polyphenol complex that is resistant to gastric hydrolysis. The formation of such complexes takes place in the upper part of the digestive tract according to Serafini et al (49). If the complexes were resistant to gastric hydrolysis from the beginning of the gastrointestinal system and therefore cannot be absorbed, how is it then possible that the $\mathrm{HP}+$ green tea-caffeine mixture group has nearly the same effect as the HP + placebo group and the AP + green tea-caffeine mixture group from which the proteins and polyphenols are absorbed? Presumably, there is a surplus of proteins such as $\alpha$ lactalbumin and $\beta$-lactoglobulin that only bind to flavonoids during the absence of caseins (42). These proteins may still be absorbed when the rest has formed complexes with polyphenols, and they are known for their ability to reduce energy intake by a hunger-suppressive effect $(58,59)$, to increase diet-induced thermogenesis ( $R$ Hursel and $M$ Wesetrterp-Plantenga, unpublished observa- 
tions, 2008), and to preserve lean body mass at the expense of FM (60). The results of the blood variables show that they accompany the weight changes but are also independent from them. In accordance with Kovacs et al. (25) and Diepvens et al. (61), no effect of the green tea-caffeine mixture was seen on the blood variables, because all groups, except for leptin in the AP + placebo group, showed comparable results. Leptin is positively correlated with FM, which contributes to the explanation of the findings in this study (62). Fat oxidation increased during weight loss, because FFA and BHB increased and triacylglycerol decreased. During weight maintenance, a reversal effect was seen in these variables, which indicated that fat oxidation had decreased again. This means that there was no effect of green tea and caffeine on fat oxidation additional to the effect of weight loss.

In conclusion, no synergistic effect of green tea and caffeine supplementation was seen on an HP diet on body weight maintenance after weight loss. Weight maintenance after the HP + green tea-caffeine mixture group was comparable with the results of the HP + placebo group and the AP + green teacaffeine mixture group. Formations of complexes presumably caused a reduction in absorption; therefore, a synergistic effect failed to occur. Beneficial effects of weight loss on the blood variables were reversed during the weight maintenance period; except for leptin, only the AP + placebo group reversed and the others remained low.

\section{Acknowledgements}

We acknowledge Manuela $\mathrm{P}$ Lejeune for her contribution to data collection. The authors' responsibilities were as follows: $\mathrm{RH}$ and MSW-P: designed the study, analyzed the data and, wrote the manuscript; $\mathrm{RH}$ : contributed to the interpretation of the data; MSW-P: supervised the execution of the study and reviewed the manuscript. None of the authors had a personal or financial conflict of interest.

\section{References}

1. Seidell JC. Obesity in Europe. Obes Res 1995;3 Suppl 2:89s-93s.

2. Noppa $\mathrm{H}$. Body weight change in relation to incidence of ischemic heart disease and change in risk factors for ischemic heart disease. Am J Epidemiol 1980;111:693-704.

3. Hubert HB, Feinleib M, McNamara PM, Castelli WP. Obesity as an independent risk factor for cardiovascular disease: a 26-year follow-up of participants in the Framingham Heart Study. Circulation 1983;67:968-77.

4. Kromhout D. Body weight, diet, and serum cholesterol in 871 middle-aged men during 10 years of follow-up (the Zutphen Study). Am J Clin Nutr 1983;38:591-8.

5. Goldstein DJ. Beneficial health effects of modest weight loss. Int J Obes Relat Metab Disord 1992;16:397-415.

6. Wing RR, Jeffery RW, Burton LR, Thorson C, Kuller LH, Folsom AR. Change in waist-hip ratio with weight loss and its association with change in cardiovascular risk factors. Am J Clin Nutr 1992;55:1086-92. 
7. Van Gaal LF, Wauters MA, De Leeuw IH. The beneficial effects of modest weight loss on cardiovascular risk factors. Int J Obes Relat Metab Disord 1997;21 Suppl 1:S5-9.

8. Wadden TA, Stunkard AJ, Liebschutz J. Three-year follow-up of the treatment of obesity by very low calorie diet, behavior therapy, and their combination. J Consult Clin Psychol 1988;56:925-8.

9. Kramer FM, Jeffery RW, Forster JL, Snell MK. Long-term follow-up of behavioral treatment for obesity: patterns of weight regain among men and women. Int J Obes 1989;13:123-36.

10. Pasman WJ, Westerterp-Plantenga MS, Saris WH. The effectiveness of long-term supplementation of carbohydrate, chromium, fibre and caffeine on weight maintenance. Int J Obes Relat Metab Disord 1997;21:1143-51.

11. Pasman WJ, Westerterp-Plantenga MS, Muls E, Vansant G, van Ree J, Saris WH. The effectiveness of long-term fibre supplementation on weight maintenance in weight-reduced women. Int J Obes Relat Metab Disord 1997;21:548-55.

12. Pasman WJ, Saris WH, Muls E, Vansant G, Westerterp-Plantenga MS. Effect of exercise training on long-term weight maintenance in weight-reduced men. Metabolism 1999;48:15-21.

13. Westerterp-Plantenga MS, Kempen KP, Saris $\mathrm{WH}$. Determinants of weight maintenance in women after diet-induced weight reduction. Int J Obes Relat Metab Disord 1998;22:1-6.

14. Dulloo AG, Seydoux J, Girardier L. Potentiation of the thermogenic antiobesity effects of ephedrine by dietary methylxanthines: adenosine antagonism or phosphodiesterase inhibition? Metabolism 1992;41:1233-41.

15. Dulloo AG, Geissler CA, Horton T, Collins A, Miller DS. Normal caffeine consumption: influence on thermogenesis and daily energy expenditure in lean and postobese human volunteers. Am J Clin Nutr 1989;49:44-50.

16. Astrup A, Toubro S, Cannon S, Hein P, Breum L, Madsen J. Caffeine: a double-blind, placebocontrolled study of its thermogenic, metabolic, and cardiovascular effects in healthy volunteers. Am J Clin Nutr 1990;51:759-67.

17. Bracco D, Ferrarra JM, Arnaud MJ, Jequier E, Schutz Y. Effects of caffeine on energy metabolism, heart rate, and methylxanthine metabolism in lean and obese women. Am J Physiol 1995;269:E671-8.

18. Borchardt RT, Huber JA. Catechol O-methyltransferase. 5. Structure-activity relationships for inhibition by flavonoids. J Med Chem 1975;18:120-2.

19. Dulloo AG, Duret C, Rohrer D, et al. Efficacy of a green tea extract rich in catechin polyphenols and caffeine in increasing 24-h energy expenditure and fat oxidation in humans. Am J Clin Nutr 1999;70:1040-5.

20. Kao YH, Hiipakka RA, Liao S. Modulation of endocrine systems and food intake by green tea epigallocatechin gallate. Endocrinology 2000;141:980-7.

21. Astrup A, Breum L, Toubro S, Hein P, Quaade F. The effect and safety of an ephedrine/caffeine compound compared to ephedrine, caffeine and placebo in obese subjects on an energy restricted diet. A double blind trial. Int J Obes Relat Metab Disord 1992;16:269-77.

22. Toubro S, Astrup AV, Breum L, Quaade F. Safety and efficacy of long-term treatment with ephedrine, caffeine and an ephedrine/caffeine mixture. Int J Obes Relat Metab Disord 1993;17 Suppl 1:S69-72.

23. Rumpler W, Seale J, Clevidence B, et al. Oolong tea increases metabolic rate and fat oxidation in men. J Nutr 2001;131:2848-52.

24. Arciero PJ, Ormsbee M, Tiede M, et al. Comparison of green tea, caffeine, and ephedrine combinations on energy expenditure in humans. Presented at: 49th Annual Meeting of the American College of Sports Medicine 2002, May 28-June 1, St. Louis, Missouri.

25. Kovacs EM, Lejeune MP, Nijs I, Westerterp-Plantenga MS. Effects of green tea on weight maintenance after body-weight loss. Br J Nutr 2004;91:431-7.

26. Westerterp-Plantenga MS, Lejeune MP, Nijs I, van Ooijen M, Kovacs EM. High protein intake sustains weight maintenance after body weight loss in humans. Int $\mathrm{J}$ Obes Relat Metab Disord 2004;28:57-64.

27. Lejeune MP, Kovacs EM, Westerterp-Plantenga MS. Additional protein intake limits weight regain after weight loss in humans. Br J Nutr 2005;93:281-9. 
28. Westerterp-Plantenga MS, Lejeune MP, Kovacs EM. Body weight loss and weight maintenance in relation to habitual caffeine intake and green tea supplementation. Obes Res 2005;13:1195204.

29. Hulshof KF, Brussaard JH, Kruizinga AG, Telman J, Lowik MR. Socio-economic status, dietary intake and $10 \mathrm{y}$ trends: the Dutch National Food Consumption Survey. Eur J Clin Nutr 2003;57:128-37.

30. van Marken Lichtenbelt WD, Westerterp KR, Wouters L. Deuterium dilution as a method for determining total body water: effect of test protocol and sampling time. Br J Nutr 1994;72:491-7.

31. Schoeller DA, van Santen E, Peterson DW, Dietz W, Jaspan J, Klein PD. Total body water measurement in humans with $18 \mathrm{O}$ and $2 \mathrm{H}$ labeled water. Am J Clin Nutr 1980;33:2686-93.

32. Stunkard AJ, Messick S. The three-factor eating questionnaire to measure dietary restraint, disinhibition and hunger. J Psychosom Res 1985;29:71-83.

33. Herman CP, Polivy J. Restrained eating. In: Stunkard AJ (Ed), Obesity. Philadelphia: W.B. Saunders 1980:208-224.

34. Schoffelen PF, Westerterp KR, Saris WH, Ten Hoor F. A dual-respiration chamber system with automated calibration. J Appl Physiol 1997;83:2064-72.

35. Weir JB. New methods for calculating metabolic rate with special reference to protein metabolism. J Physiol 1949;109:1-9.

36. Ekelund U, Yngve A, Sjostrom M, Westerterp K. Field evaluation of the Computer Science and Application's Inc. Activity monitor during running and skating training in adolescent athletes. Int $J$ Sports Med 2000;21:586-92.

37. Goris $\mathrm{AH}$, Meijer EP, Kester A, Westerterp KR. Use of a triaxial accelerometer to validate reported food intakes. Am J Clin Nutr 2001;73:549-53.

38. Isaksson B. Urinary nitrogen output as a validity test in dietary surveys. Am J Clin Nutr 1980;33:4-5.

39. Harris JA, Benedict FG. A Biometric Study of Human Basal Metabolism. Proc Natl Acad Sci U S A 1918;4:370-3.

40. Westerterp-Plantenga MS, Rolland V, Wilson SA, Westerterp KR. Satiety related to $24 \mathrm{~h}$ dietinduced thermogenesis during high protein/carbohydrate vs high fat diets measured in a respiration chamber. Eur J Clin Nutr 1999;53:495-502.

41. Diepvens K, Kovacs EM, Nijs IM, Vogels N, Westerterp-Plantenga MS. Effect of green tea on resting energy expenditure and substrate oxidation during weight loss in overweight females. $\mathrm{Br}$ J Nutr 2005;94:1026-34.

42. Brown PJ, Wright WB. An Investigation of the Interactions between Milk Proteins and Tea Polyphenols. J Chromatogr 1963;11:504-14.

43. Haslam E. Polyphenol-protein interactions. Biochem J 1974;139:285-8.

44. Luck G, Liao H, Murray NJ, et al. Polyphenols, astringency and proline-rich proteins. Phytochemistry 1994;37:357-71.

45. Siebert KJ, Troukhanova NV, Lynn PY. Nature of polyphenol-protein interactions. J Arg Food Chem 1996;44:80-85.

46. Arts MJ, Haenen GR, Voss HP, Bast A. Masking of antioxidant capacity by the interaction of flavonoids with protein. Food Chem Toxicol 2001;39:787-91.

47. Jobstl E, Howse JR, Fairclough JP, Williamson MP. Noncovalent cross-linking of casein by epigallocatechin gallate characterized by single molecule force microscopy. J Agric Food Chem 2006;54:4077-81.

48. Hertog MG, Sweetnam PM, Fehily AM, Elwood PC, Kromhout D. Antioxidant flavonols and ischemic heart disease in a Welsh population of men: the Caerphilly Study. Am J Clin Nutr 1997;65:1489-94.

49. Serafini M, Ghiselli A, Ferro-Luzzi A. In vivo antioxidant effect of green and black tea in man. Eur J Clin Nutr 1996;50:28-32.

50. Langley-Evans SC. Antioxidant potential of green and black tea determined using the ferric reducing power (FRAP) assay. Int J Food Sci Nutr 2000;51:181-8.

51. Krul C, Luiten-Schuite A, Tenfelde A, van Ommen B, Verhagen H, Havenaar R. Antimutagenic activity of green tea and black tea extracts studied in a dynamic in vitro gastrointestinal model. Mutat Res 2001;474:71-85. 
52. Arts MJ, Haenen GR, Wilms LC, et al. Interactions between flavonoids and proteins: effect on the total antioxidant capacity. J Agric Food Chem 2002;50:1184-7.

53. Lorenz M, Jochmann N, von Krosigk A, et al. Addition of milk prevents vascular protective effects of tea. Eur Heart J 2007;28:219-23.

54. van het Hof $\mathrm{KH}$, Kivits GA, Weststrate JA, Tijburg LB. Bioavailability of catechins from tea: the effect of milk. Eur J Clin Nutr 1998;52:356-9.

55. Leenen R, Roodenburg AJ, Tijburg LB, Wiseman SA. A single dose of tea with or without milk increases plasma antioxidant activity in humans. Eur J Clin Nutr 2000;54:87-92.

56. Hollman PC, Van Het Hof KH, Tijburg LB, Katan MB. Addition of milk does not affect the absorption of flavonols from tea in man. Free Radic Res 2001;34:297-300.

57. Reddy VC, Vidya Sagar GV, Sreeramulu D, Venu L, Raghunath M. Addition of milk does not alter the antioxidant activity of black tea. Ann Nutr Metab 2005;49:189-95.

58. Veldhorst M, Nieuwenhuizen AG, Hochstenbach-Waelen A, et al. A breakfast with alphalactalbumin, gelatin, or gelatin+Trp lowers energy intake at lunch compared with a breakfast with casein, soy, whey or whey-GMP. Submitted 2008.

59. Nieuwenhuizen AG, Hochstenbach-Waelen A, Veldhorst M, et al. Acute effects of alphalactalbumin, and gelatin with or without Trp protein breakfasts on hunger, 'satiety' hormones, and amino acid profiles. Submitted 2008.

60. Pichon L, Potier M, Tome D, et al. High-protein diets containing different milk protein fractions differently influence energy intake and adiposity in the rat. $\mathrm{Br} \mathrm{J}$ Nutr 2008;99:739-48.

61. Diepvens K, Kovacs EM, Vogels N, Westerterp-Plantenga MS. Metabolic effects of green tea and of phases of weight loss. Physiol Behav 2006;87:185-91.

62. Trayhurn P, Hoggard N, Mercer JG, Rayner DV. Leptin: fundamental aspects. Int J Obes Relat Metab Disord 1999;23 Suppl 1:22-8. 
Chapter 9

Effects of sleep fragmentation on energy expenditure, substrate oxidation physical activity and exhaustion measured over $48 \mathrm{~h}$ in a respiratory chamber

Hursel R, Rutters F, Gonnissen HKJ, Martens EAP and

Westerterp-Plantenga MS

Submitted for publication 


\section{Abstract}

Background. Epidemiological studies show an inverse or U-shaped relationship between sleep duration and BMI. Decreases in total energy expenditure (TEE) and physical activity (PA) have been suggested to be contributing factors.

Methods. Fifteen healthy male subjects (BMI: $24.1 \pm 1.9 \mathrm{~kg} / \mathrm{m}^{2}$, age: $23.7 \pm 3.5$ years) were included in a randomized, crossover study in which EE, substrate oxidation and PA (by radar) were measured twice for 48hrs in a respiration chamber while being monitored by electroencephalography(EEG) to determine slow-wave sleep(SWS), rapid eye movement(REM)-sleep, and total sleeping time(TST). During two nights, sleep (23.30-07.30hrs) was either fragmented or non-fragmented.

Results. Fragmented sleep lead to reductions in TST, SWS and REM-sleep $(P<0.001)$. Mean energy expenditure did not differ $(9.96 \pm 0.17 \mathrm{MJ} / \mathrm{d}$ vs. $9.83 \pm 0.13 \mathrm{MJ} / \mathrm{d}$; NS), nor did the components of EE, except for activity induced energy expenditure (AEE; fragmented sleep:1.63 $\pm 0.15 \mathrm{MJ} / \mathrm{d}$ vs. non-fragmented sleep:1.42 $\pm 0.13 \mathrm{MJ} / \mathrm{d}, \mathrm{P}<0.05)$. Physical activity, exhaustion, sleepiness, respiratory quotient, and carbohydrate oxidation were elevated compared to nonfragmented sleep: physical activity counts: $2371 \pm 118$ vs. $2204 \pm 124$ counts/d, $\mathrm{P}<0.02$; exhaustion: $40.1 \pm 3.8$ vs. $21.8 \pm 2.4$ mmVAS, $\mathrm{P}<0.001$; sleepiness: $47.4 \pm 4.2$ vs. $33.9 \pm 4.6 \mathrm{mmVAS}, \mathrm{P}<0.001$; respiratory quotient $(R Q): 0.95 \pm 0.01$ vs. $0.93 \pm 0.01, P<0.01$; and carbohydrate oxidation: $525.6 \pm 18.4$ vs. $486.1 \pm 15.6$ grams/d, $P<0.01$; while fat oxidation was reduced: $37.5 \pm 4.5$ vs. $44.1 \pm 5.1$ grams/d, $P<0.05$.

Conclusion. Fragmented vs. non-fragmented sleep induced reductions in the most important sleep phases, coinciding with elevated AEE, physical activity, exhaustion and sleepiness; $R Q$ and carbohydrate oxidation were increased and fat oxidation reduced, that may underscore previously reported insulin insensitivity, and may create a vulnerable condition in the etiology of overweight.

Keywords: $\quad$ Slow wave sleep, REM-sleep, $R Q$, carbohydrate oxidation, fat oxidation and physical activity 


\section{Introduction}

According to epidemiologic data, the current increase in the prevalence of obesity is accompanied by a decrease in sleep duration (1-5). This resulted in research on the effects of reductions in the different sleep stages, namely nonrapid eye movement (non-REM) sleep that consists of stage 1-4, with its most important stage 3-4: slow wave sleep (SWS), REM sleep, and total sleeping time (TST), on energy balance and metabolic syndrome characteristics. Experimental research focused on endocrine functions such as insulin sensitivity, glucose homeostasis. For instance, Stamatakis et al. (6) found a decrease in insulin sensitivity after two nights of sleep fragmentation. Tasali et al. (7) even showed suppression of SWS, without affecting total sleep time, increasing the risk for developing type 2 diabetes, as the initiation of SWS coincides with hormonal changes that affected glucose homeostasis (7). Spiegel et al. (8) also described an alteration in endocrine function after sleep restriction. After only four hours of sleep per night during six consecutive nights, glucose tolerance was lower in the sleep-restricted condition compared with the fully-rested condition because the acute insulin response to glucose was $30 \%$ lower (8). Furthermore, they found a decrease in leptin concentrations and an increase in ghrelin concentrations associated with short sleep duration $(9,10)$, which was confirmed by other groups (11-15). Coinciding with these alterations in endocrine function, food intake appeared to increase, due to increased feelings of hunger and appetite $(13,14,16$ 18). The designs of those studies were quite extreme. Spiegel et al. (8) contrasted $4 \mathrm{hrs}$ of sleep with the catch-up sleep for $10 \mathrm{hrs}$ afterwards and compared severe sleep deprivation with the long catch-up sleep hours. Tasali et al. (7) intervened subjects specifically during their SWS thus reducing SWS by nearly $90 \%$. Previous studies in which sleep was restricted to only $4 \mathrm{hrs}$, observed alterations in the glucose metabolism leading to a reduction in glucose tolerance and insulin sensitivity. The discussion of these studies point at insulin resistance, and increasing appetite that already would be present during mild deprivation of sleep, that may be an explanation for a positive energy balance finally leading to overweight and obesity. Energy balance is maintained when energy intake equals energy expenditure. Also, energy expenditure and physical activity have been suggested to decrease (14), thus contributing to a positive energy balance, which eventually will lead to weight gain. Evidence for the suggestion that sleep restriction may result in decreased energy expenditure and physical activity is hardly present.

Therefore, the aim of the present study was to examine the effect of sleep fragmentation vs. non-fragmented sleep on energy expenditure, physical activity and substrate oxidation in energy-balance, in a fully controlled situation in the respiratory chamber. We chose for mild sleep deprivation since based upon the observations by Stamatakis et al. (6) even mild sleep deprivation might already 
induce a positive energy balance; moreover this is a more realistic approach resembling daily life.

\section{Methods}

Subjects

Fifteen healthy male volunteers (BMI: $24.1 \pm 1.9 \mathrm{~kg} / \mathrm{m}^{2}$, age: $23.7 \pm 3.5$ years) were recruited by advertisements on notice boards at the university. All volunteers participated in an initial screening that involved measurements of body weight and height and included completion of questionnaires related to eating behavior (Three Factor Eating Questionnaire, TFEQ (19)), health, use of medication, physical activity, alcohol consumption, food allergies, smoking behavior and sleeping behavior. Selected subjects were in good health, non-smokers, not using medication, at most moderate alcohol consumers, unrestrained eaters (as assessed by factor 1 of the TFEQ) and sleeping 7 to 8 hours a night. Baseline characteristics of the subjects are presented in Table 1. Subject recruitment started in June 2009 and the study was conducted between September 2009 and May 2010. This study was conducted according to the guidelines laid down in the Declaration of Helsinki and all procedures involving human subjects were approved by the Medical Ethical Committee of Maastricht University Medical Centre. Written informed consent was obtained from all subjects. The study was registered as follows: ISRCTN, registration number NTR1919.

Table 1. Subject characteristics.

\begin{tabular}{|c|c|c|}
\hline & \multicolumn{2}{|c|}{ Total $(n=15)$} \\
\hline & Mean & SD \\
\hline Age (years) & 23.7 & 3.5 \\
\hline Body mass (kg) & 80.0 & 6.8 \\
\hline Height $(m)$ & 1.82 & 0.06 \\
\hline BMI $\left(\mathrm{kg} / \mathrm{m}^{2}\right)$ & 24.1 & 1.9 \\
\hline \multicolumn{3}{|l|}{ Body composition } \\
\hline FFM $(\mathrm{kg})$ & 63.0 & 6.5 \\
\hline FM (kg) & 17.2 & 4.1 \\
\hline $\mathrm{BF}(\%)$ & 21.4 & 4.7 \\
\hline
\end{tabular}

BMI, body mass index; FFM: fat free mass; FM, fat mass; BF, body fat.

Values are means $\pm \mathrm{SD}$. 


\section{Experimental design}

The study had a randomized, single-blind, crossover design. Subjects came to the university twice with at least two weeks between sessions. Each time, they stayed for $48 \mathrm{hr}$ in a respiration chamber where energy expenditure, physical activity and substrate oxidation were measured, during a condition with fragmented sleep vs. a condition with non-fragmented sleep. Subjects had fixed bedtimes, indicated by the lights that switched off automatically at 23.30 hours and switched on at 7.30 hours, resulting in eight hours sleeping time a night. During the daytime they were not allowed to sleep. To ensure this, the researchers addressed them on regular basis and polygraphic recordings were made continuously, with an electroencephalograph (EEG: BrainRT Digital EEG System, OSG bvba, Rumst, Belgium). Furthermore, during the day questionnaires concerning sleep and tiredness were completed. Artificial light intensity in the respiration chamber was always $>400$ lux (Energy Saver Tornado E27 900 lumen, Philips Lightning, Eindhoven, The Netherlands). Fragmentation of sleep was accomplished with approximately hourly wake-up calls varying in frequency between $500-2000 \mathrm{~Hz}$ and intensity between $40-110 \mathrm{~dB}$; confirmation of waking up was expressed by the subjects since they had to put off the alarm after two minutes.

Subjects were individually fed in energy balance two days before their stay in the respiration chamber. This diet had the same macronutrient distribution (12/55/33 En\% protein/carbohydrate/fat) as the diet they received during the subsequent stay in the respiration chamber and consisted of normal, every-day food products.

\section{Sleep recordings}

Before subjects entered the respiration chamber at 20.00 hours, electrodes for EEG, electrocardiogram, electromyogram and electrooculogram recordings were placed according to the appropriate standardized criteria (20). Polygraphic recordings were obtained throughout the entire 48hours (EEG: BrainRT Digital EEG System, OSG bvba, Rumst, Belgium). All records were visually scored in 30 -s epochs according to the standardized criteria by a skilled researcher for whom the conditions were blinded (20).

\section{Energy intake}

Calculations for both the diet at home and in the respiration chamber were based upon average daily energy requirements. The daily energy requirement for the diet at home was estimated as 1.75 times the resting metabolic rate (RMR) (21). RMR was calculated with the formula of Harris and Benedict (22). The energy requirement in the respiration chamber was calculated as 1.35 times the 
measured SMR of the first night. Daily energy intake was divided over three meals: breakfast $20 \%$, lunch $40 \%$, and dinner $40 \%$. Breakfast was given at 08:30 hours, lunch at 13:30 hours and dinner at 18:30 hours.

\section{Energy expenditure, physical activity and substrate oxidation}

Subjects stayed in the respiration chambers from 20:00 hours in the evening on day 1 until 20:00 hours in the evening of day 3 . The respiration chamber is a $14 \mathrm{~m}^{3}$ room, furnished with a bed, chair, desk with computer, TV, DVD-player, video recorder, telephone, intercom, sink and toilet. During the $48 \mathrm{hr}$ stay in the respiration chamber oxygen $\left(\mathrm{O}_{2}\right)$ consumption and carbon dioxide $\left(\mathrm{CO}_{2}\right)$ production were measured. The room was ventilated with fresh air at a rate of $70-80$ $\mathrm{L} / \mathrm{min}$. Flow was measured using electronically modified dry gasmeters (G6, gasmeterfabriek Schlumberger, Dordrecht, The Netherlands). The concentrations of oxygen and carbon dioxide were measured with dual pairs of infrared carbon dioxide analysers (ABB/Hartman\&Braun Uras, Frankfurt a.M., Germany) and paramagnetic oxygen analysers (Servomex 4100, Crowborough, England and ABB/Hartman\&Braun Magnos, Frankfurt a.M., Germany). During each 15min period, 6 samples of outgoing air for each chamber, 1 sample of fresh air, zero gas, and calibration gas were measured. The gas samples to be measured were selected by a computer that also stored and processed the data (23). With the exception of strenuous exercise and sleeping, subjects were allowed to move freely from 07:30-23:30 hours. Total energy expenditure (TEE), respiratory quotient $(\mathrm{RQ})$ and macronutrient balance were calculated. A radar system based on the Doppler principle was used to measure the physical activity of the subjects in the chamber. The following components of energy expenditure were calculated: sleeping metabolic rate (SMR), resting metabolic rate (RMR), and activity induced energy expenditure (AEE). TEE was calculated by the following formula of Carpenter, as published by Brouwer (24): TEE (kJ/day) $=+16{ }^{\star} \mathrm{O}_{2}$ (L/day) $+5^{\star} \mathrm{CO}_{2}$ (L/day) $-0.95^{\star} \mathrm{P}$ ( $\mathrm{P}=$ oxidized protein in $\mathrm{g} /$ day $)$. SMR was calculated by assessing the lowest mean activity of the subjects during three consecutive hours between 00:00h and 07:00h during the second night of their stay in the respiration chamber. Sleeping metabolic rate was the mean energy expenditure during the three consecutive hours in which activity was the lowest. RMR was calculated by plotting energy expenditure (y-axis) against radar output ( $x$ axis), both being averaged over 30-min intervals of the last 24 hours of the stay in the respiration chamber. By filling in the earlier mentioned lowest mean activity into the formula of the linear regression line of the plot, RMR was calculated. AEE was calculated by subtracting RMR from TEE.

Substrate oxidation was calculated from $24 \mathrm{hr}$ urinary nitrogen, $\mathrm{O}_{2}$ consumption and $\mathrm{CO}_{2}$ production. $24 \mathrm{Hr}$ urine was collected from 20.00 hours day 1 till 08.00 hours day $2,08.00$ hours day 2 till 20.00 hours day 2 , and 20.00 hours day 2 till 08.00 hours day 3 , and 08.00 hours day 3 till 20.00 hours day 3 . To prevent 
nitrogen loss through evaporation, 24-hour urine was collected in containers with $10 \mathrm{~mL} \mathrm{H}_{2} \mathrm{SO}_{4}$ (sulfuric acid), while total volume was measured afterwards. Nitrogen concentrations were measured with a nitrogen analyzer (CHN-O-Rapid; Heraeus, Hanau, Germany). Protein oxidation ( $P$, gram/day) was calculated by multiplying the $24 \mathrm{hr}$ urinary nitrogen (gram/day) with 6.25. Carbohydrate $(C)$ and fat oxidation (F) were calculated with the following formulas of Carpenter, as published by Brouwer (24):

$\mathrm{C}($ gram $/$ day $)=-2.97^{\star} \mathrm{O} 2(\mathrm{~L} /$ day $)+4.17^{\star} \mathrm{CO} 2(\mathrm{~L} /$ day $)-0.39^{\star} \mathrm{P}(\mathrm{gram} /$ day $)$

$\mathrm{F}$ (gram/day) $=+1.72^{\star} \mathrm{O} 2$ (L/day) $-1.72^{\star} \mathrm{CO} 2$ (L/day) $-0.32^{\star} \mathrm{P}$ (gram/day)

Body composition was determined between both sessions with the deuterium dilution $\left({ }^{2} \mathrm{H}_{2} \mathrm{O}\right)$ technique $(25,26)$.

\section{Questionnaires}

The sleep questionnaire was composed of Visual Analogue Scale (VAS, in mm) questions on subjective feelings of napping, physical exhaustion, alertness, sleepiness and how satisfying the sleep was. Opposing extremes of each feeling were described at either end of a $100 \mathrm{~mm}$ horizontal line, and subjects marked the line to indicate how they felt at that moment.

\section{Statistical analysis}

Data from energy expenditure, physical activity, $\mathrm{RQ}$ and substrate balances are presented as means \pm SEM, unless otherwise indicated. Data have been analysed comparing the condition with fragmented sleep with the condition with unfragmented sleep. This analysis was applied to SWS, REM, TST, total energy expenditure, and its components, physical activity, sleeping questionnaire parameters, and substrate oxidation. A 2-factor repeated-measures ANOVA was carried out for determination of possible differences between the conditions. The level for establishing significant differences was taken at $p<0.05$. Data were analyzed using SPSS 11 (SPSS Inc. Chicago, IL, USA).

\section{Results}

The duration of the sleep phases, namely the non-REM sleep stage 1-4, SWS and REM sleep, and TST were reduced during the nights with sleep fragmentation (Figure 1). Reductions in duration were as follows: mean TST (395.3 \pm 10.3 $\min$ vs. $476.5 \pm 5.9 \mathrm{~min} ; \mathrm{p}<0.001)$; mean REM-sleep $(88.9 \pm 4.4 \mathrm{~min}$ vs. $111.9 \pm 5.4$ min; $p<0.001)$; mean SWS-sleep (88.3 $\pm 5.8 \mathrm{~min}$ vs. $106.8 \pm 7.3 \mathrm{~min} p<0.001)$.

Fragmented sleep resulted in TEE: $9.96 \pm 0.17 \mathrm{MJ} / \mathrm{d}$, consisting of RMR: $8.33 \pm 0.08 \mathrm{MJ} / \mathrm{d}$ and $\mathrm{AEE}: 1.63 \pm 0.15 \mathrm{MJ} / \mathrm{d}$. Non-fragmented sleep resulted in TEE: $9.83 \pm 0.13 \mathrm{MJ} / \mathrm{d}$ consisting of RMR: $8.41 \pm 0.05 \mathrm{MJ} / \mathrm{d}$ and $\mathrm{AEE}: 1.42 \pm 0.13$ 
$M J / d$. TEE and RMR did not significantly differ while AEE was significantly $(\mathrm{P}<0.05)$ increased by fragmented sleep (Figure 2). Physical activity was increased $(2371 \pm 118$ vs. $2204 \pm 124$ counts/d; $P<0.02)$. SMR $(7.49 \pm 0.10 \mathrm{MJ} / \mathrm{d}$ vs. $7.35 \pm 0.10 \mathrm{MJ} / \mathrm{d}$; NS), as part of RMR, was not affected.

Fragmented sleep also coincided with an increase in $R Q(0.95 \pm 0.01$ vs. $0.93 \pm 0.01 ; \mathrm{P}<0.01)$, increased carbohydrate oxidation $(525.6 \pm 18.4$ vs. $486.1 \pm 15.6$ grams $/ d ; P<0.01)$ and reduced fat oxidation $(37.5 \pm 4.5$ vs. $44.1 \pm 5.1$ grams/d; $\mathrm{P}<0.05)$.

Scores on the sleep questionnaire did not differ significantly (data not shown), except those for exhaustion and sleepiness. Coinciding with fragmented sleep, subjects were more exhausted $(40.1 \pm 3.8$ vs. $21.8 \pm 2.4$ mmVAS; $P<0.001)$ and sleepier $(47.4 \pm 4.2$ vs. $33.9 \pm 4.6$ mmVAS, $\mathrm{P}<0.001)$.

\section{Discussion}

During fragmented vs. non-fragmented nights, subjects woke up about seven times, and reductions in TST, SWS and REM-sleep took place, that coincided with elevated activity-induced energy expenditure, respiratory quotient, carbohydrate oxidation, physical activity counts, exhaustion and sleepiness, while fatoxidation was reduced. Energy expenditure and its components RMR and SMR did not differ significantly.

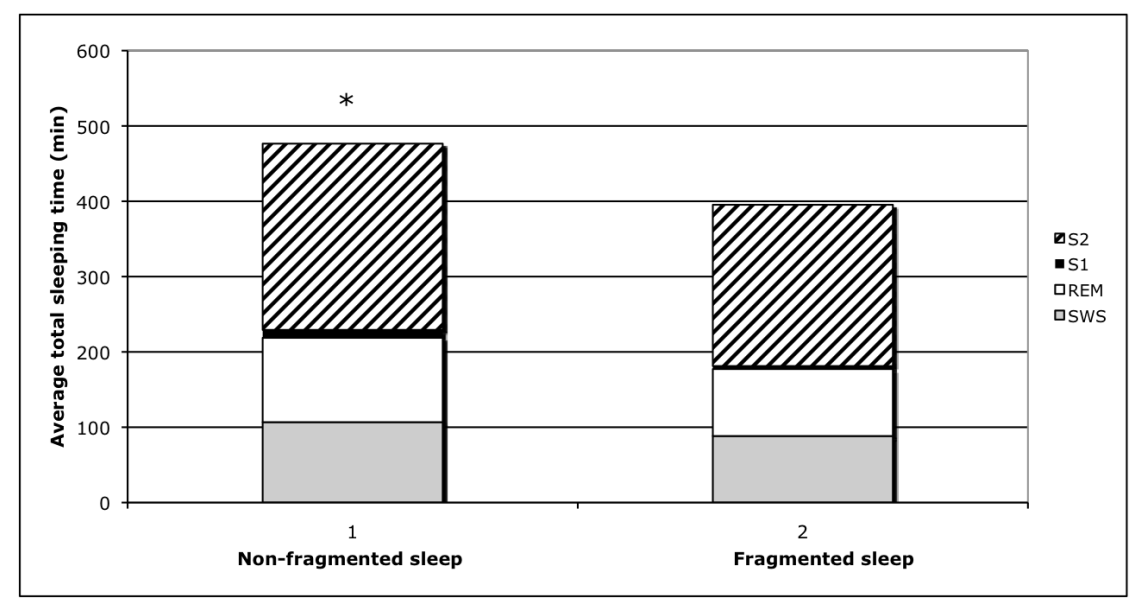

Figure 1. Sleep stages 1 (S1, $\min )$ and 2 (S2, min); slow wave sleep (SWS, min); rapid eye movement sleep (REM, min); total sleeping time (TST, min). Values are means \pm SE. ANOVA repeated measures $(n=15)$. For non-fragmented nights vs. fragmented nights, all sleep stages differed significantly, ${ }^{*} \mathrm{P}<0.001$. 


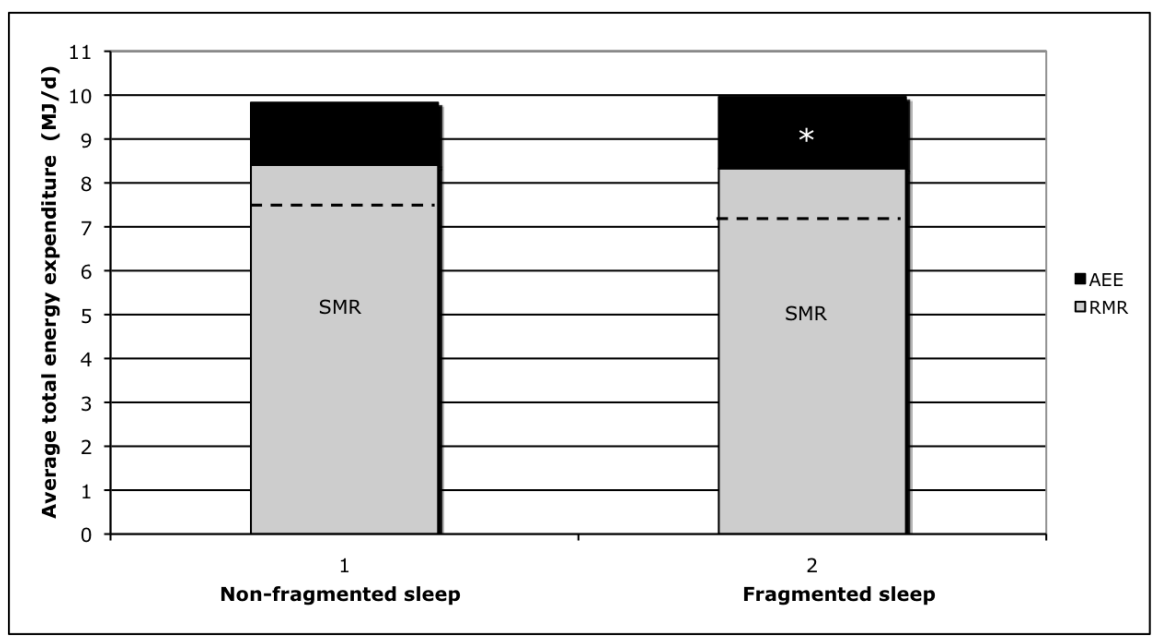

Figure 2. Average total energy expenditure (TEE, MJ/day) for non-fragmented nights vs. fragmented nights $(n=15)$. Resting metabolic rate (RMR, MJ/d); sleeping metabolic rate (SMR, MJ/d) as part of RMR; and activity-induced energy expenditure (AEE, MJ/d). Values are means $\pm \mathrm{SE}$. ANOVA repeated measures. For non-fragmented nights vs. fragmented nights, only AEE differed significantly, ${ }^{\star} \mathrm{P}<0.05$.

Our findings with respect to energy expenditure correspond with Nedeltcheva et al. (27). Other studies (28-30) found an increase in metabolic rate initiated after an (acute) disturbance of sleep. In a study from Brebbia et al. it was found that $\mathrm{Vo}_{2}$ was related to sleep stages, with the highest $\mathrm{Vo}_{2}$ during REM and the lowest $\mathrm{Vo}_{2}$ during SWS (31). Fontvieille et al. concluded that sleep stages indeed were associated with small differences in metabolic rate (32). Bonnet et al. have shown that even arousals during sleep, without waking up the subjects, caused elevations in $\mathrm{Vo}_{2}$ for another 3-9 minutes (28). The small differences in metabolic rate measured over relatively short periods of time and partly controlled conditions may be transient in nature. Our study was fully controlled and corresponds with the results of Nedeltcheva et al. (33) where no effect on TEE was found. In addition, our results showed an increase in RQ and carbohydrate oxidation, while fat-oxidation was decreased.

Nedeltcheva et al. reported no differences in TEE after measuring 10 subjects, who spent either $5.5 \mathrm{hr}$ or $8.5 \mathrm{hr}$ time in bed, with doubly-labeled water for 14 days during caloric restriction (27). They found a decreased RMR after only $5.5 \mathrm{hr}$ in bed compared with the $8.5 \mathrm{hr}$, which may be due to a decrease in SMR because of less sleeping hours. They also reported that subjects spending $5.5 \mathrm{hr}$ in bed lost less FM and more FFM than the subjects spending $8.5 \mathrm{hr}$ in bed. Comparable to our results, they report that $\mathrm{RQ}$ was increased for the short sleepers, which implies less fat oxidation and more carbohydrate oxidation (27). These results were explained as the increased need for glucose by the brain in the wake state and other glucose-dependent tissues, thereby converting body 
protein into glucose (33). Fontvieille et al. found a decreased RQ during REM stage and a negative correlation between duration spent in REM and FM (32). Our results that show an increase in $R Q$ and carbohydrate oxidation, and a decrease in fat-oxidation, underscore diminished insulin sensitivity that we, and others $(6-8,13,34)$, found in the same subjects during a $24 \mathrm{hr}$ test in which insulin concentrations appeared to be increased after a disturbed night (Gonnissen et al. Submitted). This shift in substrate oxidation, implying increased carbohydrate oxidation may lead to glycogen depletion leading to hypoglycemia, that may underscore the reported increased food intake/snack consumption $(16,18)$. Bosy-Westphal et al. also showed an increase in carbohydrate oxidation, though they did not find a reduction in insulin sensitivity, neither did they observe an effect of 4 nights of consecutive increasing sleep curtailment on TEE (35). Katayose et al. (36) found that REM-sleep is associated with increased energy expenditure, $\mathrm{RQ}$ and carbohydrate oxidation and decreased fat oxidation. This would mean that a reduced amount of REM-sleep would correspond with reductions in energy expenditure, $\mathrm{RQ}$ and carbohydrate oxidation; our results indicate the opposite.

Physical inactivity is another aspect that is suggested to play a role in the etiology of obesity. Speculations about a decrease in physical activity after fragmented sleep were confirmed by Schmid et al. who reported that a short-term sleep loss decreased physical activity under free-living conditions (37). Here we showed an increase in physical activity and AEE due to sleep-fragmentation, however this resulted in increased exhaustion and sleepiness. We speculate that when sleep-fragmentation is prolonged, that the observed exhaustion and sleepiness may dominate and abolish the increase in PA. Further, the increased activity that we showed corresponds with the increased carbohydrate oxidation, thus depleting glycogen.

A limitation of the present study is the mild sleep disturbance, in comparison to the studies using $4 \mathrm{hrs}$ sleep reduction. On the other hand, our study shows that even after mild sleep disturbance, that often occurs in a 'natural' way in today's society with its modern lifestyle a shift in substrate oxidation already occurred.

In conclusion, sleep fragmentation while staying in a respiration chamber for $48 \mathrm{hrs}$ induced reductions in the most important sleep phases, coinciding with elevated AEE, physical activity, exhaustion and sleepiness, increased $R Q$, carbohydrate oxidation and reduced fat oxidation, that may underscore previously reported insulin insensitivity, and may create a vulnerable condition in the etiology of overweight.

\section{Acknowledgements}

$\mathrm{RH}, \mathrm{FR}, \mathrm{HKJG}$ and MSW-P designed the study. RH, FR, HKJG and EAPM collected and analyzed the data. $\mathrm{RH}$ wrote the manuscript and MSW-P contributed 
to the interpretation of the data and reviewed the manuscript. The study was executed under the supervision of MSW-P. None of the authors had a personal or financial conflict of interest.

\section{References}

1. Marshall NS, Glozier N, Grunstein RR. Is sleep duration related to obesity? A critical review of the epidemiological evidence. Sleep Med Rev 2008.

2. Patel SR. Reduced sleep as an obesity risk factor. Obes Rev 2009;10 Suppl 2:61-8.

3. Patel SR, Blackwell T, Redline S, et al. The association between sleep duration and obesity in older adults. Int J Obes (Lond) 2008;32:1825-34.

4. Patel SR, Hu FB. Short sleep duration and weight gain: a systematic review. Obesity (Silver Spring) 2008;16:643-53.

5. Patel SR, Malhotra A, White DP, Gottlieb DJ, Hu FB. Association between reduced sleep and weight gain in women. Am J Epidemiol 2006;164:947-54.

6. Stamatakis KA, Punjabi NM. Effects of sleep fragmentation on glucose metabolism in normal subjects. Chest;137:95-101.

7. Tasali E, Leproult R, Ehrmann DA, Van Cauter E. Slow-wave sleep and the risk of type 2 diabetes in humans. Proc Natl Acad Sci U S A 2008;105:1044-9.

8. Spiegel K, Leproult R, Van Cauter E. Impact of sleep debt on metabolic and endocrine function. Lancet 1999;354:1435-9.

9. Spiegel K, Leproult R, L'Hermite-Baleriaux M, Copinschi G, Penev PD, Van Cauter E. Leptin levels are dependent on sleep duration: relationships with sympathovagal balance, carbohydrate regulation, cortisol, and thyrotropin. J Clin Endocrinol Metab 2004;89:576271.

10. Spiegel K, Tasali E, Penev P, Van Cauter E. Brief communication: Sleep curtailment in healthy young men is associated with decreased leptin levels, elevated ghrelin levels, and increased hunger and appetite. Ann Intern Med 2004;141:846-50.

11. Chaput JP, Despres JP, Bouchard C, Astrup A, Tremblay A. Sleep duration as a risk factor for the development of type 2 diabetes or impaired glucose tolerance: analyses of the Quebec Family Study. Sleep Med 2009;10:919-24.

12. Chaput JP, Despres JP, Bouchard C, Tremblay A. Association of sleep duration with type 2 diabetes and impaired glucose tolerance. Diabetologia 2007;50:2298-304.

13. Knutson KL. Impact of sleep and sleep loss on glucose homeostasis and appetite regulation. Sleep Med Clin 2007;2:187-197.

14. Knutson KL, Spiegel K, Penev P, Van Cauter E. The metabolic consequences of sleep deprivation. Sleep Med Rev 2007;11:163-78.

15. Van Cauter E, Holmback U, Knutson K, et al. Impact of sleep and sleep loss on neuroendocrine and metabolic function. Horm Res 2007;67 Suppl 1:2-9.

16. Nedeltcheva AV, Kilkus JM, Imperial J, Kasza K, Schoeller DA, Penev PD. Sleep curtailment is accompanied by increased intake of calories from snacks. Am J Clin Nutr 2009;89:126-33.

17. Penev PD. Sleep deprivation and energy metabolism: to sleep, perchance to eat? Curr Opin Endocrinol Diabetes Obes 2007;14:374-81.

18. Brondel L, Romer MA, Nougues PM, Touyarou P, Davenne D. Acute partial sleep deprivation increases food intake in healthy men. Am J Clin Nutr;91:1550-9.

19. Stunkard AJ, Messick S. The three-factor eating questionnaire to measure dietary restraint, disinhibition and hunger. J Psychosom Res 1985;29:71-83.

20. Rechtschaffen A, Kales A. A Manual of Standardized Terminology, Techniques and Scoring System for Sleep stages of Human Subjects. Bethesda, Md., U. S. National Institute of Neurological Diseases and Blindness 1968.

21. Westerterp KR, Speakman JR. Physical activity energy expenditure has not declined since the 1980 s and matches energy expenditures of wild mammals. Int J Obes (Lond) 2008. 
22. Harris JA, Benedict FG. A Biometric Study of Human Basal Metabolism. Proc Natl Acad Sci U S A 1918;4:370-3.

23. Schoffelen PF, Westerterp KR, Saris WH, Ten Hoor F. A dual-respiration chamber system with automated calibration. J Appl Physiol 1997;83:2064-72.

24. Brouwer E. On simple formulae for calculating the heat expenditure and the quantities of carbohydrate and fat oxidized in metabolism of men and animals, from gaseous exchange (Oxygen intake and carbonic acid output) and urine-N. Acta Physiol Pharmacol Neerl 1957;6:795-802.

25. Schoeller DA, van Santen E, Peterson DW, Dietz W, Jaspan J, Klein PD. Total body water measurement in humans with $18 \mathrm{O}$ and $2 \mathrm{H}$ labeled water. Am J Clin Nutr 1980;33:2686-93.

26. van Marken Lichtenbelt WD, Westerterp KR, Wouters L. Deuterium dilution as a method for determining total body water: effect of test protocol and sampling time. $\mathrm{Br} J \mathrm{Nutr}$ 1994;72:491-7.

27. Nedeltcheva AV, Kilkus JM, Imperial J, Schoeller DA, Penev PD. Insufficient sleep undermines dietary efforts to reduce adiposity. Ann Intern Med;153:435-41.

28. Bonnet $\mathrm{MH}$, Berry RB, Arand DL. Metabolism during normal, fragmented, and recovery sleep. J Appl Physiol 1991;71:1112-8.

29. Bonnet $\mathrm{MH}$, Arand $\mathrm{DL}$. 24-Hour metabolic rate in insomniacs and matched normal sleepers. Sleep 1995;18:581-8.

30. Jung CM, Melanson EL, Frydendall EJ, Perreault L, Eckel RH, Wright KP. Energy expenditure during sleep, sleep deprivation and sleep following sleep deprivation in adult humans. J Physiol;589:235-44.

31. Brebbia DR, Altshuler KZ. Oxygen consumption rate and electroencephalographic stage of sleep. Science 1965;150:1621-3.

32. Fontvieille AM, Rising R, Spraul M, Larson DE, Ravussin E. Relationship between sleep stages and metabolic rate in humans. Am J Physiol 1994;267:E732-7.

33. Boyle PJ, Scott JC, Krentz AJ, Nagy RJ, Comstock E, Hoffman C. Diminished brain glucose metabolism is a significant determinant for falling rates of systemic glucose utilization during sleep in normal humans. J Clin Invest 1994;93:529-35.

34. Nedeltcheva AV, Kessler L, Imperial J, Penev PD. Exposure to recurrent sleep restriction in the setting of high caloric intake and physical inactivity results in increased insulin resistance and reduced glucose tolerance. J Clin Endocrinol Metab 2009;94:3242-50.

35. Bosy-Westphal A, Hinrichs S, Jauch-Chara K, et al. Influence of partial sleep deprivation on energy balance and insulin sensitivity in healthy women. Obes Facts 2008;1:266-73.

36. Katayose Y, Tasaki M, Ogata H, Nakata Y, Tokuyama K, Satoh M. Metabolic rate and fuel utilization during sleep assessed by whole-body indirect calorimetry. Metabolism 2009;58:920-6.

37. Schmid SM, Hallschmid M, Jauch-Chara K, et al. Short-term sleep loss decreases physical activity under free-living conditions but does not increase food intake under time-deprived laboratory conditions in healthy men. Am J Clin Nutr 2009;90:1476-82. 
Chapter 10

\section{General discussion}


The research presented in this thesis focuses on different factors that, in the context of body-weight regulation, may affect energy expenditure. The thermogenic ingredients green tea, caffeine and capsaicin that affect energy expenditure and for the latter also satiety, are discussed, while including evidence provided by short-term and long-term studies (1).

Similarly, dietary protein and its multifactorial role in body-weight regulation is discussed, with an emphasis on the thermogenic effect of dietary protein (2, $3)$. The thesis provides evidence for the beneficial effect of catechin rich teas and caffeine on weight loss and weight maintenance after initial weight loss, highlighting energy expenditure and fat oxidation as intermediair metabolic targets $(4,5)$. Moreover, it discusses possible synergistic effects or the absence thereof, with protein intake together with green tea catechins $(6,7)$. Finally, results addressing effects of fragmented sleep on energy expenditure, substrate oxidation and physical activity are discussed. Additionally, the role of increased carbohydrate oxidation during sleep deprivation in relation to development of insulin insensitivity is dealt with (8).

\section{Thermogenic ingredients and their role in regulating energy balance}

Maintaining the level of daily energy expenditure is as important as maintaining satiety while decreasing energy intake, during weight loss and weight maintenance. In this context, ingredients such as caffeine (9-15), capsaicin (16-23) and different teas for instance green, white and oolong tea (24-52) have been proposed as strategies for maintaining energy expenditure and increasing fatoxidation during weight loss and weight maintenance. Since, they appear to increase energy expenditure by relatively $4-5 \%$, and fat oxidation by relatively $10-16 \%$ these ingredients are proposed to counteract the usual decrease in metabolic rate that is present during weight loss. Although these ingredients may be useful for body-weight loss since daily increases in thermogenesis of approximately $300-400 \mathrm{~kJ}$ can eventually lead to a substantial weight loss, their effects are of greater importance after a for instance meal replacement induced weight loss, namely during weight maintenance. These functional ingredients have the potential to produce significant effects on the metabolic targets satiety, thermogenesis, and fat oxidation, yet a clinically significant outcome also depends on full compliance of subjects. Combinations of several bioactive ingredients have also been examined, showing mixed results with respect to energy expenditure and energy intake (53-55). Nevertheless, thermogenic ingredients may be considered as functional agents that could help in preventing a positive energy balance and obesity (56). 


\section{Genetic predisposition and other moderators}

Catechin rich teas were praised for their potential, though indecisiveness still occurred as studies published contradictive outcomes, with mostly Asian studies showing beneficial effects of catechin rich teas on body weight regulation and Caucasian studies reporting no effects. Even recently, Basu et al. (57) showed in obese subjects a decrease in body weight and BMI after eight weeks of green tea intervention (57). Nonetheless, Lonac et al. (58) did not find any effect of an EGCG supplement on resting energy expenditure and diet-induced thermogenesis (58). This might also indicate that the weight-lowering effect as reported by Basu et al. (57) is due to diminished fat absorption, however they did not measure energy expenditure and neither of them measured fat absorption, making it difficult to draw conclusions form these two studies. Therefore, the metaanalyses presented in this thesis may have provided a solution for the question whether catechin rich teas have an effect on body weight regulation, energy expenditure and fat oxidation.

The meta-analysis addressing body weight regulation has shown that EGCG-caffeine mixtures have a positive effect on weight loss and on weight maintenance. Moreover, it also showed that habitual caffeine intake and ethnicity may be moderators, especially due to interactions of the different $A D O R A 2 A$ and COMT polymorphisms and ethnicity while different doses of catechins did not have a significantly different effect (5).

The meta-analysis emphasizing energy expenditure and fat oxidation showed that a catechin-caffeine mixture and caffeine-only have a stimulating effect on energy expenditure. Furthermore, a catechin-caffeine mixture has also a stimulating effect on fat oxidation compared with placebo in contrast to caffeine-only. In addition, it also shows that people with increased BMI may benefit from the sympathoadrenal stimulating effect of a catechin-caffeine mixture while different doses of catechins have a significantly different effect. What strikes immediately is the dosage effect in the latter meta-analysis, which is not present in the first (4). The larger variability in dosage between the included studies of the second meta-analysis appears to be responsible for this result. However, interesting is the fact that all studies supply their subjects with similar dosages, instead of administrating a subject-specific dosage per kilogram body-weight, that might yield unambiguous results. The previously suggested moderators can partly explain the heterogeneity within the meta-analyses. For instance, in chapter 2, 4 and 5 we hypothesized that genetic predisposition plays an important role in whether or not bioactive ingredients efficiently increase thermogenesis. Studies with functional foods report great intra-variability between subjects concerning effects on satiety and energy expenditure (59). With respect to green tea different polymorphisms for the COMT enzyme exist. A wide variability in flavonoid O-methylation, a major pathway of flavonoid metabolism, by the enzyme COMT was stated by Hodgson et al (60). The Val158Met polymorphism, replaces valine by methionine, thereby changing the 
enzyme activity. Allele frequencies show that the more favorable polymorphism is highly abundant in Asians, in contrast with Caucasians where only a minority possesses this polymorphism (61). Larsen et al. (62) found pre-prandially but not post-prandially, an association between the G-allele that reduces COMT enzyme activity and a decreased $R Q$ and increased fat oxidation, in obese subjects while no association was found with respect to energy expenditure (62). This may underscore the hypothesis that subjects with $\mathrm{COMT}^{\mathrm{H}}$ polymorphisms benefit from green tea only with respect to fat oxidation, and not with respect to energy expenditure. More evidence is needed to understand this mechanism completely. Capsaicin may have a similar mechanism as green tea that underlies their effects. As earlier mentioned the TRPV1 Val585/le polymorphism, a different genetic variant for the TRPV1 receptor, is associated with more abdominal fat loss compared to the Ile/lle variant after capsiate treatment (63). For caffeine there appears to be ability for tolerating caffeine intake in people who consume caffeine on a regular basis. Cornelis et al. (64) showed that Hispanic Americans with an ADORA2A 1083 TT genotype are more likely to limit their caffeine intake than the $C C$ and $C T$ genotype (64). These persons appeared to be more sensitive for the differences between caffeine and the adenosinergic system. This genotype codes for the $A_{2 a}$ receptor, at which caffeine antagonizes the actions of adenosine, a key process in the stimulating properties of caffeine. Furthermore, habitual caffeine intake was also a moderator, supporting the results from Westerterp-Plantenga et al. (65), which showed more weight gain in high habitual caffeine consumers compared to low habitual caffeine consumers after 12 weeks of daily EGCG-caffeine mixture supplementation. Another moderator that might contribute to the variability of the results is composition or way of processing of the catechin-caffeine mixtures. Some studies use extractions while others use beverages prepared with actual tealeaves. Further, catechin composition will most likely differ between studies with differences in for instance amounts of EGC, ECG and EC. Catechin composition differs strongly between teas, depending on features such as geographical location and environmental conditions like soil and temperature. Furthermore, this difference in catechin composition and way of processing might affect the qualitative and quantitative profiles of the catechins in tea consumed that will alter absorption and likely metabolism by COMT or other pathways such as glucuronidation and sulfation (66). Hence, the metabolism and ultimate "activity" of the catechin mixture is likely influenced by tea composition as well. Another factor that may influence the issue of responders vs. nonresponders is not having found a potential receptor that is responsible for the uptake of catechins, yet. The rapid activation of kinases after tea consumption implies a signal cascade after uptake by a receptor, which is assumed to be located in the small intestine (67). Differences in such a receptor between individuals for the uptake of catechins may explain the existence of responders and non-responders as well. Earlier increased ratings of hunger after green tea consumption were described, which in a controlled study environment would not 
lead to weight gain or counterbalance the expected weight loss. However this might explain why some long-term studies did not find effects on weight loss of weight maintenance, since subjects are being studied under free-living conditions with merely diaries to record food intake that are susceptible for underreporting. Therefore, increased food intake after green tea consumption might negatively influence outcome parameters. A possible mechanism behind the increased appetite might be explained by the inhibition of nuclear factor- $\mathrm{K} B$ $(\mathrm{NF} \kappa \mathrm{B})$ by tea catechins. NFKB, controls the expression of many genes including the tumor necrosis alpha $(\operatorname{TNF} \alpha)$ gene $(68,69)$ and lipid-metabolizing enzymes involved in fat oxidation (70). Thereby, TNF $\alpha$ levels that among others are involved in the suppression of appetite are decreased, which might result in more appetite as shown in humans (71). Finally, the food matrix might contribute to the heterogeneity as well. Especially protein seems to interfere with catechin rich teas as shown in chapter $\mathbf{7}$ and $\mathbf{8}$, in the short-term as in the longterm $(6,7)$. Supplementation of green tea in addition to a yoghurt drink breakfast containing milk protein did not have an additional effect on diet-induced thermogenesis, which could be explained by the inhibitory effects of milk protein on the effects of green tea on DIT due to formations of protein-polyphenol complexes that reduce the absorption or which metabolites yield no thermogenic effects (72-75). Further, no synergistic effect of green tea and caffeine supplementation was observed on a high-protein diet on body weight maintenance after weight loss. Weight maintenance after the high-protein + green tea-caffeine mixture group was comparable with the results of the highprotein + placebo group and the adequate-protein + green tea-caffeine mixture group. Beneficial effects of weight loss on the blood parameters were reversed during the weight maintenance period, except for leptin were only the adequateprotein + placebo group reversed and the others remained low.

\section{Fat metabolism}

The proposed role for genetic predisposition in the efficacy of thermogenic ingredients may play a role in fat metabolism as well. Subjects differ in levels of fat oxidation (76-78), and the same may apply for fat absorption. Furthermore, it may be hypothesized that there is a balance between fat absorption and fat oxidation, with some individuals responding through a decrease in fat absorption and others more likely via enhancement in fat oxidation (79). This is interesting to investigate, as catechin-caffeine mixtures have the potential to increase fat oxidation and perhaps also to decrease fat absorption through inhibition of pancreatic and gastric lipases thereby probably attenuating fat emulsification (43, 80-84). 


\section{Trace elements}

A relatively new area with respect to green tea is the role of trace elements in human metabolism. Tea contains for instance chromium that is involved in lipid and carbohydrate metabolism and zinc that contributes to carbohydrate, protein and lipid synthesis and degradation (85). Therefore, these trace elements also may play a role in the anti-obesogenic effect of green tea.

Overall, the research related to thermogenic ingredients presented in this thesis provides promising effects but also shows its limitations, since there are many moderators that may influence the eventual outcome of a treatment.

\section{Protein-induced satiety and energy expenditure and quality of proteins}

Prevention of weight gain after weight loss and during weight maintenance, can be achieved when certain metabolic targets such as sustained satiety, sustained energy expenditure, sparing of fat free mass are stimulated, together resulting in a high energy inefficiency (86-90). These requirements need to be fulfilled despite being in negative energy balance, as a successful weight loss or weight maintenance study depends on the combination of the three. Amino acids, varying the quality of proteins, play an important role as an excessive intake leads to a sustained satiety and sustained energy expenditure. For the relative increase in energy expenditure, gluconeogenesis, as recently shown in a study form Veldhorst et al. (91), and net protein synthesis are important contributors. The possible relationship between net protein synthesis and sparing fat free mass remains to be elucidated.

\section{Protein-induced energy expenditure}

The study presented in chapter 6 reports the effect of quantity and quality on energy expenditure and satiety, as measured with indirect calorimetry over the short-term (3). High-protein breakfasts increased thermogenesis more than an adequate protein breakfast, which can be attributed to amount of protein but also to the higher bioactivity of $\alpha$-lactalbumine and whey compared to milk protein. $\alpha$ lac is a 'complete' protein, which contains high concentrations of indispensable amino acids such as cystine, lysine and tryptophan (92). The previously elaborated Mellinkoff hypothesis $(93,94)$ explains the increase in energy expenditure as a surplus of amino acids is oxidized, causing an increase in energy expenditure. Nevertheless, the amount of protein that is attended with an increase in energy expenditure can also for nearly $50 \%$ be clarified by gluconeogenesis (91). 


\section{Protein-induced satiety}

Furthermore, $\alpha$-lactalbumine suppressed hunger more than whey and placebo. A ketogenic state contributes to appetite suppression, especially in high protein diets that consist mostly out of ketogenic amino acids such as lysine and leucine, which may lead to increased ketone body concentrations (95). $\alpha$-lac and whey, both contain same levels of ketogenic amino acids except for tryptophan that has been suggested to affect appetite regulation via serotonin, however Nieuwenhuizen et al. concluded the opposite (96). In conclusion, addition of $\alpha$-lac, respectively whey, to a milk protein yoghurt drink containing an adequate protein amount increases diet-induced thermogenesis; additional $\alpha$-lac also suppresses hunger and desire to eat.

Another approach in dietary protein research, that should be taken into account, is the protein-leverage hypothesis from Simpson et al. (97), which holds that individuals regulate protein intake and prioritize it over fat and carbohydrates, leading to excessive energy consumption in diets containing a low percentage of protein. This hypothesis presumes that protein is the most important macronutrient with respect to regulation of energy balance, as the amount of protein intake will determine the amount of energy intake (97). Protein balance also seems to be regulated more strictly than energy balance, which supports Simpson's theory. An often advised decrease in fat and carbohydrate intake to induce weight loss is only of importance as long as the absolute daily need of dietary protein, namely $0.8-1.2 \mathrm{~g} / \mathrm{kg}$ body weight is maintained (98).

\section{Fragmented sleep affecting energy expenditure, substrate oxidation and physical activity}

Approximately, one third of our lifetime is spent sleeping, which expresses the significance of sleep in relation to the wellbeing of an individual. An interference of sleep, leading to a decrease in the quality of sleep can affect the homeostasis of the body, thereby inducing positive energy balance (99-101). In chapter 9, it was concluded that fragmented sleep had no effect on total energy expenditure. Activity-induced energy expenditure and physical activity were increased, as well as exhaustion and sleepiness. In the long-term, these may dominate resulting in a decrease in physical activity and thereby a sedentary lifestyle (8). No effect on total energy expenditure has been reported previously but initially the opposite was anticipated to contribute to the negative effects of sleep restriction (102). The effect of the increased exhaustion and sleepiness on physical activity deserves more attention, as they seem to be induced remarkably, and might have a relatively large impact on energy expenditure eventually (103). Fragmented sleep also appeared to induce increases in $R Q$ and carbohydrate oxidation and 
a decrease in fat oxidation (8), which may cause acute hypoglycaemia, and subsequently appears to show decreased insulin sensitivity, underscoring the reported insulin resistance (104). Both these factors, presently due to sleep fragmentation, play a role in the etiology of obesity and the metabolic syndrome. Metabolic changes concerning concentrations of glucose, insulin, leptin and ghrelin are perpetually reported by many independent studies, supporting the negative effect of fragmented sleep on homeostasis $(105,106)$. The reversed neuropeptide concentrations may also explain the increases reported in food intake after sleep curtailment $(107,108)$, thereby completing all the facets that determine energy balance.

Orexin, a neuropeptide excreted by the hypothalamus, might fulfill an important role, as the link between sleep, energy homeostasis and the metabolic factors $(109,110)$.

\section{Summary of conclusions}

The different studies dealt with in this thesis have separately lead to the following conclusions:

- Catechins significantly promote body-weight loss or prevent weight gain after weight loss with approximately 1.3 kilogram.

- Catechin-caffeine mixtures and caffeine-only supplementation increase energy expenditure significantly over $24 \mathrm{hrs}$ with $428.0 \mathrm{~kJ}(4.7 \%)$ and $429.1 \mathrm{~kJ}$ (4.8\%), respectively. $24 \mathrm{~h}$ fat oxidation, however, was only increased by catechincaffeine mixtures $12.2 \mathrm{~g}(16.0 \%)$ and $9.5 \mathrm{~g}(12.4 \%)$, respectively. $24 \mathrm{~h}$ energy expenditure and fat oxidation are increased on average with $0.53 \mathrm{~kJ} / \mathrm{mg}$ and $0.02 \mathrm{~g} / \mathrm{mg}$ for catechin-caffeine mixtures and $0.44 \mathrm{~kJ} / \mathrm{mg}$ and $0.01 \mathrm{~g} / \mathrm{mg}$ for caffeine-only.

- Consumption of a breakfast yoghurt drink with added whey or $\alpha$-lac increased energy expenditure, protein balance and decreased fat balance compared to normal protein. $\alpha$-lac enriched yoghurt drink suppressed hunger and desire to eat more than whey enriched yoghurt drink.

- Consumption of milk-protein inhibits the effect of green tea on diet-induced thermogenesis.

- Green tea-caffeine mixture, as well as a high-protein diet improved weightmaintenance independently, through thermogenesis, fat oxidation, sparing fat free mass, and for the high-protein diet through satiety; a possible synergistic effect failed to appear.

- Sleep fragmentation induced reductions in SWS, REM-sleep and TST, coinciding with elevated AEE, physical activity, exhaustion and sleepiness, increased $R Q$, carbohydrate oxidation and reduced fat oxidation, that may underscore previously reported insulin insensitivity, and may create a vulnerable condition in the etiology of overweight. 
Taken together, energy balance, in the context of body-weight regulation appears to be unfavorably affected by sleep fragmentation, in that carbohydrate oxidation seems to be increased and fat oxidation seems to be reduced, thereby possibly decreasing insulin sensitivity as well.

Energy balance at a decreased level of body weight, after body-weight loss, may be maintained by consumption of energy containing ingredients such as a sustained absolute amount of high quality proteins, supporting maintenance of satiety, energy expenditure, and lean body-mass, that prevents the yo-yo effect.

Moreover, energy balance at a decreased level of body weight after weight loss may be maintained by consumption of green tea catechins, mixed with caffeine. For a possible synergistic role between the effects of protein and green tea catechins with caffeine no evidence was obtained.

\section{Future Research and Perspectives}

The studies presented in this thesis report the beneficial effects of green tea on body-weight regulation, however great intra-variability with respect to the outcomes between subjects was already reported by other studies.

Moreover, contradicting results are also reported between studies that included subjects of Caucasian origin and those that included subjects of Asian origin. As addressed in the discussion section these differences need to be assessed more closely.

Moreover, the relation between green tea and fat metabolism needs to be studied as well, since animal research indicates that green tea inhibits pancreatic lipases that decrease the fat absorption of the food, thereby increasing the energy content and fat content of the faeces. Also it is necessary to investigate the balance between fat absorption and fat oxidation after consuming green tea, as individuals differ in this respect.

Furthermore, effects of polyphenols on gut microbiota have been suggested and deserve further investigation.

Research concerning the effect of circadian alignment and misalignment is still undeveloped and deserves more attention. Establishing relationships between treatment of sleep fragmentation effects and consumption of high quality proteins $(111-113)$ or bioactive components $(114,115)$ would be a challenging topic for further research. A possible relation between green tea and sleep quality with respect to body-weight regulation would be alluring as well. Green tea contains the amino acid L-theanine, which increases $\alpha$-wave activity that is associated with being in an awake and mentally relaxed state. However certain, studies reported stimulating effects on $\delta$-waves, associated with deep sleep, and $\theta$-waves, associated with light sleep, thereby perhaps affecting sleep quality. With the results from this thesis, that show effects of green tea and sleep fragmentation on energy expenditure, it seems promising to investigate. Particularly, if you bare in mind that functional polymorphisms for COMT that are suggested 
to play a role in the effects of green tea, also modulate sleep homeostasis due to their dopaminergic signalling $(116,117)$.

Experimental research, including bioactive ingredients and circadian alignment and misalignment is required, since these are promising contributors for energy balance, thereby providing insight in possible mechanisms that underlie or prevent overweight, obesity and the metabolic syndrome.

\section{References}

1. Hursel R, Westerterp-Plantenga MS. Thermogenic ingredients and body weight regulation. Int $\mathrm{J}$ Obes (Lond) 2010;34:659-69.

2. Hursel R, Westerterp-Plantenga $M$. The multifactorial role of dietary protein in body weight regulation. Curr Top Pept Protein Res 2009;10:23-36.

3. Hursel R, van der Zee L, Westerterp-Plantenga MS. Effects of a breakfast yoghurt, with additional total whey protein or caseinomacropeptide-depleted alpha-lactalbumin-enriched whey protein, on diet-induced thermogenesis and appetite suppression. Br J Nutr 2010;103:775-80.

4. Hursel R, Viechtbauer W, Dulloo AG, et al. The effects of catechin rich tea and caffeine on energy expenditure and fat oxidation: A meta-analysis. Obes Rev; In press.

5. Hursel R, Viechtbauer W, Westerterp-Plantenga MS. The effects of green tea on weight loss and weight maintenance: a meta-analysis. Int J Obes (Lond) 2009;33:956-61.

6. Hursel R, Westerterp-Plantenga M. Consumption of milk protein combined with green tea modulates diet-induced thermogenesis. Submitted for publication 2011.

7. Hursel R, Westerterp-Plantenga MS. Green tea catechin plus caffeine supplementation to a highprotein diet has no additional effect on body weight maintenance after weight loss. Am J Clin Nutr 2009;89:822-30.

8. Hursel R, Rutters F, Gonnissen H, Martens E, Westerterp-Plantenga M. A circadian-induced shift in energy expenditure, physical activity and substrate oxidation after sleep disturbance in a respiration chamber. Submitted for publication 2011.

9. Dulloo AG, Geissler CA, Horton T, Collins A, Miller DS. Normal caffeine consumption: influence on thermogenesis and daily energy expenditure in lean and postobese human volunteers. Am J Clin Nutr 1989;49:44-50.

10. Bracco D, Ferrarra JM, Arnaud MJ, Jequier E, Schutz Y. Effects of caffeine on energy metabolism, heart rate, and methylxanthine metabolism in lean and obese women. Am J Physiol 1995;269:E671-8.

11. Acheson KJ, Zahorska-Markiewicz B, Pittet P, Anantharaman K, Jequier E. Caffeine and coffee: their influence on metabolic rate and substrate utilization in normal weight and obese individuals. Am J Clin Nutr 1980;33:989-97.

12. Arciero PJ, Gardner AW, Calles-Escandon J, Benowitz NL, Poehlman ET. Effects of caffeine ingestion on NE kinetics, fat oxidation, and energy expenditure in younger and older men. Am J Physiol 1995;268:E1192-8.

13. Astrup A, Toubro S, Cannon S, Hein P, Breum L, Madsen J. Caffeine: a double-blind, placebocontrolled study of its thermogenic, metabolic, and cardiovascular effects in healthy volunteers. Am J Clin Nutr 1990;51:759-67.

14. Jung RT, Shetty PS, James WP, Barrand MA, Callingham BA. Caffeine: its effect on catecholamines and metabolism in lean and obese humans. Clin Sci (Lond) 1981;60:527-35.

15. Lopez-Garcia E, van Dam RM, Rajpathak S, Willett WC, Manson JE, Hu FB. Changes in caffeine intake and long-term weight change in men and women. Am J Clin Nutr 2006;83:674-80.

16. Lejeune MP, Kovacs EM, Westerterp-Plantenga MS. Effect of capsaicin on substrate oxidation and weight maintenance after modest body-weight loss in human subjects. $\mathrm{Br} J$ Nutr 2003;90:651-59. 
17. Yoshioka M, Doucet E, Drapeau V, Dionne I, Tremblay A. Combined effects of red pepper and caffeine consumption on $24 \mathrm{~h}$ energy balance in subjects given free access to foods. Br $\mathrm{J}$ Nutr 2001;85:203-11.

18. Yoshioka M, Imanaga $\mathrm{M}$, Ueyama $\mathrm{H}$, et al. Maximum tolerable dose of red pepper decreases fat intake independently of spicy sensation in the mouth. Br J Nutr 2004;91:991-5.

19. Yoshioka M, Lim K, Kikuzato S, et al. Effects of red-pepper diet on the energy metabolism in men. J Nutr Sci Vitaminol (Tokyo) 1995;41:647-56.

20. Yoshioka M, St-Pierre S, Drapeau V, et al. Effects of red pepper on appetite and energy intake. Br J Nutr 1999;82:115-23.

21. Yoshioka M, St-Pierre S, Suzuki M, Tremblay A. Effects of red pepper added to high-fat and high-carbohydrate meals on energy metabolism and substrate utilization in Japanese women. $\mathrm{Br}$ J Nutr 1998;80:503-10.

22. Galgani JE, Ryan DH, Ravussin E. Effect of capsinoids on energy metabolism in human subjects. Br J Nutr 2009:1-5.

23. Hachiya S, Kawabata F, Ohnuki K, et al. Effects of $\mathrm{CH}-19$ Sweet, a non-pungent cultivar of red pepper, on sympathetic nervous activity, body temperature, heart rate, and blood pressure in humans. Biosci Biotechnol Biochem 2007;71:671-6.

24. Wang H, Wen Y, Du Y, et al. Effects of Catechin Enriched Green Tea on Body Composition. Obesity (Silver Spring) 2009.

25. Rudelle S, Ferruzzi MG, Cristiani I, et al. Effect of a thermogenic beverage on 24-hour energy metabolism in humans. Obesity (Silver Spring) 2007;15:349-55.

26. Rumpler W, Seale J, Clevidence B, et al. Oolong tea increases metabolic rate and fat oxidation in men. J Nutr 2001;131:2848-52.

27. Komatsu T, Nakamori M, Komatsu K, et al. Oolong tea increases energy metabolism in Japanese females. J Med Invest 2003;50:170-5.

28. Kao YH, Hiipakka RA, Liao S. Modulation of obesity by a green tea catechin. Am J Clin Nutr 2000;72:1232-4.

29. He RR, Chen L, Lin BH, Matsui Y, Yao XS, Kurihara H. Beneficial effects of oolong tea consumption on diet-induced overweight and obese subjects. Chin J Integr Med 2009;15:34-41.

30. Chan CC, Koo MW, Ng EH, Tang OS, Yeung WS, Ho PC. Effects of Chinese green tea on weight, and hormonal and biochemical profiles in obese patients with polycystic ovary syndrome-a randomized placebo-controlled trial. J Soc Gynecol Investig 2006;13:63-8.

31. Chantre P, Lairon D. Recent findings of green tea extract AR25 (Exolise) and its activity for the treatment of obesity. Phytomedicine 2002;9:3-8.

32. Chen WY, Yang ZB, Hosoda K, et al. Clinical efficacy of oolong tea on anti-simple obesity. Jpn J Clin Nutr 1998;20:83-90.

33. Auvichayapat $\mathrm{P}$, Prapochanung $\mathrm{M}$, Tunkamnerdthai $\mathrm{O}$, et al. Effectiveness of green tea on weight reduction in obese Thais: A randomized, controlled trial. Physiol Behav 2008;93:486-91.

34. Berube-Parent S, Pelletier C, Dore J, Tremblay A. Effects of encapsulated green tea and Guarana extracts containing a mixture of epigallocatechin-3-gallate and caffeine on $24 \mathrm{~h}$ energy expenditure and fat oxidation in men. Br J Nutr 2005;94:432-6.

35. Boschmann M, Thielecke F. The effects of epigallocatechin-3-gallate on thermogenesis and fat oxidation in obese men: a pilot study. J Am Coll Nutr 2007;26:389S-395S.

36. Cabrera C, Artacho R, Gimenez R. Beneficial effects of green tea--a review. J Am Coll Nutr 2006;25:79-99.

37. Diepvens K, Kovacs EM, Nijs IM, Vogels N, Westerterp-Plantenga MS. Effect of green tea on resting energy expenditure and substrate oxidation during weight loss in overweight females. $\mathrm{Br}$ J Nutr 2005;94:1026-34.

38. Diepvens K, Kovacs EM, Vogels N, Westerterp-Plantenga MS. Metabolic effects of green tea and of phases of weight loss. Physiol Behav 2006;87:185-91.

39. Dulloo AG, Duret C, Rohrer D, et al. Efficacy of a green tea extract rich in catechin polyphenols and caffeine in increasing 24-h energy expenditure and fat oxidation in humans. Am J Clin Nutr 1999;70:1040-5.

40. Harada U, Chikama A, Saito S, et al. Effects of long-term ingestion of tea catechins on energy expenditure and dietary fat oxidation in healthy subjects. J Health Sci 2005;51:248-252. 
41. Hsu CH, Tsai TH, Kao YH, Hwang KC, Tseng TY, Chou P. Effect of green tea extract on obese women: a randomized, double-blind, placebo-controlled clinical trial. Clin Nutr 2008;27:363-70.

42. Kajimoto $\mathrm{O}$, Kajimoto $\mathrm{Y}$, Yabune $\mathrm{M}$, et al. Tea catechins with a galloyl moiety reduce body weight and fat. Journal of Health Science 2005;51:161-171.

43. Klaus S, Pultz S, Thone-Reineke C, Wolfram S. Epigallocatechin gallate attenuates diet-induced obesity in mice by decreasing energy absorption and increasing fat oxidation. Int $\mathrm{J}$ Obes (Lond) 2005;29:615-23.

44. Kovacs EM, Lejeune MP, Nijs I, Westerterp-Plantenga MS. Effects of green tea on weight maintenance after body-weight loss. Br J Nutr 2004;91:431-7.

45. Kozuma K, Chikama A, Hishino E, et al. Effect of intake of a beverage containing $540 \mathrm{mg}$ catechins on the body composition of obese women and men. Prog Med 2005;25:185-197.

46. Nagao T, Hase T, Tokimitsu I. A green tea extract high in catechins reduces body fat and cardiovascular risks in humans. Obesity (Silver Spring) 2007;15:1473-83.

47. Nagao $\mathrm{T}$, Komine $\mathrm{Y}$, Soga $\mathrm{S}$, et al. Ingestion of a tea rich in catechins leads to a reduction in body fat and malondialdehyde-modified LDL in men. Am J Clin Nutr 2005;81:122-9.

48. Nagao T, Meguro S, Soga S, et al. Tea catechins suppress accumulation of body fat in humans. J Oleo Sci 2001;50:717-728.

49. Otsuka K, Uchida H, Yuzawa M, et al. Effects of tea catechins on body fat metabolism in women. Japanese Journal of Nutritional Assessment 2002;19:365-376.

50. Shixian Q, VanCrey B, Shi J, Kakuda Y, Jiang Y. Green tea extract thermogenesis-induced weight loss by epigallocatechin gallate inhibition of catechol-O-methyltransferase. J Med Food 2006;9:451-8.

51. Wolfram S, Wang Y, Thielecke F. Anti-obesity effects of green tea: from bedside to bench. Mol Nutr Food Res 2006;50:176-87.

52. Phung OJ, Baker WL, Matthews LJ, Lanosa M, Thorne A, Coleman Cl. Effect of green tea catechins with or without caffeine on anthropometric measures: a systematic review and metaanalysis. Am J Clin Nutr;91:73-81.

53. Belza A, Frandsen E, Kondrup J. Body fat loss achieved by stimulation of thermogenesis by a combination of bioactive food ingredients: a placebo-controlled, double-blind 8-week intervention in obese subjects. Int J Obes (Lond) 2007;31:121-30.

54. Belza A, Toubro S, Astrup A. The effect of caffeine, green tea and tyrosine on thermogenesis and energy intake. Eur J Clin Nutr 2009;63:57-64.

55. Reinbach HC, Smeets A, Martinussen T, Moller P, Westerterp-Plantenga MS. Effects of capsaicin, green tea and $\mathrm{CH}-19$ sweet pepper on appetite and energy intake in humans in negative and positive energy balance. Clin Nutr 2009.

56. Westerterp-Plantenga M, Diepvens K, Joosen AM, Berube-Parent S, Tremblay A. Metabolic effects of spices, teas, and caffeine. Physiol Behav 2006;89:85-91.

57. Basu A, Sanchez K, Leyva MJ, et al. Green tea supplementation affects body weight, lipids, and lipid peroxidation in obese subjects with metabolic syndrome. J Am Coll Nutr;29:31-40.

58. Lonac MC, Richards JC, Schweder MM, Johnson TK, Bell C. Influence of Short-Term Consumption of the Caffeine-Free, Epigallocatechin-3-Gallate Supplement, Teavigo, on Resting Metabolism and the Thermic Effect of Feeding. Obesity (Silver Spring).

59. Dulloo AG, Fathi M, Mensi N, Girardier L. Twenty-four-hour energy expenditure and urinary catecholamines of humans consuming low-to-moderate amounts of medium-chain triglycerides: a dose-response study in a human respiratory chamber. Eur J Clin Nutr 1996;50:152-8.

60. Hodgson JM, Puddey IB, Burke V, Croft KD. Is reversal of endothelial dysfunction by tea related to flavonoid metabolism? Br J Nutr 2006;95:14-7.

61. Palmatier MA, Kang AM, Kidd KK. Global variation in the frequencies of functionally different catechol-O-methyltransferase alleles. Biol Psychiatry 1999;46:557-67.

62. Larsen L, Angquist L, Larsen T, et al. The effect of Catechol-O-methyltransferase Val158Met variant (rs4680) on energy expenditure and weight loss. 11th International Congress on Obesity. 2010.

63. Snitker S, Fujishima $\mathrm{Y}$, Shen $\mathrm{H}$, et al. Effects of novel capsinoid treatment on fatness and energy metabolism in humans: possible pharmacogenetic implications. Am J Clin Nutr 2009;89:45-50. 
64. Cornelis MC, El-Sohemy A, Campos H. Genetic polymorphism of the adenosine A2A receptor is associated with habitual caffeine consumption. Am J Clin Nutr 2007;86:240-4.

65. Westerterp-Plantenga MS, Lejeune MP, Kovacs EM. Body weight loss and weight maintenance in relation to habitual caffeine intake and green tea supplementation. Obes Res 2005;13:1195204.

66. Ferruzzi MG. The influence of beverage composition on delivery of phenolic compounds from coffee and tea. Physiol Behav;100:33-41.

67. Del Rio D, Calani L, Scazzina F, Jechiu L, Cordero C, Brighenti F. Bioavailability of catechins from ready-to-drink tea. Nutrition;26:528-33.

68. Yang F, de Villiers WJ, McClain CJ, Varilek GW. Green tea polyphenols block endotoxin-induced tumor necrosis factor-production and lethality in a murine model. J Nutr 1998;128:2334-40.

69. Yang F, Oz HS, Barve S, de Villiers WJ, McClain CJ, Varilek GW. The green tea polyphenol (-)epigallocatechin-3-gallate blocks nuclear factor-kappa B activation by inhibiting I kappa B kinase activity in the intestinal epithelial cell line IEC-6. Mol Pharmacol 2001;60:528-33.

70. Murase T, Nagasawa A, Suzuki J, Hase T, Tokimitsu I. Beneficial effects of tea catechins on dietinduced obesity: stimulation of lipid catabolism in the liver. Int $\mathrm{J}$ Obes Relat Metab Disord 2002;26:1459-64.

71. Himmerich H, Sheldrick AJ. TNF-alpha and ghrelin: opposite effects on immune system, metabolism and mental health. Protein Pept Lett;17:186-96.

72. Brown PJ, Wright WB. An Investigation of the Interactions between Milk Proteins and Tea Polyphenols. J Chromatogr 1963;11:504-14.

73. Arts MJ, Haenen GR, Voss HP, Bast A. Masking of antioxidant capacity by the interaction of flavonoids with protein. Food Chem Toxicol 2001;39:787-91.

74. Arts MJ, Haenen GR, Wilms LC, et al. Interactions between flavonoids and proteins: effect on the total antioxidant capacity. J Agric Food Chem 2002;50:1184-7.

75. Siebert KJ, Troukhanova NV, Lynn PY. Nature of polyphenol-protein interactions. J Arg Food Chem 1996;44:80-85.

76. Westerterp KR, Smeets A, Lejeune MP, Wouters-Adriaens MP, Westerterp-Plantenga MS. Dietary fat oxidation as a function of body fat. Am J Clin Nutr 2008;87:132-5.

77. Nagy TR, Goran MI, Weinsier RL, Toth MJ, Schutz Y, Poehlman ET. Determinants of basal fat oxidation in healthy Caucasians. J Appl Physiol 1996;80:1743-8.

78. Schutz Y, Flatt JP, Jequier E. Failure of dietary fat intake to promote fat oxidation: a factor favoring the development of obesity. Am J Clin Nutr 1989;50:307-14.

79. Schutz Y. The adjustment of energy expenditure and oxidation to energy intake: the role of carbohydrate and fat balance. Int J Obes Relat Metab Disord 1993;17 Suppl 3:S23-7; discussion S41-2.

80. Raederstorff DG, Schlachter MF, Elste V, Weber P. Effect of EGCG on lipid absorption and plasma lipid levels in rats. J Nutr Biochem 2003;14:326-32.

81. Wang S, Noh SK, Koo SI. Epigallocatechin gallate and caffeine differentially inhibit the intestinal absorption of cholesterol and fat in ovariectomized rats. J Nutr 2006;136:2791-6.

82. Koo SI, Noh SK. Green tea as inhibitor of the intestinal absorption of lipids: potential mechanism for its lipid-lowering effect. J Nutr Biochem 2007;18:179-83.

83. Juhel C, Armand M, Pafumi Y, Rosier C, Vandermander J, Lairon D. Green tea extract (AR25) inhibits lipolysis of triglycerides in gastric and duodenal medium in vitro. $\mathrm{J}$ Nutr Biochem 2000;11:45-51.

84. Shishikura Y, Khokhar S, Murray BS. Effects of tea polyphenols on emulsification of olive oil in a small intestine model system. J Agric Food Chem 2006;54:1906-13.

85. Cabrera C, Gimenez R, Lopez MC. Determination of tea components with antioxidant activity. J Agric Food Chem 2003;51:4427-35.

86. Westerterp-Plantenga MS. The significance of protein in food intake and body weight regulation. Curr Opin Clin Nutr Metab Care 2003;6:635-8.

87. Westerterp-Plantenga MS. Protein intake and energy balance. Regul Pept 2008;149:67-9.

88. Westerterp-Plantenga MS, Kempen KP, Saris WH. Determinants of weight maintenance in women after diet-induced weight reduction. Int J Obes Relat Metab Disord 1998;22:1-6. 
89. Westerterp-Plantenga MS, Lejeune MP. Protein intake and body-weight regulation. Appetite 2005;45:187-90.

90. Westerterp-Plantenga MS, Lejeune MP, Nijs I, van Ooijen M, Kovacs EM. High protein intake sustains weight maintenance after body weight loss in humans. Int J Obes Relat Metab Disord 2004;28:57-64.

91. Veldhorst MA, Westerterp-Plantenga MS, Westerterp KR. Gluconeogenesis and energy expenditure after a high-protein, carbohydrate-free diet. Am J Clin Nutr 2009;90:519-26.

92. Heine WE, Klein PD, Reeds PJ. The importance of alpha-lactalbumin in infant nutrition. J Nutr 1991;121:277-83.

93. Mellinkoff SM, Boyle D, Frankland M, Greipel M. The effect of amino acid administration upon the blood sugar concentration. Stanford Med Bull 1955;13:117-24.

94. Mellinkoff SM, Frankland M, Boyle D, Greipel M. Relationship between serum amino acid concentration and fluctuations in appetite. J Appl Physiol 1956;8:535-8.

95. Veldhorst $M$, Smeets $A$, Soenen $S$, et al. Protein-induced satiety: effects and mechanisms of different proteins. Physiol Behav 2008;94:300-7.

96. Nieuwenhuizen AG, Hochstenbach-Waelen A, Veldhorst MA, et al. Acute effects of breakfasts containing alpha-lactalbumin, or gelatin with or without added tryptophan, on hunger, 'satiety' hormones and amino acid profiles. Br J Nutr 2009;101:1859-66.

97. Simpson SJ, Raubenheimer D. Obesity: the protein leverage hypothesis. Obes Rev 2005;6:13342.

98. Soenen S, Hochstenbach-Waelen A, Westerterp-Plantenga M. Sustained intake of required protein optimal for weight loss, supra-sustained protein intake optimal for weight maintenance. Submitted for publication 2010.

99. Vanitallie TB. Sleep and energy balance: Interactive homeostatic systems. Metabolism 2006;55:S30-5.

100. Knutson KL, Spiegel K, Penev P, Van Cauter E. The metabolic consequences of sleep deprivation. Sleep Med Rev 2007;11:163-78.

101. Penev PD. Sleep deprivation and energy metabolism: to sleep, perchance to eat? Curr Opin Endocrinol Diabetes Obes 2007;14:374-81.

102. Nedeltcheva AV, Kilkus JM, Imperial J, Schoeller DA, Penev PD. Insufficient sleep undermines dietary efforts to reduce adiposity. Ann Intern Med;153:435-41.

103. Schmid SM, Hallschmid M, Jauch-Chara K, et al. Short-term sleep loss decreases physical activity under free-living conditions but does not increase food intake under time-deprived laboratory conditions in healthy men. Am J Clin Nutr 2009;90:1476-82.

104. Spiegel K, Knutson K, Leproult R, Tasali E, Van Cauter E. Sleep loss: a novel risk factor for insulin resistance and Type 2 diabetes. J Appl Physiol 2005;99:2008-19.

105. Spiegel K, Leproult R, Van Cauter E. Impact of sleep debt on metabolic and endocrine function. Lancet 1999;354:1435-9.

106. Van Cauter E, Holmback U, Knutson K, et al. Impact of sleep and sleep loss on neuroendocrine and metabolic function. Horm Res 2007;67 Suppl 1:2-9.

107. Nedeltcheva AV, Kessler L, Imperial J, Penev PD. Exposure to recurrent sleep restriction in the setting of high caloric intake and physical inactivity results in increased insulin resistance and reduced glucose tolerance. J Clin Endocrinol Metab 2009;94:3242-50.

108. Nedeltcheva AV, Kilkus JM, Imperial J, Kasza K, Schoeller DA, Penev PD. Sleep curtailment is accompanied by increased intake of calories from snacks. Am J Clin Nutr 2009;89:126-33.

109. Mieda M, Yanagisawa M. Sleep, feeding, and neuropeptides: roles of orexins and orexin receptors. Curr Opin Neurobiol 2002;12:339-45.

110. Sakurai T. Roles of orexin/hypocretin in regulation of sleep/wakefulness and energy homeostasis. Sleep Med Rev 2005;9:231-41.

111. Minet-Ringuet J, Le Ruyet PM, Tome D, Even PC. A tryptophan-rich protein diet efficiently restores sleep after food deprivation in the rat. Behav Brain Res 2004;152:335-40.

112. Guesdon B, Messaoudi M, Lefranc-Millot C, Fromentin G, Tome D, Even PC. A tryptic hydrolysate from bovine milk alphaS1-casein improves sleep in rats subjected to chronic mild stress. Peptides 2006;27:1476-82. 
113. Guesdon B, Minet-Ringet J, Tome DG, Even PC. Restriction-refeeding of calories and protein induces changes to slow wave and paradoxical sleep that parallel changes in body lipid and protein levels in rats. Behav Brain Res 2005;164:156-64.

114. Dimpfel W, Kler A, Kriesl E, Lehnfeld R. Theogallin and L-theanine as active ingredients in decaffeinated green tea extract: II. Characterization in the freely moving rat by means of quantitative field potential analysis. J Pharm Pharmacol 2007;59:1397-403.

115. Mason R. $200 \mathrm{mg}$ of Zen: L-Theanine boosts alpha waves, promotes alert relaxation. Alternative and Complementary Therapies 2001;April:91-95.

116. Bodenmann S, Landolt HP. Effects of modafinil on the sleep EEG depend on Val158Met genotype of COMT. Sleep;33:1027-35.

117. Bodenmann S, Xu S, Luhmann UF, et al. Pharmacogenetics of modafinil after sleep loss: catechol-O-methyltransferase genotype modulates waking functions but not recovery sleep. Clin Pharmacol Ther 2009;85:296-304. 



\section{Summary}


Targeting overweight and obesity is essential since excessive weight has become a major health problem in the $21^{\text {st }}$ century. This thesis focuses on triggers for increasing energy expenditure such as bioactive ingredients and dietary protein, which may be able to promote weight loss or prevent excessive weight gain, separately or synergistically. Furthermore, the relation between sleep quality and energy expenditure has been investigated since questions were raised concerning a possible decreased energy expenditure after sleep deprivation, thereby causing a shift towards positive energy balance.

First, the impact of thermogenic ingredients and protein on body weight regulation were reviewed, addressing the short-term effects, long-term effects, mechanisms of action and their safety. Ingredients for obesity management including caffeine, capsaicin and different teas such as green, white and oolong tea increased on average energy expenditure with $4-5 \%$ and fat oxidation with $10-16 \%$ and they may counteract the decrease in metabolic rate that is present during weight loss. A daily increase in thermogenesis of approximately 300-400 $\mathrm{kJ}$ can eventually lead to substantial weight loss. Furthermore, amino acids, quantity as well as quality, in terms of 'complete' and 'incomplete' proteins, play an important role as an excessive intake leads to a sustained satiety and sustained energy expenditure mainly by gluconeogenesis and net protein synthesis.

Second, two meta-analyses were conducted; one of these evaluated shortterm effects of green tea mixtures on energy expenditure and fat oxidation and the other meta-analysis evaluated long-term effect of green tea mixtures on body-weight loss and weight maintenance. Different outcomes of the effect of green tea mixtures have been reported in studies with subjects differing in ethnicity and habitual caffeine intake. Therefore these meta-analyses elucidated whether a green tea mixture indeed plays a role in body-weight regulation. A catechin-caffeine mixture and caffeine-only treatment showed a stimulating effect on energy expenditure and a catechin-caffeine mixture also showed a stimulating effect on fat oxidation compared with placebo. Moreover, people with increased BMI may benefit from the sympathoadrenal stimulating effect of a catechin-caffeine mixture while different doses of catechins had a significantly different effect, $24 \mathrm{~h}$ energy expenditure and fat oxidation are increased on average with $0.5 \mathrm{~kJ} / \mathrm{mg}$ and $0.02 \mathrm{~g} / \mathrm{mg}$ for catechin-caffeine mixtures and $0.4 \mathrm{~kJ} / \mathrm{mg}$ and $0.01 \mathrm{~g} / \mathrm{mg}$ for the caffeine-only treatment. It was also shown that EGCG-caffeine mixtures have a positive effect on weight loss and on weight maintenance. Catechins significantly promoted body-weight loss or prevented weight gain after weight loss with approximately 1.3 kilogram. Moreover, it also shows that habitual caffeine intake and ethnicity may be moderators, especially due to interactions of the different ADORA2A and COMT polymorphisms and ethnicity.

Third, previous studies had shown effects of high-protein diets, especially whey-protein on energy expenditure and satiety, yet a possible distinction between effects of whey or alpha-lactalbulmin, had not been made. Therefore, the effects of addition of total whey protein (whey) or casein-macropeptide-depleted alpha-lactalbulmin enriched whey protein $(\alpha-l a c)$ to breakfast yoghurt drink on 
energy expenditure and appetite suppression in humans was assessed. The consumption of a breakfast yoghurt drink with added whey or $\alpha$-lac increased energy expenditure, protein balance and decreased fat balance compared to normal protein breakfast yoghurt drink. Furthermore, an $\alpha$-lac enriched yoghurt drink suppressed hunger and desire to eat more than a whey enriched yoghurt drink.

Fourth, green tea mixtures and protein separately were able to increase dietinduced thermogenesis. Hence, a combination of both was examined to study the acute effect of milk-protein on green tea mixture induced diet-induced thermogenesis, as well as on the long-term effect where its contribution to weight maintenance after weight loss was assessed. In the short-term, consumption of milk-protein inhibited the effect of green tea on diet-induced thermogenesis. In the long-term, green tea-caffeine mixture, as well as a high-protein diet improved weight-maintenance independently, via multiple pathways such as thermogenesis, fat oxidation, sparing fat free mass, and for the high-protein diet through satiety. Nevertheless, a possible synergistic effect failed to appear, most presumably by formations of protein-polyphenol complexes that reduce the absorption.

Finally, the effect of fragmented sleep on energy expenditure, substrate oxidation and physical activity was investigated, since the relation between sleep and obesity gained interest recently. Epidemiological studies show an inverse or $U$-shaped relationship between sleep duration and BMI. Decreases in total energy expenditure and physical activity have been suggested to be contributing factors. Fragmented sleep showed to have no effect on total energy expenditure. Activity-induced energy expenditure and physical activity were increased, as well as, exhaustion and sleepiness. In the long-term, these may dominate, resulting in a decrease in physical activity and thereby a sedentary lifestyle. Fragmented sleep induced increases in carbohydrate oxidation and $R Q$, and reduced fat oxidation that may underscore the previous reported insulin insensitivity. Both these factors, presently due to sleep fragmentation, play a role in the etiology of overweight.

Prevention of weight gain after weight loss and during weight maintenance, can be achieved when certain metabolic targets such as sustained satiety, sustained energy expenditure, sparing of fat free mass are stimulated, together resulting in a high energy inefficiency. These requirements need to be fulfilled despite being in negative energy balance, since successful weight loss or weight maintenance depends on the combination of the three. Triggers for energy expenditure as mentioned in the present thesis may be able to fulfill these requirements. 



\section{Samenvatting}


De aanpak van overgewicht en obesitas is cruciaal sinds een overmaat aan gewicht een van de grootste bedreigingen van de gezondheid in de 21 ste eeuw vormt. Dit proefschrift richt zich op stimulatoren van het energiegebruik waaronder thermogene ingrediënten en een hoge eiwitinname, die mogelijk er toe in staat zijn om gewichtsverlies te bevorderen of een toename in gewicht te voorkomen, zowel afzonderlijk als synergistisch. Verder is de relatie tussen normale slaap, gefragmenteerde slaap en energiegebruik onderzocht omdat er gesuggereerd werd dat het energiegebruik daalt na slaap deprivatie, waardoor er een kentering plaatsvindt in de richting van een positieve energiebalans.

Ten eerste werd het effect van thermogene ingrediënten en eiwitinname op de gewichtsregulatie onderzocht waarbij korte termijn effecten, lange termijn effecten, mechanismen en veiligheid werden besproken. Ingrediënten voor beheersing van het lichaamsgewicht, waaronder cafeïne, capsaicine en verschillende soorten thee zoals groene, witte en oolong thee stimuleren het energiegebruik gemiddeld met $4-5 \%$ en de vetoxidatie met $10-16 \%$; hiermee blijken ze een daling van het metabolisme, dat gepaard gaat met gewichtsverlies, te kunnen voorkomen. Een dagelijkse verhoging van het energiegebruik met ongeveer 300$400 \mathrm{~kJ}$ kan uiteindelijk leiden tot substantieel gewichtsverlies. Voorts kunnen aminozuren, zowel kwantitatief als kwalitatief, waarbij er sprake is van 'complete' en 'incomplete' eiwitten, een belangrijke rol spelen aangezien een grotere inname kan leiden tot een duurzame verzadiging en energiegebruik, voornamelijk geïnduceerd door gluconeogenese en netto eiwit synthese.

Ten tweede werden er twee meta-analyses uitgevoerd; een waarbij de korte termijn effecten van groene thee op het energiegebruik en de vetoxidatie werd geanalyseerd, en een waarbij de lange termijn effecten van groene thee op gewichtsverlies en gewichtsbehoud werd onderzocht. Verschil in resultaten tussen studies met betrekking tot het effect van groene thee met proefpersonen die verschilden wat betreft etniciteit en dagelijkse cafeïne-inname werden gepubliceerd. De uitgevoerde meta-analyses kunnen mogelijk een oplossing verschaffen voor de discrepantie die bestaat tussen de verschillende studies en daardoor aantonen of groene thee daadwerkelijk een gunstig effect heeft op gewichtsregulatie. Uit de meta-analyse bleek dat een mix van catechinen en cafeïne zowel als een cafeïne interventie een stimulerend effect hadden op het energiegebruik, waarbij de mix van catechinen en cafeïne tevens de vetoxidatie verhoogde. Bovendien lijken mensen met een verhoogd BMI ook te profiteren van het stimulerend effect van de mix van catechinen en cafeïne, terwijl een toename in dosering gepaard gaat met een toename in effect, waarbij het 24uurs energiegebruik en de vetoxidatie gemiddeld toenemen met $0.5 \mathrm{~kJ} / \mathrm{mg}$ en $0.02 \mathrm{~g} / \mathrm{mg}$ voor de mix van catechinen en cafeïne en $0.4 \mathrm{~kJ} / \mathrm{mg}$ en $0.01 \mathrm{~g} / \mathrm{mg}$ voor de cafeïne interventie. Bovendien werd aangetoond dat de mix van catechinen en cafeïne een positief effect heeft op gewichtsverlies en gewichtsbehoud. De mix stimuleerde gewichtsverlies met ongeveer 1.3 kilogram of voorkwam een toename van gewicht na gewichtsverlies. Tevens werd waargenomen dat dagelijkse cafeïne-inname 
en etniciteit het positieve effect kunnen verminderen, waarschijnlijk door interacties tussen verschillende ADORA2A en COMT polymorfismen en etniciteit.

Ten derde werden in voorgaande studies effecten aangetoond van hoogeiwit diëten, met name effecten van het wei-eiwit op energiegebruik en verzadiging. Echter een mogelijk onderscheid tussen effecten van wei en alfalactalbumine was nog niet onderzocht. Daarom werden de effecten van een toevoeging van totaal wei-eiwit (wei) of een wei-eiwit verrijkt met alfalactalbumine zonder caseine-macropeptide ( $\alpha$-lac) aan een yoghurt drink-ontbijt op het energiegebruik en de verzadiging bij mensen getest. Het consumeren van een yoghurt drink-ontbijt met toegevoegde wei of $\alpha$-lac stimuleerde het energiegebruik, de eiwitbalans en verminderde de vetbalans vergeleken met een yoghurt drink-ontbijt met melkeiwit. Tevens onderdrukte het met $\alpha$-lac verrijkte yoghurt drink-ontbijt de honger en de wens om te eten meer dan het met wei verrijkte yoghurt drink-ontbijt.

Ten vierde, er was reeds aangetoond dat groene thee en een hoogeiwit dieet afzonderlijk in staat zijn om de dieetgeïnduceerde thermogenese te verhogen. Daarom werd een combinatie van beiden onderzocht waarbij het acute effect van melkeiwit op de door groene thee geïnduceerde toename van de thermogenese werd bestudeerd. Daarnaast werd ook het lange termijn effect van de combinatie groene thee en het hoogeiwit dieet op gewichtsbehoud na gewichtsverlies onderzocht. Op korte termijn veroorzaakte de consumptie van melkeiwit een remming van het effect van groene thee op de dieetgeïnduceerde thermogenese. Op lange termijn, zorgden een groene thee-cafeïne mix en een hoogeiwit dieet afzonderlijk voor een verbetering van het gewichtsbehoud op verschillende manieren zoals via thermogenese, vetoxidatie, behoud van vetvrijemassa en voor het hoogeiwit dieet via een toename in verzadiging. Desalniettemin, van een mogelijk synergistisch effect was geen sprake, hoogstwaarschijnlijk door een formatie van eiwit-polyfenol complexen die de absorptie remmen.

Tenslotte werd het effect van een gefragmenteerde slaap op het energiegebruik, de substraatoxidatie en de fysieke activiteit onderzocht aangezien epidemiologisch onderzoek hypotheses doet genereren ten aanzien van de relatie tussen slaap en obesitas. Epidemiologische studies hebben een omgekeerde of U-vormige relatie tussen slaaptijd en BMI aangetoond. Een van de hypotheses is dat een door slaapfragmentering geïnduceerde afname in totaal energiegebruik en fysieke activiteit zou bij dragen aan een toename in gewicht. Gefragmenteerde slaap vertoonde geen effect op energiegebruik. Activiteitsgeïnduceerd energiegebruik en fysieke activiteit waren toegenomen, net als uitputting en slaperigheid. Op lange termijn, kunnen deze gaan overheersen wat kan resulteren in een afname van fysieke activiteit en een sedentaire levenstijl. Gefragmenteerde slaap induceerde een toename in koolhydraatoxidatie en $R Q$, en een afname in vetoxidatie hetgeen een eerder 
gerapporteerde insuline ongevoeligheid kan ondersteunen. Beide bevindingen kunnen een rol spelen in de etiologie van overgewicht.

Het voorkomen van gewichtstoename na gewichtsverlies en tijdens gewichtsbehoud kan worden bereikt wanneer bepaalde metabole doelen zoals duurzame verzadiging, duurzaam energiegebruik en behoud van vetvrijemassa worden gestimuleerd, en samen resulteren in een hogere energie inefficiëntie. Aan deze randvoorwaarden moet worden voldaan ondanks het verkeren in een negatieve energie balans, aangezien een succesvolle gewichtsvermindering of gewichtsbehoud daarna afhankelijk is van een combinatie van de drie. Stimulatoren van het energiegebruik zoals beschreven in het huidige proefschrift zijn in staat om aan deze randvoorwaarden bij te dragen. 
Dankwoord 
Eindelijk mag ik het meest gelezen hoofdstuk, en volgens sommigen het literair hoogtepunt, van dit proefschrift gaan schrijven. Nadenkende wie te bedanken, is de eenvoudigste manier om niemand te vergeten een algemeen dank je wel. Vandaar simpelweg ALLEN BEDANKT!

Echter er zijn altijd mensen die een speciale dank verdienen wegens hun bijdrage aan de totstandkoming van dit proefschrift tijdens de afgelopen jaren en daardoor niet onder dezelfde noemer mogen vallen. Vandaar dat ik me realiseerde dat ook ik het niet kort kan houden.

Ten eerste mijn promoter Margriet, na mijn sollicitatie kun je wel stellen dat het lot ons samenbracht, wat uiteindelijk heeft geleid tot een goede en productieve samenwerking. Ik hoop dat we dit in de toekomst kunnen vasthouden. Jou efficiënte manier van werken is een van de redenen dat ik mijn promotie binnen vier jaar heb kunnen volbrengen. Ook wil ik je bedanken voor alle congressen die ik heb mogen bezoeken, welke zeer leerzaam waren. Vervolgens zou ik Klaas willen bedanken. Naast het beoordelen van dit proefschrift als voorzitter van de beoordelingscommisie, heb ik veel kennis en de basis wat betreft onderzoek naar energiegebruik als student van jou mogen leren. Verder wil ik de overige leden van de beoordelingscommisie bestaande uit prof. dr. R. Mensink, prof. dr. A. Masclee, prof. dr. A. Astrup en dr. J. Plat bedanken voor de beoordeling van en de interesse in mijn werk.

Mijn dank gaat ook uit naar Loek, Paul, Jos, Wendy, Hasibe, Claudia, Desiree, llona en Shelly voor de hulp bij algemene zaken, analyses en het oplossen van problemen.

Grote dank ben ik verschuldigd aan Wolfgang Viechtbauer zonder wiens grote expertise in meta-analyses nooit twee van de huidige manuscripten tot stand zouden zijn gekomen. Het duurde even maar het uiteindelijke resultaat mag er wezen.

Tevens een dank aan de Koninklijke FrieslandCampina voor het sponsoren van een tweetal studies en hun bijdrage aan de drukkosten van dit proefschrift.

Naast alle (oud)collega's van Humane Biologie, wil ik vooral mijn (oud)collega's van ons cluster bedanken voor de prettige samenwerking en werksfeer op en buiten de UM, als tijdens congressen: Ananda, Astrid, Freeha, Arie, Jurriaan, Mieke, Eveline, Siti, Stefan, Guy, Femke (Thirst, anyone?!?), Alberto (for your hilarious Italian accent!), Sofie (voor het samen ten einde brengen van ons promotietraject, gedeelde smart is halve smart. Op het moment dat je dit boekje ontvangt ben je waarschijnlijk al Dr. Lemmens, goed gedaan!), Sanne (voor je gezelligheid en alle 'starters', veel geluk met jullie eerste kindje), Anneke en Margriet (voor de mooie en unieke ervaring als dubbel-paranimf, alsmede de gezellige tijd met jullie als kamergenoten), Marcel en Stijn (voor de memorabele gebeurtenissen tijdens congressen).

Vervolgens wil ik mijn paranimfen Hanne en Chris van harte danken dat zij mij willen steunen tijdens deze belangrijke dag.

Hanne, na terugkomst van mijn zomervakantie in 2009 was je er opeens samen met Eveline om de lege plekken die Anneke en Margriet hadden achter- 
gelaten op te vullen. Uiteraard zoals dat gaat met mensen die elkaar net leren kennen was het eerst aftasten, maar uiteindelijk klikte het, mede dankzij de zware studie vol avond- en nachtdiensten die we samen met Femke hebben uitgevoerd. Bedankt dat je mijn vele pesterijtjes zo sportief oppakt en voor de gezelligheid en alle humor op onze kamer, die ik overigens graag de komende jaren nog met je wil delen. Tevens wil ik jou partner Pieter bedanken voor het sublieme ontwerp van de omslag en de uitnodigingen.

Chris, acht jaar geleden heb ik je leren kennen tijdens onze studie gezondheidswetenschappen. Hier konden we meteen goed met elkaar opschieten en naast collega-studenten werden we ook collega's bij SnowWorld waar we een bijbaantje hadden tijdens onze studie. Na onze studie werden we wederom collega's op de universiteit waar we bijna dagelijks alle weertypes trotseerden tijdens onze pauzes om de dagelijkse beslommeringen te bespreken. Buiten collega en medestudent kan ik oprecht zeggen dat je ook een goede vriend bent geworden waarop ik kan bouwen en waarmee ik kan lachen. Ik wens je veel sterkte toe bij het afronden van jou promotietraject en ik wens jou en Kelly veel geluk toe samen wanneer jullie na deze zomer als echtgenoten door het leven gaan.

Verder wil ik mijn familie en vrienden bedanken voor de interesse, steun, hoognodige ontspanning (zeker degenen waar ik al duizenden kilometers mee heb afgelegd omwille van de gemeenschappelijke liefde voor de muziek) en in sommige gevallen zelfs hun inzet als proefpersoon (Ellen en Sven, veel geluk met mijn eerste neefje of nichtje!!) tijdens de afgelopen jaren.

Pap en mam, bedankt voor al jullie hulp en de mogelijkheid die jullie mij hebben geboden om het punt te bereiken waar ik nu ben aanbeland. Zonder jullie zou dit nooit gelukt zijn.

Eveline, bedankt voor je liefde, steun, vertrouwen de afgelopen jaren en begrip voor alle keren dat je me hebt moeten missen. Dit proefschrift komt pagina's tekort om mijn waardering voor jou te laten blijken. 



\section{List of publications}




\section{First Author}

Hursel R, Westerterp-Plantenga MS. Green tea catechin plus caffeine supplementation to a high-protein diet has no additional effect on body weight maintenance after weight loss. Am J Clin Nutr. 2009 Mar;89(3):822-30. Epub 2009 Jan 28

Hursel R, Viechtbauer W and Westerterp-Plantenga MS. Effects of green tea on weight loss and weight maintenance: A meta-analysis. Int J Obes (Lond). 2009 Sep;33(9):956-61. Epub 2009 Jul 14.

Hursel R, Van der Zee L and Westerterp-Plantenga MS. Effects of a breakfast yoghurt, with additional total whey protein or CMP-depleted alpha-lactalbumin enriched whey protein, on diet-induced thermogenesis and satiety. BJN. Br J Nutr. 2010 Mar;103(5):775-80. Epub 2009 Oct 29.

Hursel R and Westerterp-Plantenga MS. The multifactorial role of dietary protein in body weight regulation. Curr Top Pept Protein Res 2009; 10: 23-36

Hursel R and Westerterp-Plantenga MS. Thermogenic ingredients and bodyweight regulation. Int J Obes (Lond). 2010 Apr;34(4):659-69. Epub 2010 Feb 9.

Hursel R, Viechtbauer W, Dulloo AG, Tremblay A, Tappy L, Rumpler W and Westerterp-Plantenga MS. Effect of catechin rich tea and caffeine on energy expenditure and fat oxidation: A meta-analysis. Obes Rev; in press.

Hursel R and Westerterp-Plantenga MS. Consumption of milk protein combined with green tea modulates diet-induced thermogenesis. Submitted for publication.

Hursel R, Rutters F, Gonnissen HKJ, EAP Martens and Westerterp-Plantenga MS. Effects of sleep fragmentation on energy expenditure, substrate oxidation, physical activity and exhaustion, measured over $48 \mathrm{~h}$ in a respiratory chamber. Submitted for publication.

Hursel R and Westerterp-Plantenga MS. Green tea catechins and their role in prevention or treatment of overweight and cancer. Submitted for publication.

Hursel R and Westerterp-Plantenga MS. Catechin and caffeine rich teas for control of body-weight. Submitted for publication.

\section{Co-author}

Veldhorst M, Smeets A, Soenen S, Hochstenbach-Waelen A, Hursel R, Diepvens $K$, Lejeune $M$, Luscombe-Marsh N, Westerterp-Plantenga M. Protein- 
induced satiety: Effects and mechanisms of different proteins. Physiol Behav. 2008 May 23;94(2):300-7.

Gonnissen HKJ, Hursel R, Rutters F, EAP Martens and Westerterp-Plantenga MS. Effects of sleep disturbance on insulin sensitivity and satiety in a controlled metabolic unit. Submitted for publication.

Rutters F, Gonnissen H, Hursel R, Lemmens S, Martens E and WesterterpPlantenga M. Inter-individual relationships between sleep characteristics and obesity related parameters in normal weight men measured over $48 \mathrm{~h}$ in controlled conditions. Submitted for publication.

\section{Book Chapters}

Hursel R and Westerterp-Plantenga MS. The effects of a novel fat emulsion (Olibra $^{\circledR} /$ Fabuless $^{\mathrm{TM}}$ ) on energy intake, satiety, weight loss and weight maintenance. In: Cho S editor. Weight control and slimming ingredients in food technology. Chapter 4, p55-63, Blackwell Publishing, 2010.

Hursel R and Westerterp-Plantenga MS. The effects of caffeine and green tea on energy expenditure, fat oxidation, weight loss and weight maintenance. In: Cho $\mathrm{S}$ editor. Weight control and slimming ingredients in food technology. Chapter 10, p161-176, Blackwell Publishing, 2010.

\section{Oral Presentations}

Hursel R. The effects of green tea on body weight regulation. Symposium: Satiety, the latest trend in weight management? October 2008, London, United Kingdom. (Invited speaker).

Hursel R, Viechtbauer W and Westerterp-Plantenga MS. Moderators of effects of green tea on body weight regulation. $1^{\text {st }}$ Swiss winter conference on ingestive behavior March 2009, St. Moritz, Switzerland. (Invited speaker).

Hursel R, Viechtbauer and Westerterp-Plantenga MS. Effects of green tea on weight loss and weight maintenance: a meta-analysis. $10^{\text {th }}$ Benjamin Franklin Lafayette Seminar (BLFS) June 2009, Frejus, France. (Invited speaker).

Hursel R and Westerterp-Plantenga MS. Diet-induced thermogenesis with respect to highly thermogenic food components and their role in body weight regulation. $3^{\text {rd }}$ International Symposium on Physiology and Pharmacology of Temperature Regulation (PPTR) July 2009, Matsue, Japan. (Invited speaker) 
Hursel R and Westerterp-Plantenga MS. No synergistic effect of green tea catechin \& caffeine supplementation to a high protein diet on body weight maintenance after weight loss. $19^{\text {th }}$ International Congress of Nutrition (ICN) October 2009, Bangkok, Thailand, Ann Nutr Metab 2009; 55 (suppl 1): p79.

Hursel R and Westerterp-Plantenga MS. The effects of green tea and protein on body-weight regulation. International Protein Summit October 2009, Maastricht, The Netherlands. (Invited speaker).

Hursel R, Viechtbauer W and Westerterp-Plantenga MS. Effects of catechins on body-weight regulation: 2 meta-analyses on weight loss/weight maintenanceand energy expenditure/ fat oxidation. $2^{\text {nd }}$ Swiss winter conference on ingestive behavior March 2010, St. Moritz, Switzerland.

\section{Poster Presentations}

Hursel R and Westerterp-Plantenga MS. No synergistic effect of green tea catechin \& caffeine supplementation to a high protein diet on body weight maintenance after weight loss. $17^{\text {th }}$ European Congress on Obesity (ECO) May 2009, Amsterdam, The Netherlands, Obesity Facts 2009; 2 (suppl 2): p159.

Hursel R, Viechtbauer and Westerterp-Plantenga MS. Effects of green tea on weight loss and weight maintenance: a meta-analysis. $17^{\text {th }}$ European Congress on Obesity (ECO) May 2009, Amsterdam, The Netherlands, Obesity Facts 2009; 2 (suppl 2): p160.

Hursel R and Westerterp-Plantenga MS. No synergistic effect of green tea catechin \& caffeine supplementation to a high protein diet on body weight maintenance after weight loss. $17^{\text {th }}$ Annual meeting of the Society for the Study of Ingestive Behavior (SSIB) July 2009, Portland (OR), United States, Appetite 2009; 52 (3): p838.

Hursel R, Viechtbauer and Westerterp-Plantenga MS. Effects of green tea on weight loss and weight maintenance: a meta-analysis. $17^{\text {th }}$ Annual meeting of the Society for the Study of Ingestive Behavior (SSIB) July 2009, Portland (OR), United States, Appetite 2009; 52 (3): p838.

Hursel R and Westerterp-Plantenga MS. No synergistic effect of green tea catechin \& caffeine supplementation to a high protein diet on body weight maintenance after weight loss. $3^{\text {rd }}$ World Congress on Tea \& Health December 2009, Dubai, United Arab Emirates. 
Hursel R, Viechtbauer and Westerterp-Plantenga MS. Effects of green tea on weight loss and weight maintenance: a meta-analysis. $3^{\text {rd }}$ World Congress on Tea \& Health December 2009, Dubai, United Arab Emirates.

Hursel R, Gonnissen H, Rutters F and Westerterp-Plantenga MS. Energy expenditure overnight and slow wave sleep. $11^{\text {th }}$ International Congress on Obesity (ICO) July 2010, Stockholm, Sweden, Obes Rev 2010; 11 (suppl 1): p294.

Hursel R, Rutters F, Gonnissen H, Martens E and Westerterp-Plantenga MS. A circadian-induced shift in energy expenditure, physical activity and substrate oxidation after sleep disturbance in a respiration chamber. $18^{\text {th }}$ European Congress on Obesity (ECO) May 2011, Istanbul, Turkey. 

Curriculum vitae 

Rick Hursel was born on September $19^{\text {th }} 1984$ in Heerlen, the Netherlands. After he completed secondary school at the college Rolduc in Kerkrade in 2003 he started the study Health Sciences at Maastricht University for which he obtained his bachelor's degree in 2006. In 2007 he obtained his degree for the European master of Metabolism and Nutrition at Maastricht University.

In September 2007 he started his PhD research at the department of Human Biology of the Faculty of Health, Medicine and Life Sciences of Maastricht University under supervision of Prof. Dr. MS Westerterp-Plantenga. The research performed during this period is described in this $\mathrm{PhD}$ thesis entitled 'Triggers for energy expenditure: thermogenic ingredients \& circadian aspects'. In October 2009 he received the Young Investigator Travel Award at the International Congress of Nutrition in Bangkok, Thailand. He acquired a Kootstra Talent Fellowship from Maastricht University Medical Centre+ (MUMC+) in November 2010 and started as a post-doc at the department of Human Biology to continue his work in the field of body-weight regulation. 